University of Louisville

ThinkIR: The University of Louisville's Institutional Repository

Electronic Theses and Dissertations

$5-2008$

\title{
Lipid aldehydes are substrates and transcriptional regulators of cytochromes P450.
}

Immaculate Amunom

University of Louisville

Follow this and additional works at: https://ir.library.louisville.edu/etd

Part of the Biochemistry Commons, and the Molecular Biology Commons

\section{Recommended Citation}

Amunom, Immaculate, "Lipid aldehydes are substrates and transcriptional regulators of cytochromes P450." (2008). Electronic Theses and Dissertations. Paper 39.

https://doi.org/10.18297/etd/39

This Doctoral Dissertation is brought to you for free and open access by ThinkIR: The University of Louisville's Institutional Repository. It has been accepted for inclusion in Electronic Theses and Dissertations by an authorized administrator of ThinkIR: The University of Louisville's Institutional Repository. This title appears here courtesy of the author, who has retained all other copyrights. For more information, please contact thinkir@louisville.edu. 


\title{
LIPID ALDEHYDES ARE SUBSTRATES AND TRANSCRIPTIONAI REGULATORS OF CYTOCHROMES P450
}

\author{
By
}

Immaculate Amunom

M.S. University of Buea, 2000

\begin{abstract}
A Dissertation
Submitted to the Faculty of the

Graduate School of the University of Louisville in Partial Fulfillment of the Requirements

for the Degree of
\end{abstract}

Doctor of Philosophy

Department of Biochemistry and Molecular Biology

University of Louisville

Louisville, Kentucky

May 2008 


\title{
LIPID ALDEHYDES ARE SUBSTRATES AND TRANSCRIPTIONAL REGULATORS OF CYTOCHROMES P450
}

\author{
By
}

Immaculate Amunom

B.S., M.S. Biochemistry, University of Buea-Cameroon, 2000

A Dissertation Approved on

March 12, 2008

by the following Dissertation Committee

(Dissertation Director) 


\section{DEDICATION}

This dissertation is dedicated to my mother Ms. Celine A. Awachi, and to ny sisters Desiree, Gisele and Germaine, for encouragement, love and support. 


\section{ACKNOWLEDGEMENTS}

I have many people to thank for helping me through this academic process. First my advisor Dr. Russell A. Prough, for his untiring support and advice through out my Ph.D. research. He was always patient in listening to my questions, and offered advice. He was very supportive both academically and with other extracurricular activities and gave me the opportunity to fully experience the American culture and way of life. I am truly privileged to have worked with Dr. R.A. Prough as my mentor. I will always be grateful to him for imparting in me the ability to think critically and encouraging me to believe in myself.

In addition, I express sincere gratitude to my dissertation committee meinbers for supporting with different aspects of my dissertation research. I thank Dr. Aruni Bhatnagit: for all the discussions and contributions with for the development of the project. Aiso, Dr. Barbara J. Clark for all the advice and comments on results and research design. Dr. Robert D. Gray and Dr Kenneth S. Ramos also contributed with questicns to aid in experiment design, development and success of the project.

A special thank you to Dr. Thomas Geoghegan for assisting me adapl to life as a graduate student and for all the support through the years with trouble shooting and designing experiments.

Dr. Stephanie J. Webb has been to tremendous assistance to me. She helped with designing experiments and different aspects of data analysis. In addition. she has helped me adopt an exercise routine, which is required for a healthy graduate student. 
I am especially grateful to Ms. Laura J. Stephens for her invaluable support with running experiments and discussing. As chemistry major, she offered insightful discussion on experiments especially dealing with the xenobiotic metabolism reactions. She is a great friend and I learned from her the other great aspects of this community.

Ms Mary Pendleton who thought me and assisted me with transfections made my work easy. Thank you for always being patient, for listening and for all the ercouragement.

I am grateful to Dr. Daniel J. Conklin for all his input with sample generation and discussions on data and the progress of the research project. I also wish to extend my appreciation Dr. Cameron K. Falkner for assisting me with data analysis and with experimental design and interpretation of results.

I am highly indebted to Dr. Kristy M. Miller who helped integrate into the project. She was very instrumental during my first year in the laboratory helping me understand grasp the pace of understanding P450- mediated reactions. She was supportive and encouraged me to be persistent with my research and be cheerful. Through her influence. I have also developed a love for county music.

I wish to thank my colleagues of the 2002 class of the Biochemistry department for the friendship and kindness.

Last and not the least, the entire faculty of the Department of Biochemistry for continuous support and encouragement and to the Integrated Programs in Biomedical Sciences (IPIBS), University of Louisville for giving me the opportunity to pursue my Ph.D. in Biochemistry and molecular Biology. 


\section{ABSTRACT \\ LIPID ALDEHYDES ARE SUBSTRATES AND TRANSCRIPTIONAI. REGULATORS OF CYTOCHROMES P450 Immaculate Amunom}

\section{May 10, 2008}

4-hydroxy-2-nonenal (4-HNE) and propene-2-al (acrolein) are highly reactive $\alpha, \beta$-unsaturated aldehydes. 4-HNE and acrolein are generated in vivo as products of lipid peroxidation. These aldehydes are implicated in the onset of severai diseases including atherosclerosis and neurodegenerative disease. They also react with nucleophilic cellular macromolecules including proteins, DNA and phospholipids. Some of these reactions in vivo lead to inhibition of enzyme activities, depletion of glutathione and oxidative stress. Because of their pathophysiological relevance, attention has focused during the last decade on the ability of mammals to metabolize these lipid aldehydes.

The purpose of this study was therefore to determine the role of cytochrome P450s in the metabolism of lipid aldehydes and how exposure to lipid aldehydes influences the regulation of the expression of xenobiotic metabolizing enzymes. Cytochrome P450s are a superfamily of heme proteins that catalyze the NADPH and 0 ?dependent monooxygenation of a wide variety of compounds. In addition. P450s are capable of catalyzing the biosynthesis of several molecules including the synthesis of sterols, fatty acids, and eicosanoids. In this study used a fluorescence spectroscopy and high performance lipid chromatography technique, coupled with mass spectrometry to demonstrate that CYPs metabolize lipid aldehydes. This metabolism involves 
monooxygenation by mouse, rat and human P450s, of 4-HNE to 4-hydroxynonenoic acid and the reduction of 4-HNE to 1,4-dihydroxynonene by specific P450s. By using gencral and specific P450 inhibitors, we have determined that hepatic P450s differentially contribute to 4-HNE metabolism. While Cyp2c29 catalyzes oxidative metabolism. Cyp 3 a predominantly catalyzes the reduction of 4-HNE.

We demonstrated by microarray analysis and quantitative real-time PCR that expression of Cyp2c29, Cyp2c37 and Cyp3a25 is induced by acrolein and butylated hydroxyanisole, both activators of AP-1 in mouse liver. These P450s include (yp2:29. Cyp2a5 and Cyp1A2. BHA and acrolein also induced other xenobiotic metabolizing enzymes such as GSTm1, heme oxygenase-1 and NADHP quinone oxidoreductase

Certain transcription factors function to regulate gene expression in response to xenobiotic challenge. Lipid aldehydes in particular regulate gene expression through the action of two transcription factors, namely AP-1 and Nrf2. We determined that Cyp2029, is regulated by activator protein 1 (AP-1) transcription factor. NrP2 was not involved in the induction of Cyp2c29 expression. The results from this study show that there is lipid aldehyde-dependent regulation of $\mathrm{P} 450$ gene expression. The induced Cyp2c29 goes on to metabolize substrate in a manner reminiscent of a self-regulatory loop of biologicai activity. 


\section{TABLE OF CONTENTS}

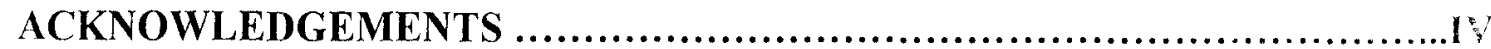

ABSTRACT

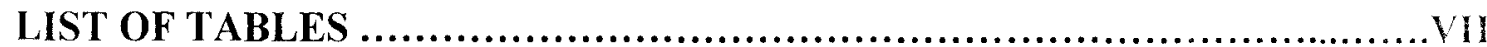

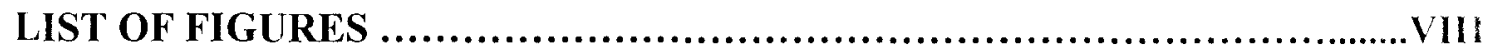

\section{CHAPTER}

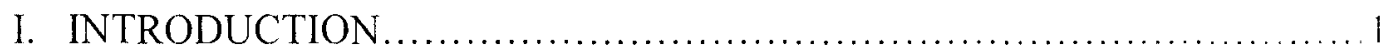

II. CYTOCHROMES P450 CATALYZE THE METABOLISM OF $\alpha, \beta-$ UNSATURATED ALDEHYDES.

III. INDUCTION OF GENE EXPRESSION IN MOUSE HEART ANI) I.IVER BY ACROLEIN AND BUTYLATED HYDROXYANISOLE.

IV. TRANSCRIPTIONAL REGULATION OF THE MOUSE: CYP2C29 GENE

V. DISCUSSION AND CONCLUCIONS

REFERENCES. 


\section{LIST OF TABLES}

TABLE

PAGE

Table 1. Different CYP isoforms found in various species, their substrates

and inducers

Table 2. Relative abundance of human cytochrome P450 enzymes and their

contribution to drug metabolism. 18

Table 3. Catalytic activities of mouse and human CYPs expressed in E. coli ......60

Table 4. Effect of alcohol dehydrogenase, aldehyde dehydrogenase, and P450)

inhibitors on recombinant CYP3A4 activity.

Table 5. BHA-regulated xenobiotic metabolizing enzyme genes in mouse

Liver.

Table 6. Acrolein-regulated xenobiotic metabolizing enzyme genes in mouse

Liver.

Table 7. Oligonucleotides showing the Cyp2c2 TRE 


\section{LIST OF FIGURES}

FIGURE

PACH

1. Molecular structure of 4-hydroxy-2-nonenal, propene-2-al and the pathways for 4-HNE synthesis.

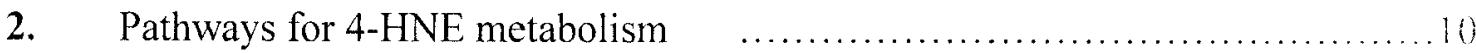

3. Generalized reactions of the cytochrome P450 reaction cycle.................. 14

4. Structure/function organization of nuclear receptors......................2

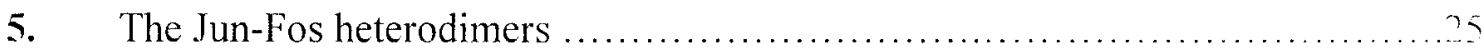

6. Cytochrome $c$ reductase activity in membrane fractions....................... 38

7. Procedure to measure 9 -anthracene aldehyde metabolites ...................42

8. Structure and fluorescence spectra of 9-anthracene aldehyde metabolites........49

9. Concentration-dependence of oxidation of anthracene-9-carboxaldchyde by Cyp2c29 and CYP3A4 ................................................. 51

10. 9-AA metabolism activity catalyzed by reconstituted CYP2B $34 \ldots \ldots \ldots \ldots \ldots \ldots .54$

11. The reconstitution of 4-HNE oxygenation activity catalyzed by rabbit

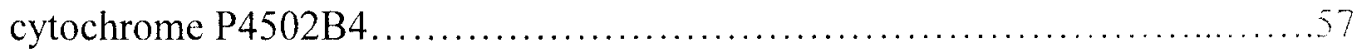

12. Mass spectra of 4-hydroxynonenoic acid generated from Cyp2c29-dependent

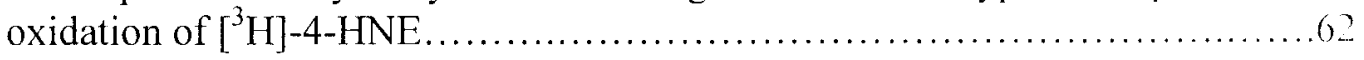

13. Kinetic analysis of inhibition by 4-HNE of anthracene-9-carboxaldehyde

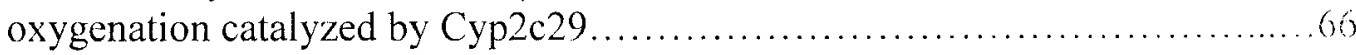

14. Inhibition of mouse liver microsomal aldehyde oxygenase activity ........... (6)

15. Inhibition of 4-HNE metabolism in primary hepatocytes from Sprague-Dawley

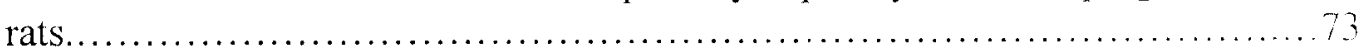

16. Reduction of 9-AA to 9-AMeOH by CYP3A4 and mouse liver microsoncs.....77 
17. HPLC profile of metabolism of 4-HNE catalyzed by CYP $3 A 4$ 79

18. Mass spectra of DHN generated from CYP3A4-dependent metabolism of $\left[{ }^{3} \mathrm{H}\right]-4-\mathrm{HNE}$

19. Lack of oxygen inhibits P450 dependent oxidation but not reduction of aldehydes. 84

20. Proposed pathway for the metabolism of 4-HNE by P450s 9!

21. Chemical structure of butylated and tert-butyl hydroquinone .98

22. Schematic representation of experimental design for analysis of gene expression in male $\mathrm{C} 57 \mathrm{BL} / 6$ mice following $\mathrm{BHA}$ or acrolein treatment. 101

23. Verification of RNA quality used for microarray and qRT-PCR analysis of gene expression 104

24. Flow chart outlining the method for microarray data reduction and classification analysis for gene expression.

25. Analysis of the specificity of qRT-PCR primers

26. Changes in gene expression in male C57BL/6 mice liver following treatment with BHA or acrolein.

27. Changes in gene expression following treatment of mice with different chomical compounds

28. Principal component analysis of data from BHA and acrolein treatments of C57B/16 mice.

29. Quantitative R'T-PCR analysis of gene expression in C57BI /6 mice heart and liver following treatment with BHA

30. Quantitative RT-PCR analysis of gene expression in C57BL /6 mouse heart and liver following treatment acrolein.

31. Quantitative RT-PCR analysis of gene expression in C57BL $/ 6$ mice following treatment acrolein by inhalation.

32. Induction of cytochrome $\mathrm{P} 450$ activity in mouse liver microsomes by BHA.

33. Expression of Cyp2c29 in mouse liver following treatment with BHA. 
34. The modified p0.164Ya-Luc plasmid showing the luciferase gene. the basic rat GST Ya promoter and the Cyp2c29-TRE ................................. 50

35. The nucleotide sequence of the $3.43 \mathrm{~Kb}$ of the Cyp2c29 5 'flanking sequence showing putative transcription factor binding sites......................... 155

36. Deletion analysis of the 5'-FS of the Cyp2c29 gene ...................... 158

37. Induction of Cyp2c29-TRELuc reporter activity following cotransfection of Fos and Jun in HEpG2 cells.

38. Induction of Collagenase-TRELuc reporter activity following cotransfection of Fos and Jun in HepG2 cells.................................................... 16 .

39. Mutation of the core TRE results in the ablation of AP-1-dependent

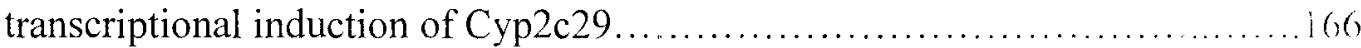

40. Mutation of the "GC" dinucleotide results in the induction of $\mathrm{AP}-1$-dependient

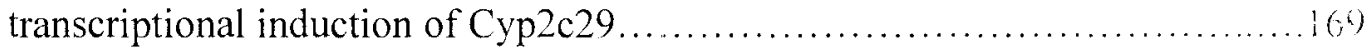

41. Effect of Nrf2, AP-1 and tBHQ on ARE-dependent activation of p( $) .16+\mathrm{Ya}$ AREluciferase activity

42. Effect of protein kinase activators and phosphatase inhibitor on Cyp2029-1RL: luciferase reporter activity .........................................

43. Luciferase reporter activity in response to tBHQ in mouse primary hepatocytes. ....

44. Quantitative RT-PCR analysis of gene expression in wild-type and $\mathrm{Nrf}^{-/-}$liver following treatment with BHA 


\section{CHAPTER I \\ INTRODUCTION}

Peroxidation of $\omega-6$ polyunsaturated fatty acids proceeds by a frec-radical chain reaction mechanism that yields lipid hydroperoxides as a major initial product.

Subsequently, decomposition of the lipid hydroperoxides generates reactive lipid aldehydes such as malondialdehyde, glyoxal, propene-2-al, 4-hydrexy-2-nonenal. and 4 oxo-2-nonenal (Uchida, 2003). Plants also produce lipid aldehydes. Truns-2-hexenal is a plant aldehyde. It occurs in green plants as a product of oxidative degradation of plant lipids (Visser et al., 1979). Studies have shown that trans-2-hexenal and other plan! aldehydes can be active as host plant attractants (Visser et al., 1978), as enhancers of other host plant odors (Guerin et al., 1988), indicators of fruit ripeness (Engel et cil.. 1988) or defensive secretions (Neri et al., 2005). Two very important lipid aldehydes to which humans are exposed are propene-2-al (Beauchamp et al.. 1985) and 4-hydroxy-2nonenal. They form the bulk of reactive endogenous lipid aldehydes characterized in vivo to date and are implicated in a series of pathological conditions including atherosclerosis and Parkinson's disease (Pauli and Shaur, 2000).

\section{4-HYDROXY-2- NONENAL (4-HNE)}

4-HNE is a long-chain $\alpha, \beta$-unsaturated aldehyde. It has 9 carbon atoms, incluting a carbonyl group and a 4-hydroxy group (Figure 1A). Initially discovered by Benecetti et 
al. (1980) during the investigation of lipid peroxidation by liver microsomes, 4-HNE has subsequently been shown to be formed predominantly from the peroxidation of the (1)- 6 polyunsaturated fatty acids linoleic acid and arachidonic acid (Schneider el al., 2001). 4HNE is the most abundant and cytotoxic lipid aldehyde described to date (Esterbauer et al., 1991 and Uchida, 2003). Lipid peroxidation resulting in the production of 4-HNE is a direct consequence of oxidative stress. Sies (1991) described oxidative stress as an imbalance between oxidants and antioxidants, potentially leading to damage. Unde: physiological conditions, the cellular concentration of $4-\mathrm{HNE}$ ranges from $0.1 \mu \mathrm{M} 1 \mathrm{3} 3$ $\mu \mathrm{M}$. However, under oxidative stress conditions in vitro, 4-HNE may accumulate to higher concentrations from $10 \mu \mathrm{M}$ to $5 \mathrm{mM}$ (Esterbauer et al., 1991; Uchida. 2003). Several mechanisms have been put forward to explain the mechanism of $4-\mathrm{HNE}$ formation. The most recent mechanism established by Schneider (2001) utilized the 9and 13-hydroperoxides of linoleic acid as starting material. Following two distinct pathways (Figure 1B), 4-hydroperoxy-2E-nonenal is generated and subsequently converted to 4-HNE.

\section{PROPENE-2-AL (ACROLEIN)}

Acrolein, like 4-HNE, is an $\alpha . \beta$-unsaturated aldehyde. It is colorless volatile and soluble in water, ethanol and diethyl ether (WHO 1992). Acrolein is a threc-carbon compound with two reactive sites: a carbon-carbon double bond and a teminal carbonyl group (Figure 1A). Acrolein was first isolated from dry distillation of fats in 1843 by Redtenbacher (Beauchamp et al., 1985 review). Since then, several other sources have been discovered. For example, acrolein is a lipid peroxidation product formed from 



\section{Figure 1}

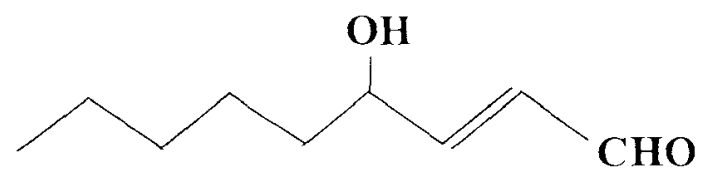

4-hydroxy-2-nonenal (4-H NE)

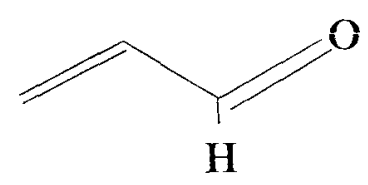

Propen e-2-al( A cro lein )

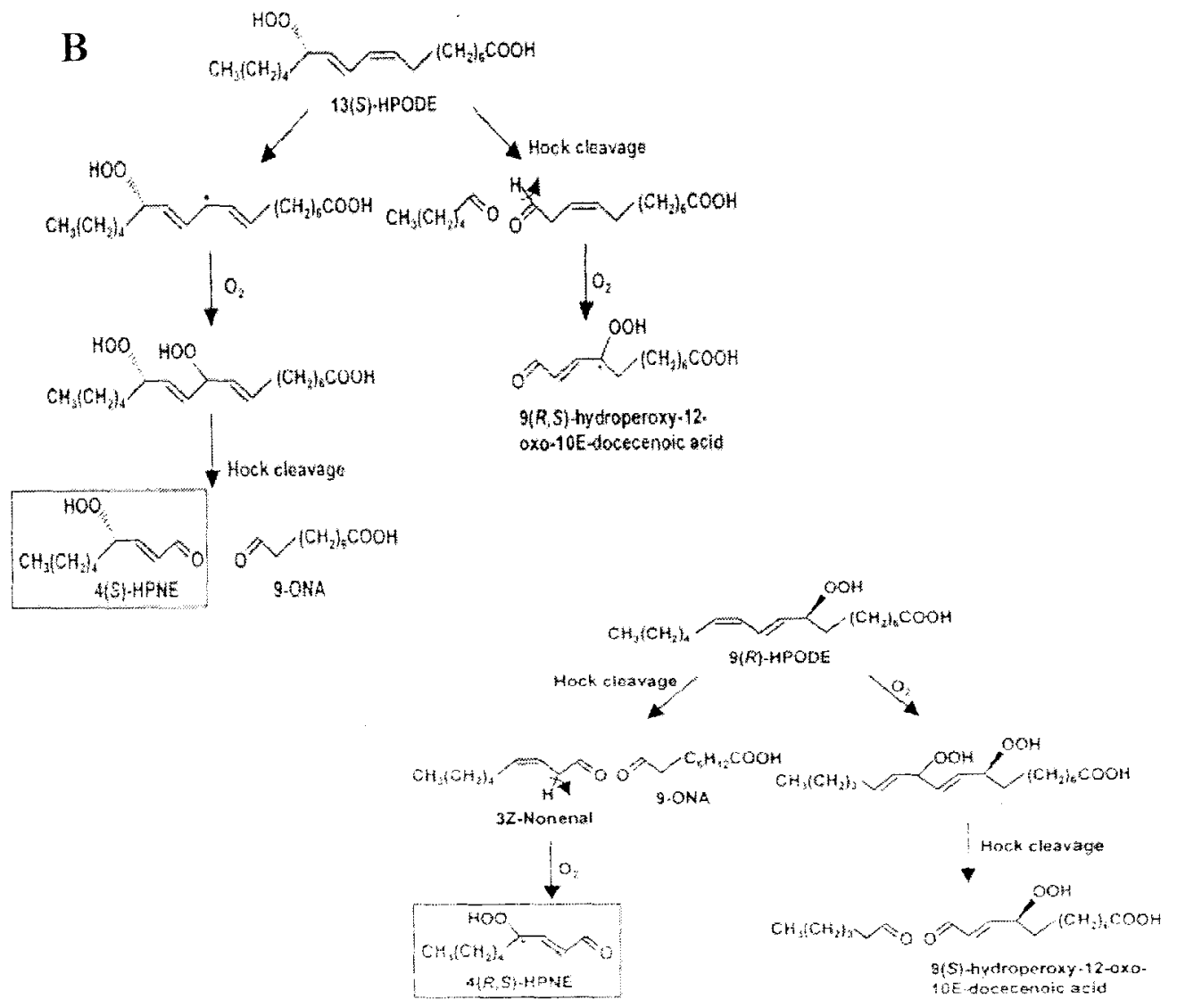


Metal-catalyzed catalyzed oxidation of arachidonic acid (Uchida et al., 1998). In addition to lipid peroxidation, acrolein is a by-product of over-heating organic matter and occurs as an ubiquitous pollutant in the environment, for example, incomplete combustion of plastic materials, cigarette smoke, and over-heating of frying oils (Beauchamp et al., 1988). $\Lambda$ recent study determined the amount of acrolein in a single puff of cigarette smoke to range from $1.6-22 \mu \mathrm{g} /$ cigarette depending on the carbon filter of the cigarette (Thweatt et al., 2007). Acrolein is formed in air as a photochemical reaction product, during the biotransformation of allyl compounds and the anticancer drug, cyclophosphamide (Boor, 1983; Fraiser et al., 1991). Acrolein is also generated from the metabolism of spermine and spermidine by the microsomal enzyme monoamine oxidase in liver and heart cells (Timbrell, 1991). It has been estimated to represent $5 \%$ of the total aldehyde found in polluted air, but is proportionally the most damaging chemical contaminant because it is highly irritating, and, as an $\alpha, \beta$-unsaturated compound. is very electrophilic (Witz, 1989) allowing it to rapidly react with many nucleophilic sites. Levels of acrolein in ambient air are estimated at only 0.04 to $0.08 \mathrm{ppm}$. although it is found at up to $90 \mathrm{ppm}$ in cigarette smoke (Costa and Amdur, 1996). Subchronicinhalation studies have reported physiological effects at $0.4 \mathrm{ppm}$. The lethal dose of acrolein in humans is a $10 \mathrm{~min}$ exposure of $351 \mathrm{mg} / \mathrm{m}^{3}$ (Stanford Research Institute. 1978).

\section{MOLECULAR EFFECTS OF 4-HNE AND ACROLEIN}

4-HNE and acrolein are diffusible aldehydes. They can act locally or enter the general circulation. Because these aldehydes are highly reactive electrophiles, they 
readily react with cellular nucleophilic macromolecules such as proteins and DN $\Lambda$ (Esterbauer et al., 1991). The use of matrix assisted laser desorption /ionization- time of flight (MALDI-TOF) mass spectrometry and liquid chromatography/mass spectrometry/mass spectrometry (LC/MS/MS) has allowed for the identification of points of macromolecular modification by 4-HNE and acrolein.

4-Hydroxy-2-nonenal can form adducts with proteins by reacting with cysteine sulfhydryl groups, histidine imidazole groups and lysine $\varepsilon$-amino groups (Uchida, 2003). Absorbed acrolein reacts directly with protein and non-protein sulfhydryl groups and with primary and secondary amines found in proteins and nucleic acids (Fry et al.. 1993). Enzymes with sulfhydryl groups in their active site can be inhibited by both 4-HNE and acrolein. For example, acrolein inhibits rat DNA polymerase (Munsch et al., 1973). High levels of acrolein inhibit GST $m u$ and GST pi (>250 $\mu \mathrm{M}$; Berhane and Mannervik, 1990). and aldehyde dehydrogenase (>200 $\mu \mathrm{M}$; Silva and O'Brien, 1989). High levels of 4-HNE differentially inhibit cytochromes P450 (Kuo et al., 1997).

4-HNE and acrolein are believed to be involved in aging, chemical-drug toxicity and the pathogenesis of a number of human diseases. The concentration of 4-HNE is elevated in diseased regions of the brain of patients with Alzheimer's disease (Markesbery and Lovell, 1998; Picklo et al., 2002), in human hippocampus after global ischemia (McKracken et al., 2001) and in Lewy bodies in neurocortical and brain siem neurons in Parkinson's disease (Zarkovic, 2003). Among other effects, recent findings suggest that in vivo, covalent modification of low-density lipoprotein (LDL) by 4-I INI: and acrolein renders LDL more atherogenic and enhances foam-cell formation (Esterbauer 1993; Uchida et al., 1998). Proteins modified by 4-HNL have been detected 
in atherosclerotic lesions. 4-HNE modification of mitochondrial proteins occurs during cardiac reperfusion in hearts isolated from senescent rats, thus, establishing a link between 4-HNE and cardiac reperfusion injury (Lucas and Szweda, 1999). Upon incubation with low density lipoprotein, acrolein preferentially reacts with lysine residues forming $\mathrm{N}^{u}$-acetyl- $\mathrm{N}^{e}$-(3-formyl-3,4-dehydropiperidino) lysine or FDP-lysine (Uchida et al. , 1998). 4-HNE and acrolein generated during oxidation of low-density lipoprotein form covalent adducts with apolipoprotein B (Hubatsch et cl., 1998) and trigger the uptake of low density lipoprotein by scavenger receptors located on vascular tissucs, including vascular smooth muscle cells (Steinbrecher et al., 1990). Therefore, the metabolism of these compounds to less reactive products that can be excreted or subjected to further metabolism is of great importance.

\section{MULTIPLE PATHWAYS ACCOUNT FOR 4-HNE METABOLISM:}

\section{Glutathione $S$-Transferase, Aldehyde Dehydrogenase And Aldose Reductase}

The ability to withstand toxic chemicals and oxidative stress is essential for the survival of all organisms. Various mechanisms have evolved to protect cells against foreign compounds and reactive oxygen species including efflux pumps, antioxidant proteins and glutathione (GSH), xenobiotic metabolism, sequestration of toxins and DN $>$ repair (Hayes and McLellan 1999). When administered in vivo, radiolabeled 4-I INI: is rapidly metabolized and excreted into urine as a group of polar products from (1)-oxidized 4-hydroxynonenoic acid (HNA) and their low density lipoprotein conjugates, as well as a group of less polar mercapturic acid thioesters originating from the metabolism of the aldehyde moiety of 4-HNE (Alary et al 1995; De Zwart et al., 1996). In the study by Alary ef al. after intravenous administration of 4-HNE into rats, HNA and mercapturic 
acid conjugates accounted for $40 \%-50 \%$ and $30 \%$ of the injected dose, respectively. This pattern indicates that both oxidation and glutathione (GSH) conjugation are the main metabolic pathways of 4-HNE metabolism. Moreover, in vitro studies of 4-HNE metabolism performed with isolated hepatocytes (Hartley et al., 1995; Siems et al. 1997; Amunom et al., 2006), enterocytes (Boon et al., 1999), liver slices (Laurent et al.. 2000), and perfused organs such as liver, kidney, and heart (Boon et al., 1999; Grune et al., 1997) suggest that HNA and glutathione-conjugated 4-HNE account for the major metabolites of 4-HNE. These metabolic studies of the lipid peroxidation-derived aldehyde 4-HNE suggest that metabolic pathways involving glutathione $S$-transferase (GST), aldehyde dehydrogenase (ALDH) and aldose reductase ( $A R$ ) arc involved in disposition of 4-HNE and related aldehydes. In isolated rat hepatocytes, GST catalyzed the Michael addition of 4-HNE to glutathione (GSH), ALDH oxidized 4-HNE to 4hydroxynonenoic acid and aldose reductase reduced 4-HNE to 1,4-dihydroxy-2-nonene (Hartley et al., 1995, Srivastava et al., 2001). Figure 2, taken from Alary et al. (2003) shows the pathways established for 4-HNE metabolism.

Little is known about the contribution of cytochromes P450 to the metabolism of lipid aldehydes. There is a single study demonstrating that in PPAR wild-type, but not PPAR knockout nice, fibrate treatment resulted in the increase in 4,9-dihydroxy-2nonenoic acid, the $\omega$-hydroxylated metabolite of 4-HNE and its oxidized form. 4hydroxy-2-nonene-1,9-dicarboxylic acid (Gueraud et al., 1999). This suggests a possible role of the Cyp4a family in 4-HNE metabolism. There are no other reports of P450s involved in lipid aldehyde metabolism. 



\section{Figure 2}

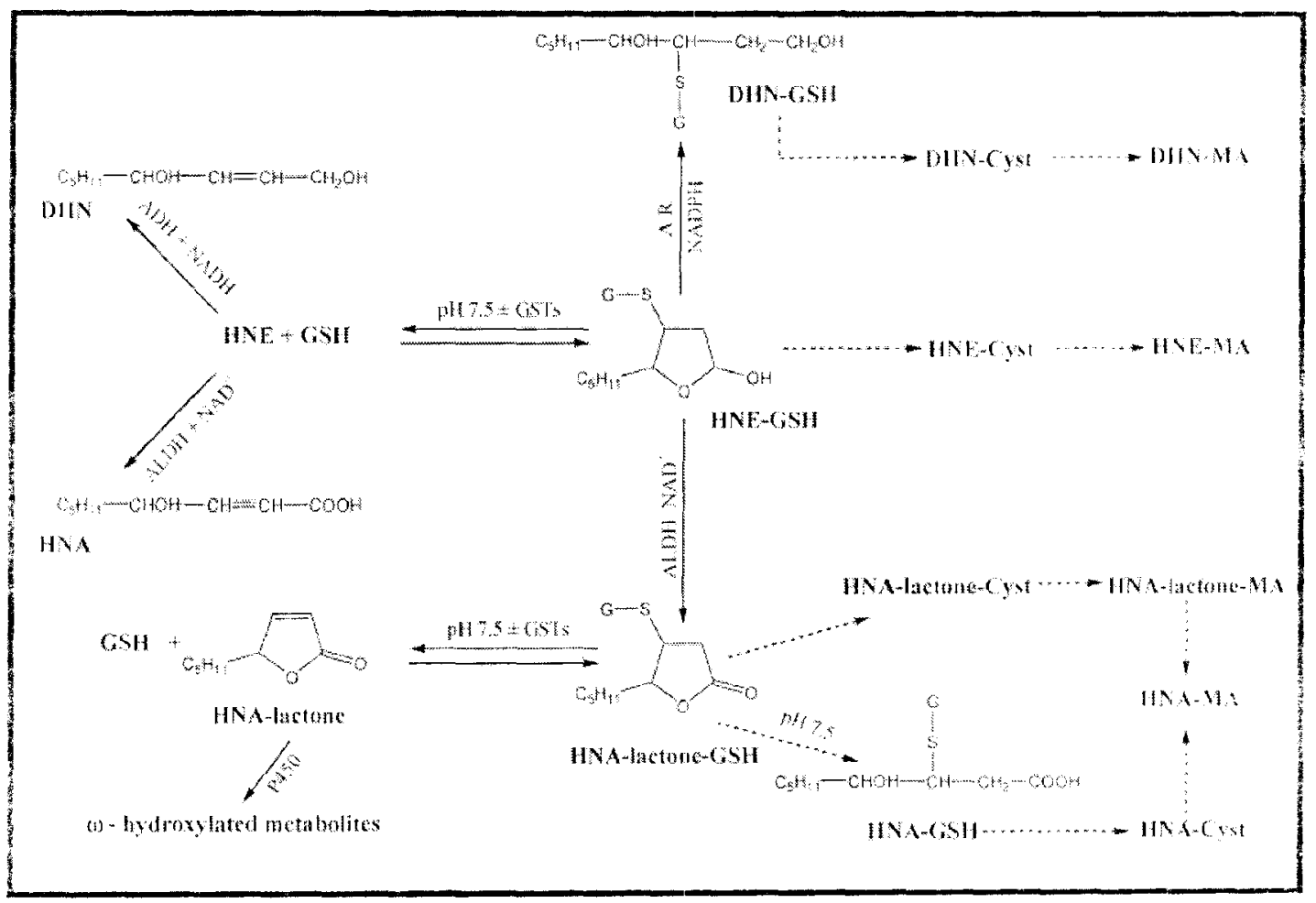




\section{CYTOCHROMES P450 (CYP)}

The history of cytochrome P450 began in 1955 with the first experimental evidence demonstrating that an enzyme system in the endoplasmic reticulum of the liver was able to oxidize xenobiotic compounds (Axelrod, 1955). Subsequently, Omura and Sato (1964) named this enzyme cytochrome $\mathrm{P} 450$ because the pigment $(\mathrm{P})$ in liver microsomes had a 450-nm spectral peak when reduced and bound to carbon monoxide. In the late 1970s, only six P450 enzymes were known to exist. With advances in cloning and purification techniques, many other P450s have since been discovered. As of 2006. there are 57 CYP genes in the human genome (http:/drnelson.utmem.edu/CytochromeP450.html).

A basic structural model for P450s has been established based on the structural comparison of published bacterial P450 crystal structures P450cam, P450BM-P. P450terp, and P450eryF (Graham-Lorence and Peterson, 1996). P450s are composed of two main domains, a predominantly $\alpha$-helical domain accounting for approximately $70 \%$ of the protein, and a predominantly $\beta$-sheet domain accounting for $22 \%$ of the protein. The $\alpha$-helices are denoted A-L with the I and L helices contacting tine hene. Residues in the $\mathrm{B}, \mathrm{I}$ and $\mathrm{F}$ helices contact the substrate. The most conserved region in the $\mathrm{P} 450$ is a scquence containing a cysteine that acts as the thiolate ligand to the heme iron. This sequence is used to identify P450s in gene banks. Along with the cysteine in the heme binding region is the highly conserved amino acid sequence F(G/S)XGX(H/R)XCXGX(I/L/F)A (Guengerich, 2000; Graham-L and Peterson. 1996).

A nomenclature system for the cytochrome P450 gene superfamily exists and is continuously updated (http://drnelson.utmem.edu/CytochromeP450.html; Nebert et al.. 
1987). Based on this nomenclature, cytochrome $\mathrm{P} 450$ proteins are arranged into families and subfamilies based on their percentage of amino acid identity. P450 enzymes that share $\geq 40 \%$ identity are assigned to a particular family and are designated by an Arabic numeral, for example CYP1. Those sharing $\geq 55 \%$ amino acid identity are grouped into a particular subfamily designated by a letter, e.g. CYP1A.

There are two main types of P450s. The type I P450s are found in bacteria and in mitochondria and reccive electrons from NADPH through a flavoprotein (ferredoxin reductase) and an iron/sulfur protein (ferredoxin). The type II P450s are found in the endoplasmic reticulum and receive electrons from NADPH through a single protein, NADPH:cytochrome P450 oxidoreductase or CYPOR (Miller, 1988). CYPOR is a $78-$ kDa protein that forms a complex with the $\mathrm{P} 450$ in the endoplasmic reticulum membrane (Hubbard et al., 2001). Of the $57 \mathrm{P} 450$ genes in the human genome. 50 are type II. Among these 50, about 15 are involved in drug metabolism, 20 are involved in the biosynthesis of sterols, fatty acids, and eicosanoids, and 15 are "orphan" enzymes, whose activilies remain unknown or ill-defined (Guengerich, 2004).

The oxidative metabolism of substrates by P450s involves the transfer of two electrons to the P450. The first electron transferred to endoplasmic reticulum-localized cytochromes P450 is always by CYPOR. The second electron can either come from CYPOR or from cytochrome $b_{5}$ (Porter, 2002). The generally accepted steps for substrate metabolism by $\mathrm{P} 450 \mathrm{~s}$ are summarized in the $\mathrm{P} 450$ catalytic cycle (Figure 3). The reactions in this cycle include oxygen binding (steps 1-6), followed by the oxidation of substrate (steps 7 and 8) and the release of product (step 9) (Guengerich, 2001). 
Figure 3. Generalized reactions of the cytochrome P450 catalytic cycle. The reactions in this cycle include oxygen binding (steps 1-6), oxidation of substrate (steps 7 and 8) and the release of product (step 9). (Copied from Guengerich, 2001. Current Drug Metabolism 2:93-115). 
Figure 3

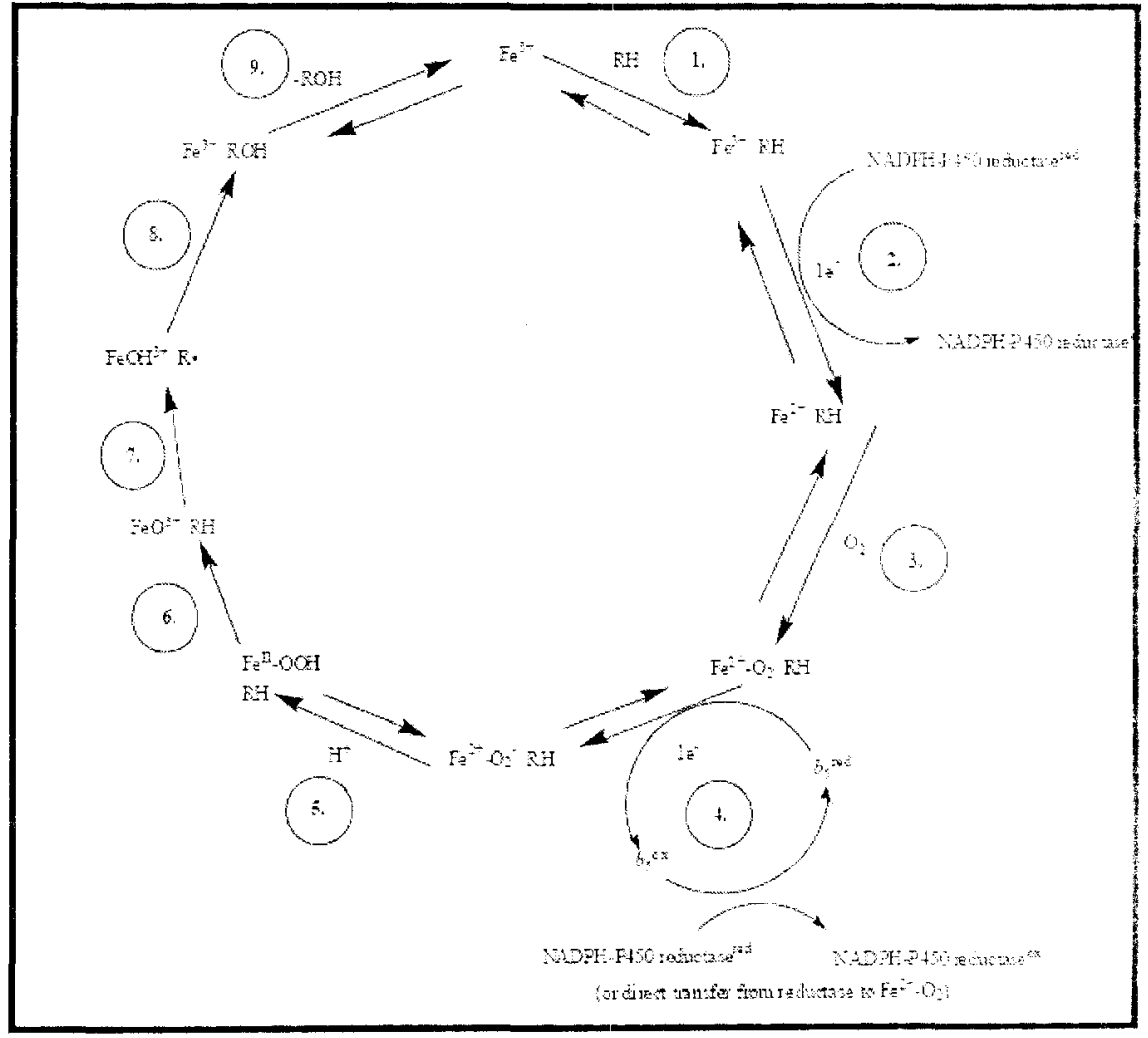


Xenobiotics include drugs, food metabolites and environmental pollutants pesticides, herbicides, and industrial combustion wastes. These compounds, as well asendogenously generated compounds are substrates for cytochromes P450. In humans, CYPs that metabolize xenobiotics are in the CYP1, CYP2, CYP3, and, to a lesser extent CYP4 families. A list of putative mammalian full-length $\mathrm{P} 450$ isoforms, their substrates and inducers are shown (Table 1). While humans have only 57 functional CYP genes. the mouse has up to 102 (Nelson et al., 2004). P450s are mostly expressed in the liver: however, some are extra-hepatic. Other organs of P450 gene expression include brain, heart, lungs, kidney, and small intestine. The most abundant mammalian P450, CYP3A4, is expressed in adult human liver and intestine (Choudhary et al., 2004). Table 2. adapted from Hewitt et al., 2007, shows the relative abundance of human hepatic cytochromes P450.

\section{NUCLEAR RECEPTORS}

Nuclear receptors comprise a superfamily of proteins which include the nuclear hormone receptors, orphan nuclear receptors, the retinoid $X$ receptor $(R X R)$ and its heterodimer partners, the thyroid hormone receptor, vitamin D3 receptor (VDR), peroxisome proliferator-activated receptor (PPAR), the constitutive andiostane receptor (CAR), and the pregnane $\mathrm{X}$ receptor (Figure 4). Nuclear receptors translocate to the nucleus in order to modulate transcription of target genes in response to extracelluar and intracellular signals, culminating in an array of responses including metabolism, differentiation and proliferation which influence physiological processes such as 
Table 1

A Summary of CYPs in various species showing the different isoforms, their substrates and inducers

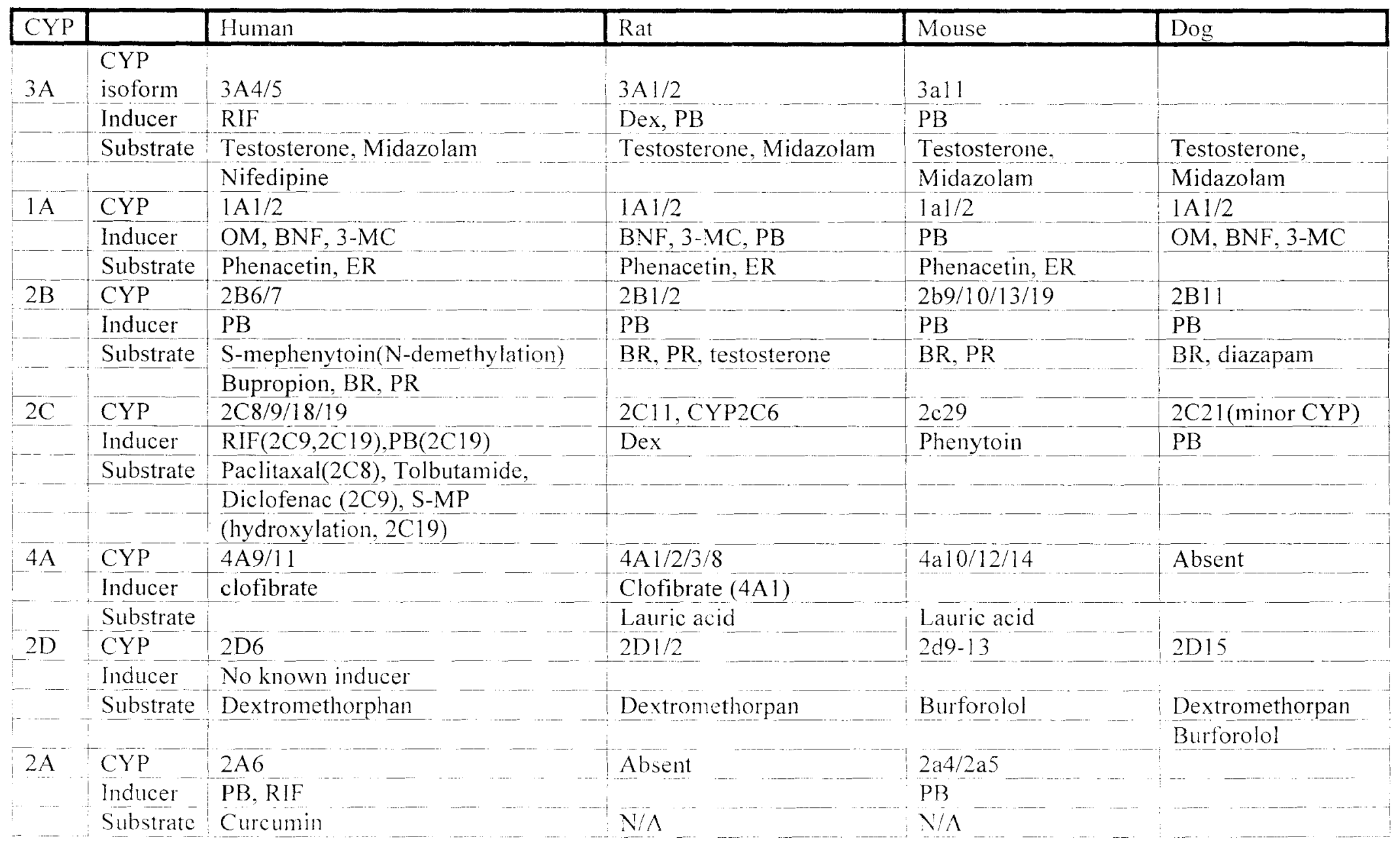




\begin{tabular}{|c|c|c|c|c|c|}
\hline $2 \mathrm{E}$ & CYP & $2 E 1$ & $2 E 1$ & $2 \mathrm{e} 1$ & \\
\hline & Inducer & Isoniazid, $\mathrm{PB}, \mathrm{RIF}$ & Ethanol Acetone pyrazine & Ethanol & (not isoniazid) \\
\hline & Substrate & Chlorzoxazone & Chlorzoxazone, $p-N P$ & Chlorzoxazone, p-NP & p-nitrophenol \\
\hline
\end{tabular}

$\mathrm{RIF}=$ rifampin, $\mathrm{PB}=$ phenobarbitone, $\mathrm{Dex}=$ dexamethasone, $\mathrm{BNF}=\beta$-napthoflavone, $3-\mathrm{MC}=3$-methylchloranthrene, $\mathrm{ER}=$ ethoxyresorufin, $\mathrm{MR}=$ methoxyresorufin, $\mathrm{BR}=$ benzyloxyresorufin, $\mathrm{PR}=$ pentoxyresorufin, $\mathrm{OM}=$ omeprazole, $\mathrm{p}-\mathrm{NP}=\mathrm{p}-\mathrm{nitrophenol}$, S- MP = S-Mephenytoin (Table adapted from Hewitt et al (2007) Drug Metabolism Reviews. 39:159-234). 
Table 2

Relative abundance of human cytochrome P450 enzymes and their contribution to drug metabolism

\begin{tabular}{|l|c|c|}
\hline Enzyme & Content in liver(\% total CYP) & $\%$ Of drugs metabolized by enzyme \\
\hline CYP3A4/5 & 29,30 & 52 \\
CYP2D6 & 1.5 & 30 \\
CYP2C9 & 12 & 10,11 \\
CYP2C8 & 7 & no reference \\
CYP2C19 & 0.2 & 4 \\
CYP1A2 & 12,13 & 4.6 \\
CYP2E1 & 7 & 2.5 \\
CYP2B6 & $1.2,5$ & 25 \\
\hline
\end{tabular}

( lable copied from Hewitt et al., (2007). Drug Metabolism Reviews. 39:159-234). 
reproduction and development (Robinson-Rechavi et al., 2003; Olefsky, 2001).

Nuclear hormone receptors are receptors for which ligands have been identified. They transduce signals from small molecules like glucocorticoids, mineralocorticoids, sex steroids (estrogen, progesterone, and androgen), thyroid hormones, and vitamin 133 within the cell cytoplasm. Orphan receptors are receptors for which the ligands are unknown. Nuclear receptors have common structural features (Figure 4). The N-terminal region contains the activation function-1 (AF-1) domain. The central region is the $\mathrm{DNA}$ binding domain (DBD) responsible for targeting the receptor to the DNA response element. The C-terminal region consists of the ligand-binding domain (LBD), responsible for binding hormonal and non-hormonal ligands and receptor activation and the activation function-2 (AF-2) domain. Nuclear receptors can exist as homo- or heterodimers with each partner binding to specific response element secuences that exis: as half-sites separated by variable length nucleotide spacers between direct or inverted half-site repeats (Olefsky, 2001). There are four categories of nuclear receptors (Manglesdorf et al.1995). Class 1 receptors include the steroid hormone receptors, which function as homodimers binding to half-site response element inverted repeats. Class 2 receptors exist as heterodimers with RXR and function in a ligand dependent manner. The class 3 receptors are the orphan receptors, which function as homodimers binding to direct repeat response elements. Class 4 receptors function as monomers, binding to a single half-site response element.

A key function of nuclear receptors is the regulation of gene expression. This is achieved through recruitment of coactivators and transcription factors to the target 
Figure 4. Structure/function organization of nuclear receptors. (Copied from Olefsky (2001) J. Biol. Chem. 276:36863-36864). 
Figure 4

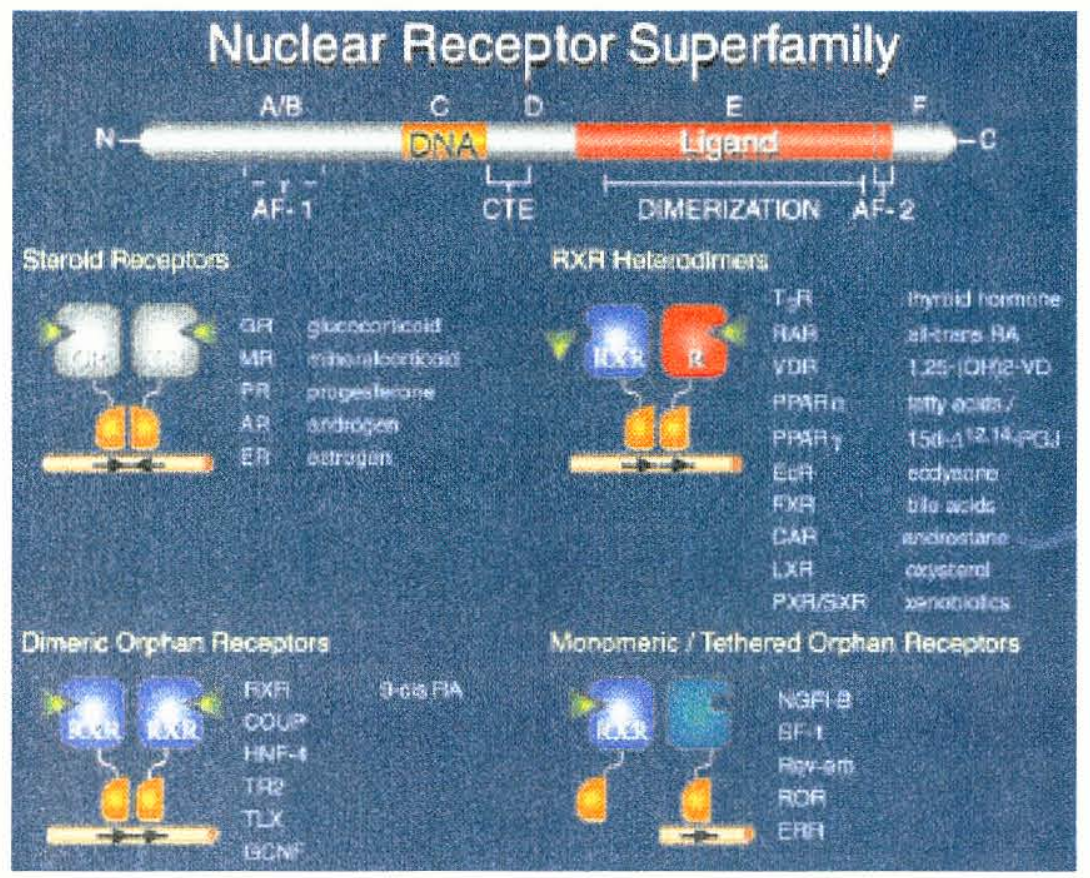


promoter, as well as chromatin remodeling. Several transcription factors are known to exist. For the purpose of this project, I will describe a group of transcription factors known as oxidative-stress sensitive transcription factors. These include activator protein1 (AP-1), nuclear factor $\mathrm{kB}(\mathrm{NF} \mathrm{kB})$, and nuclear factor E2-related factor $2(\mathrm{Nr} 2)$.

\section{OXIIDATIVE STRESS-SENSITIVE TRANSCRIPTION FACTORS}

Oxidative stress in the cell occurs when there is a production of more reactive oxygen or nitrogen species than antioxidants. These reactive oxygen species include hydrogen peroxide $\left(\mathrm{H}_{2} \mathrm{O}_{2}\right)$, hydroxyl radical $(\mathrm{OH})$, superoxide anion $\left(\mathrm{O}_{2} \cdots\right)$ and orgainic peroxides. Oxidative stress can damage cells by causing lipid peroxidation, protein. and nucleic acid modification. In order to prevent damage, cells have developed an antioxidant defense system that includes non-protein antioxidants (Vitamin C, I) and I.. glutathione) and protein antioxidants or enzymes; glutathione reductase, calalase urd superoxide dismutase. Another class of enzymes known as xenobiotic metabolizing enzymes such as glutathione $S$-transferase and quinone oxidoreductase can prevent oxidative stress by metabolizing chemicals that generate oxidative stress. The expression of many of these xenobiotic metabolizing enzymes is regulated by the oxidative stresssensitive transcription factors $\mathrm{AP}-1, \mathrm{NF}-\mathrm{kB}$ and $\mathrm{Nrf} 2$.

AP-1 is a redox-sensitive transcription factor and a member of the basic leucinc zipper family of proteins. AP-1 family members include Fos, Jun and activating transcription factor (ATF). AP-1 exists as different dimeric combinations of basic leucine zipper proteins from the Jun (c-Jun, JunB, and JunD), and Fos (c-Fos, FosB, Fra-1, and Fra-2), and ATF (ATF2, ATF3, B-ATF) families. Jun proteins form homodimers that 
bind to the AP-1 DNA recognition clement known as TPA (12-O-tctradecanoyl-phorthol13 acetate) response element or TRE. The TRE consensus sequence is 5'-TGAG/CTCA3' (Angel et al., 1987). Unlike Jun, Fos family members do not form stable homodimers. Instead, they function as heterodimers composed of Fos and Jun family member protcins. Fos and Jun heterodimerize, forming an X-shaped structure that binds to the palindromic TRE (Glover and Harrison, 1995). A common feature of the AP-1 transcription factors is a basic DNA binding domain and a leucine zipper domain collectively known a.s bZIP domain (Figure 5). The leucine zipper domain is responsible for dimerization of the protein, a prerequisite for DNA binding. The basic domain is used for INA bindin!: Whereas the bZIP domain has been well characterized, less is known about the struetura! properties of the transactivation domain. The activity of AP-1 transeription factors is regulated by many factors including cytokines, stress signals. growth factors. and oncogenic stimuli. Posttranslational regulation of AP-1 involves phosplong latin a the mitogen-activated and stress-induced protein kinases (MAPKs). Three MAPK familics have been identified in vertebrates. These are c-Jun N-terminal kinase (INK), the extracellular regulating kinase (ERK) and the p38 kinase (Robinson and Cobb. 1947).

The c-Jun N-terminal kinases (INK) are comprised of three isoforms namely JNK1, JNK2 and JNK3 (Davis, 2000). JNK is activated by a series of events in the MAPK cascade. The kinase cascade is activated by compounds like acrolein (Ranganna ct al.. 2002), butylated hydroxylanisole (BHA) and its metabolite tertiary butylated hydroquinone (tBHQ) (Keum et al., 2006) and 4-HNE (Uchida et al. 1999). The MAlk kinase kinase (MAPKK kinase) phosphorylates and activates the MAPK kinase (MAPKK) (Hibi et al., 1993). Activated MAPKK in turn phosphorylates and activates 
Figure 5. Functional domains of the activator protein-1 transcription factor. The bZIP domain of Jun is shown in blue and the bZIP domain of Fos in red. The DNA backbone is shown in yellow. The Jun and Fos proteins exhibit several domains, including the bZIP domain (leucine zipper plus basic domain), transactivation domains and docking sites for several kinases, such as JNK or ERK. INK phosphorylates serine residues within the transactivation domain of Jun at position 63 and 73 and thereby regulating its transactivation activity. Copied from Hess et al. (2004). Journal of Cell Science $117(5965-5973)$. 


\section{Figure 5}

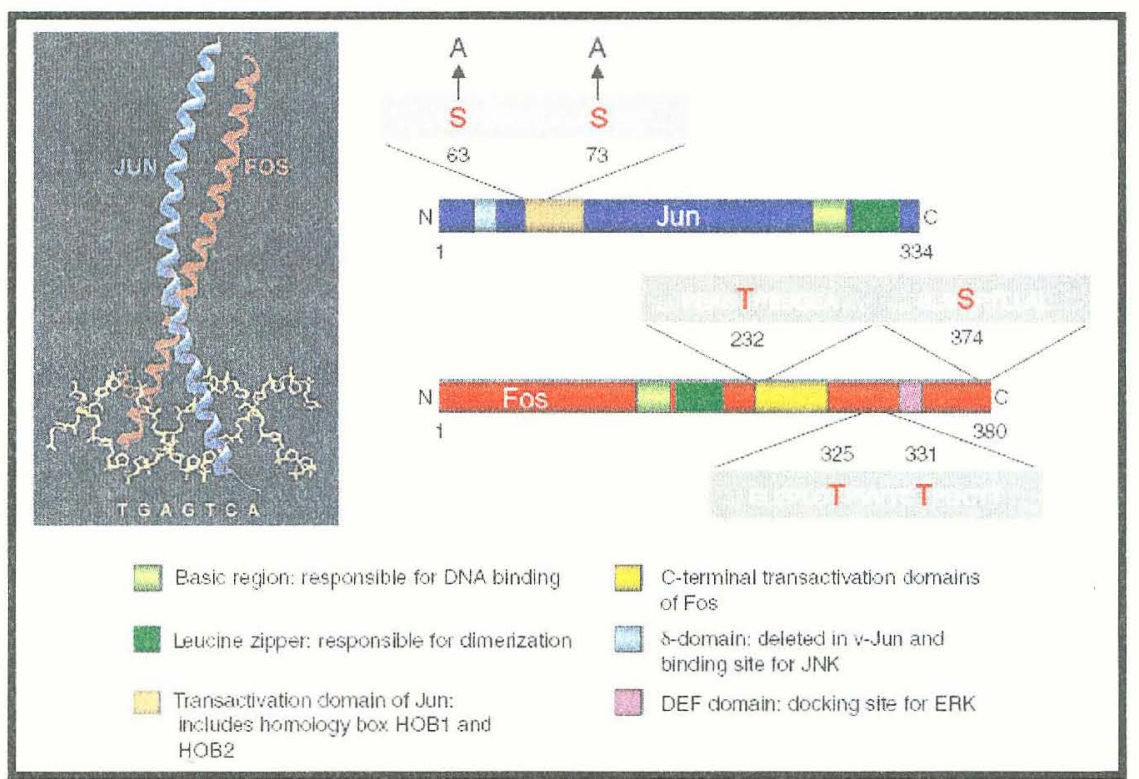


MAPK, which then phosphorylates JNK. Upon activation by the M $\triangle P K$ cascade, the JNKs translocate to the nucleus, where they phosphorylate Jun within its N-terminal domain at serine residue 63 and 73. Activated JNK is also implicated in the phosphorylation-dependent activation of transcription factor $\mathrm{Nr} 2$.

Nuclear factor $\kappa B(N F-\kappa B)$ is also a redox-sensitive transcription factor. $N F_{-\kappa B}$ family members include p50/p105, p52/p100, p65/RelA, RelB, c-Rel. Dosal. Dil. and Relish (Karin, 1999). Under basal condition. NF-KB is sequestered in the cytoplasm as an inactive complex with its inhibitor $\mathrm{I} \kappa \mathrm{B}$. Exposure to oxidative stimuli leads to the phosphorylation and proteasomal degradation of $\mathrm{I} \kappa \mathrm{B}$, thereby releasing $\mathrm{NF}-\kappa \mathrm{B} . \mathrm{N}-\mathrm{KB}$ activation is also mediated by tumor necrosis factor $\alpha$ (TNF $\alpha$ ), interleukin ! (II - I). bacterial lipopolysaccharide (LPS), viral double stranded RNA and ionizing radiation. These cause the phosphorylation-induced degradation of $\mathrm{I} \mathrm{B}$ and the distuption of $\backslash \mathrm{Y}-\mathrm{k}\}$ from ! $K B$. Free $N F-k B$ dimers then translocate to the nucless wher the bin to th: promoter of target genes and regulate their transcription. (Karin., 1999: Schmid et al., 1995).

The transcription factor nuclear factor E2-related factor $2(\mathrm{Nr} 2)$ is a key roulaton of ARE/EpRE - -driven transactivation of antioxidant genes. The cis-acting elencent known as the antioxidant response element (ARE) or electrophile response element (EpRE) is located in the promoter region of many genes encoding antioxidant and detoxifying enzymes. Nrf2 is a basic region-leucine zipper (bZip)-type transcription factor (Itohe al. 1995). Under basal conditions, NrP2 is sequestered in the cytoplasn: $5 y$ binding to Keap 1 protein, thereby repressing nuclear activation of the $\mathrm{ALE}$ by $\mathrm{Nr} 2 \mathrm{I}$ (oh ef al. 1999). Upon activation, Nrf2 dissociates from Keap], translocates to the ruteless 
and binds to the ARE as a heterodimer with the small Maf protein (Itoh ef (il. 1997) to induce gene expression.

Several factors can cause the dissociation from Keapl and activation of $\mathrm{N} \mathrm{rf}^{2} 2$. Nrf2 can be activated by exogenous compounds, endogenous products of oxidative stress or other stresses generated inside the body, such as 4-hydroxy-2-nonenal Numawaza of al., 2003; Ishii et al., 2004). Other compounds like BHA and tBHQ (Keum et al., 2006) also activate $\mathrm{Nrf2}$. tBHQ is the prototypical inducer of ARE driven genes and is a maior metabolite of the phenolic antioxidant BHA. tBHQ functions to disrupt Nrf2 from Kcap i by increasing the phosphorylation of JNK, which in turn, phosphorylates $\mathrm{Nr} 2$. NrP is then released from Keap1, and translocates to the nucleus (Keum et cl., 2006). The phosphorylation of Nrf2 occurs on serine residue 40 (Chen and Kong, 2004 ; Krak el al.. 2004). There is also compelling evidence that some strong electrophilic compounds can cause Nif2 release by direct interaction with Keap1. This occurs through the covalent modification of cysteine residues $\mathrm{C}^{257}, \mathrm{C}^{273}, \mathrm{C}^{288}$, and $\mathrm{C}^{297}$ on Keapl (Dinkora-Kostova ct al., 2002).

The ARE motif was originally identified by a mutagenesis study of the rat is lYa ARE (Rushmore and Pickett, 1990). The consensus sequence is $5^{\circ}$ ( $/$ G)TGACnnnGC-3'; n represents any nucleotide. The ART has been datected in the promoter region of the genes encoding GST-Ya (rat and mouse; liriling et cl. . 1990; Rushmore et al., 1990), GST-P' (rat; Okuda et al., 1989), and rat and human NQO-1 (Favreau and Pickett, 1991; Li and Jaiswal, 1992), mouse heme oxygenase-1 (HO-1) (Prestera el al., 1995), $\gamma$-glutamylcysteine synthetase ( $\gamma$ GCS) heavy subunit (Mulcahy 
and Gipp, 1995), mouse GST-M1 and M3 (Reinhart and Pearson, 1993), and mouse ferritin light chain (Wasserman and Fahl, 1997).

Little is known about the regulation of cytochrome P450 gene expressien by lipid aldehydes acting through the oxidative stress-sensitive transcription factors. but lately there is increasing evidence that these transcription factors may regulate P450 gene expression.

The purpose of my research project is two-fold. 1 . To determine the role of cy tochromes $\mathrm{P450}$ in the metabolism of 4-IINE; 2. To investigate the regulation of cytochrome $\mathrm{P} 450$ gene expression by lipid aldehydes. This is the first exterisive study of the P450s involved in lipid metabolism. 


\title{
CHAPTER II
}

\section{CYTOCHROMES P450 CATALYZE TIIE MET ABOLISM OF $\alpha, \beta-$ UNSATURATED ALDEHYDES}

\author{
(The oxidation reactions in this chapter were published in Archives of Biochemistry \\ and Biophysics 464:187-196(2007)).
}

\section{INTROIOUCTION}

$\alpha, \beta$-Unsaturated aldehydes are highly reactive molecules formed by biological and chemical processes. These aldehydes include propene-2-al (acrolein), trans-2hexenal, and 4-hydroxy-2-nonenal (4-HNE). Acrolein is a toxic environmental aldchyde. formed by combustion processes or metabolism of drugs like cyclophosphamide (Boor, 1983). It is among the most chemically reactive aldehydes known. Trans-2-hexenal is a major plant natural product formed from oxidation of linolenic acid that provides the odor of apples and its closely related form is cis-2-hexanal which accounts for the smell of freshly cut grass. In vitro, 4-HNE can be generated from the 9-and 13-hydroperoxides of the (0-6 polyunsaturated fatty acid, linoleic acid (Schneider ef al.. 2001). The concentration of 4-HNE is significantly increased in plasma, various organs, and cell types including liver cells under conditions of oxidative stress (Esterbauer et cl., 1991; Poli and Schaur, 2000). Significant levels of 4-HNE $(1-5 \mu \mathrm{M})$ generated during oxidative stress have been shown to be associated with onset and progression of cardiovascular and neurodegenerative diseases (Awashthi et al., 2003; Srivastava et cl., 2002). For example. modification of low density lipoproteins by 4-HNE renders this lipoprotein more atherogenic and results in foam cell formation. Moreover, 4-IINI: noditied proteins have 
been detected in atherogenic lesions (Esterbauer et al., 1993). At low $\mu \mathrm{M}$ concentrations, 4-HNE affects cell proliferation and shows genotoxic effects (Eckl et al., 1993). (.., Unsaturated aldehydes are also prevalent in the environment and they display toxic effects in $\mu \mathrm{M}$ concentrations (Esterbauer et al., 1991; Awasthi et al., 2003: Srivastava ef al., 2002).

Because of their pathophysiological relevance, attention has been focused during the last decade on the ability of mammals to metabolize aldehydes, including 4-HNE. In vitro, metabolic studies carried out with rat liver subcellular fractions showed that 4-INI: was reduced to 1,4-dihydroxy-2-nonene (DHN) by cytosolic alcohol dehydrogenase (Esterbauer et al., 1985) and oxidized by aldehyde dehydrogenases to 4-hydroxynonenoic acid (HNA). In addition to these products, the glutathione-I INE (GS-HNE) conjugates were rapidly formed during incubation of 4-HNE with hepatocytes, enterocytes, and tumor cells (Siems et cil., 1992; Ramana et al., 2006). In a study carried out after intravenous injection of 4-HNE into rats, four mercapturic conjugates were characterized in the urine, namely 1,4-dihydroxy-2-nonene mercapturic acid, 4-hydroxynonenal mercapturic acid, 4-hydroxynonenoic acid mercapturic acid, and the corresponding lactone mercapturic acid derivatives (Alary et al., 1995); glutathione conjugates of 4HNE and 1,4-dihydroxy-2-nonene were also observed. These results were further confirmed by De Zwart et al. (1996) demonstrating that conjugation of 4-HNE: with GSH is a high capacity, first pass metabolic step in the elimination of this aldehyde.

Cytochromes P450 (P450) are enzymes that metabolize xenobiotics and endogenous and compounds. They are integral membrane-bound heme-containing proteins, localized in the endoplasmic reticulum of hepatocytes (Black, 1992) and 
extrahepatic tissues as a complex with NADPH:P450) oxidoreductase (CYPOR) (Nelson and Strobel, 1987). A number of reports have demonstrated that exposure to high concentrations of aldehydes. e.g. 4-HNE; inactivate these hemoproteins in a direct or mechanism-based reaction (Kuo et al., 1997). The sensitivity of P450s to 4-IINE is varied, with CYP2B4 and CYP2B1 being inactivated to the greatest extent and $2 \mathrm{C} 3,1 \Lambda 2$, 2E1, and $1 \mathrm{~A} 1$ to a lesser extent. The $\mathrm{K}_{\text {inactivation }}$ for 4 -HNE is normally greater than 0.3 $\mathrm{mM}$ for these P450s. However, levels of lipid-derived aldehydes probably do not normally attain sufficiently high levels in vivo to cause extensive inactivation of the P450s. $A$ role for cytochromes P450 in the metabolism of endogenous and exogenous $\alpha, \beta$-unsaturated aldehydes has not been fully established. In this study, we demonstrate that mammalian cytochromes P450, namely, mouse Cyp2c29, human CYP $3 \wedge 4$ and CYP2B6, and rabbit CYP2B4, catalyze the facile oxidation of $\alpha, \beta$-unsaturated aldehydes to their carboxylic acids at low $\mu \mathrm{M}$ concentrations of aldehyde substrate, while some enzyme inactivation occurs at higher concentrations. Using mouse liver microsomes and primary hepatocytes in conjunction with selective P450 inhibitors, we show that, in addition to aldehyde dehydrogenase, some hepatic P450s, such as CYP2B6, CYP3A4. CYP2C29 and CYP2J2 participate significantly in oxidative metabolism of these aldehydes and display low $\mathrm{K}_{\mathrm{M}}$ values for these reactions. Interestingly, in addition to the oxidation reaction, we observed that CYP3A4, CYP32B6, CYP31A2, Cyp2c29 and CYP32J2 also participate in the reduction of 4-HNE to 1,4-dihydroxy-2-nonene.

\section{MATERIAIS AND METIIODS}


Chemicals and plasmids. The expression plasmid. pCW-Cyp2c29, with Cyp2c29 cDNA cloned into Nde I and Hind III restriction enzyme site was provided by J.A. Goldstein. National Institutes of Environmental Health Sciences, Research Triangle Park, NC (Luo et al., 1998). The CYPOR expression plasmid was provided by Mark Doll and David Hein, Department of Pharmacology and Toxicology, University of I ouisville School of Medicine. All plasmids were restriction enzyme digested to confirm the identity of the cDNA of interest. Preparations of Escherichia coli membranes containing recombinant $\mathrm{CYPOR}$ and $\mathrm{CYP} 1 \mathrm{~A} 2,2 \mathrm{~B} 6,2 \mathrm{E} 1$, or $3 \mathrm{~A} 4$ were prepared as described (Guengerich and Martin, 1999). In these preparations, the ratio of P450 to CYPOR was noted to be between 0.8-2.0. Human CYP2J2 and CYPOR expressed in insect cells was gencrously provided by Darryl Zeldin, National Institutes of Environmental I fealth Sciences, Research Triangle Park, NC. Anthracene-9-carboxaldehyde (9-AA), ()anthracene methanol (9-AMeOH) and anthracene-9-carboxylic acid (9- $\triangle \mathrm{C} A$ ) were purchased from Sigma-Aldrich Chem. St. Louis, MO and dissolved in DMSO before use. ${ }^{3}[\mathrm{H}]-4-\mathrm{HNE}$ was prepared as described previously (Srivastava el al., 2002). and 4-HNE was purchased from Calbiochem, San Diego, CA. The HN $\Lambda$ standard was gencrated by incubating 4-HNE with yeast aldehyde dehydrogenase (Sigma Chemical Co.. St. Louis, $\mathrm{MO}$ ) and, after monitoring $\mathrm{NAD}^{+}$reduction for completion of the reaction, the products were extracted into ethyl acetate (Srivastava et al., 2002; Ramana ef al., 2006).

Escherichia coli growth conditions. Glycerol stocks containing dual expression plasmids, pCW-Cyp2c29 and pACYC-1 Duet CYPOR gene in E. coli BI.21 (Dl:3) served as innoculum for the expression experiment. Cells were grown overnight with 
vigorous shaking $(250 \mathrm{rpm})$ at $37^{\circ} \mathrm{C}$ in Luria broth containing $54 \mathrm{mg} / \mathrm{mI}$, of ampicillin and $34 \mathrm{mg} / \mathrm{mL}$ chloramphenicol. $A 1 / 1000$ dilution of E. coli cells was made into $500 \mathrm{~mL}$, of Terrific Broth and grown at $37^{\circ} \mathrm{C}$ to an optical density of 0.6 at $600 \mathrm{~nm}$. One hour prior to induction, the growth medium was supplemented with $0.5 \mathrm{mM} \delta$-aminolevulinic acid. Enzyme expression was then induced with $1 \mathrm{mM}$ isopropyl- $\beta$-D-thiogalactopyranoside and the culture incubated at $30^{\circ} \mathrm{C}$ with orbital shaking at $190 \mathrm{rpm}$. $\Lambda \mathrm{fter} 48 \mathrm{~h}$, the cells were harvested by centrifugation at $5,000 \mathrm{x}$ for $10 \mathrm{~min}$. The cell pellet was suspended in $100 \mathrm{mM}$ Tris buffer, $\mathrm{pH} 7.8$, containing $20 \%$ glycerol $(\mathrm{v} / \mathrm{v})$, and $0.5 \mathrm{mM}$ EDTA to achieve a volume equal to $15 \%$ of the original volume of culture. Membrane preparation was carried out at $4^{\circ} \mathrm{C}$ as described (Richardson et al., 1995) with some modifications. Lysozyme was added to a final concentration of $0.2 \mathrm{mg} / \mathrm{mL}$, and an equal volume of icecold water with gentle stirring. After an additional 30 min of stirring, the resulting spheroplasts were centrifuged at $8,000 \mathrm{xg}$ for $10 \mathrm{~min}$ and resuspended in 0.05 volume of TMK buffer (50 mM Tris- $\mathrm{HCl}$, pH 7.3, $50 \mathrm{mM} \mathrm{KCl}$ and $10 \mathrm{mM} \mathrm{MgCl}_{2}$ ). The cell pellet was frozen at $-80^{\circ} \mathrm{C}$ and upon thawing, a protease cocktail for bacterial cells (Sigma, St. I.ouis Mo.) was added as recommended by the manufacturer. The spheroplasts were lyzed by sonication using six 10-sec pulses at $40 \%$ power using a Branson 200 series sonificr fitted with a micro tip. Cell debris was removed by centrifugation at $5,000 \times \mathrm{g}$ for $10 \mathrm{~min}$, and the supernatant was ultra-centrifuged at $143.000 \mathrm{xg}$ for $60 \mathrm{~min}$. The resulting membranes were suspended in $10 \mathrm{mM}$ potassium phosphate buffer, $\mathrm{pH} 7.4$ containing 20\% glycerol and $0.1 \mathrm{mM}$ EDTA by homogenizing in a Potter-Elvehjem homogenizer to form spherosomes and stored at $-80^{\circ} \mathrm{C}$ until used. 
Preparation of mouse liver microsomal fractions. Male C5713L/6J mice (22 g to $27 \mathrm{~g}:$ Jackson Laboratories, Bar Harbor, MA) were fed ad libitum for 1 week with AIN-76A dict (Purina Test Diet, Richmond, IN) or AIN-76A diet supplemented with 0.45\% BHA. All procedures for handling the mice were approved by the University of Louisville IACUC Committee and conformed to the Public Health Service Policy on Humane Care and Use of Laboratory Animals. Animals were anaesthetized with $\mathrm{CO}_{2}$ and euthenized by spinal dislocation prior to harvesting the liver into ice-cold $0.9 \% \mathrm{NaCl}$ solution. The livers were cut into small pieces and homogenized in a Potter-Elvehjem homogenizer (Sears Drill Press Stand Model 25921, Chicago IL) with 4 volumes of $50 \mathrm{mM}$ potassium phosphate buffer, pH 7.4, containing $0.25 \mathrm{M}$ sucrose per gram of liver. Microsomal fractions were isolated by differential centrifugation as described by Remmer et al. (1966). Microsomal fractions were resuspended in $0.1 \mathrm{M} \mathrm{Tris-HCl}$ buffer (ply 7.4). containing $0.25 \mathrm{M}$ sucrose and sedimented a second time. The final preparation was resuspended in Tris- $\mathrm{HCl}$ buffer containing sucrose and $10 \%$ glycerol and stored at $-80^{\circ} \mathrm{C}$.

Determination of protein and $\mathbf{P 4 5 0}$ content. Total protein concentrations were determined by measuring formation of bicinchoninic acid- $\mathrm{Cu}^{+}$complex at $562 \mathrm{~nm}$ (Pierce Chemical Co, Rockville, IL). P450 content was determined by the CO-difference spectra of dithionite reduced P450 (Omura and Sato, 1964) using a Varian Model 50 spectrophotometer (Varian, Palo Alto, CA). Cytochrome P450 content was calculated by assuming a molar extinction coefficient of $91 \mathrm{mM}^{-1} \mathrm{~cm}^{-1}$. The $\mathrm{P} 450$ content of liver microsomal fractions from untreated C57BL/6J mice was $0.23 \mathrm{amol} / \mathrm{mg}$. The final homogenization of membranes to obtain spherosomes resulted in significant loss of 
Cyp2c29 activity. Volk et al. (1995) observed a remarkable tendency of this P450 to dissociate from membranes during homogenization. It is possible that this results in the loss of activity due to conversion to the inactive P420. The maximum amount of active Cyp2c29 obtained in spherosomes was $1.52 \mathrm{nmol} / \mathrm{mg}$ of protein.

NADPH:Cytochrome P450 oxidoreductase activity measurement. The co-expression of each P450 of interest and the CYPOR was performed using E. coli BL21 (DE3). The activity of CYPOR in spherosomes was determined by measuring the reduction of the artificial substrate cytochrome $c$. The reactions were carried out at $37^{\circ} \mathrm{C}$ in $0.05 \mathrm{M}$ potassium phosphate buffer, pH 7.4 containing $40 \mu \mathrm{M}$ cytochrome $c$, diluted aliquots of the spherosome (contain the P450 and CYPOR), and $100 \mu \mathrm{M}$ NADPH. The absorbance change was monitored at roon temperature at $550 \mathrm{~nm}$ with a Cary 50 Bio UV-Visible spectrophotometer. The CYPOR activity was determined assuming a molar extinction coefficient of $21 \mathrm{mM}^{-1} \mathrm{~cm}^{-1}$ (Masters et al., 1966). During the preparation of spherosomes several fractions were tested and that with the highest CYPOR activity (Figure 6) was then used in metabolism assays. Similar fractions were used for the reconstitution experiments.

Primary hepatocyte culture. Male Sprague-Dawley rats (180 g-200 g; Hsd:SD, I Iarlan Indianapolis, IN) were used for liver perfusion as described by the method of Bayliss and Skett (1996). Cell survival was determined by trypan blue exclusion (Berry et al., 1991) and hepatocytes having viability greater than $80 \%$ were plated at a density of $4 \times 10^{6}$ cells/dish onto 60-mm plastic dishes precoated with collagen in Williams E-F12 1:1 
mixed medium described by Ferrini et al. (1998) and Isom et al. (1984). After allowing the cells to attach for $4 \mathrm{~h}$, the medium was changed and renewed every 24 h thereafter in the absence of serum. The cells were treated with $50 \mu \mathrm{M} 4-\mathrm{HNE}$ and the reactions terminated at 0,10 , and 20 min with trichloroacetic acid (TCA) to achieve 7.5 TCA concentration. The resulting samples were frozen at $-80^{\circ} \mathrm{C}$ prior to analysis by IPIC C as described below. The inhibitors $(0.5 \mathrm{mM}$ miconazole, phenytoin, or cyanamide) were added just prior to 4-HNE. When $0.5 \mathrm{mM}$ troleandomycin was added as an inhibitor to the hepatocytes, the cells were pre-incubated with troleandomycin 10 min prior to adding 4-HNE.

\section{Purification of rabbit liver cytochrome CYP2B4 and NADPH:cy tochrome P450}

oxidoreductase. CYP2B4 was purificd from rabbit liver in the Prough Laboratory as described by Dean and Gray (Dean and Gray, 1982) to a purity of approximately 18 nmol hemoprotein/mg protein. Rabbit liver CYPOR was purified by the method of Yasukochi and Masters (1976) to a specific activity of $38.2 \mu$ mol cytochrome $c$ reduced per min per mg flavoprotein. Both preparations displayed a single major protein band upon analysis by SDS-PAGE.

Cvtochrome $\mathbf{P 4 5 0}$ activity assay. CYP3A activity was determined in mouse liver microsomes by measuring $O$-dealkylation of the benzyl ether of resorufin to the fluorescent product, resorufin (Prough et al., 1978). Reactions were carried out at $37^{\circ} \mathrm{C}$ in $2 \mathrm{~mL}$ volume with $1 \mathrm{mM}$ NADPH, and $0.25 \mathrm{mg} / \mathrm{mL}$ (50 nM P450) microsomal protein in $0.1 \mathrm{M}$ potassium phosphate buffer, $\mathrm{pH} 7.4$. The production of resorufin was monitored at 
Figure 6. Determination of cytochrome $c$ reductase activity in membranc fractions. NADPH-cytochrome P450 oxidoreductase was expressed in E. coli and membrane fractions called spherosomes prepared by sonication, centrifugation and homogenization. CYPOR activity was then determined by measuring cytochrome $c$ reduction using enzyme-containing spherosomes, spherosomes from mock-transformed plasmid or the pellet obtained from centrifugation. The reduction of cytochrome $c$ was measured at 550 $\mathrm{nm}$. Oxidoreductase activity was used to calculate the concentration of CYPOR using the factor $1.360 \mu \mathrm{mol}$ cytochrome $c$ reduced per minute per $\mu \mathrm{M}$ of oxidoreductase protein (Yasukochi and Masters, 1976). The data is the mean \pm SD of a triplicate incubation. 


\section{Figure 6}

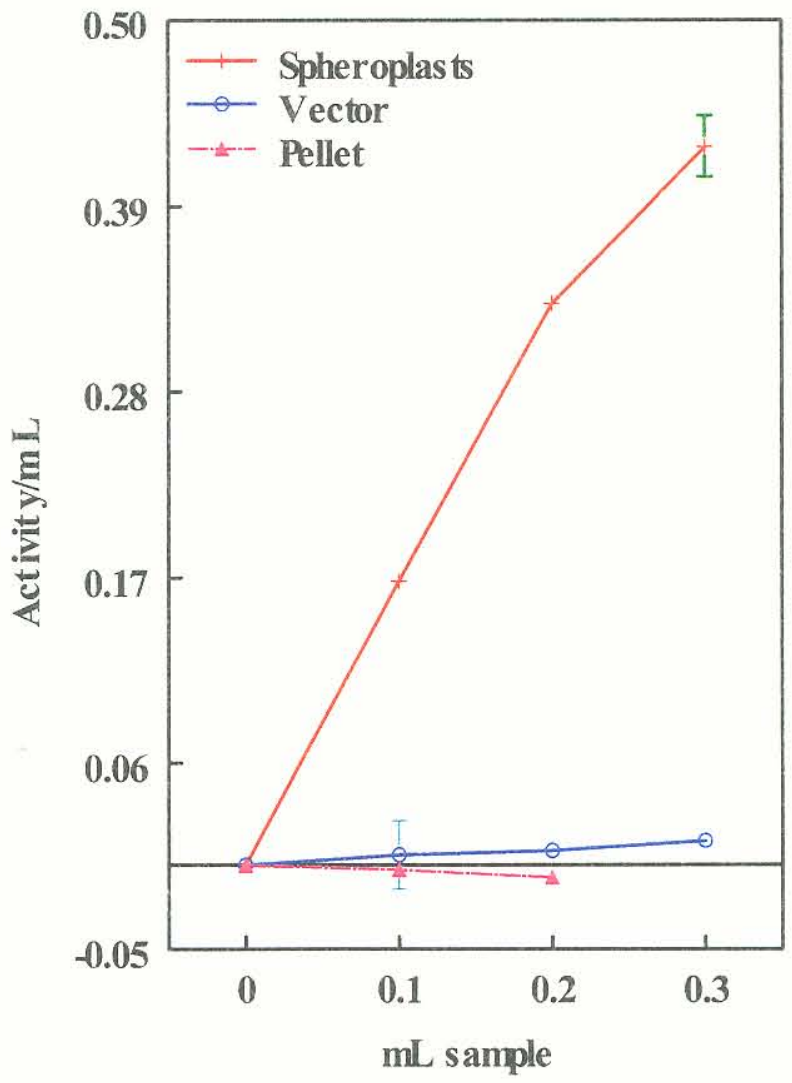


an excitation wavelength of $535 \mathrm{~nm}$ and emission wavelength of $586 \mathrm{~nm}$ with a luminescence spectrometer (Model I.S50B, Perkin-Flmer, Boston, MA). A standard curve for the product, resorufin, was constructed to calculate enzyme activity normalized to microsomal protein concentration.

Anthracene-9-carboxaldehyde oxidation assay. The oxidation of anthracene-9carboxaldehyde (9-AA) by P450 enzymes was determined by measuring the formation of anthracene-9-carboxylic acid (9-ACA) as described by Watanabe et al., 2002 and Marini et al., 2003. In brief, the incubation mixture included recombinant P450s (50 nM) or mouse liver microsomes $(0.25 \mathrm{mg} / \mathrm{mL}, \sim 50 \mathrm{nM} \mathrm{P} 450)$, an NADPH-regenerating system consisting of $100 \mu \mathrm{M} \mathrm{NADPH}, 4.25 \mathrm{mM}$ isocitric acid, $50 \mathrm{mM} \mathrm{MgCl}_{2}$, and $1.3 \mathrm{Units} / \mathrm{ml}$, isocitrate dehydrogenase, $25 \mu \mathrm{M}$ 9-AA, and $0.1 \mathrm{M}$ potassium phosphate buffer, pH 7.4 The reaction was carried out at $30^{\circ} \mathrm{C}$ for $10-30 \mathrm{~min}$ and terminated with $1 \mathrm{mI}$ of $0.5 \mathrm{~N}$ $\mathrm{NaOH}$. Ethyl acetate $(4 \mathrm{~mL})$ was added to allow product separation between the aqueous and the organic phase. The formation of $9-\mathrm{AMeOH}$ was determined in the alkaline organic phase at $255 \mathrm{~nm}$ excitation and $411 \mathrm{~nm}$ emission wavelength with a spectrofluorimeter (Model LS50B). Aqueous phase (1 mL) was subsequently acidified with $1 \mathrm{~mL}$ of $0.5 \mathrm{~N} \mathrm{HCl}$ and 9-ACA extracted with $4 \mathrm{~mL}$ ethyl acetate. The fluorescence of 9-ACA in the acidic organic phase was measured at $255 \mathrm{~nm}$ excitation and $458 \mathrm{~nm}$ emission wavelengths (Figure 7). The fluorescence excitation and emission spectra of the metabolites was nearly identical to authentic anthracene-9-carboxylic acid and 9anthracene methanol. The 9-AA metabolism assay was used as an initial indication of aldehyde oxidation or reduction by $\mathrm{P} 450 \mathrm{~s}$. 
The 9-AA metabolism assay was also performed with reconstituted CYP2B4. CYP2B4 and CYPOR were separately expressed in E coli and spherosomes containing both enzymes used. The reconstitution was performed in $0.05 \mathrm{mM}$ dilauroylphosphatidylcholine, $86 \mathrm{nM}$ pig CYPOR and $50 \mathrm{nM}$ CYP2B4. The incubation reaction was initiated by adding $100 \mu \mathrm{M}$ NADPH and continued for 10 min at $30^{\circ}(\therefore$. The reaction was terminated with $1 \mathrm{~mL}$ of $0.5 \mathrm{~N} \mathrm{NaOH}$ and products extracted using $4 \mathrm{mI}$, ethyl acetate as previously described.

Metabolism of 4-HNE by cytochrome P450s. 4-HNE metabolism was performed by incubating $50 \mu \mathrm{M}\left[{ }^{3} \mathrm{H}\right]-4-\mathrm{HNE}$ with either $E$. coli expressed $\mathrm{P} 450(50 \mathrm{nM})$ or mouse microsomal protein $(0.25 \mathrm{mg} / \mathrm{mL}, \sim 50 \mathrm{nM}$ P450). Incubations were carried out in $0.1 \mathrm{M}$ potassium phosphate buffer, $\mathrm{pH} 7.6$, containing $0.5 \mathrm{mM}$ NADPH in a $1 \mathrm{~mL}$ reaction volume for $20 \mathrm{~min}$ in a $37^{\circ} \mathrm{C}$-water bath with orbital shaking at $200 \mathrm{rpm}$. The NADPII regenerating system was not used with 4-HNE due to the formation of additional analytes associated with the isocitrate/isocitrate dehydrogenase mixture. Recombinant P450s (50) nM), purified rabbit CYP2B4 (200 nM P450 plus 600 nM CYPOR) or mouse liver microsomes $(0.25 \mathrm{mg}$ protein $/ \mathrm{mL})$ were analyzed for aldehyde oxidation activity. The reaction was initiated by adding $50 \mu \mathrm{M}\left[{ }^{3} \mathrm{H}\right]-4-\mathrm{HNE}$. The reactions were terminated after $20 \mathrm{~min}$ incubation by flash freezing sample tubes in liquid nitrogen. The frozen samples were thawed upon adding TCA and the denatured protein sedimented at 13,000 x 9 for 5 min at $4^{\circ} \mathrm{C}$. The supernatant was injected into the HPLC column after an aliquot was removed to measure radioactivity in a Packard Tricarb $2100 \mathrm{TR}$ scintillation counter (Packard Instrument Co., Downers Grove, II.) with Ultimagold (Packard Instrument Co., 
Figure 7. Procedure to measure 9-anthracene aldehyde metabolites. 9-Anthracene aldehyde $(25 \mu \mathrm{M})$ was incubated with P450 as described under methods. 9-anthracene methanol was extracted into the organic phase of the basic incubation reaction and measured at $\lambda$ excitation $255 \mathrm{~nm}$ and $\lambda$ emission $411 \mathrm{~nm}$. Aqueous phase $(1 \mathrm{~mL})$ was acidified with $0.5 \mathrm{~N} \mathrm{HCl}$, followed by extraction with $4 \mathrm{~mL}$ ethyl acetate, and 9anthracene carboxylic acid was measured in the organic phase at $\lambda$ excitation $255 \mathrm{~nm}$ and Remission $458 \mathrm{~nm}$. 
Figure 7

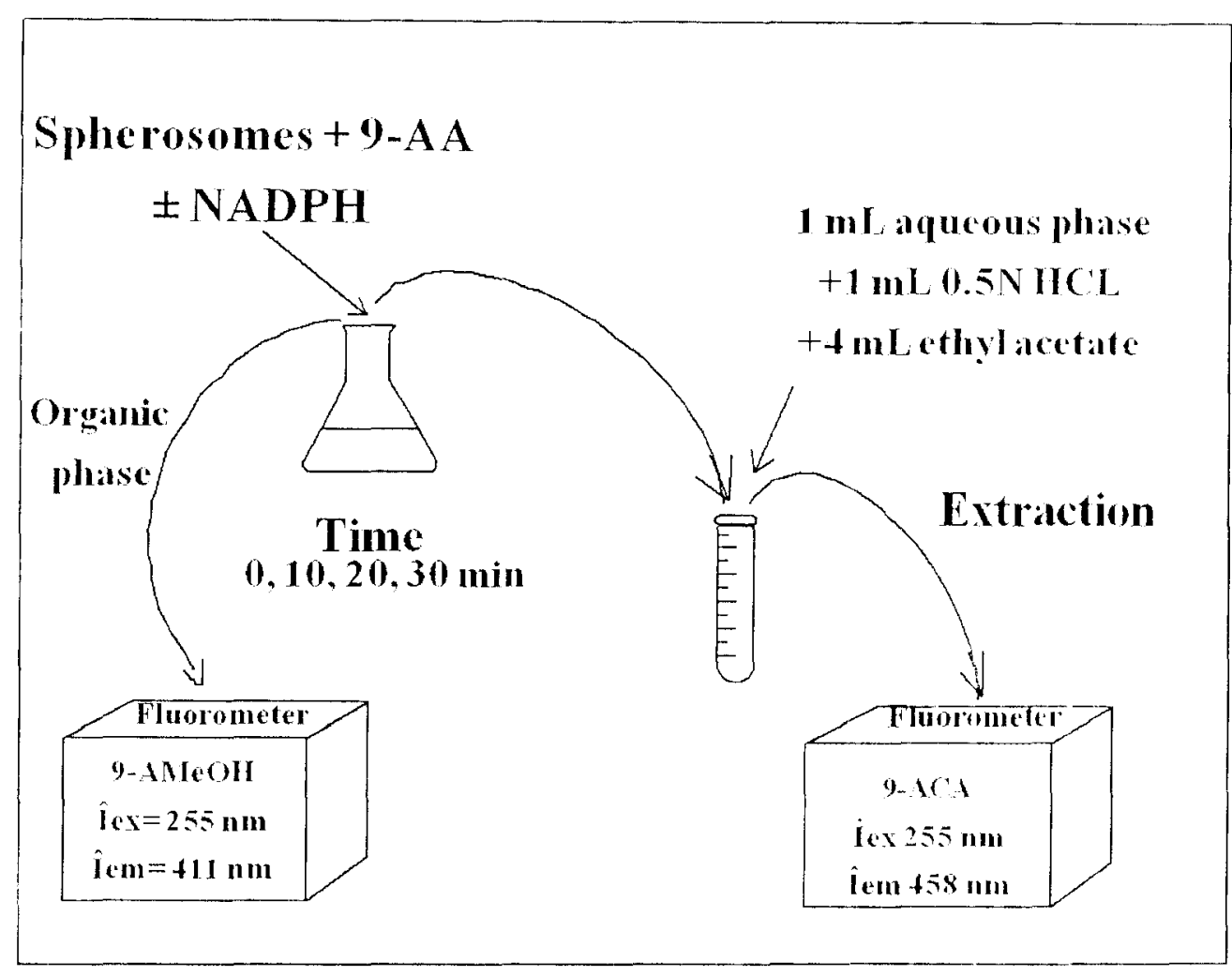


Downers Grove, IL) as the scintillation cocktail, prior to separation by high performance liquid chromatography. The recovery of $\left[{ }^{3} \mathrm{H}\right]$ radioactivity from the reaction mixtures were $>98 \%$ and the recoveries from HPLC were determined to be $>95 \%$. All of the P450s displayed linear reactions to 20 min with $4-\mathrm{HNE}$.

Inhibition of aldehyde metabolism by cytochrome P450 inhibitors. Metabolic assays with cither 9-AA or 4-HNE were performed with either membranes containing expressed P450 or mouse liver microsomes as described above. except for the addition of selective inhibitors. Phenytoin and troleandomycin $(0.5 \mathrm{mM})$ were used to inhibit Cyp2c29 and Cyp3a, while cyanamide $(0.5 \mathrm{mM})$ was used as an inhibitor of aldehyde dehydrogenase. Miconazole $(0.5 \mathrm{mM})$ was utilized as a general inhibitor of $\mathrm{P} 450$. Troleandomycin was preincubated with microsomal or expressed P450 fractions and $0.5 \mathrm{mM}$ NADPII for 10 min before 9-AA or $\left.{ }^{3} \mathrm{H}\right]-4-\mathrm{HNE}$ was added. Miconazole, phenytoin, and cyanamide were added to the reaction immediately prior to the aldehyde substrate.

\section{Anaerobic metabolism of 9- $\Lambda \mathrm{A}$ and 4 -HNE by mouse liver microsomes. The} incubation reaction was prepared as described above for 9-anthracene aldehyde and 4IINE: in an Erlenmeyer flask fitted with a serum stopper fitted with syringes. First, the buffer was bubbled for 5 min with carbon monoxide or argon followed by addition of the P450. A mixture of glucose $(74 \mathrm{mM})$, glucose oxidase $(0.33 \mathrm{mg} / \mathrm{mL})$ and catalase $(1400$ $\mathrm{U} / \mathrm{mL}$ ) was also added. The headspace of the reaction mixture was llushed with either carbon monoxide or argon for $3 \mathrm{~min}$ and the reaction initiated with $100 \mu \mathrm{M}$ NADPH. The reaction was conducted for $20 \mathrm{~min}$ and during this time, the headspace of the reaction 
was continuously flushed with either argon of carbon monoxide. The reaction was terminated by adding $\mathrm{NaOH}$ (for the 9-AA incubation) or frozen in liquid nitrogen (the 4HNE incubation). Extraction of products was performed as described above.

Kinetic analysis of 9-AA metabolism by Cyp2c29. The reaction contained prepared sonicated membranes (containing both $50 \mathrm{nM} \mathrm{CYP2c29}$ and approximately $100 \mathrm{nM}$ CYP(OR), 0.1 M potassium phosphate buffer $\mathrm{pH} 7.4$, and the NADPH-regenerating system. The membranes were co-incubated with $25 \mu \mathrm{M}$ or $50 \mu \mathrm{M} 4$-I INE and increasing concentrations of 9 -anthracene aldeyde for $10 \mathrm{~min}$ at $30^{\circ} \mathrm{C}$ shaking at $200 \mathrm{rpm}$. The reaction was terminated with $0.1 \mathrm{M} \mathrm{NaOH}$ and product extracted with ethyl acetate as described above. Fluorimetric measurements were performed as described above. Analysis of the data was performed using the Kineti77 program (Clark and Carol, 1986).

High performance liquid chromatography (IIPLC). The HPLC system consisted of a Waters automated gradient controller with dual model 510 pumps (Milford, M $\wedge$ ). a Waters manual injector ( $2 \mathrm{~mL}$ loop) and a C18 reversed phase column $(5 \mu \mathrm{m}, 250 \mathrm{~mm} \mathrm{x}$ $4.6 \mathrm{~mm}$ Varian, Walnut Creek, CA) connected to a radioactivity detector (Radiometric Flo-one B model A-515 detector, Packard Instrument Co., Downers (irove, IL) or to a fraction collector (Biorad Model 2210 Biorad. Hercules, $\mathrm{CA}$ ). The mobile phase was a linear gradient ranging from $100 \%$ solvent $\mathrm{A}(0.1 \%(\mathrm{v} / \mathrm{v}) \mathrm{TFA}$ in water $)$ to $100 \%$ solvent B (40\% solvent $A, 60 \%$ acetonitrile). Solvents were delivered at a flow rate of $1 \mathrm{~mL} / \mathrm{min}$ for 75 min as follows: linear gradients from $100 \%$ to $76 \%$ solvent $\Lambda(0-15 \mathrm{~min})$. from $76 \%$ A $1074 \%$ A (15-40 min), from $74 \%$ to $40 \%$ A (40-45 min), from $40 \%$ to $0 \% \wedge(45-$ 
$60 \mathrm{~min})$, and then eluted with $100 \% \wedge(60-75 \mathrm{~min})$. 'The conditions were changed to $100 \% \mathrm{~A}$ over 10 minutes prior to starting the next run. The incubation and HPLC analysis were performed in triplicate.

\section{Gas chromatography-electrospray ionization/mass spectrometry of 4-HNE}

metabolites. For GC-MS analyses, the samples were derivatized in $20 \mu \mathrm{L}$ of acetonitrile with $20 \mu \mathrm{L}$ of $\mathrm{N}, \mathrm{O}$-bis(trimethylsilyl)-trifluoroacetamide (BSTFA) for 1 h at $60^{\circ} \mathrm{C}$ as described previously (Srivastava et al., 2000). The mixture was cooled to room temperature and $1 \mu \mathrm{L}$ aliquots were used for analysis. The GC-EI/MS analysis was performed using an Agilent 6890/5973 GC/MS system (Agilent Technologies) under 70 eV electron ionization conditions. The compounds were separated on a bonded phase capillary column (DB-5MS, $30 \mathrm{~m} \times 0.25 \mathrm{~mm}$ ID $\times 0.25 \mu \mathrm{m}$ film thickness from $\mathrm{I7} \mathrm{W}$ Scientific Folsom, CA, USA. The GC injection port and interface temperature were set to $280^{\circ} \mathrm{C}$. with helium gas (carrier) maintained at 14 psi. Injections were made in the splitless mode with the inlet port purged for 1 min following injection. The GC oven temperature was held initially at $100^{\circ} \mathrm{C}$ for $1 \mathrm{~min}$, and then increased at a rate of $10^{\circ} \mathrm{C}$ $\min ^{-1}$ to $280^{\circ} \mathrm{C}$, which was held for $5 \mathrm{~min}$. Under these conditions, the retention time for HNA derivative was $9.67 \mathrm{~min}$.

Statistical analysis. Experiments were conducted in triplicate and the means and standard deviations (SD) were determined. Where appropriate at Student's t-Test was used for statistical analysis with $\mathrm{p} \leq 0.05$ as the criterion for significance. Alternatively, analysis of variance (ANOVA) was performed when required. 


\section{RESULTS}

\section{Flourescence spectra of the 9-anthracene aldehyde metabolites 9-anthracene}

carboxylic acid and 9-anthracene methanol. The method for measuring 9-anthracenc carboxylic acid, the oxidized product of 9-anthracene aldehyde. had been previously described (Marini et al., 2003). The excitation and emission wavelengths of $255 \mathrm{~mm}$ and $458 \mathrm{~nm}$ respectively were used to measure 9-anthracene carboxylic acid formation. 9anthracene methanol is a reduced product of 9-anthracene aldchyde. Using the Perkin Elmer model 50B spectrofluorimeter we determined the excitation and cmission wavelength of 9 -anthracene methanol to be $255 \mathrm{~nm}$ and $411 \mathrm{~nm}$ respcctively (Figure 8). The emission wavelengths for both 9-anthracene carboxylic acid and 9-anthracene methanol were strikingly different, thus enabling us to measure these products fiom P450 incubation reactions using appropriate standard curves for the two florescent metabolites.

9-Anthracene methanol was measured in the ethyl acetate of the organic phase after raising the $\mathrm{pH}$ with base. The fluorescence intensity of 9-anthracenc methanot was high in this phase suggesting efficient extraction into the organic phase. 9-Anthracene carboxylic acid was extracted into ethyl acetate following acidification of the acpueous phase.

\section{Evaluation of $\mathrm{P450}$ s capable of oxidizing anthracene-9-carboxaldehyde to}

anthracene-9-carboxylic acid. Watanabe et al. (1991) demonstrated that Cyp2c29 is an aldehyde oxygenase utilizing a cannabinoid aldehyde at low $\mu \mathrm{M}$ concentrations as a substrate. Therefore, we sought to evaluate the ability of a number of $\mathrm{P} 450$ s for their ability to oxidize a synthetic aldehyde substrate, 9-A $\Lambda$ (Watanabe et al.. 2002; Marini $e$ t 
al., 2003). Several P450s rapidly metabolized the aldehyde compound, while others apparently did not oxidize this aldehyde to its carboxylic acid (Table 3). For example, (). anthracene aldehyde oxidation activity for human CYP3A4, human CYP2B6, and mouse Cyp2c29 was appreciable, while the ability of CYP1A2. CYP2E1 and CYP2.I2 to oxidiz this model aldehyde was negligible. There were also significant levels of activity seen with liver microsomes from mice $(1.5 \mathrm{nmol} / \mathrm{min} / \mathrm{nmol} \mathrm{P} 450)$. We sought to determine the kinetics of 9-AA oxidative metabolism by murine CYP2c29, as well as the human CYP3A4 (Figure 9). The P450s were incubated with varying concentrations of 9anthracene aldehyde at $30^{\circ} \mathrm{C}$ and subsequently analyzed to determine the $\mathrm{K}_{\mathrm{M}}$ for oxidation to acid. Recombinant mouse Cyp2c29 expressed with CYPOR in L. coli membranes oxidized 9-AA to 9-ACA with a $\mathrm{K}_{\text {cat }}$ of $7.4 \mathrm{~min}^{-1}$ and a $\mathrm{K}_{\mathrm{M}}$ of $7 \pm 0.9 \mu \mathrm{M}$ with apparent normal Michaelis-Menten kinetics. We observed a slight deviation of CYP3A4 from simple Michaelis-Menten Kinctics toward cooperativity. (YYPA4 displayed a $\mathrm{K}_{\text {cat }}$ of $7.6 \mathrm{~min}^{-1}$ and an $\mathrm{S}_{0.5}$ of $15 \mu \mathrm{M}$. These reactions were inhibited by more than $98 \%$ by addition of either $0.5 \mathrm{mM}$ miconazole or by omission of NADPII from the reaction mixture (results not shown). The $\mathrm{K}_{M}$ values were in the $\mu \mathrm{M}$ range. Therefore, we assayed all P450s at a concentration of $25 \mu \mathrm{M}$, since this value was at least 3-10-fold higher than the $\mathrm{Km}$ for Cyp2c29 and CYP3 44.

CYP2B4 was used in a reconstitution experiment to measure 9-A $\mathrm{A}$ metabolism (Figure 10). Reconstitution was performed in dilauroylphosphatidylcholinc and pig CYPOR. The reductase concentration (1.75 fold ratio of reductase to P450) that gave highest activity for the P450 was used in the reconstitution. Maximum oxidation of 
Figure 8. Structure and fluorescence spectra of 9-anthracene aldehyde metabolites. The spectra of (A) 9-anthracene aldehyde (9-AA), its oxidized form, 9-anthracene carboxylic acid (9-ACA) and its reduced form, 9-anthacene methanol (9-AMeOH). (B) Excitation and emission spectrum of 9-ACA, excitation and emission spectra of 9$\mathrm{AMeOH}$. $\mathrm{Y}$-axis $=$ relative fluorescence intensity, $\mathrm{X}$-axis $=$ wavelength $(\mathrm{nm})$. 

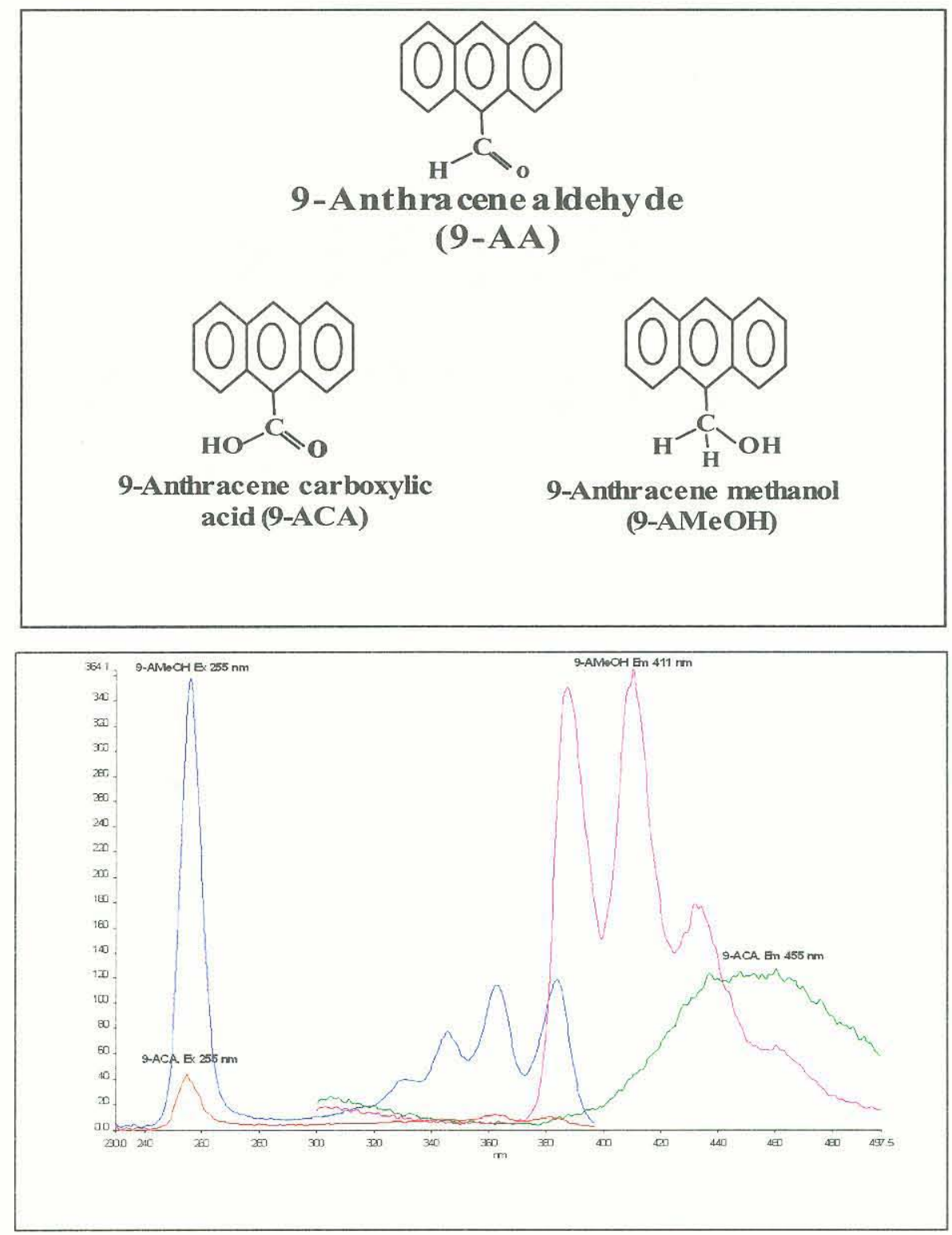


\section{Figure 9. Concentration dependence of oxidative metabolism of 9-anthracene}

aldehyde Cyp2c29 and CYP3A4. The concentration of 9-AA was varied and the initial rates of metabolism measured in the presence of an NADPH regencrating system.

NADPII, and either recombinant Cyp2c29 or CYP3A4. The P450 concentrations were 50 $\mathrm{nM}$ and both P450s were expressed into E. coli spherosomes with their flavoprotein oxidoreductase, NADPH:CYPOR. The data were mean \pm SD collected in triplicate and analyzed using a double reciprocal plot. The $\mathrm{K}_{\mathrm{m}}$ and $\mathrm{S}_{0.5}$ values are shown. 
Figure 9

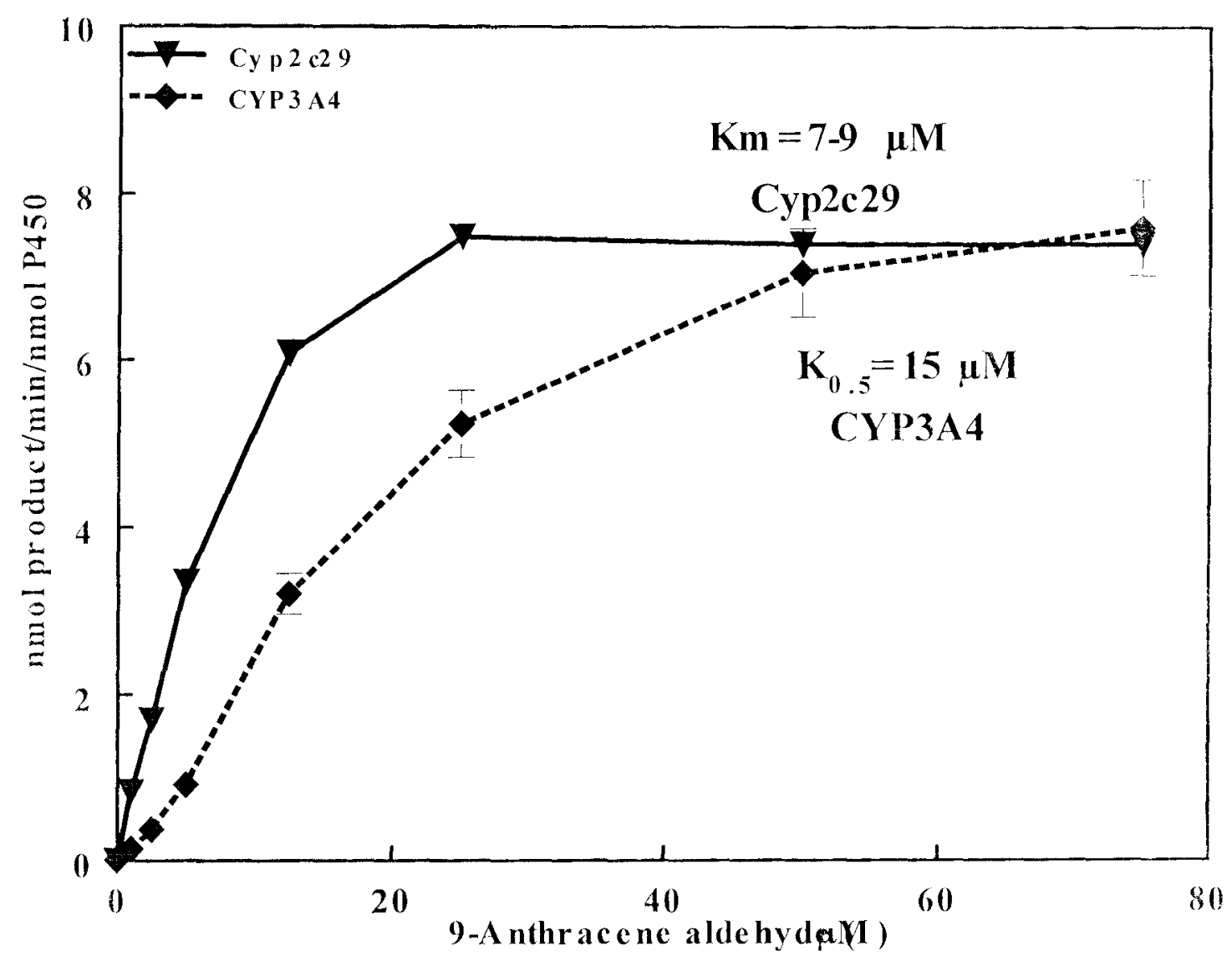


9-AA was observed when CYP2B4, the reductase and dilauroylphosphatidylcholine were all present. Little reduction of 9-AA was observed for this P450.

Analysis of 4-IINE metabolites generated by CYP2B4. HPLC and gas chromatography-mass spectrometry were used to characterize the oxidative metabolites of 4-HNE formed by recombinant cytochromes P450. $\left[{ }^{3} \mathrm{H}\right]-4-\mathrm{HNE}$ at concentration of 50 $\mu \mathrm{M}$ was incubated with CYP2B4 and CYPOR for $20 \mathrm{~min}$ in the presence of NADPH. Preliminary experiments with the recombinant samples demonstrated that the rates of 4HNE metabolism were linear for this time period. A representative cliromatogram of $4-$ HNE and its metabolites separated by HPLC when oxidized in a reconstituted system containing $200 \mathrm{nM}$ purified rabbit CYP2B4, $600 \mathrm{nM}$ CYPOR, $50 \mu \mathrm{M}$ dilauroylphosphatidylcholine, $0.5 \mathrm{mM} \mathrm{N} \wedge \mathrm{DPH}$, and $50 \mu \mathrm{M}$ 4-INNE is shown (ligure 11). Spontaneous decomposition of 4-HNE during the extraction and resolution procedure was minimal, as shown by the limited formation of any analytes that were retained slightly longer than 4-INE at the zero time point (Figure 11A). Morcover, when NADPH-P450 oxidoreductase and dilauroylphosphatidyl choline were reconstituted in the absence of $\mathrm{P} 450$, little product was formed (Figure 11B). Identical results were obtained when the NADPH, the oxidoreductase, or P4502B4 was omitted (results not shown). When all three components were reconstituted over a 20 min incubation period. $3 \%$ of the total ${ }^{3}[\mathrm{H}]-4-\mathrm{HNE}$ was converted to a product with a retention time $\left({ }_{k}\right)$ of 56 minutes (Figure 11C, Table 3), indicating that this rabbit P450 effectively metabolized 4HNE to one major product. Based on the co-migration of the authentic 4hydroxynonenoic acid standard generated with yeast aldehyde dehydrogenase, we 
Figure 10. Metabolism of 9-Anthracene by reconstituted CYP2B4. The reconstitution of CYP2134 was conducted in $50 \mu \mathrm{M}$ dilauroylphosphatidylcholine, $86 \mathrm{nM}$ pig NAIPPH:CYPOR and $50 \mathrm{nM}$ CYP2B4. Incubation with 9-AA $(25 \mu \mathrm{M})$ was initiated by adding $100 \mu \mathrm{M} \mathrm{NADPH}$ and continued for $10 \mathrm{~min}$ at $30^{\circ} \mathrm{C}$. Formation of $9-\mathrm{ACA}$ and 9AMeOH was determined by spectrofluorometry. Data represent the mean S.I. of a triplicate incubation. Statistical significance was determined using the Student's / test. *** Significant increase in 9-AA oxidation in the presence of CYP2B4, CYPOR and dilaurcylphosphatidylcholine, $p<0.001$. 
Figure 10

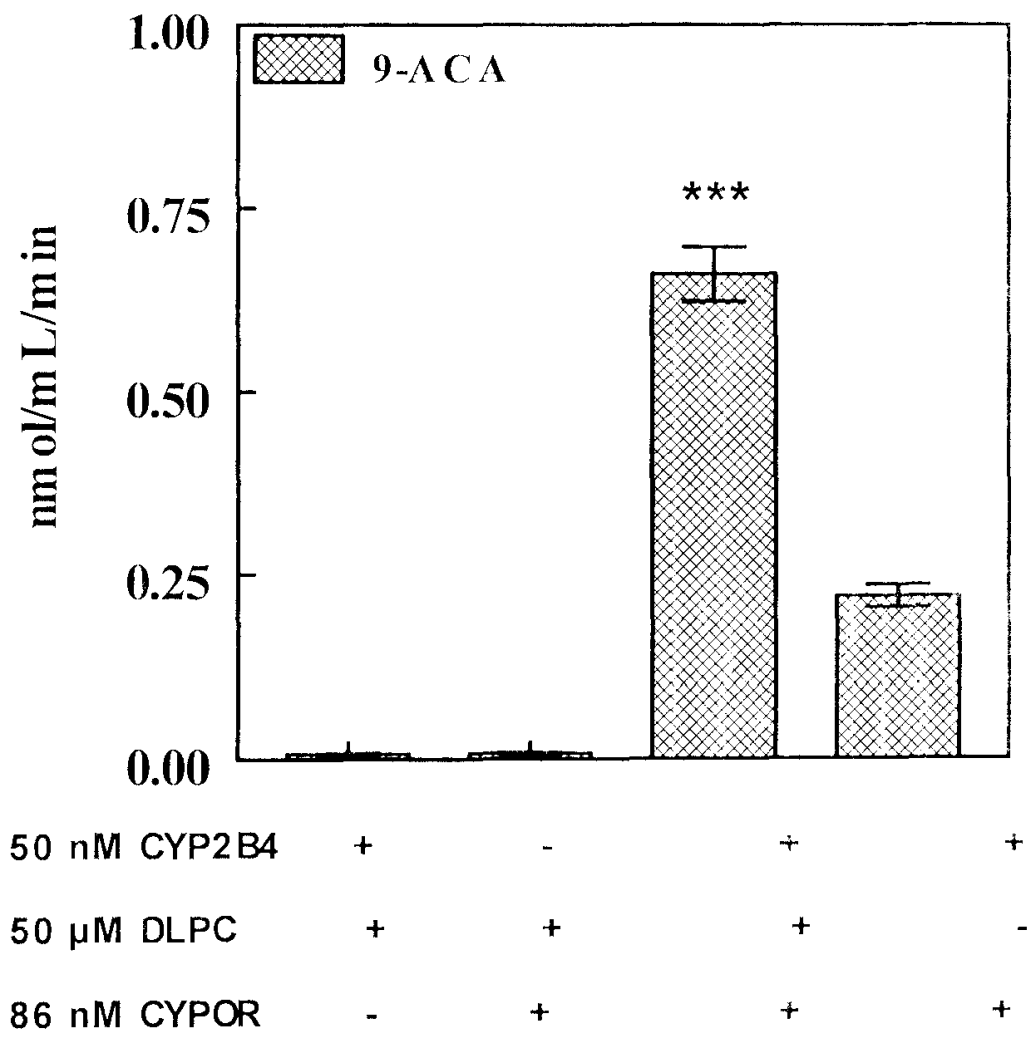


tentatively assigned the identity of the product with a retention time generated by CYP2B4 to 4-hydroxy nonenoic acid. An unknown metabolite (3\% conversion, putative lactone) eluted slightly more slowly than the substrate 4-HNE $\left(I_{R} 60 \mathrm{~min}\right.$ for the unknown and $t_{R} 58 \mathrm{~min}$ for 4-HNE); this analyte was present at zero time with purified.

reconstituted $\mathrm{CYP} 2 \mathrm{~B} 4$ and did not increase with time. Inclusion of $0.5 \mathrm{mM}$ miconarole as a P450 inhibitor with the fully reconstituted CYP2B4 system completely inhibited HNA formation, but had little or no effect on the amount of unknown product generated (Figure 11D), suggesting that it may not be generated enzymatically. NADPII and + HNE incubated alone for $20 \mathrm{~min}$ did not result in analytes other than the small amount of an unknown metabolite (data not shown). These results demonstrate that reconstitution of purified rabbit CYP2B4 with CYPOR and lipid results in metabolism of 4-HNE to 4-

hydrexynonenoic acid. Similar results were obtained with other P450s tested using ['H]4-HNE, cxcept that several P450s displayed products eluting in the region near that scen with the unknown metabolite and several displayed products that were more polar than 4 hydroxynonenoic acid. These results demonstrate that CYP2B4 generates 4hydroxynonenoic acid from the oxidation of 4-HNE.

\section{Evaluation of P450s in oxidative metabolism of 4-HNE to 4-hydroxynonenoic acid.}

Using a fixed concentration of $50 \mu \mathrm{M} 4-\mathrm{HNE}$, we examined several P450s as catalysts for oxidation of this aldehyde to its carboxylic acid. After metabolism, the products were analyzed by HPLC with radiometric detection of product. The reactions with either CYP2C29 or CYP3A4 were shown to be linear to 20 min with $50 \mu \mathrm{M}$ 4-HNE substrate. Using a fixed concentration of $50 \mu \mathrm{M} 4-\mathrm{HNE}$, we examined several P'450s as catalysts 


\section{Figure 11. The reconstitution of 4-HNE oxygenation activity catalyzed by rabbit}

CYP2134. Purified rabbit CYP2B4 was used to catalyze the NADPH-dependent oxygenation of $\left[{ }^{3} \mathrm{H}\right]-4-\mathrm{HNE}$ in the presence of purified CYPOR and dilaurylphosphatidylcholine at $37^{\circ} \mathrm{C}$. The CYP2B4 concentration was $250 \mathrm{nM}$ and the amount of NADPH:cytochrome P450 oxidoreductase was the amount that caused maximal 7-benzyloxyresufin debenzylation in the presence of dilaurylphosphatidylcholine (data not shown). The reaction was linear to 20 minutes and after terminating the reaction with an equal volume of $1 \%$ TFA in water, 4-HINE and its products were analyzed by HPLC with a radiochemical detector. A. Zero time sample. B. 20-Minute time point with reconstituted $\mathrm{P} 450$ and oxidoreductase without dilaurylphosphatidylcholine. C. 20-minute incubation reaction with reconstituted CYP2134, oxidoreductase and dilaurylphosphatidylcholine. The arrow points to the putative 4-hydroxynonenoic acid peak. D. 20-minute incubation reaction with reconstituted CYP2B4, oxidoreductase and dilaurylphosphatidylcholine in the presence of $0.5 \mathrm{mM}$ miconazole. $\mathrm{L}$ is the tentative lactone peak, $1 \mathrm{~L}=$ reconstitution in lipid alone, $\mathrm{R}+\mathrm{I}+\mathrm{E}=\mathrm{r}$ reconstitution in CYPOR, lipid and CYP. 


\section{Figure 11}
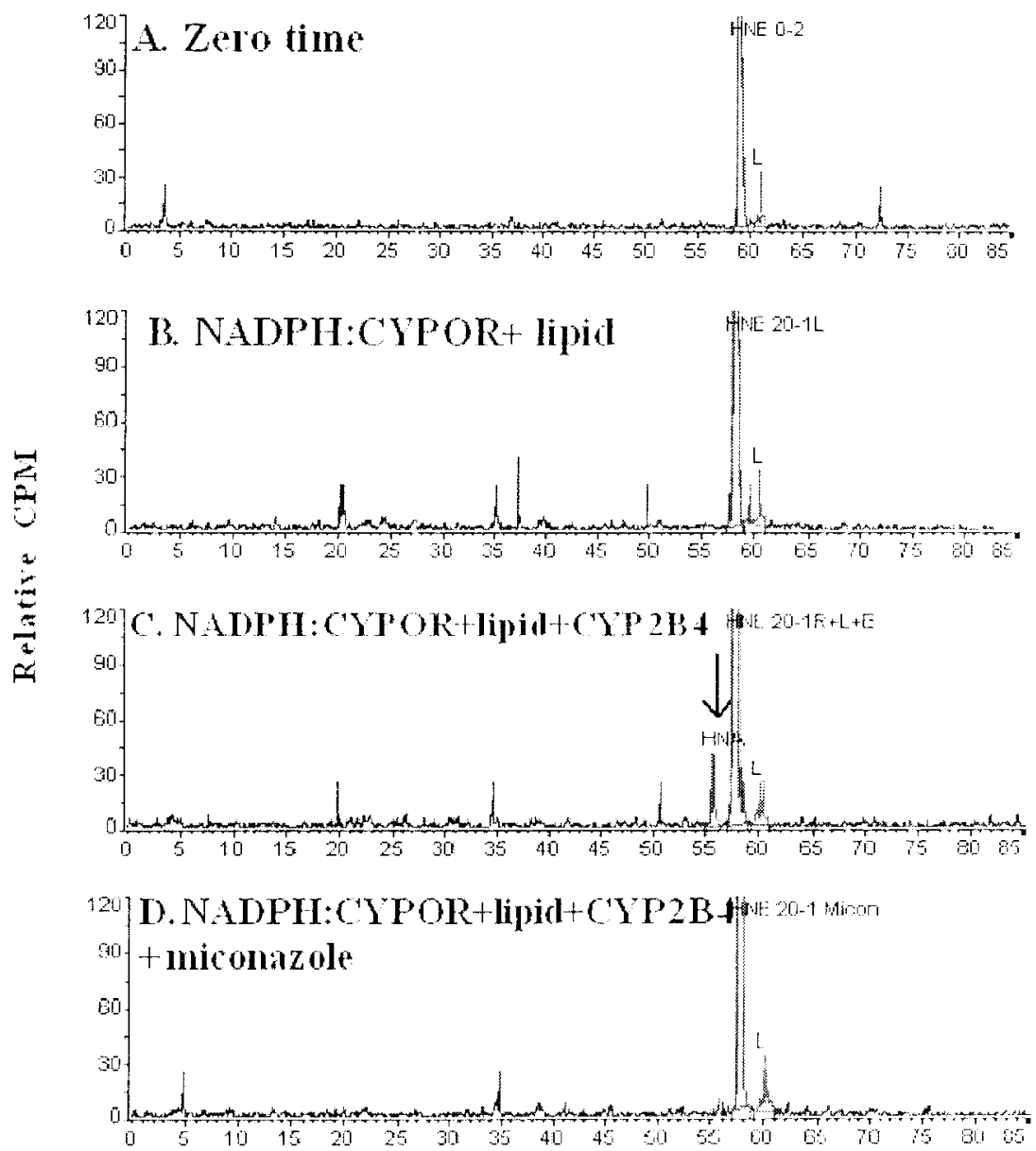

Retention Time ( $R$ : enim) 
for oxidation of this aldehyde to its carboxylic acid. After metabolism, the products were analyzed by HPLC with radiometric detection of product. The reactions with either CYP2c29 or CYP3A4 were shown to be linear to $20 \mathrm{~min}$ with $50 \mu \mathrm{M} 4$-HNE substrate. In addition to the reconstituted rabbit CYP2B4, some human and murine P450s also catalyzed 4-HNE metabolism. The rates of 4-HNE oxidation shown in Table 3 were in the order of CYP2B $>$ CYP $3 A 4>C y p 2 c 29>C Y P 2 J 2>C Y P 2 B 4$. CYP $1 A 2$ and $C Y P ? E 1$ were analyzed and did not appreciably oxidize 4-HNE.

Mass spectral analysis of products of aldehyde oxidation by P450s. Based on the fluorescence spectra of the products formed from 9-anthracene aldehyde, the products in the aqueous phase of the reaction appear to be identical to that of 9-anthracene carboxylic acid. Iowever, in order to validate that the major product formed from 4-HNE is 4hydroxynonenoic acid, we used HPLC to analyze the ability of Cyp2c29, CYP3А4. CYP2B4, and CYP2B6 to metabolize 4-HNE to its carboxylic acid. The product that comigrated on HPLC analysis with the ALDH-biosynthesized carboxylic acid metabolite was collected and derivatized with $N$-methyl- $N$-(t-butylidimethylsilyl)trifluoroacetamide prior to analysis by GC-MS. The mass spectra of the AI.DHbiosynthesized product, HNA, was identical to that of the putative HNA product formed by Cyp2c29 (Figure 12). A faint parent peak was noted at $\mathrm{m} / \mathrm{z} 316$, and major ions at $\mathrm{m} / \mathrm{t}$ of $301\left(\mathrm{M}-\mathrm{CH}_{3}\right.$ due to loss of a methyl group from the trimethyl silyl group) and at $\mathrm{m} / \mathrm{z}$ $245\left(\mathrm{M}-\mathrm{C}_{5} \mathrm{H}_{11}\right.$ due to loss of the 5 carbon alkyl side chain to cleavage between $\mathrm{C} 5$ and $\mathrm{C} 6$ of 4-HNE). The mass spectra of the products formed by CYP3A4 and CYP2134 were nearly identical to that observed in the presence of Cyp2c29 (datia not shown), 
Table 3

Catalytic activities of mouse and human CYPs expressed in $E$. coli

\begin{tabular}{|c|c|c|c|c|}
\hline CYP & $\begin{array}{c}\text { 9-AA Oxidation } \\
\text { Activity }\end{array}$ & $\begin{array}{c}\text { 4-HNE } \\
\text { Oxidation } \\
\text { Activity }\end{array}$ & DHN formation & $\begin{array}{c}\text { Iactone } \\
\text { formation }\end{array}$ \\
\hline Cyp2c29 & 7.4 & 0.96 & 0.30 & 7.83 \\
\hline CYP3A4 & 7.6 & 2.39 & 25.1 & 3.83 \\
\hline CYP2B6 & 2.3 & 53.1 & 33.3 & 20.63 \\
\hline CYP2J2 & $<0.1$ & 0.95 & 1.72 & 23.28 \\
\hline CYP2B4 & $?$ & 0.36 & $<0.1$ & 0.03 \\
\hline CYP1A2 & $<0.1$ & $<0.1$ & 7.39 & $<0.1$ \\
\hline CYP2E1 & $<0.1$ & $<0.1$ & $<0.1$ & $<0.1$ \\
\hline Microsomes & 1.5 & 0.37 & 1.02 & 0.45 \\
\hline
\end{tabular}

The enzyme activities are expressed as turnover number and were the average of 4 assalys with a standard deviation of less than $5 \%$ of the average. Mouse liver microsomal fractions were prepared from animals fed AIN-76A dict containing $0.5 \%$ butylated hydroxyanisole for 7 days. The concentration of 9 -AA used was $25 \mu \mathrm{M}$ and of $4-\mathrm{HNE}$ Was $50 \mu \mathrm{M}$. 
Figure 12. Mass spectra of authentic 4-hydroxynonenoic acid and product generated from Cyp2e29-dependent oxidation of $\left[{ }^{3} \mathrm{H}\right]-4-H N E$. After metabolism. the samples were analyzed by HPLC and the fractions eluting with the same retention time as the 4hydroxynonenoic acid standard were collected and subjected to electrospray ionizationmass spectral analysis. A. Authentic 4-hydroxynonenoic acid. B. 4-hydroxynonenoic acid produced by Cyp2c29. 
Figure 12

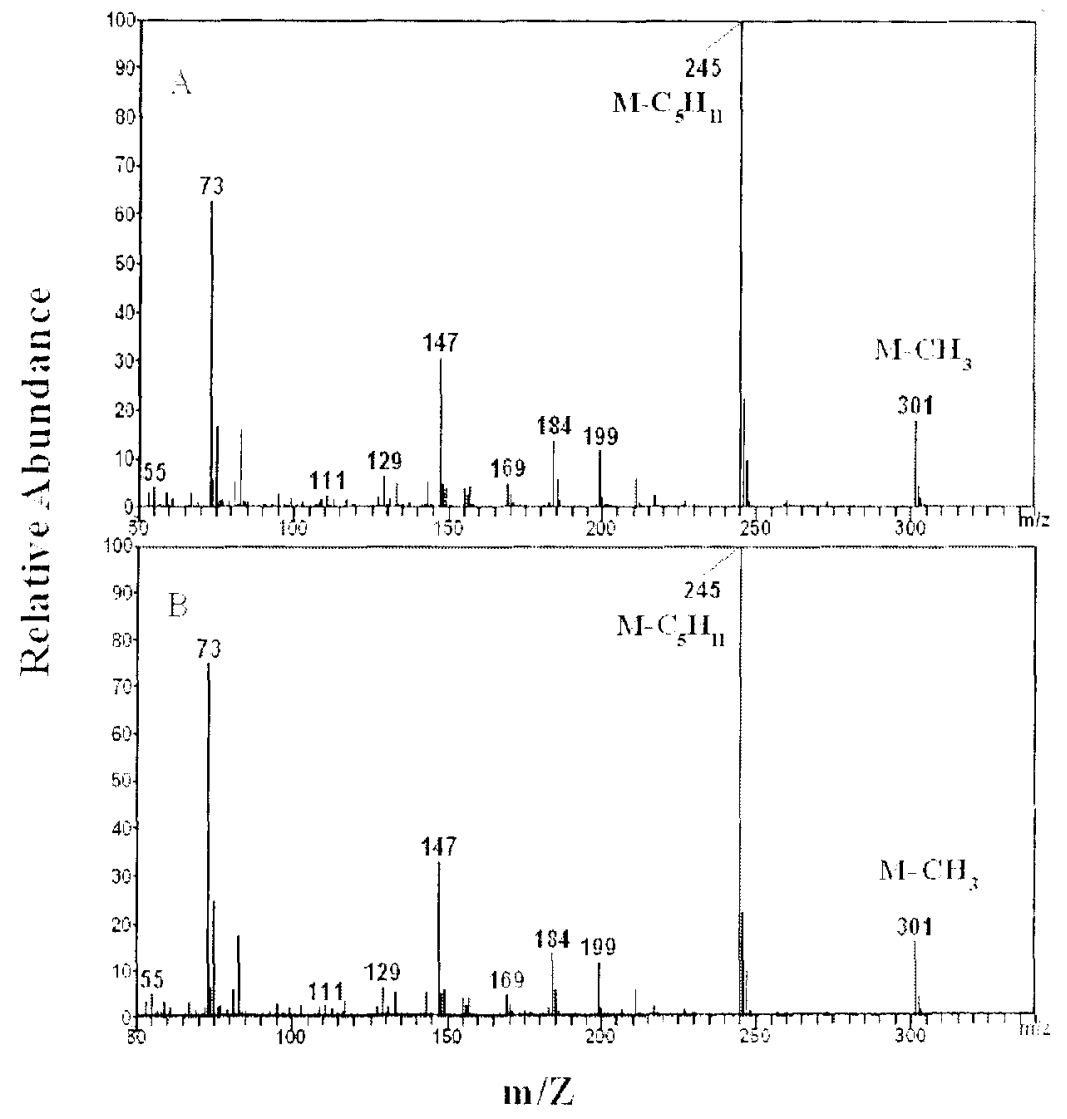


documenting that a primary oxidation product formed from 4-HNE by several P450s was identified as 4-hydroxynonenoic acid, the expected oxidation product.

\section{Kinetic analysis of 4-HNE-inhibition of 9-ACA metabolism catalyzed by Cyp2c2\%.}

The observation that Cyp2c29 catalyzed the oxidation of both 9-anthracene aldehyde and 4-HNE to their carboxylic acids led us to measure the steady-state kinetic parameters for Cyp2c29 oxidation of 9-anthracene aldehyde in the presence of increasing concentrations of 4-HNE. Previous studies by Coon and coworkers (1995) established that ('YP2I:1 is inactivated at high concentrations of 4-HNE (140-400 $\mu \mathrm{M})$. providing a direct tool for us to determine the mechanism of 4-HNE as an inhibitor of 9-anthracene carboxylic acid formation by Cyp2c29 at low. Since $\alpha . \beta$-unsaturated aldehydes may inactivate these P450s, we incubated most of the P450s shown in Table 3 with 4-hydroxynonenal, acrolcin, and trans-2-hexenal to assess whether they are irreversible inhibitors (dati not shown). After 20 minutes incubation, the samples were diluted 10-fold and the 9- $\Lambda \mathrm{C} \wedge$ formation or other enzyme assay measured. Acrolein and trans-2-hexenal had little or no effect on any P450 tested (data not shown), but in the case of 4-HNE. there was some inhibition. However, this inhibition was dependent on the initial concentration of 4-IINF: added. Enzyme kinetic parameters were determined by fitting kinetic data using nonlinear regression analysis to various models using the enzyme kinetic analysis progam Kineti 77 (Clark and Carol, 1989). The best fit for Cyp2c29 was a mixed competitive inhibition by of 9-AA metabolism by 4-HNE (Figures 13). The $\mathrm{V}_{\max }$ for 9-AA oxidation in the absence of 4-HNE was $130 \pm 7$. The apparent $\mathrm{K}_{1}$ of 4-HNE for Cyp2e29 was approximately $32 \pm 4 \mu \mathrm{M}$ calculated from the double reciprocal plot $(1 / \mathrm{V}$ vs. $1 /[\mathrm{S}]$ in the 
presence of 4-HNE; see inset Figure 13A). In separate studies not shown, we determined an apparent $\mathrm{K}_{\mathrm{m}}$ for 4 -HNE oxidation to HNA by Cyp2c29 of $\sim 15 \mu \mathrm{M}$. These results suggest that at low concentrations. 4-HNE is a competitive substrate for (yp2c29 with )$\triangle A$ (Figure 13B). At 4-HNE concentrations above $300 \mu \mathrm{M}$. significant inactivation of many P450s occurs (Kuo et al., 1997). There was no effect of 4-HNE (100 بM) on CYPOR activity with up to 30 min incubation in the presence of NADPH (data not shown).

Oxidation of 9-anthracene aldehyde by mouse liver microsomes. The oxidation of 9 -

$\Lambda \Lambda$ by liver microsomal protein $(0.25 \mathrm{mg} / \mathrm{mL})$ from mice fed with $0.5 \% 13 H \wedge$ in $\Lambda \mathrm{N}$ $76 \mathrm{~A}$ diet was also determined (Table 3). The rate of formation of 9-ACA was 1.5 nmol $/ \mathrm{min} / \mathrm{nmol} \mathrm{P} 450$. In order to deduce which $\mathrm{P} 450$ s may be involved in this reaction in mouse liver microsomes, we used selective cytochrome P450 inhibitors previously established to be effective in primary hepatocytes. Miconazole $(500 \mu \mathrm{M})$ caused approximately 50\% inhibition, as expected (Figure 14). Lower concentrations of miconazole $(100 \mu \mathrm{M})$ caused $20-25 \%$ inhibition suggesting that Cyp3a enzymes may be partially involved in 9-AA oxidation (data not shown). Phenytoin $(500 \mu \mathrm{M})$ is a competitive substrate for Cyp2c29 (Jackson et al.. 2004) and caused approximately 40\% inhibition of $9-\mathrm{A} \Lambda$ oxidation activity. On the other hand, troleandomycin is a specific mechanism-based inhibitor for CYP3A enzymes (Chauret et al., 1997) and incubation of $500 \mu \mathrm{M}$ troleandomycin, $0.5 \mathrm{mM}$ NADPH, and liver microsomes for $10 \mathrm{~min}$ prior to 9 A $A$ oxidation assays, resulted in $40 \%$ inhibition of the reaction in mouse liver mmicrosomes. The aldehyde dehydrogenase inhibitor cyanamide did not significantly 
Figure 13. Kinetic analysis of inhibition by 4-IINE of anthracene-9-carboxaldehyde oxygenation by Cyp2e29. The concentration dependence of 4-HNE inhibition of 9-AA oxidation was performed by incubating increasing concentrations of 9-A A with 0.50 or $100 \mu \mathrm{M} 4-\mathrm{HNE}$ in the presence of $0.25 \mathrm{mg} / \mathrm{mL}$ Cyp2c29-containing spherosomes and $100 \mu \mathrm{M} \mathrm{NADPH}$ at $30^{\circ} \mathrm{C}$ for $10 \mathrm{~min}$ in a shaking water bath. A. $0,0 \mu \mathrm{M} 4-\mathrm{HNE} ; \Delta, 50$ $\mu \mathrm{M}$ 4-HNE, $\square, 100 \mu \mathrm{M}$ 4-HNE. Data shows the mean activity $\pm \mathrm{SD}$ of a triplicate incubation. Inset: double reciprocal plot of $1 /$ rate of metabolism vs. 1/anthracene-9carboxaldehyde concentration. B. Scheme accounting for mixed competitive inhibition. 
Figure 13

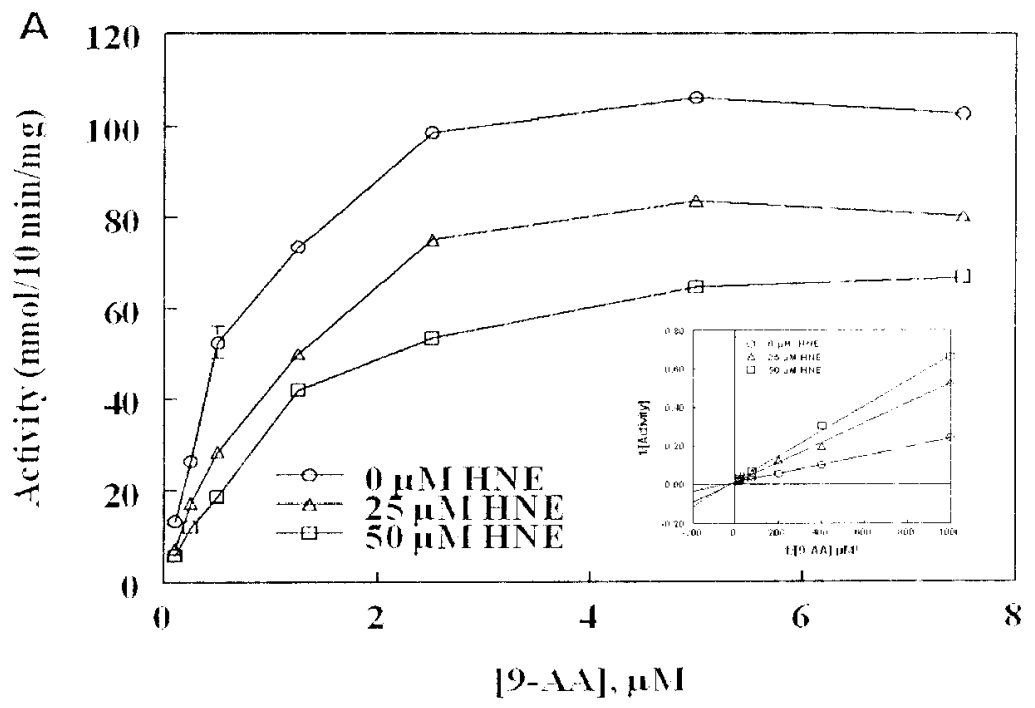

B

$\mathrm{E}+9-\Lambda \mathrm{A} \stackrel{\mathrm{k}^{\mathrm{A}+\lambda}}{\longrightarrow} \mathrm{E}+9-\Lambda \mathrm{CA}$

$\Downarrow+\mathrm{HNE}$
$\mathbf{E}+\mathrm{HNE} \stackrel{\mathrm{k}_{\mathrm{IINE}}}{\longrightarrow} \mathrm{E}+\mathrm{IINA}$

$\overbrace{\text { Inactivation }}^{k_{\text {inutur }}}$ 
inhibit microsomal oxidation of 9-AA, suggesting that there was little or no contribution of ALDH in the microsomal preparation (Table 4). These results demonstrate that roth murine Cyp2c29 and Cyp3a11 (or related P450s) likely catalyzed the oxidation of 9-AA with tiver microsomes from C57BL/6 mice. Further, the partial inhibition by the two compounds suggests the participation of multiple P450s in the microsomal reaction. namely Cyp2c29 and Cyp3a (Table 3).

Metabolism of 4-HNE by mouse liver microsomes. The oxidation of 4 -HNE by mouse liver microsomal protein was also determined by HPLC as described previously (Srivastava et al., 2002). The reaction was performed by incubating $50 \mu \mathrm{M} \Gamma^{3} \mathrm{H} \mid-4-\mathrm{HNl}$, NADPH, and microsomes. 4-HNE was oxidized at a rate of $0.37 \mathrm{nmol} / \mathrm{min} / \mathrm{nmol} \mathrm{P} 450$ (Table 3). As with the E. coli-expressed Cyp2c29, the mouse liver microsomal fractions generated an unknown metabolite $\left(t_{R}=62 \mathrm{~min}\right)$. In addition, a polar metabolite $\left(\mathrm{t}_{\mathrm{R}} \sim 4\right.$ min) was observed near the beginning of the gradient, which has not been characterized to date. Miconazole, a general P450 inhibitor, caused approximately $40 \%$ inhibition of 4 HNE oxidative metabolism to 4-hydroxynonenoic acid by mouse liver microsomal protein fractions (Figure 14). The Cyp2c29 inhibitor phenytoin caused $70 \%$ inhibition of total 4-HNE metabolism, while troleandomycin, a specific inhibitor of Cyp3a, caused $40 \%$ inhibition. These data demonstrate the importance of the two murine P450s. in the oxidation of 4-HNE and suggest that multiple P450s are involved in the oxidative metabolism of 4-HNE. 
Figure 14. The effect of specific inhibitors on mouse liver microsomal aldehyde oxygenase activity for 9-anthracene aldehyde and 4-hydroxynonenal. Liver microsomes from C57BL/6.J mice fed AIN-76A diet supplemented with $0.45 \%$ BHA was used to perform the 9-AA and 4-HNE oxygenase activities. Specilic P450 inhibitors $(0.5$ $\mathrm{mM}$ miconazole or phenytoin) were added to the reaction mixtures or preincubated $(0.5$ $\mathrm{mM}$ troleandomycin) with liver microsomes and NADPH prior to adding aldehyde substrate. The enzyme activities are the mean \pm of a triplicate incubation. Statistical significance was determined using analysis of variance. ${ }^{*}$ Significantly different from the uninhibited control, $p=0.05$. 
Figure 14

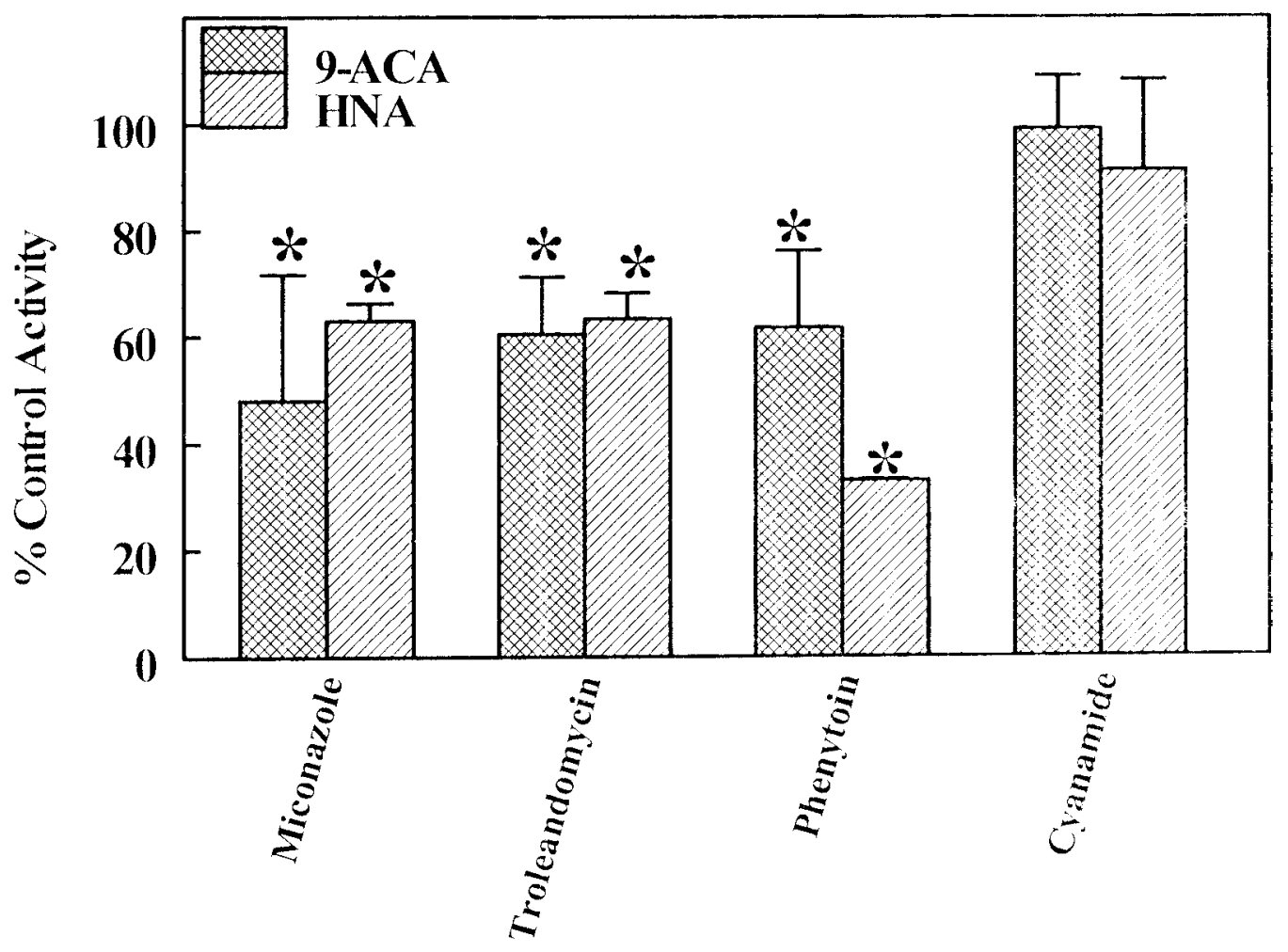

Inhibitor $(0.5 \mathrm{mM})$ 
Table 4

Effect of alcohol dehydrogenase, aldehyde dehydrogenase, and P450 inhibitors on recombinant CYP3A4 activity.

\begin{tabular}{|c|c|}
\hline Inhibitor $(\mathbf{1 0 0} \boldsymbol{\mu M})$ & \% of control activity \\
\hline Control & 100 \\
\hline miconazole & 15 \\
\hline troleandomycin & 3 \\
\hline cyanamide & 92 \\
\hline benomyl & 37 \\
\hline 4-methylpyrazole & 2 \\
\hline
\end{tabular}

The activity of CYP3A4 was measured at $25^{\circ} \mathrm{C}$ using the 7-benzyl ether of resorufin as substrate in the presence of $0.5 \mathrm{mM}$ NADPH and E. coli membranes expressing both CYP3 $\triangle 4$ and NADPH:cytochrome P450 oxidoreductase. The activities were an arerage of three assays and the standard deviation was never more than $5-8 \%$ of the average value. 
Metabolism of 4-HNE in primary cultures of rat hepatocytes. Studics by Petersen and coworkers (Hartley et al., 1995) demonstrated that primary cultures of rat hepatocytes metabolize 4-HNE to its carboxylic acids by oxidative reactions, its dihydroxy form through reductive reactions and its glutathione adduct through GSH conjugation reactions. Based on the use of inhibitors, they concluded that aldehyde dehydrogenases were the major catalysts of the oxidative reaction. However, our results suggest that some P450s are sensitive to the known inhibitors of aldehyde dehydrogenases For example, $100 \mu \mathrm{M}$ benomyl caused $65 \%$ inhibition of CYP3A4 and $1 \mu \mathrm{M} 4$ methylpyrazole, alcohol dehydrogenase inhibitor caused 98\% inhibition of CYP3A4, Table 4. Miconazole and troleandomycin are known to be potent inhibitors of CYP3A (Chauret et al., 1997). Only syanamide was shown to be a specific inhibitor of aldehyde dehydrogenase at $500: 1 \mathrm{M}$. and did it not inhibit benzyloxyresorufin $O$-debenzylase activity of CYP3A4. Since two major classes of enzyme catalyze the oxidation of aldehydes to carboxylic acids, namely aldehyde dehydrogenases and the P450s, we sought to test the reiative participation of these two systems in aldehyde oxidation in a cellular model. Specific inhibitors of $\triangle$ LDH (cyanamide) and P450s (miconazole and troleandomycin) were utilized to determine the relative participation of these enzymes in the metabolism of $\left[{ }^{3} H\right]-4-H N I$ in primary cultures of rat hepatocytes. Because CYP3A4 is inhibited by 4-methylpvrazole and benomyl (Table 4), we did not utilize these inhibitors previously believed to be specific for alcohol dehydrogenase and aldehyde dehydrogenase, respectively. The HPLC profile for the 4-HNE metabolites formed in rat hepatocytes (Figure 15A), polar metabolites (1R 5 min), GSH conjugates of 4-HNE ( $t_{R} 41.5,45$, and 49 min), DHN ( $t_{R} 55$ min), HNA ( $t_{R}$ $57 \mathrm{~min}$ ) and the slower eluting metabolite ( $\left.t_{R} 62 \mathrm{~min}\right)$, similar to that reposted by Petersen 
Figure 15. Use of specific inhibitors of aldehyde dehydrogenase (cyanamide) and P450 (miconazole and troleandomycin) on 4-HNE metabolism in primary hepatocytes from Sprague-Dawley rats. Primary rat hepatocytes were prepared as described in Methods with a viability of $>95 \%$ and immediately treated with 4-HNE. The reactions were quenched by adding $1 \%$ TFA and frozen at $-80^{\circ} \mathrm{C}$. The products were measured by HPLC and radioactivity determined using a radiomatic detector. $\mathrm{A}$. HPLC elution profile for 4-HNE metabolized by rat hepatocytes. B. Effect of inhibitors $(0.5$ mM) of aldehyde dehydrogenase (cyanamide) or P450 (miconazole or troleandomycin) on formation of HNA. Four preparations of rat hepatocytes was used to obtain statistical significance compared with the absence of inhibitor. ${ }^{*}, p=0.05 ; * *, p=0.001$. 
Figure 15
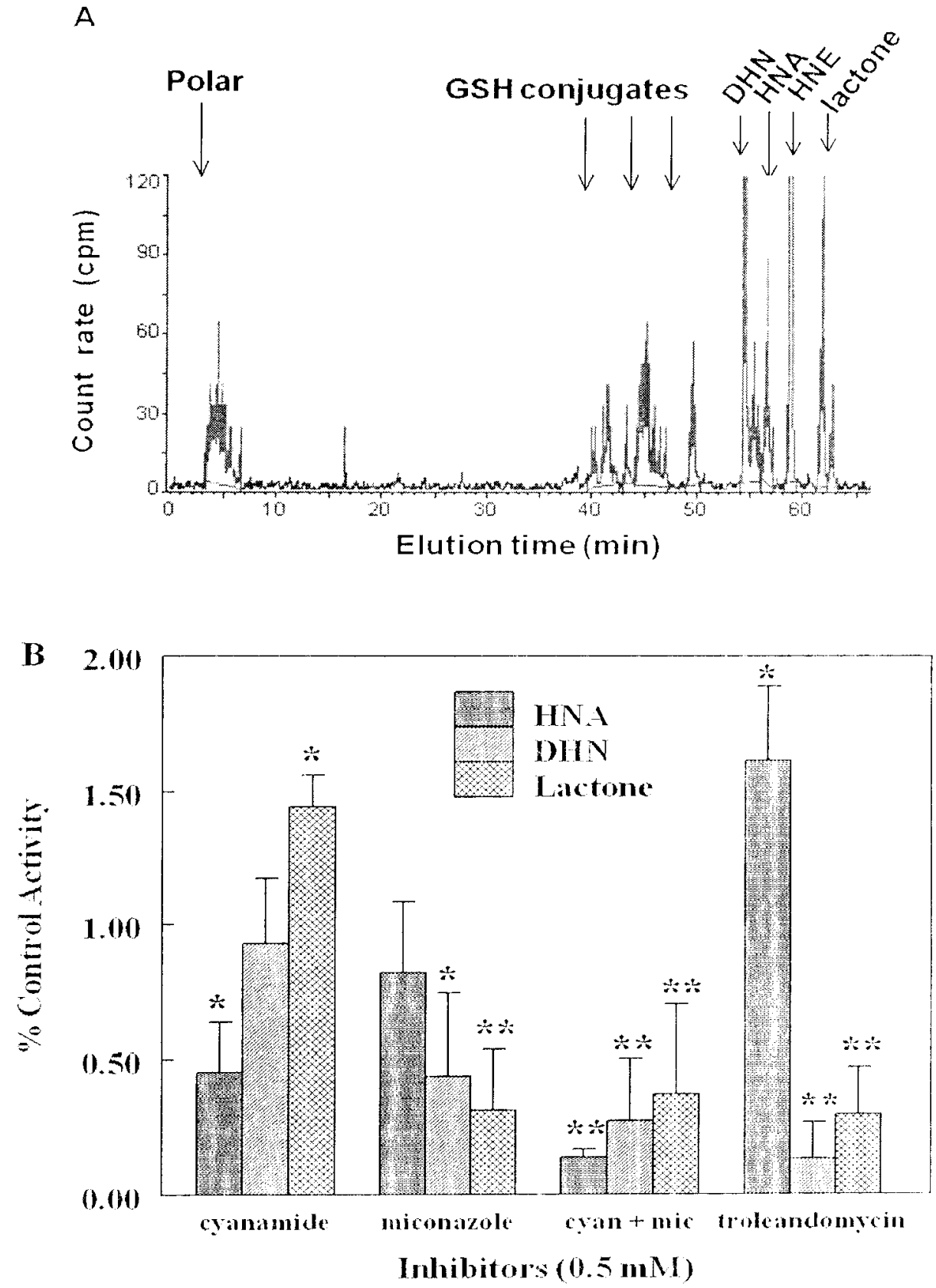
and coworkers (Hartley et al., 1995). We treated hepatocytes with an $A L_{1} \mathrm{D} H$ inhibitor (cyanamide), a general P450 inhibitor (miconazole), or the specific CYP3A inhibitor (troleandomycin) at $500 \mu \mathrm{M}$, concentrations shown to maximally inhibit aldehyde dehydrogenases or P450s in microsomes or expressed recombinant P450s, respectively (results not shown). The effect of these inhibitors on production of various unconjugated hepatocyte metabolites are shown in Figure 15B. Addition of the $\triangle \mathrm{LDH}$ inhibitor cyanamide caused a $55 \%$ inhibition of HNA production, while miconazole caused $\sim 25 \%$ inhibition of HNA formation. When cyanamide and miconazole were added logether, INN $A$ formation was inhibited by $85 \%$. Troleandomycin, the inhibitor of Cyp3a. stimulated HINA formation by $175 \%$. Miconazole alone, or miconazole plus cyanamide decreased formation of the polar metabolite, but increased GSH conjugatc formation (data not shown). These results demonstrate that the increase in GSH conjugates when $\mathrm{P} 450$ and $\mathrm{ALDH}$ are inhibited is most likely the result of all three pathways of metabolism being similar in their metabolic rate and affinity, ard that the glutathione $S-$ twansferases utilized the remaining free $4-\mathrm{HNF}$.

\section{Reduction of 9-anthracene aldehyde to 9-anthracene methanol by cytochromes}

P450. Cytochromes P450 are mostly known to catalyze substrate nonooxygenation. In studying aldehyde metabolism by cytochromes $\mathrm{P} 450$, we definitively observed oxidation to the carboxylic acid. Interestingly, in addition to the oxidation reaction, a limited number of $\mathrm{P} 450 \mathrm{~s}$ reduced the aldehydes to their corresponding alcohols. Incubation experiments were performed with either $50 \mathrm{nM} \mathrm{recombinant} \mathrm{P} 450$ or $0.25 \mathrm{mg} / \mathrm{mL}$. mouse liver microsomes as described under materials and methods. Incubation with mousc liver 
microsomes caused the reduction of 9-AA to 9-anthracene methanol at a rate of 0.25 nmol/min/nmol enzyme. Likewise, the incubation of human CYP3A4 with 9-anthracene aldehyde caused reduction at a rate of $0.32 \mathrm{nmol} / \mathrm{min} / \mathrm{mmol}$ CYP (Figure 16). This is in comparison with 9-AA oxidation activity of $1.5 \mathrm{nmol} / \mathrm{min} / \mathrm{nmol}$ CYP for microsomes and $7.6 \mathrm{nmol} / \mathrm{min} / \mathrm{nmol}$ CYP3A4 (Table 3 ).

\section{Reduction of 4-HNE by P450s and identification of metabolite by HPLC-mass}

spectrometry. To study the reduction of 4-HNE by cytochromes P450, $50 \mathrm{nM}$ of cach P450 was incubated with $50 \mu \mathrm{M}\left[{ }^{3} \mathrm{H}\right]-4-\mathrm{HNE}$ and NADPH for 10 nim. The NADPII regenerating system consisting of IDH was omitted because we observed a reaction? between 4-HNE and components of the regenerating system. The incubation of 4-I INI: with $\mathrm{P} 450$ generated a product that migrated at a $t_{\mathrm{R}}$ of $55 \mathrm{~min}$ by HPLC. The profile shown in Figure 17 was obtained by incubating 4-HNE with CYP3A4. The identity of this compound was determined by gas chromatography electron impact-mass spectrometry to be the reduced form of 4-HNE, namely 1,4-dihydroxy-2-nonene (I)HN) (Figure 18). The parent peak was not observed at $\mathrm{m} / \mathrm{z} 318$, but major ions were observed at $\mathrm{m} / \mathrm{z}$ of $287\left(\mathrm{M}-\mathrm{CH}_{3}\right.$ due to loss of a methyl group from the trimethyl silyl grcup) and at $\mathrm{m} / \mathrm{z} 231\left(\mathrm{M}-\mathrm{C}_{5} \mathrm{H}_{11}\right.$ due to loss of the 5-carbon alkyl side chain by cleavage between $\mathrm{C} 5$ and $\mathrm{C} 6$ of 4-HNE). In addition, incubation of 4-HNE with rat primary hepatocytes resulted in 4-HNE reduction to DHN. 
Figure 16. Reduction of 9-anthracene aldehyde to 9-antracene methanol by CYP3 $\Lambda 4$ and mouse liver microsomes. 9-AA $(25 \mu \mathrm{M})$ was incubated in $0.1 \mathrm{M}$ potassium phosphate bulfer, pH 7.4 with $50 \mathrm{nM}$ CYP3A 4 or $0.25 \mathrm{mg} / \mathrm{mL}$ mouse liver microsomal protein at $30^{\circ} \mathrm{C}$ for $10 \mathrm{~min}$ in a final volume of $2 \mathrm{~mL}$. The reaction was terminated with 1 $\mathrm{ml}$ of (0.5 N NaOH. Following extraction in $4 \mathrm{~mL}$ ethyl acetate, 9-AMeOH was measured by fluorescence spectroscopy ( $\lambda$ excitation, $255 \mathrm{~nm}$; $\lambda$ enission, $411 \mathrm{~nm}$ ) in the organic phase. The results are expressed as the average of triplicate experiments of three reactions in which the $\mathrm{SD}$ varied by $\leq 5 \%$. 
Figure 16

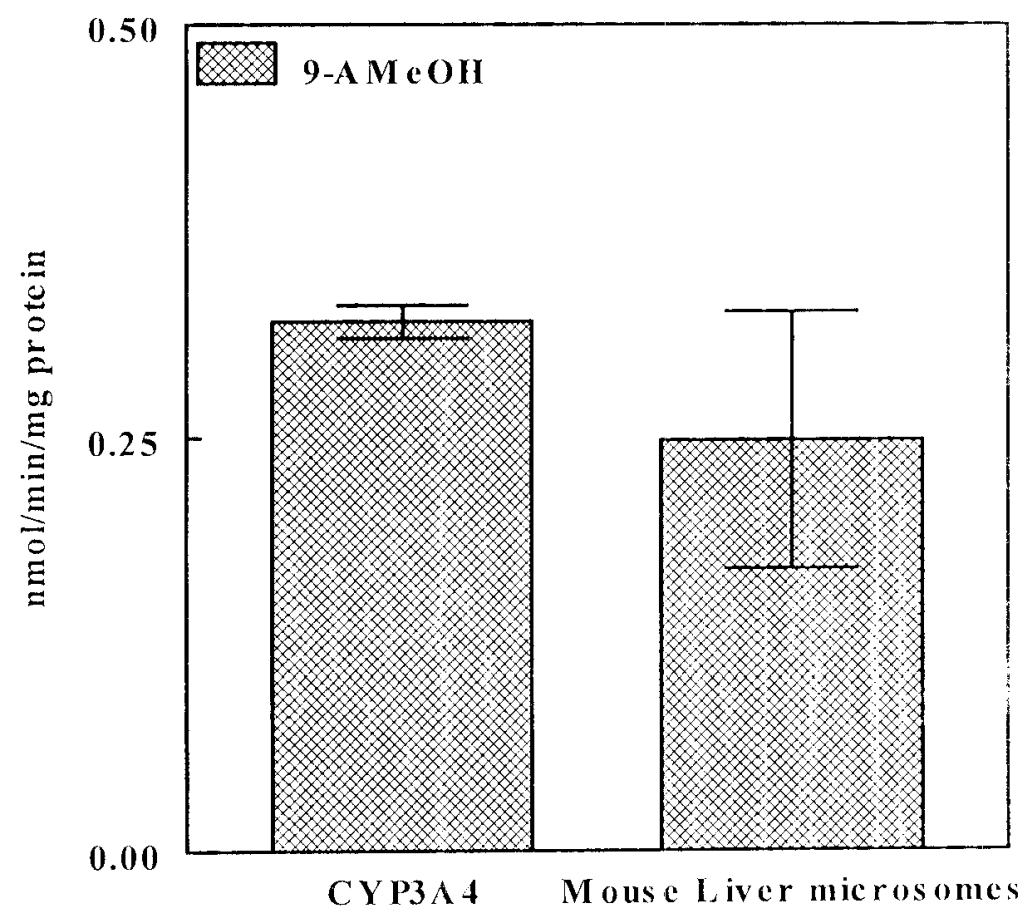


Figure 17. HPLC profile of metabolism of 4-HNE catalyzed by CYP3A4. The metabolic assay was performed in triplicate with $2 \mathrm{~mL}$, of reaction mixture containing $E$. coli expressed CYP3A4 (50 nM) and $50 \mu \mathrm{M}\left[{ }^{3} \mathrm{H}\right]-4-\mathrm{HNE}$ and $100 \mu \mathrm{M}$ at $37^{\circ} \mathrm{C}$ for 20 minutes in a shaking water bath. The reaction was terminated by flash freezing in liquid nitrogen. The reaction was thawed upon adding TCA, centrifuged and the supernatant injected onto the HPLC column.1,4-dihydroxy-2-nonene is eluted at 56 minutes and 4hydroxynonenoic acid at 57 minutes. 
Figure 17

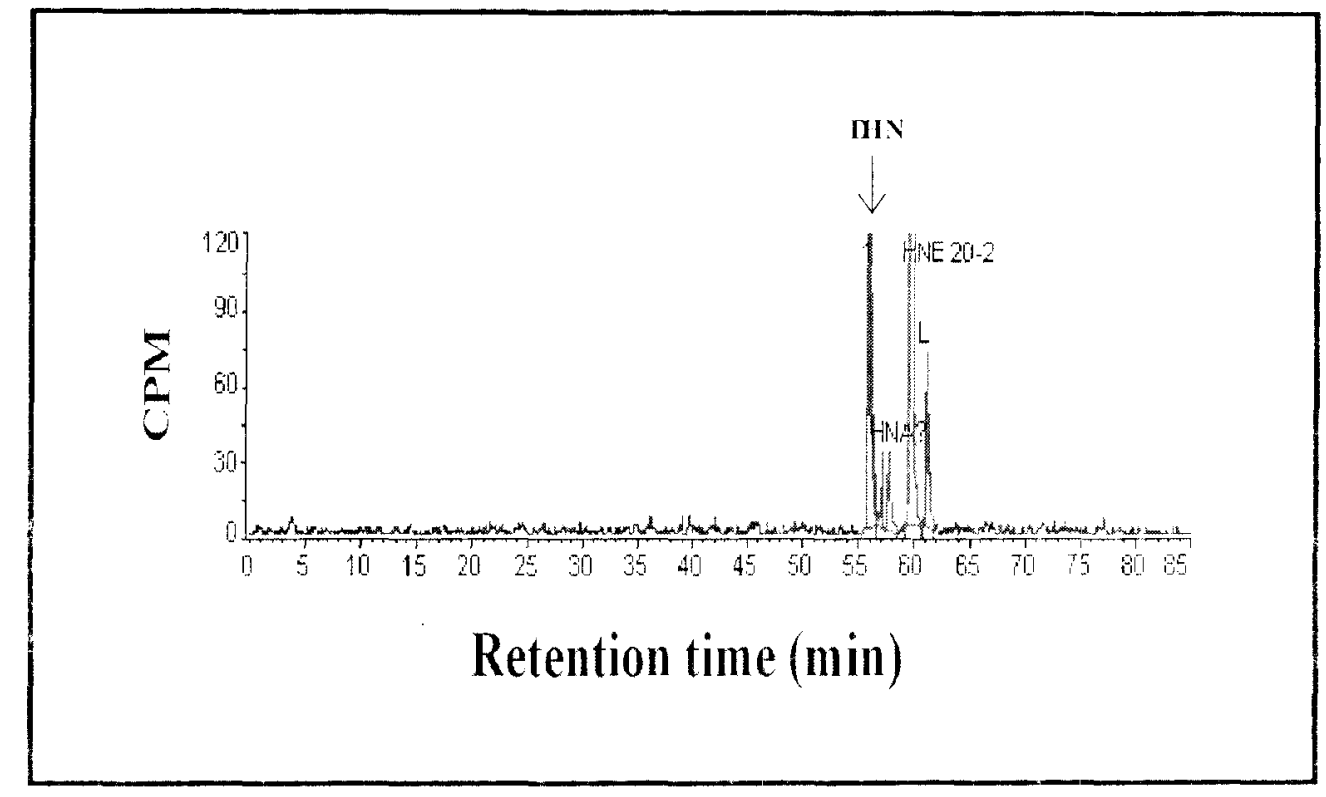


Figure 18. Mass spectra of 1,4-dihydroxy-2-nonene (DHN) generated from CYP3A4-dependent metabolism of ${ }^{3} \mathbf{H} \mid$-4-HNE. After metabolism, the samples were analyzed by IIPLC and the fractions that eluted with the same retention time as the DHN standard at $\mathrm{t}_{\mathrm{k}} \mathbf{5 6}$ min were collected and subjected to mass spectral analysis. A. Authentic DHN, B. DHN produced by CYP3A4. 
Figure 18

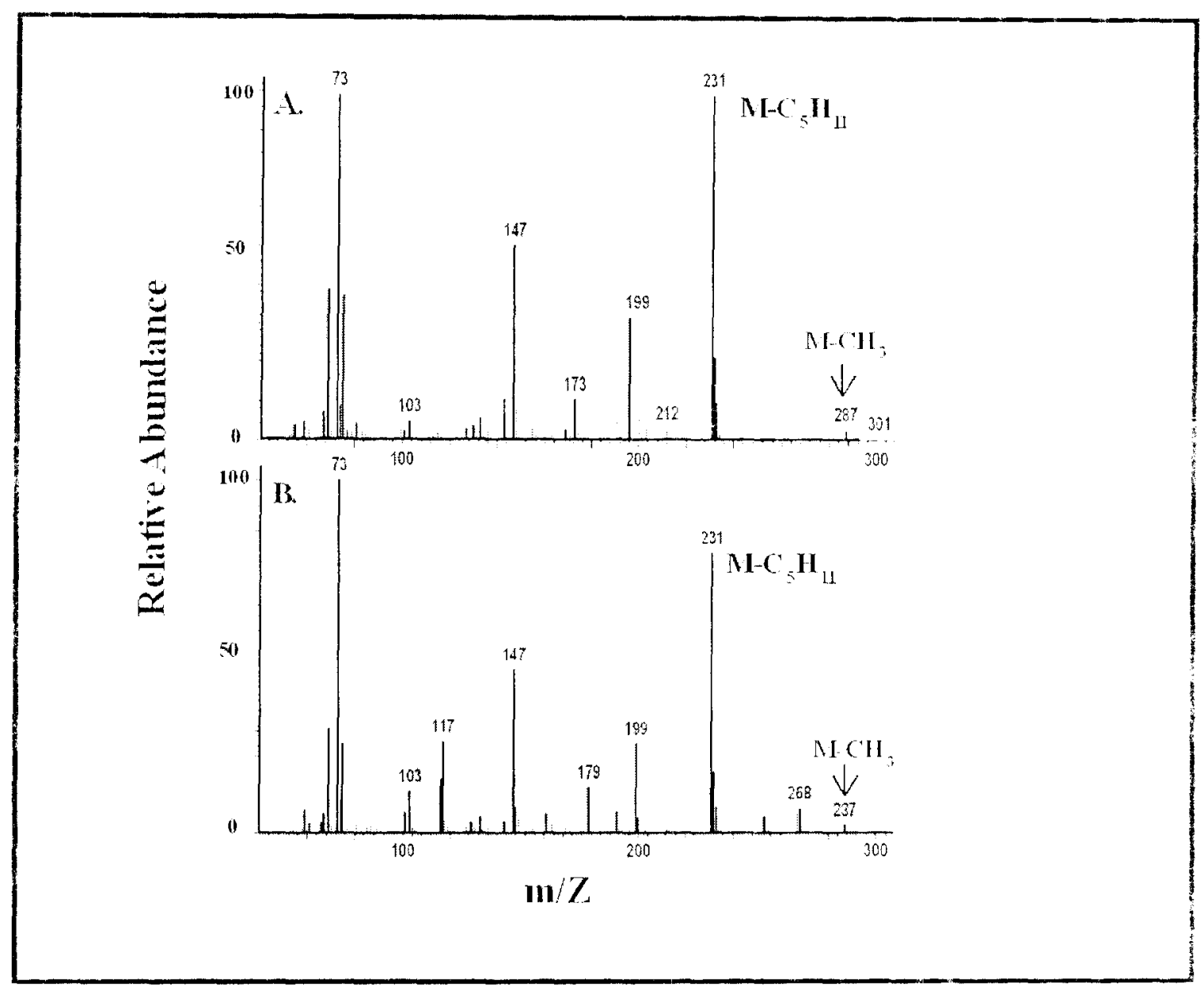


We have not been able to confirm the identity of the lactone, which may be due to its rearrangement to a more complex molecular (J. Cai and W.M. Pierce. Ph.D., University of Louisville School of Medicine, privileged communication).

The formation of DHN in rat hepatocytes was inhibited by the P 450 inlibitor miconazole (57\%) and troleandomycin (83\%), the ALDH inhibitor cyanamide inhibited DIIN formation (8\%) (Figure 15). A combination of cyanamide and miconazole caused a further inhibition of $73 \%$ of inhibition of DHN formation. Taken together, this data suggests that $\mathrm{P} 450$ s participate in both the oxidative and reductive metabolism of $4-\mathrm{HNF}$. There is also a competition for 4-HNE metabolism as seen with the increase in DIIN formation following inhibition of the oxidation pathway by cyanamide.

\section{Aacrobic conditions inhibit $\mathbf{P 4 5 0}$-dependent oxidation but not reduction of}

alduhydes. To catalyze a monooxygenation reaction, cytochromes $\mathrm{P} 450$ require molecular oxygen, CYPOR and NAISPH. We developed a methed to validate the oxidative and reductive metabolism of 9-AA and 4-HNE by cytochromes P450. This method involves anaerobic metabolism in the presence of either argon or carbon monoxide. The anaerobic environment was created by two different mehods In the first method. we bubbled the headspace of the reaction with argon and then added to the incubation reaction glucose oxidase, glucose, and catalase. The glucose oxidase reaction consumed molecular oxygen to catalyze glucose oxidation to glucuronic acid, a reaction that generates hydrogen peroxide. The hydrogen peroxide was removed by its conversion to $1 / 2 \mathrm{O}_{2}$ and water by added catalase. The residual oxygen in the system was minimized by continuous flushing of the headspace of the incubation reaction with argon. 


\section{Figure 19. Lack of oxygen inhibits $\mathrm{P} 450$ dependent oxidation but not reduction of}

aldehydes. The incubation reaction was prepared in an Erlenmeyer flask fitted with a serum stopper fitted with syringes. Following initiation of the reaction, the headspace of the reaction was continuously flushed with argon (anaerobic) or carbon monoxide (CO). The reaction was terminated with $0.5 \mathrm{~N} \mathrm{NaOH}(9-\mathrm{AA})$ or by flash freezing in liquid nitrogen (4-HNE). 9-ACA and 9-AMeOH were extracted with ethyl acetate and measured by fluorescence spectroscopy while 4-hydroxynonenoic acid and 1,4dihydroxy-2-nonene were measured by HPLC. 
Figure 19

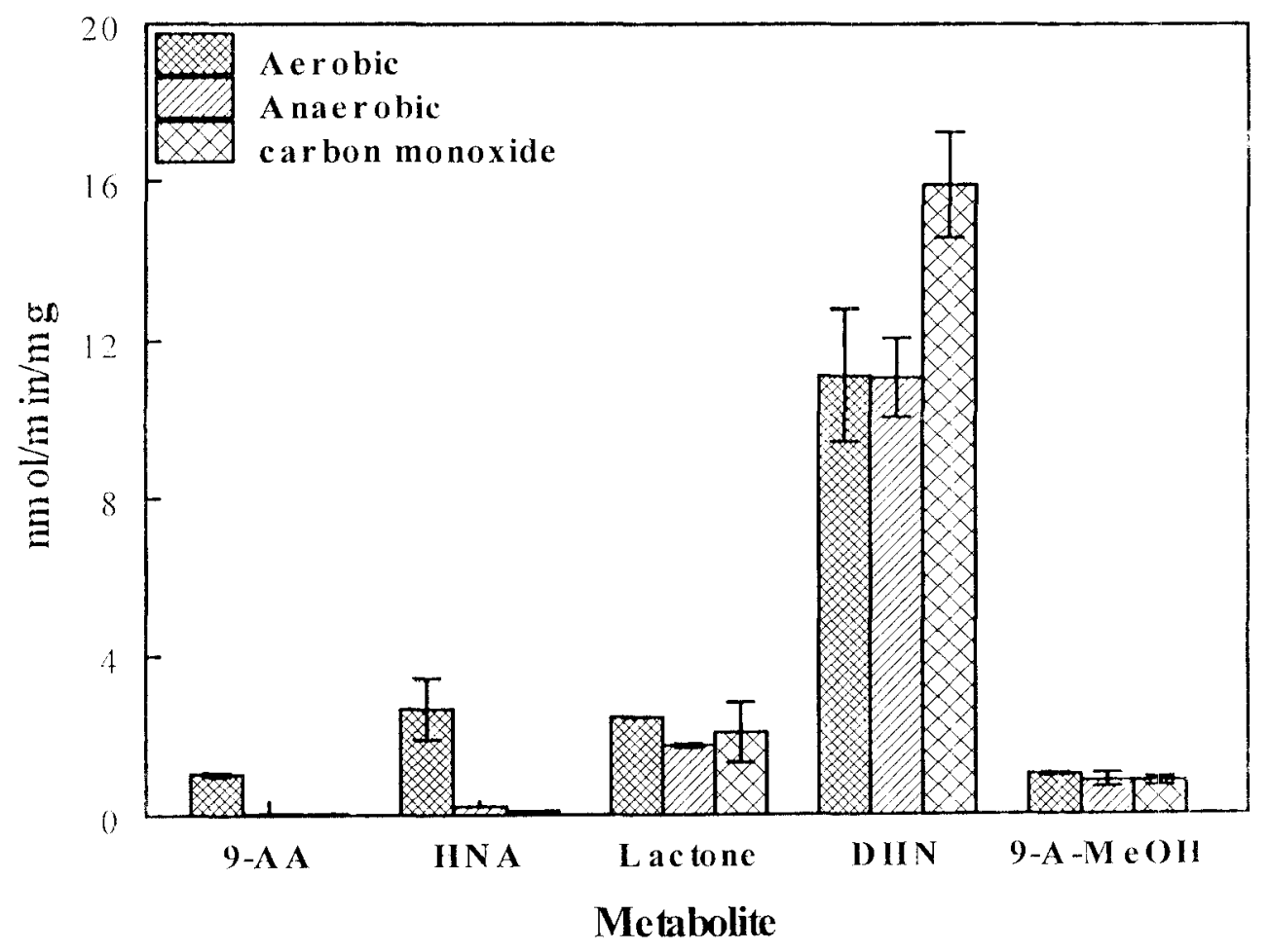


The second method was by flushing the headspace of the reaction with carbon monoxide. $\mathrm{CO}$ binds to the sixth coordination position of heme in the P450 preventing the binding of oxygen. From these experiments, we observed that the oxidation of $9-\wedge A$ to $9-\Lambda C \wedge$ and 4-HNE to 4-hydroxynonenoic acid by mouse liver microsomes was signilicantly inhibited by more than $90 \%$ (Figure 19 ). The $\mathrm{P} 450$-mediated reduction of $9-\wedge \wedge$ to 9 AMeOH and 4-HNE to 1,4-dihydroxy-2-nonene was not affected by the anaerobic environment. The reduction of 4-HNE to 1,4-dihydroxy-2-nonene was slightly elevated by the presence of $\mathrm{CO}$ suggesting that while $\mathrm{O}_{2}$ is required for oxygenation, it is not required for the reduction reaction by the $\mathrm{P} 450 \mathrm{~s}$. In addition. $\mathrm{CO}$ does not inhibit the cy tochrome $\mathrm{P} 450$ dependent reduction.

\section{DISCUSSION}

A typical reaction catalyzed by $\mathrm{P} 450 \mathrm{~s}$ is the hydroxylation of an unfunctionalized alkyl group. However, examples are also known in which P450s catalyze the oxidation of aldehydes to acids with the incorporation of molecular oxygen into the products (Guengerich, 2001). Several critical P450-catalyzed reactions have been shown io involve oxidation of aldehydes or hemiacetals, namely the aromatase and sterol $14 u-$ demethylase reactions. The formation of estrogen requires oxidation of the 19-methyl group of 4-androstenedione to a methyl alcohol derivative. followed by two consecutive oxidation steps to form an intermediate aldehyde and carboxylic acid derivative. The thermodynamics of dehydration drives this reaction to produce aromatization of the Aring of 4 -androstenedione. A similar reaction also occurs during the removal of the 14 - 1 methyl group of sterols via this same reaction pathway to form the essential sterol ergosterol; inhibition of this $\mathrm{P} 450$ in microorganisms has been shown to be an effective 
method to inhibit the growth of fungi. Human liver microsomes possess the ability to oxidize aromatic aldehydes such as $11-$ oxo- $\Lambda^{8}$-tetrahydrocannabinol to acids by the P450 system (Watanabe et al., 2002). More recently, model substrates, 9-A.A and 4biphenylaldehyde, have been used to measure the activity of several P450s (Marini er al. 2003). These fluorogenic substrates provide simple methods to measure the acid products formed from the P450-dependent oxidation of aromatic aldchydes.

Our studies addressed the possible role of various P450s in the metabolism of aromatic $\alpha, \beta$-aldehydes (e.g., anthracene-9-carboxaldehyde) and the aliphatic $\alpha, \beta$ aldehydes (c.g., 4-HNE). Our initial observation of murine Cyp2c29-catalyzed oxidation of 4-HNE suggested that Cyp2c29 and other related P450s may also be involved in 4HNE metabolism in the heart and liver in vivo, where it is reportedly expressed (Luo ef al., 1998). Cyp2c29 was initially identified as a microsomal aldehyde oxygenase (P450 MUT-2) by Yamamoto et al. (1991), who observed that Cyp2c29 was the primary microsomal P450 responsible for oxidation of a cannabinoid aldehyde. We observed that P450s of the 2B, 2J, and $3 \mathrm{~A}$ subfamilies also catalyzed oxygenation of aromatic aldehydes to their carboxylic acids. These results collectively demonstrate that P450) also contribute to aldehyde oxidation, as suggested by Marini et al. (2003). However. two other P450s, P4501A2 and 2E1 were analyzed and appear to be poor catalysts of 4-HINE oxidation (Table 3). Our studies suggest that some of the P450s produce products in addition to HNA. Furthermore, we provide data showing that 4-IINE is a competitive substrate for 9-AA metabolism by Cyp2c29 and suggests that other short chain aldehydes may be substrates for the $\mathrm{P} 450$. The $\mathrm{K}_{\mathrm{m}}$ values were in the range of $1-20 \mu \mathrm{M}$. 
To evaluate the relative participation of $\mathrm{P} 450 \mathrm{~s}$ and aldehyde dehydrogenases in oxidation of aromatic and aliphatic $\alpha, \beta$-aldehydes, we studied their activity in murine liver microsomes or with expressed recombinant P450s and its flavoprotein oxidoreductase. The oxygenase activity of liver microsomes was found to be inhibited $>$ $50 \%$ by $0.5 \mathrm{mM}$ miconazole, an inhibitor of most P450s. Using specific inhibitors, we also showed the participation of Cyp3a (troleandomycin) and Cyp2c29 (phenytoin) activity in mouse liver microsomes. We observed the presence of an appreciable $\mathrm{N} A D \mathrm{P}^{+}$-dependent oxidation of $9-\mathrm{A} A$ to $9-\Lambda \mathrm{CA}$ in the cytosolic fractions of mouse liver microsomes that was inhibited by cyanamide (data not shown).

Studies were performed to evaluate the specificity of known inhibitors of aldehyde metabolizing enzymes using cyanamide (ALDH), 4-methylpyrazole (alcohol dehydrogenase), and benomyl (ALDH). CYP3A4 was shown to be potently inhibited by beth 4-methylpyrazone and benomyl, suggesting that cyanamide was the only AIDII specific inhibitor that can be used to distinguish $\Lambda$ LDHs from P450s. These inhibitors were utilized in experiments with primary cultures of rat hepatocytes to evaluate the relative participation of ALDH and P450s in 4-HNE metabolism. Cyanamide inhibited HNA formation by $>55 \%$ and miconazole only inhibited HNA formation around 25 $30 \%$. Troleandomycin actually stimulated formation of HNA, suggesting that Cyp3a enzymes may be involved in formation of other products from 4-HNL: As a result. inhibition of the Cyp3a reactions apparently increased the steady-state concentration of 4HNE and led to higher levels of formation of HNA through other P450s, as well as AIDH. The production of polar products derived from 4-HNE in hepatocytes was inhibited by miconazole, suggesting that these products are formed by P450s. I However. 
these polar metabolites may also be due to tritiated water released during oxidative metabolism. We observed a slight difference in the retension time of the metabolites between the different HPLC profiles (Figure 15 and Figure 17). We believe that this was due to differences in the room temperature are the time of separation of the different metabolite fractions by HPLC.

The GSH-conjugates were increased by P450 inhibitors, suggesting that upon blocking the $\mathrm{P} 450$ reactions, more substrate is available for GSH conjugation of 4-1 $\mathrm{NE}$ (data not shown). These results demonstrate that in hepatocytes the three pathways involving glutathione S-transferases, aldehyde dehydrogenases and cytochrome P450s apparently function at similar rates. Cytochromes P450 account for a significant portion of the oxidative metabolites of 4-HNL in hepatocytes at the concentration studied. Petersen and coworkers (1995) may have underestimated the role of P450s in rat hepatic netabolism due to the sensitivity of P4503 $\Lambda$ to the $\mathrm{ALDH}$ and alcohol dehydrogenas: inhibitors used.

During the study of the mouse liver microsomes and the different P450s that metabolized 9-AA and 4-HNE, we found that some P450s are able to reduce these compounds to the corresponding alcohol. We developed a method lor screcning $\mathrm{P} 450 \mathrm{~s}$ involved in aldehyde reduction by using a fluorescence measurement of 9-AMcol. Differential extraction separates the carboxylic acid and the alcohol, allowing us to measure the two metabolites in the two organic phases. Human CYP3 $A+$ and mouse liver microsomes were able to reduce 9-AA to 9-AMeOH. CYP3A4 is the major adult human liver P450 and metabolizes the most xenobiotics. We also observed that this P450 catalyzed the reduction of 4-HNE to DHN. The magnitude of 4-HNE reduction by the 
individual P450s analyred was CYP2B 1 > CYP3A4 $>\mathrm{CYP} 1 \wedge 2>\mathrm{CYP} 2.12>\mathrm{Cyp} 2 \mathrm{C} 2 \%$. Mouse liver microsomes also catalyzed 4-HNE, reduction. The observation of reduction of 4-HNE with the different P450 was further confirmed by using the P450-specific inhibitors.

Reductive catalysis by cytochromes $\mathrm{P} 450$ is uncommon except for a few substrates at low oxygen tension. Some reduced products may not be stable as i-electronand 2-eletron-reduced intermediates in the presence of molecular oxygen. Azo dyes are widely used in cosmetics, food, textiles and drugs. The azo compound sulfonazo III and aramanth are reduced by rat hepatic microsomes (Peterson et al., 1988). The hopatocarcinogen dimethylaminoazobenzene is reduced by rat liver microsomes in an oxygen- and CO-insensitive manner (Levine and Raza 1988). The bioreductive activation of the quinine 2,3,5,6-tetramethy-1,4-benzoquinone is catalyzed by CYP2B1 (Goeptar : (il., 1992).

P450s require NADPH and oxygen for oxidative metabolism. Therefore, in the absence of either. the $\mathrm{P} 450$-dependent monooxygenation reaction is inhibited. In addition to the use of chemical inhibitors, we were able to demonstrate that the lack of oxygen inhibited the P450-dependent oxidation of both 9-AA and 4-HNE, but not the reduction of either compound. An anaerobic environment was created by bubbling the reaction mixture with argon or $\mathrm{CO}$. Argon lowers the $\mathrm{pO}_{2}$ to zero thereby creating a relative anactobic environment; residual oxygen is removed by the glucose oxidase/catalase reaction. CO binds to the sixth coordination position of heme iron, preventing oxygen binding. By using chemical inhibitors, $\mathrm{CO}$ and argon, we suecessfuily demonstrated tine role of $\mathrm{P} 450 \mathrm{~s}$ in lipid aldehyde metabolism. 
Figure 20. Proposed pathway for the metabolism of 4-HNE by P450s with the involvement of the oxyferryl $(\mathrm{Fe}(\mathrm{V})=\mathrm{O})$ and the ferrous (Fe-II) species of the P450. Fe depicts the iron in the heme of the $\mathrm{P} 450$. The $\mathrm{Fe}-\mathrm{O}^{\mathrm{V}}, \mathrm{Fe}-\mathrm{O}^{\mathrm{IV}}$ and $\mathrm{Fe}^{3+}$ oxidation states contribute to 4-HNE oxidation to HNA. The $\mathrm{Fe}^{2+}$ oxidation state contributes of 4-HNE reduction to DHN. 
Figure 20

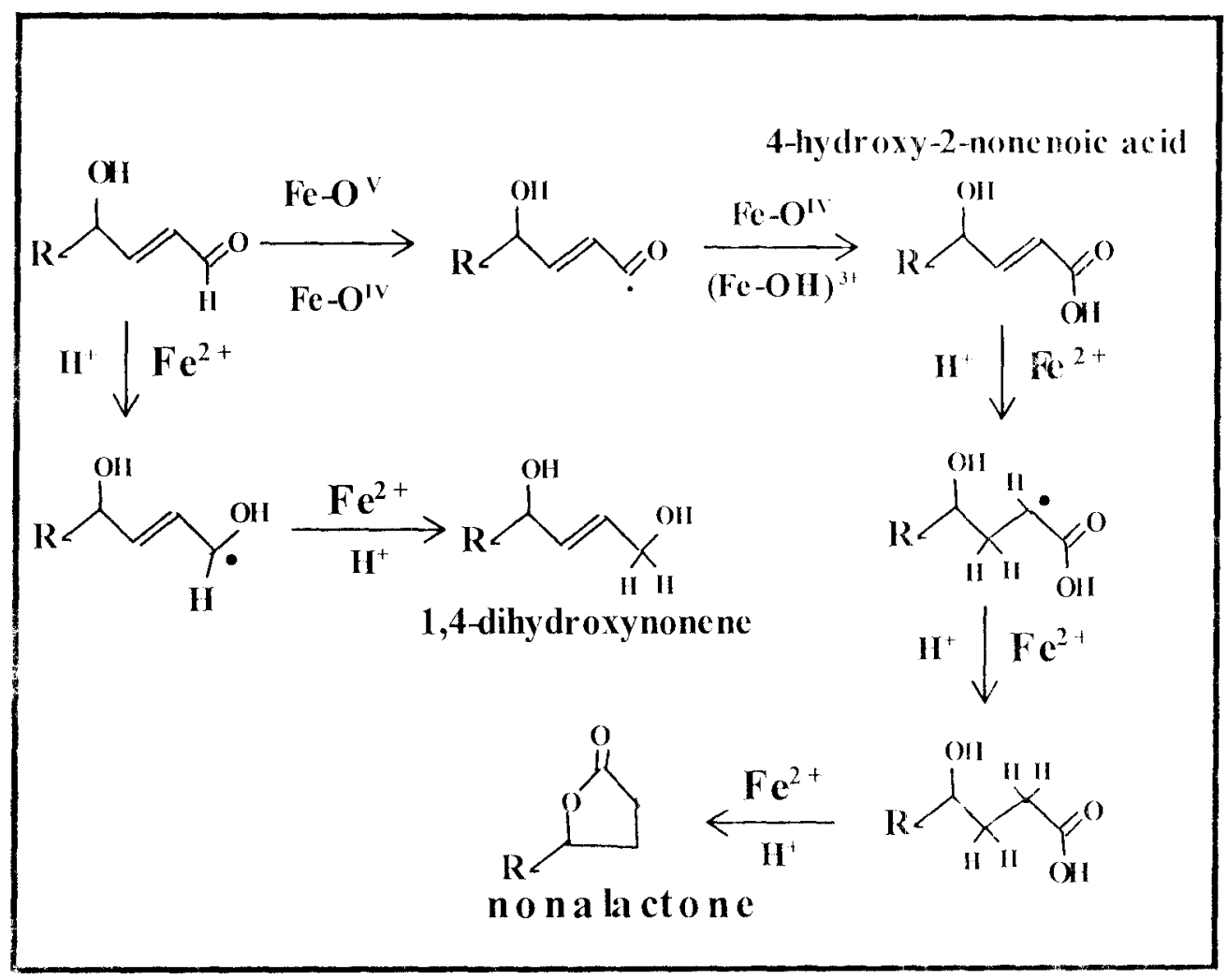


The proposed pathway for 4-HNE metabolism by CYPs is shown (Figure 20). During the metabolism of substrate, P450s exist in different oxidation states. These oxidation states can influence the product generated by the P450 (Figure 3). The oxidation state of the P450 that generates HNA is the perferryl (Fe-O ${ }^{\mathrm{V}}$ ) or oxyferryl (Fe$\mathrm{O}^{\mathrm{IV}}$ ), requiring oxygen, electrons and NADPH. Hydrogen is abstracted from 4-HNE: forming a carbonyl carbon radical, which can then react with the iron-bound hydroxyl radical generating 4-hydroxy-2-nonenoic acid. The HNA may then undergo further reactions involving electron rearrangement, protonation and oxidation to form a lactone. The cytochrome P450-dependent reductions are catalyzed by the ferrous (Fe (II)) stateP450, the electrons being transferred from NADPH to the P450 by NADPH:CYPOR (Mansuy, 1994).This may be the oxidation state of the P450 that generates 1,4dihydroxy-2-nonene. It has been noted that the P450 Fe(II) state can occur during conditions of low oxygen tension.

İn conclusion, our results demonstrate that several P450s are cfficient catalysts in the oxidative and reductive transformation of lipid-derived aldehydes to carboxylic acids: 4-hydroxynonenoic acid, and alcohols; 1,4-dihydroxy-2-nonene, and add a new facet to the biological activity of these metabolites. P450s are expressed in hepatic and extrahepatic tissue. By metabolizing 4-HNE, CYPs convert this reactive lipid aldehyde to a less reactive product. which could either be excreted of subjected to further metaboiism. Our studies suggest that P450-mediated metabolism operates in parallel with other metabolic transformations of aldehydes; hence, the P450s could serve as reserve or compensatory mechanisms when other high capacity pathways of aldehyde elimination are compromised due to disease or toxicity. Finally, because 4-HNE like unsaturated 
aldehydes, such as acrolein, trans-2-hexenal, and crotonaldehyde, are also food constituents or environmental pollutants, P450s may be significant regulators of toxicity due to xenobiotic aldehydes as well. 


\section{CHAPTER III}

\section{INDUCTION OF GENE EXPRESSION IN MOUSE IIEART ANI) LIVER BY}

\section{BUTYLATED HYDROXYANISOLE AND ACROLEIN}

\section{INTRODUCTION}

To determine the changes in gene expression related to chenical exposure. disease, toxicant and hazard prediction, researchers have extensively used the technicue of DNA microarray analysis. By analyzing global gene expression changes, it is possible to predict regulatory pathways for action of specific chemical compounds, as well as, mechanisms for environmental disease progression. In this study, we used C $5713 \mathrm{~L} / 6$ mice to investigate the role of butylated hydroxyanisole (BHA) and acrolein in the regulation of gene expression. Based on the hypothesis of Paul Talalay (Prestera and Talalay. 1995), there is a paradigm that phase I enzymes are not generally induced by electrophilic agents like BHA and tBHQ or even 4-HNE and acrolein. We therefore sought to identify changes, if any, of $\mathrm{P} 450 \mathrm{~s}$ expressed in the liver and the cardiovascular system. In addition, we verified a number of phase I and phase II xenobiotic metabolizing enzymes whose gene expression is altered after exposure to BHA and acrolein

The detoxification of many chemicals proceeds through a three-step enzymatic process, commonly referred to as phase I, phase II and phase III metabolism. In the first step, phase I enzymes such as cytochromes P450, dehydrogenases, reductases and oxidases modify lipophilic compounds. This allows for subsequent moditication by conjugation to water soluble compounds by phase II enzymes like glutathione S- 
transferases (GSTs), NADPH quinone oxidoreductase 1 (NQOR1), and UDP

glucuronosyl transferases. Phase II reactions consist mainly of glucuronidation. sulfation,

glutathionylation, methylation, or conjugation with amino acids. In addition, esterases,

amidases, imidases, epoxide hydratase, or other hydrophilic processes increase the

hydrophilic nature of these compounds. Lastly, transporter proteins, also known as phase III enzymes, localized in the sinusoidal and the apical membranes of hepatocytes, intestinal, and kidney cells, regulate the intracellular levels of these compounds by transport and excretion (Jakoby and Ziegler, 1994). The interaction of phase I, phase II and phase III enzymes and proteins ensures the metabolism and disposition of xenobiotics, thereby regulating their levels in vivo.

The aim of this study was to investigate the regulation of gene expression by lipid aldehydes, particularly, to determine the role of lipid aldehydes. in the regulation of gene expression of lipid aldehyde metabolizing enzymes, including cytochromes $\mathrm{P} 450$. Humans are exposed to a number of aldehydes, two of which we have studied, 4-HNl: and acrolein. These aldehydes are generated in vivo predominantly generated during the process of oxidative stress. Exposure can also occur via ingestion of foods containing these carbonyl compounds. Acrolein, a key component of cigarette smoke, is associated with a variety of diseases. It has been determined that the amount of carbonyl compounds obtained during the combustion of a regular size cigarette ranges from 1.92 to 3.14 $\mathrm{mg} / \mathrm{cigarette}$. Of these, acrolein represents 0.22 to $0.47 \mu \mathrm{g} / \mathrm{cigarette}$ (Fujioka and Shibamoto 2006).

By their chemical nature, acrolein and 4-HNE are highly reactive electrophiles. Several studies have demonstrated that these lipid aldehydes regulate gene 
expression through the activation of transcription factors. These transcription factors. generally referred to as oxidative stress-sensitive transcription factors, include $N \cdot N^{2}, A P-1$ and $\mathrm{NF}-\mathrm{\kappa} \mathrm{B}$.

High acrolein concentrations cause GSH depletion. In addition, acrolcin reacts with nucleophilic groups such as the amino group of lysine. the sulthydryl of eysteine and with the imidazole group of histidine (Uchida et al., 1993). These reactions modify the function of macromolecules. These actions of acrolein, especially the depietion of glutathione, result in oxidative stress. Cells respond to this stress by activating the mitogen-activated protein kinases (MAPKs) such as ERK1 and the c-Jun N-terminal kinase JNK $1 / 2$ (Yuan et al., 2006). The downstream effects of JNK1 activation on oxidative stress-sensitive transcription factor activation are two- fold. First, phosphorylation and activation of Jun results in the induction of gene expression by the AP-1 transcription factor through binding to the 12-()-tetradecanoylphorbol 13-acetateresponse clement or TRE (Angel et al., 1987). Second, activated ERK and JNK can phosphorylate $\mathrm{Nrf} 2$ at serine residue 40 , causing $\mathrm{Nrf} 2$ release from $\mathrm{Keap}-1$ and subsequent translocation to the nucleus. In the nucleus, Nrf2 binds to the antioxidant response element as a heterodimer with other proteins, small Mafs, c/EBP' and Jun, resulting in an increase in gene expression.

BHA is a phenolic antioxidant widely used to study the induction of Phase II xenobiotic metabolizing enzymes. In addition to its antioxidant property, BH $\Lambda$ is used to study the induction of gene expression resulting from oxidative stress (Pinkus ct al.. 1996: Yuan et al., 2006). In vivo, BHA is ()-demethylated to tertiary-butyl hydroquinone (tIBHQ: Figure 21) by phenobarbital-induced microsomal enzymes (Cummings et cil., 
1985). Both BHA and $\mathrm{BHQ}$ induce gene expression through the oxidative stresssensitive transcription factors. Since BHA, tBHQ and acrolein all induce gene expression through similar set of transcription factors, we hypothesize that P450s of interest may be regulated by Nrf2. Therefore, we used BHA as a control for acrolein treatment of mice fo: the analysis CYP P450 gene expression by reactive lipid aldehydes.

In order to achieve our goal of identifying genes regulated by acrolein, we submitted RNA samples from treated mice to the Bradfield Laboratory for microarray analysis of gene expression using the environment, drug and gene expression (I:DGE) data base program. This program was developed by the Bradfield laboratory at the McArdle Laboratory for Cancer Research, University of Wisconsin Medical School. This resource is a public database that allows two modes of researcher interaction. First, investigators can query a large and growing database of toxicant induced transeriptional profiles generated using a common microarray protocol and platform. Second, the liDGE resource accepts RNA sample submissions from laboratorics interested in developing novel toxicant-induced transcriptional profiles for inclusion in the open access database (Hayes et al., 2005).

In addition to the microarray analysis, we performed quantitative real-time PCR (gRT-PCR) analysis to verify the results of the microarray analysis. Irom the same tissue, we prepared liver microsomes and used these in metabolism assays to investigate changes in microsomal P450 activity following treatment with BHA. Finally, Western blotting was performed with the same microsomes for Cyp2c29, to verify changes in protein level following treatment of mice with BHA. 
Figure 21. Chemical structure of butylated hydroxyanisole (BHA; butyl-4.

hydroxyanisole) and tertiary-butylated hydroquinone (tBHQ). In vivo, BHA is oxidatively demethylated by microsomal P450s to generate $\mathrm{BHHQ}$. 
Figure 21

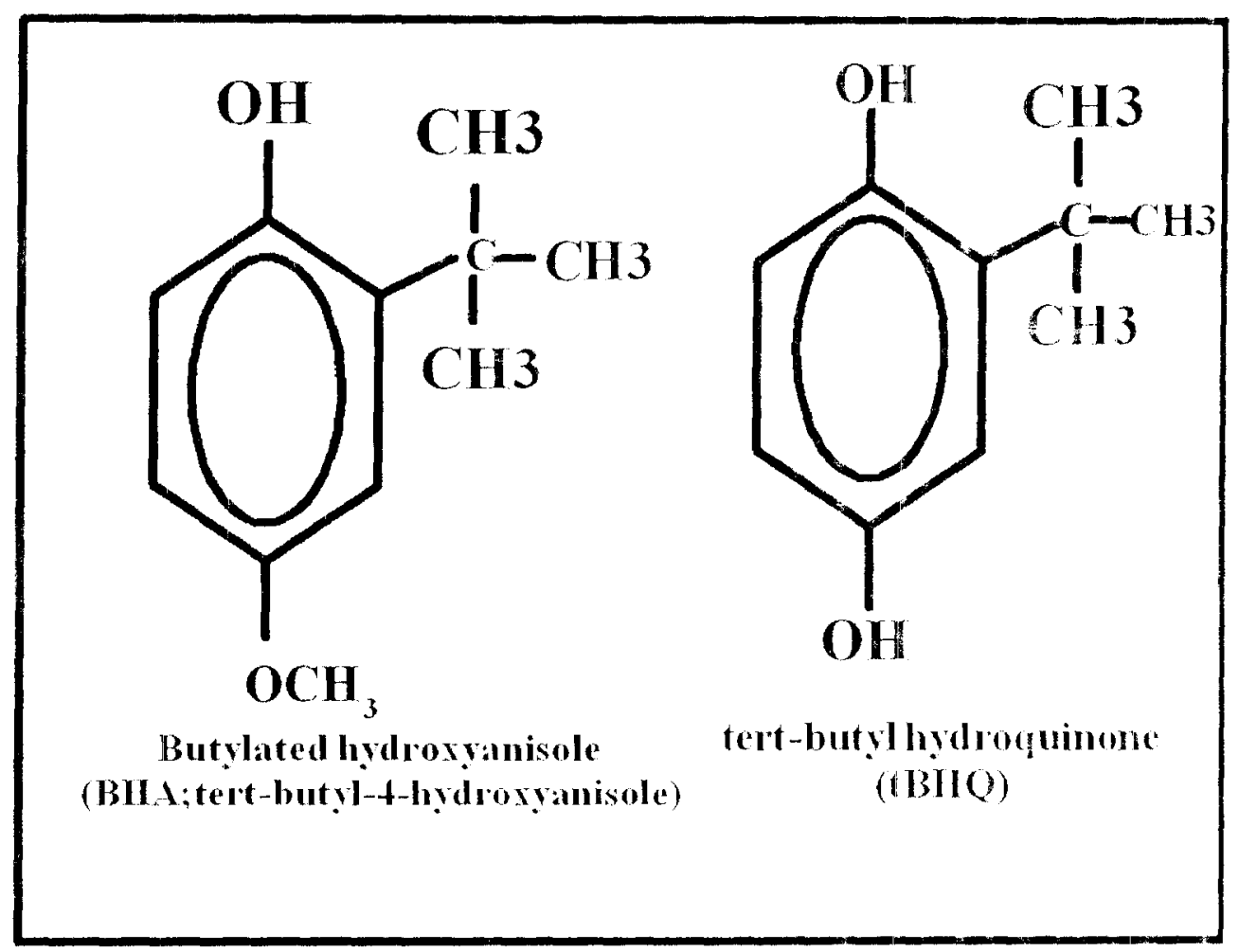




\section{MATERIALS AND METHODS}

Treatment of Animals. Mice (C57BL/6, $22 \mathrm{~g}$ to $27 \mathrm{~g}$; Jackson Laboratories, Bar Harbor. MA) were divided into two groups based on the chemical treatment they received. Group 1 was fed ad libitum for 1 week with either AIN-76A diet (Purina Test Diet, Richmond. IN) alone (control) or AIN-76A diet supplemented with $0.45 \%$ BHA. Group 2 was divided into two subgroups. Subgroup 1 received a daily dose of either saline or acrolein in saline ( $5 \mathrm{mg} / \mathrm{kg}$ acrolein, Sigma, St Louis MO) by gavage for 7 days. The animals were fed Purina mouse chow (Richmond, IN). The second subgroup was exposed for 6hrs daily to 5-ppm acrolein by inhalation for 5 days. The control group was exposed to normal air for the same amount of time. The entire treatment and experiment scheme is summarized in Figure 22. The mice were sacrificed and the liver and heart harvested and stored at $-80^{\circ} \mathrm{C}$ until used. All procedures were approved by the University of Louisville IACUC Committee and conformed to the USPHS Policy on Humane Care and Use of Laboratory Animals. The exposure of mice to acrolein by inhalation was performed at the inhalation core facility of the Program Project Grant P01 ES directed by Aruni Bhatnagar, Ph.D. The duration of exposure was selected based on their toxicological data following exposure at different time intervals.

Total RNA isolation and purification. For total RNA preparations. about $0.1 \mathrm{~g}$ of frozen liver tissue or an entire mouse heart was homogenized in $1 \mathrm{~mL}$ of TRIzol $\mathbb{B}$ (Invitrogen, Carlsbad, CA). The mouse heart is fibrous and required maceration in a mortar and pestle containing liquid nitrogen prior to homogenization with a pellet pestleß motor (Fischer Scientific, Pittsburg, PA). The supernatant was transferred to a sterile tube and incubated for $5 \mathrm{~min}$ at room temperature to permit the dissociation of 
Figure 22. Schematic representation of experimental design for analysis of gene expression in male C57BL/6 mice following treatment with either BILA or acrolein. 


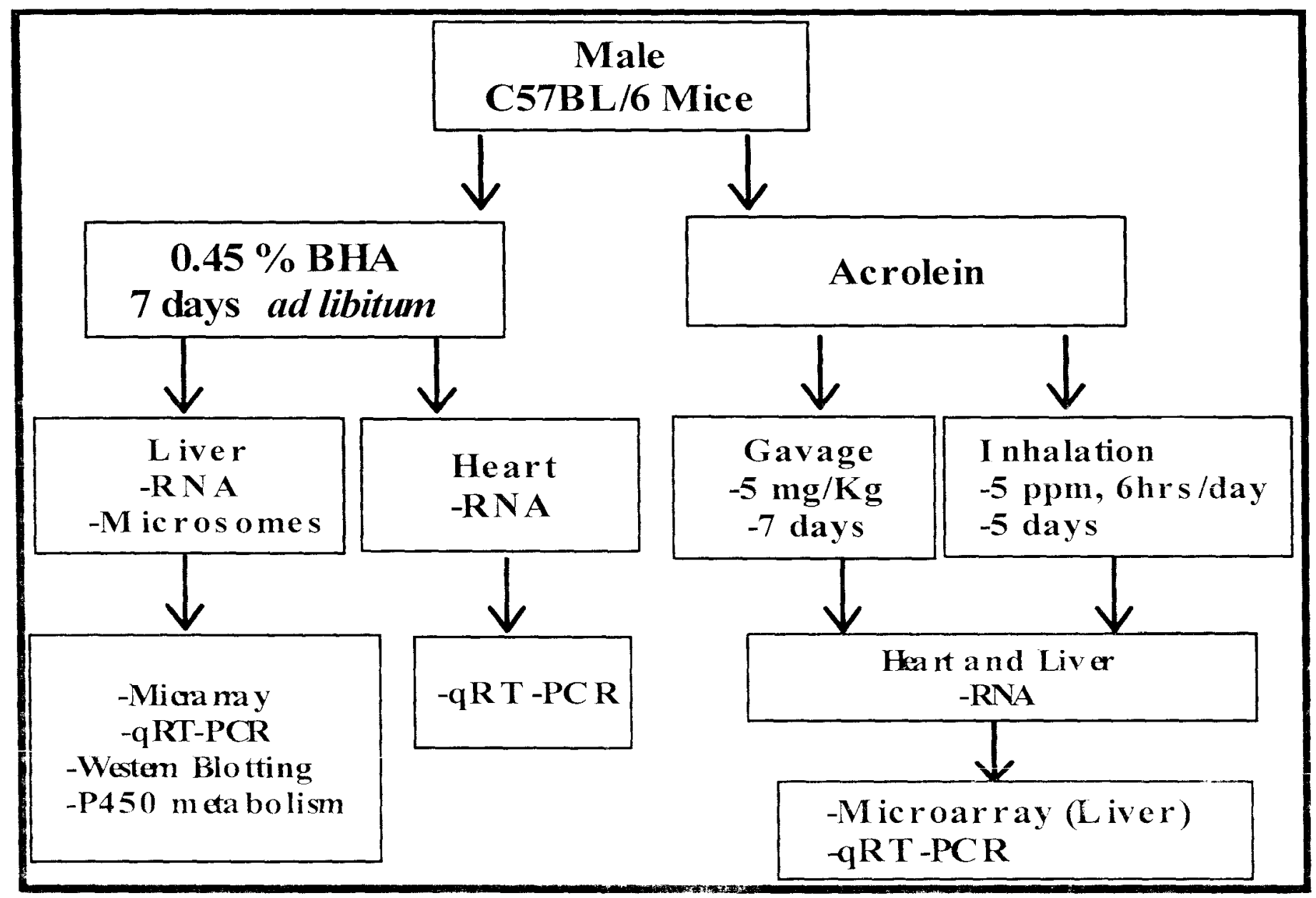


nucleoprotein complexes. Chloroform $(0.2 \mathrm{ml}$, per $1 \mathrm{~mL}$ TRIzcl reagent) was added to each tube. the sample shaken vigorously for 15 seconds, and then incubated at room temperature for $2 \mathrm{~min}$. The samples were sedimented at $12,000 \mathrm{xg}$ for 15 min at $4^{\prime \prime} \mathrm{C}$. The colorless aqueous phase containing the RNA was further extracted by mixing with $0.5 \mathrm{~mL}$ isopropyl alcohol followed by incubation at room temperature for $10 \mathrm{~min}$ and sedimentation at $12,000 \times \mathrm{g}$ for $10 \mathrm{~min}$ at $4^{\circ} \mathrm{C}$. The RNA pellet was washed with $1 \mathrm{~mL}$ of $75 \%$ ethanol, followed by centrifugation at $7,500 \mathrm{xg}$ at $4^{\circ} \mathrm{C}$. The RNA pellet was air dried for $5 \mathrm{~min}$ and dissolved in $60^{\circ} \mathrm{C}$ RNAse free water. The RNA was purilied using silica membrane spin columns (RNeasy® reagent; Qiagen, Valencia, CA). RNA integrity was then assessed using the 600 LabChip $\mathbb{B}$ kit with a 2100 Bioanalyzer (Agilent Technologies, Palo Alto, CA) and quantified using the Nano Drop spectrophotometer. The RNA was aliquoted and stored at $-80^{\circ} \mathrm{C}$ until used.

Sample preparations for microarray analysis. RNA samples for microarray analysis of gene expression were prepared according to the requirements of the linvironment, Drugs and Gene Expression (EDGE) program. RNA quality (Figure 23) and quantity was determined as explained above. At least $60 \mu \mathrm{g}$ of RNA per sample was provided for analysis to the Bradfield Laboratory. The samples were analyzed using the Genisphere 31) Array 50 kit protocol adapted from Genisphere, Inc (Hatfield, PA). The detailed protocol for microarray analysis can be found at the EDGI program website http://edge.oncology.wisc.edu. 
Figure 23. Verification of RNA quality used for microarray and quantitative realtime PCR analysis of gene expression. Aliquots of independent RNA samples extracted from mice heart and liver were analyzed with the RNA 6000 Nano-I abchip on the Agilen 2100 Bioanalyzer. (A) The gel picture shows the RNA ladder (lane 1 ) and four samples (lane 2 -5). (B) Representative electrophoregrams depict two peaks for the $28 \mathrm{~S}$ and i 8.5 rRNA in the RNA samples. 
Figure 23

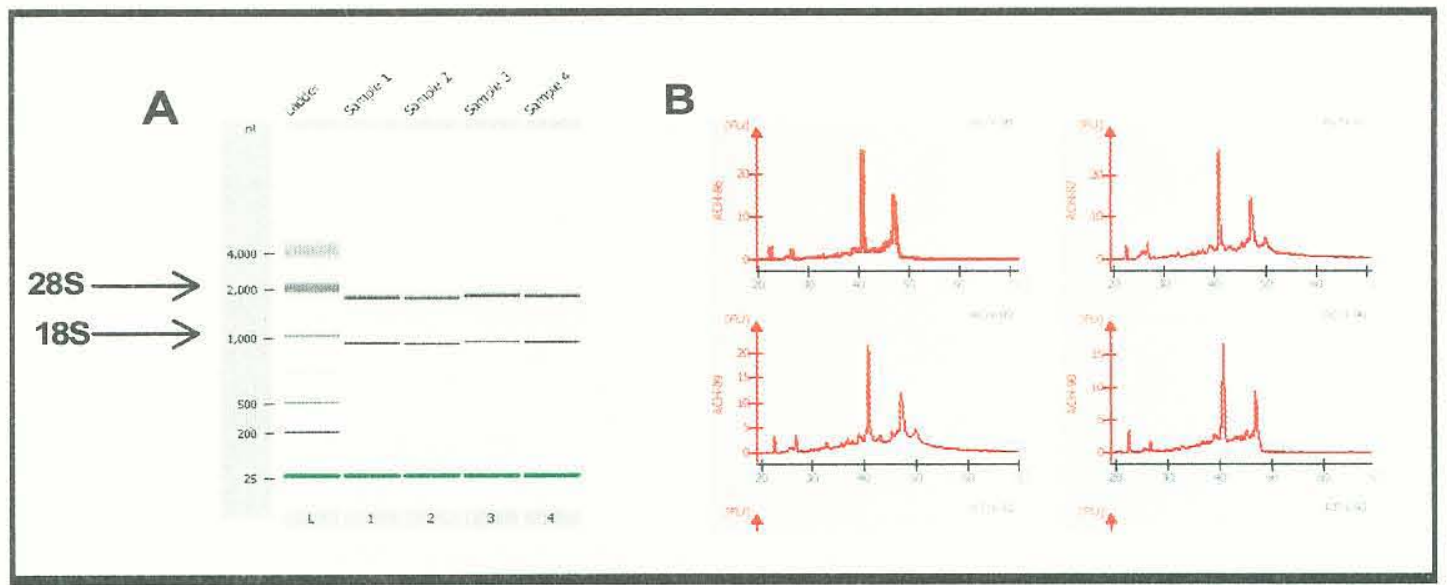


Microaarray data analysis. The Bradfield Laboratory performed microarray construction, image and data analysis and the detailed protocol has been published (Thomas et al., 2001). Gene expression was measured using a microarray chip that contained approximately 1,200 minimally redundant cDNAs from an expressed sequence tag (EST) project executed by the Bradfield laboratory, as well as, a public EST effort. The results for the genes were first collapsed into a fully non-redundant set by averaging the results from multiple copies of the same gene. After collapsing, the data set was screened for genes that did not respond to the treatments used in the study. A threshold of 2 -fold change in gene expression was typically used as the cut-off value. Only genes that showed greater than a 2-fold change in response to treatment were selected for further analysis. Finally, the gene expression values were discretized such that mRNA induced greater than 2-fold were given a value of one, mRNA decreased greater than 2-fold were given a value of minus one, and mRNA expressed with less than a 2-fold change were given a value of zero. A flow chart for the data reduction scheme adapted from a Bradfield Laboratory publication is shown (Figure 24).

Principle Component Analysis of Microarray data. The data are plotted in a 3D PCA map with Principal Component 1 ( $\mathrm{PC} 1$ ) the $\mathrm{x}$-axis representing $100 \%$ of variation in the data, PC2 the $y$-axis representing $2.62-0.06 \%$ of the variation. Control housekeeping genes used to normalize the data, center around coordinate 0,0 . Gene sets predominantly affected by BHA treatment (blue) and those predominantly affected by acrolein (red), map to different coordinates suggesting they are differentially affected by the two treatments. We wish to thank Amir Singh and Thomas Knudsen, Ph.D., for their 
assistance in the analysis of this data through the resources of Birth Defects Center in the Department of Molecular, Cellular and Craniofacial Biology, University of Louisville, School of Dentistry.

Quantitative real-time PCR (qRT-PCR) for microarray data validation. To verify the results of the microarray analysis, qRT-PCR was performed on mRNAs from control or mice that were treated with either BHA or acrolein. Quantitative RT-PCR was also performed on 5-ppm acrolein heart and liver samples from mice that were exposed to by inhalation. We selected eight genes for verification based on our interests in lipid aldehyde metabolism. cDNA was synthesized from total RNA using the Advantage RTfor-PCR kit (Invitrogen, Carlsbad, CA). RNA ( $1 \mu \mathrm{g}), 20$ pmol random hexamer, 5X reaction buffer ( $50 \mathrm{mM}$ Tris- $\mathrm{HCl}, \mathrm{pH} 8.3,75 \mathrm{mM} \mathrm{KCl}, 3 \mathrm{mM} \mathrm{MgCl}$ ), $0.5 \mathrm{mM}$ dNTP, 1 unit/ $\mathrm{LL}$ RNase inhibitor and 200 units/ $\mu \mathrm{g}$ MMLV reverse transcriptase were used in a 20 $\mu \mathrm{L}$ reaction. Residual RNA was digested with $1.5 \mathrm{U}$ of $\mathrm{RNase} \mathrm{H}$ at $37^{\circ} \mathrm{C}$ for $20 \mathrm{~min}$. The cDNA was then diluted 5-fold with nuclease-free water and stored at $-80^{\circ} \mathrm{C}$ until used. Quantitative real-time PCR was performed using the ABI 7900HT Sequence Detector System according to the manufacturer's instructions (Applied Biosystems, Foster City, CA). FAM dye-labeled primers for Cyp2c29, Cyp3a11, Cyp2a5, GST mu1, nQOR-1, CYP1A2, HO-1 and ALDH1A1 were designed by the Prough laboratory at www.invitrogen/lux and purchased from Invitrogen (Carlsbad, CA). The qRT-PCR reaction was prepared as follows: TaqMan ${ }^{\circledR}$ Universal PCR Master Mix No AmpErase ${ }^{\circledR}$ UNG (Applied Biosystems, Foster City, CA; half the reaction volume), $50 \mathrm{nM}$ of each primer, $2 \mathrm{ng} / \mu \mathrm{L} \mathrm{cDNA}$ and water in a final volume of $15 \mu \mathrm{L}$. All qRT-PCR experiments were performed in triplicate using cDNA samples from independent RNA sets. For each 
Figure 24. Flow chart outlining the method for microarray data reduction and classification analysis for gene expression. Copied from thomas el al.. (2002).

Methods in Linzymology. Vol. 357: Pages 198-205. (Bradficld Laboratory publication). 


\section{Figure 24}

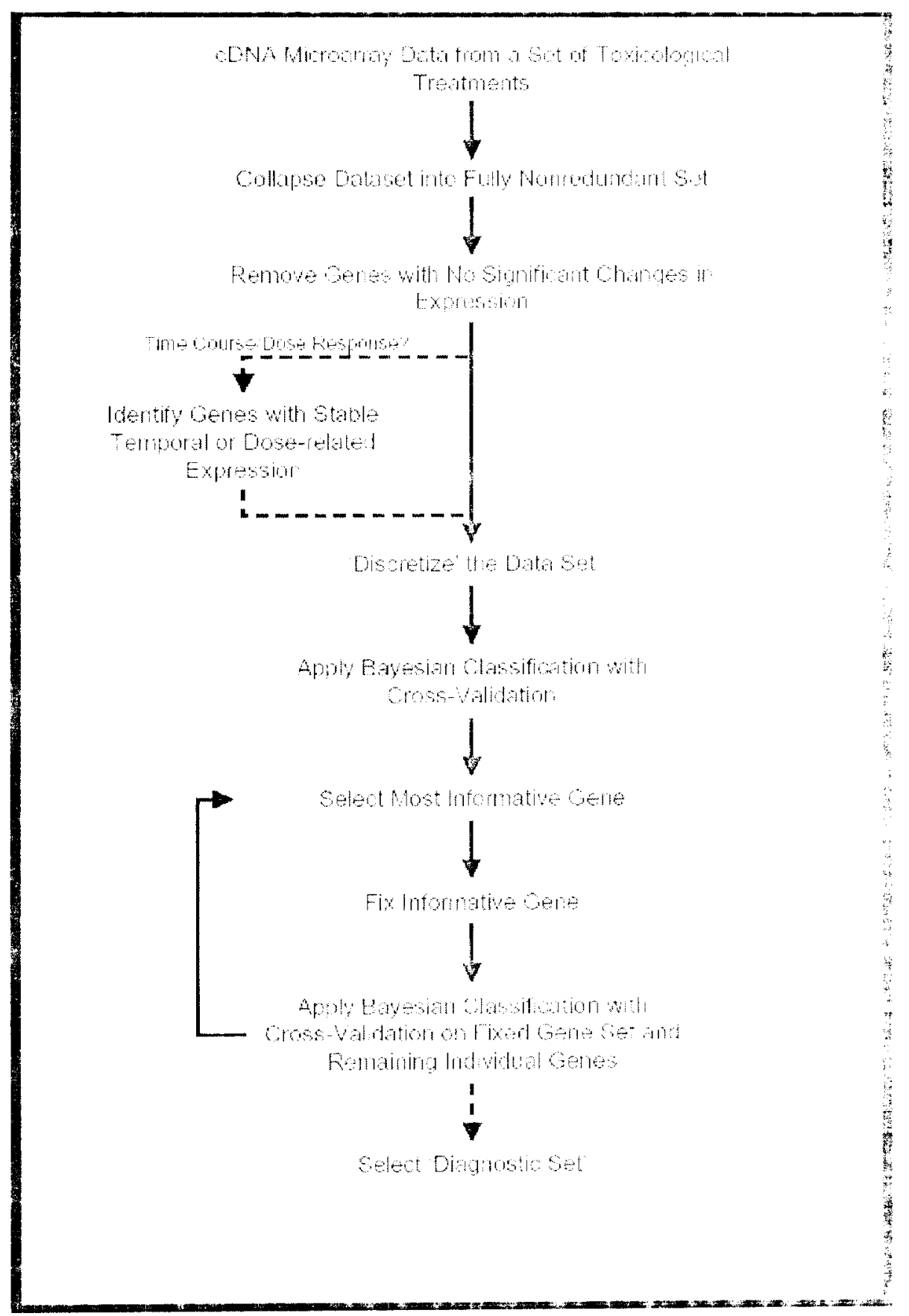


gene, a serial dilution of cDNA was performed to establish a standard curve. $\Lambda$ ll gene expression levels were normalized to $18 \mathrm{~S}$ rRN $\Lambda$. Primer specificity for the different genes was verified by melting temperature (Tm) analysis and by performing an agarose gel electrophoresis. The curves obtained following Tm analysis showed a single peak for each gene (ligure 25A). In addition. agarose gel electrophoresis of the qR'I-PC R roduct revealed a single band per gene per sumple (Figure 25B). These observations indicaled that the primers used for the qRT-PCR analysis were highly specilie.

Gene expression was calculated by determining the cycle threshold ( $\mathrm{C}$ ) obtainet from the fluorescence emission recorded in the geometric phase of gene amplification. The $\Delta C_{1}$ value was then calculated by subtracting the $C_{1}$ of the tareet from that of its respective $18 \mathrm{~S} \mathrm{rRNA}$. After determining the $2^{-\mathrm{ACr}}$, the fold changes in the level of gene cxpression of treated samples over control samples were calculated by assigning a mit value to the control samples.

Western blot analysis of Cyp2029 expression in mouse liver. Microsones were prepared from the liver of mice that were led $\Lambda I N-76 \Lambda$ diet only or $0.45 \% \mathrm{BISA-}$ supplemented $\mathrm{AN}-76 \Lambda$ diet. Total microsomal protein was determined by the BC $\mathrm{A}$ assay as previously described. Liver microsomal proteins $(20 \mu$ ) were resolved on a sodium dodecyl sulfate-polyacrylamide gel electrophoresis gel (PACHE $10 \%$ polyacrylamide) and transfered to a polyvinylidene difluoride menbane. The membranes were incubated with antibodies against (yp2e29) (antibody 1847 ) or (yp2e39) (antibody 1549). After incubation with the secondary antibudy, the mmanoreactive bands were visualized with enhanced chemilumineseence Wester hiotting systent Anershom 
Fisure 25. Analysis of the specificity of quantitative real-time PCR primers. ( $A$ ) The melting curve (Tm) analysis was performed for each gene and primer specificity veritid by a single amplified peak. A representative melting curve is shown for (yp 2c29). n() SR1. Cyp3a11 and 18S rRNA. (B) A 1\% agarose gel electrophoresis of the products of the ch T-PCR analysis shows a single band for each sample well loaded. 


\section{Figure 25}
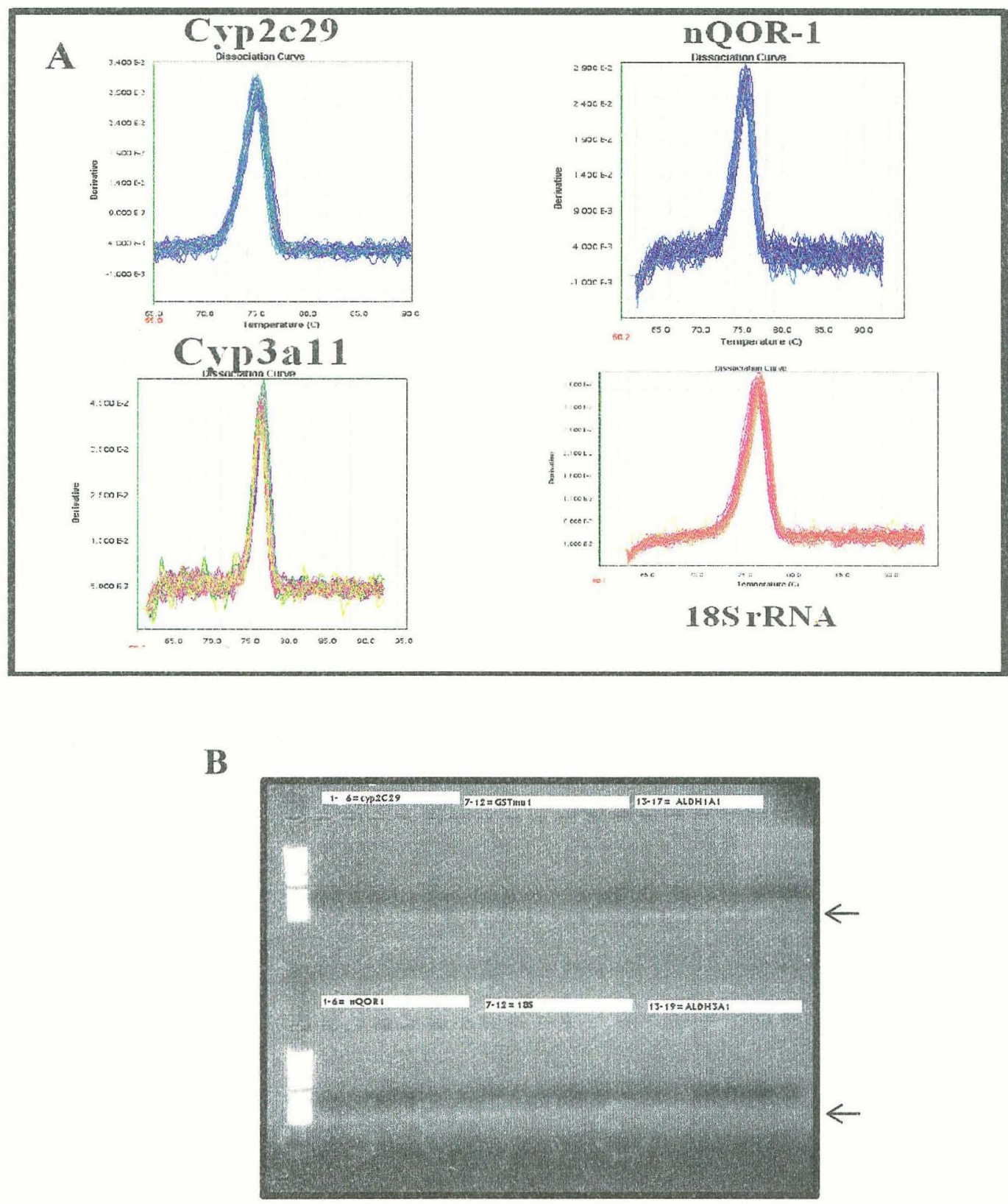
Biosciences). The Western blotting experiments were performed by the laboratory of I r. Joyce A. Goldstein (Laboratory for Pharmacogenomics, NIEHS, Research Triangle Park, NC).

Cytochrome $\mathbf{P 4 5 0}$ enzyme activity assay. Mouse liver microsomes were prepared from mice led with AIN-76A diet only or $0.45 \%$ BHA in AIN-76A dict and used to perform 9anthracene aldehyde metabolism assays. The P450 content of the microsomes from cach mouse liver was determined by $\mathrm{CO}$-difference spectra of dithionite reduced $\mathrm{P} 450$ (() mura and Sato, 1964). Microsomal protein fractions containing $50 \mathrm{nM}$ were used to measure 9anthracene aldehyde oxidative and reductive metabolism as previously described.

\section{RESULTS}

Changes in gene expression following exposure to xenobiotics. An important objective of the EDGE program is to create a public-access database of gene expression in response to different chemicals. Figure 26, adapted from the EDGE database, shows profiles obtained by feeding mice with 2,3,7,8-tetrachlorodibenzo-p-dioxin (TCDD, an aryl hydrocarbon receptor ligand), pregnenolone 16a-carbonitrile (PCN. a pregnane X receptor ligand), phenobarbital (PHB, a constitutive androstane receptor activator), and our test compound, BHA ( Nrf2 and AP-1 activator). As observed, different genes were induced or repressed by the four compounds. However, some genes were regulated (up or down) in a similar fashion between the four compounds, suggesting that these genes maybe regulated by more than one signaling mechanism. These genes include Cyp2e29 (PB, TCDD and BHA), Cypla2 (PB, TCDD, and BHA) and Cyp2a4, GS Tml (PB. 
BHA). These four compounds also individually regulated unique subsets of genes, thus resulting in a divergent response to exposure to these compounds: Hsd 17b2 (TCDD), Cyp3a25 (PCN) and Ugp2 (BHA). The genes that were uniquely regulated can serve as characteristic markers for TCDD, PCN, PHB and BHA, thereby assisting in the prediction of outcome of exposure and the receptor or transcription factor involved.

\section{Determination of the changes in gene expression following the exposure to acrolein}

or BHA. C57BL/6 mice were exposed to BHA or acrolein for 7 days prior to sacrifice, and RNA extracted from the heart and liver. The duration of exposure was chosen based on prior studies demonstrating that the maximum expression of genes for foreign compound metabolizing enzymes occurred in rats between 5 and 8 days following exposure to phenobarbital or dehydroepiandrosterone (Remmer, 1958, 1972; Conney et al., 1960; Prough et al., 1994).

From the electronic data provided following microarray analysis, we generated a heat map for genes responding to our treatments. A condensed heat map (Figure 27) was generated by assuming a cutoff for minimum induction of 2 -fold and a minimum repression of minus 2-fold of gene expression in response to BHA or acrolein. $\Lambda$ color scheme is used to show the expression pattern: red indicates induction; green indicates repression and black signifies no change in gene expression. From this analysis, we observed a difference in the absolute fold change in gene expression level in the liver between the two control groups of mice, acrolein vs. BHA, per os. 
Figure 26. Heat map of microanalysis obtained from treating mice with different chemical compounds. 2,3,7,8-tetrachlorodibenzo-p-dioxin (TCDD; an aryl hydrocarbon receptor ligand), pregnenolone $16 \mathrm{a}$-carbonitrile ( $\mathrm{PCN}$; a pregnane $\mathrm{X}$ receptor ligand), phenobarbital (PHB; a constitutive androstane receptor activator), and $\mathrm{BHA}$ ( a $\mathrm{Nrf} 2$ activator and AP-1 activator and inducer of oxidative stress). The PHB, TCDD and PCN data are from the database located at http://edge.oncology.wisc.edu. 


\section{Figure 26}

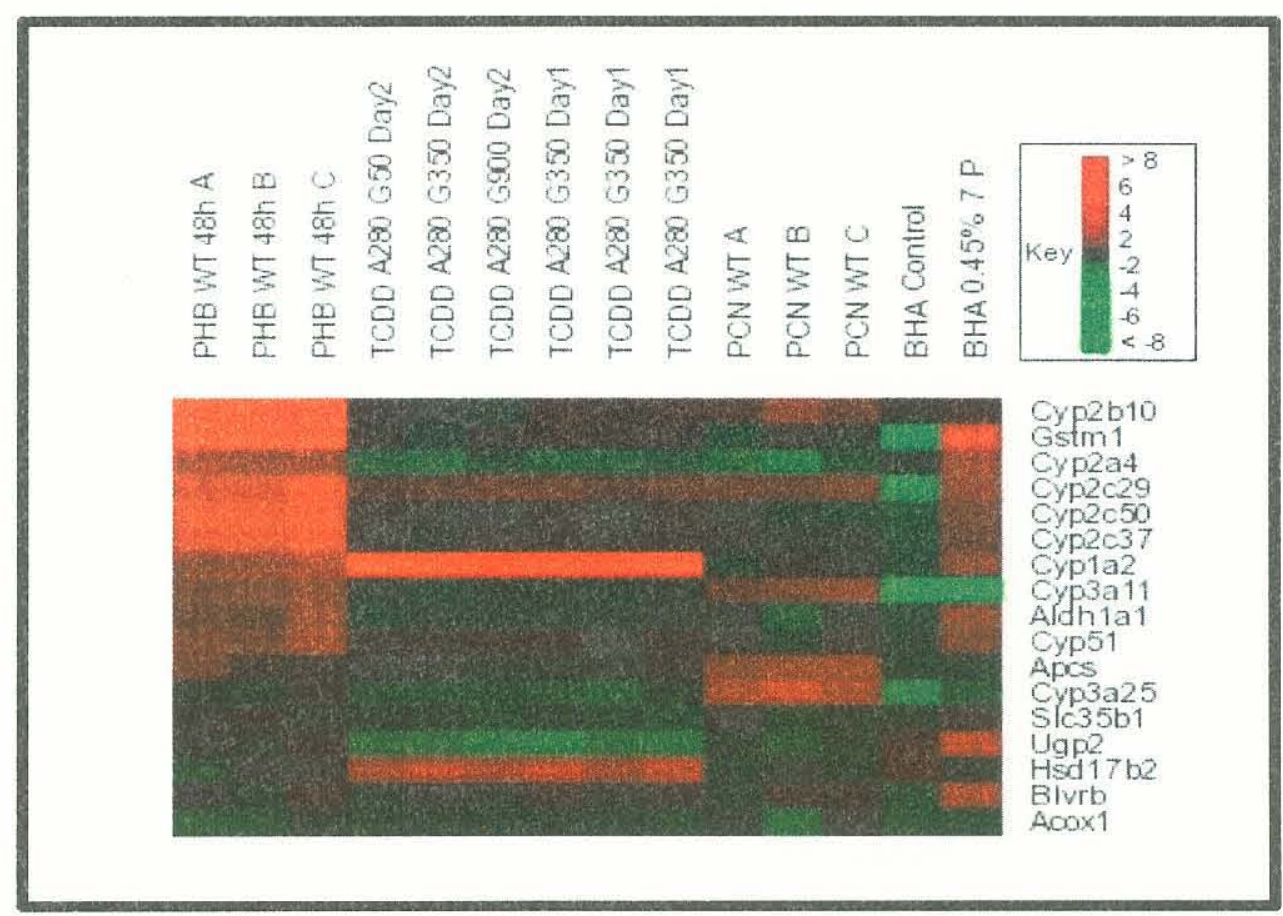


mice liver. Since our initial evaluation of the data from BHA exposure per os and acrolein exposure by gavage or inhalation demonstrated differences between the control mRNAs, we assumed that the two diets differentially affected expression of the control mRNAs used to normalize the results of the two data sets. Unfortunately, we could not control the differences in diet, since the samples for acrolein exposure per os and by inhalation required use of chow diet for the inhalation facility at the University of Alabama Birmingham (E. Postlewaithe, Ph.D., personal communication). Therefore, we consulted with Amir Singh, Birth Defects Systems Manager (http://systemsanalysis.louisville.edu) who recommended we compare the genes induced by either BHA or acrolein (increase by 2.0 or more) and normalize those two sets of data using the control mRNAs utilized by the EDGE system to scale the results. The data was then plotted in a principle component map. As shown in Figure 28, one can see that the control (housekeeping genes) map to position $(0,0)$, and the two sets of genes induced by either BHA or acrolein are very different sets of gene products. In addition, the magnitude of change was much less for acrolein than BHA. We interpret these data as indicating that $\mathrm{BHA}$ and acrolein at the concentrations used regulate different sets of targets genes. In addition, the responses for acrolein administration by gavage were much lower in magnitude, raising the concern that the dosage of acrolein used $(5 \mathrm{mg} / \mathrm{kg}$ body weight to avoid death of the mice) might not be sufficient to achieve dosages necessary for induction of the set of genes regulated by BHA. From results in the literature, acrolein is toxic to cells. When assessing target gene expression, cell death becomes a significant feature of the experiment, before significant induction of gene expression is seen (Winner et al., 1997). 
Figure 27. Heat map showing changes in gene expression in male C5713L/6 mice liver following treatment with BHA or acrolein. The first column represents control $\triangle \mathrm{IN}-76 \mathrm{~A}$-fed mice, the second column represents mice fed diet containing $0.45 \% \mathrm{BHA}$ ad libitum for 7 days, the third column corresponds with mice treated with saline by gavage while the fourth column represents mice administered $5 \mathrm{mg} / \mathrm{kg}$ acrolein in saline by gavage while on chow diet. The hierarchical clustering of genes is a total of four arrays generated using a condense clustering assuming a minimal induction of 2-fold and a minimal repression of minus 2 -fold. The color scheme is used to show the expression pattern; red indicates induction, green indicates repression and black represents no change in mRNA in response to BHA or acrolein treatment. Circle shows changes in (iSTm 1, Cyp2c29 and Cyp2a4 in the different samples. 
Figure 27

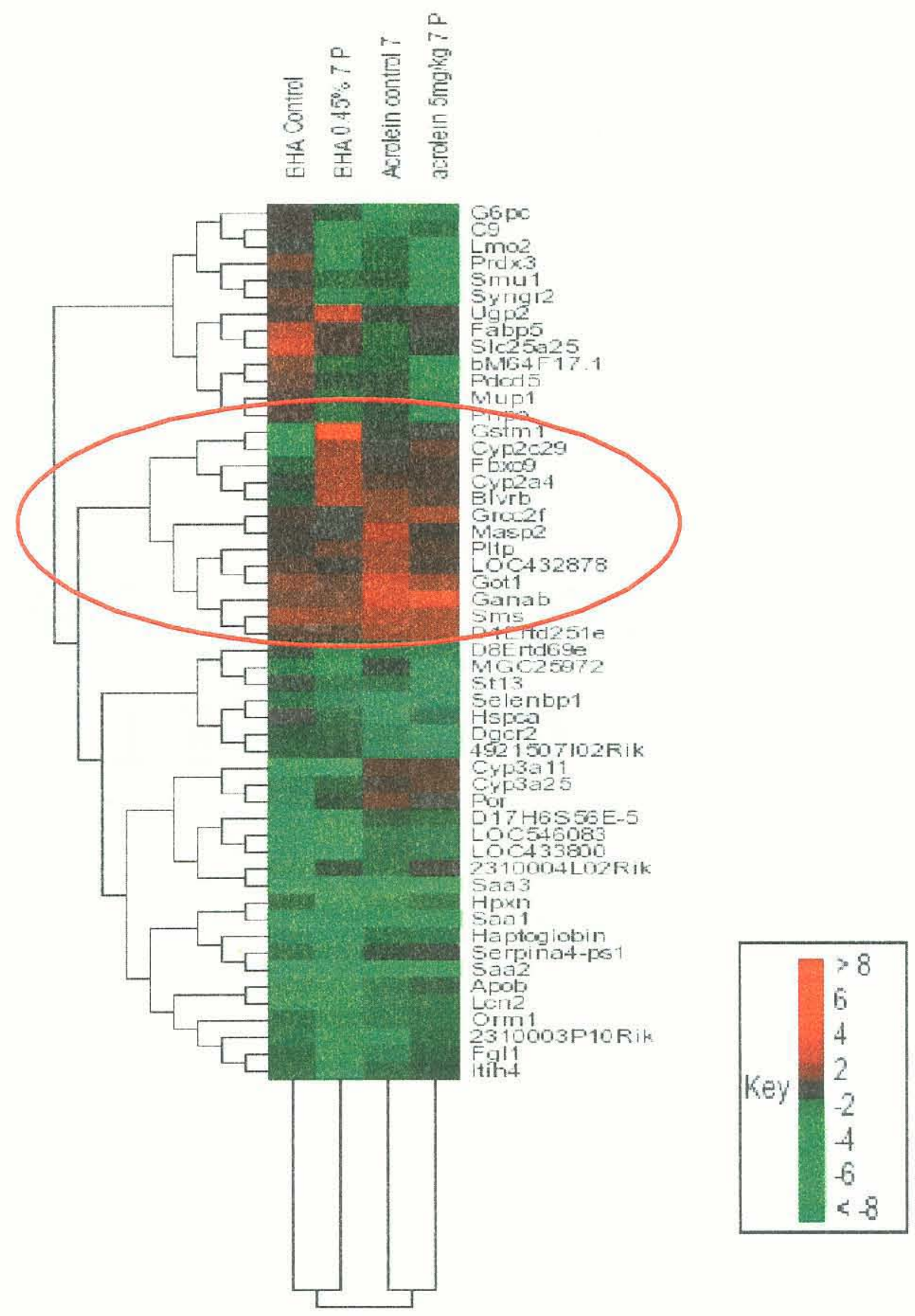


Changes in gene expression following exposure to BHA. Lipid aldehydes produced during oxidative stress are metabolized through conjugation to GHS by the GSTs (Esterbauer et al., 1975). BHA caused the induction of mRNA expression of GSTa3, GSTm 1 and GSTt1. The aldehyde dehydrogenases catalyze NAD(P)H-dependent oxidation of aldehydes including 4-HNE to their respective acids. The aldehyde dehydrogenase ALDH1, ALDH1a7, ALDH4 and ALDH5 were all induced by BHA. The aldo-keto reductases (AKRs) are a family of NADPH-dependent enzymes that catalyze the reduction of aldehydes to alcohols (Jin and Penning, 2007). BHA caused induction of the mRNA level of aldo-ketoreductases AKR1c6, AKR1c13 and AKR1c19 (Table 5). Enzymes of the GST, ALDH and AKR (Ellis, 2007) family are known to be induced by compounds that activate $\mathrm{Nrf2}$. Our data has demonstrated that BHA, a Nrf2 activator induces the expression of these enzymes and therefore correlates with previous observations (Nair et al., 2006, Purdon-Dickinson et al., 2006)..

P450s are induced by a variety of compounds including substrates and nonsubstrates of this superfamily of enzymes. From the microarray analysis data, some CYPS were induced in response to BHA. These include Cyp1a2, Cyp2a4, Cyp2c29, Cyp2c37. Cyp2c40, Cyp2c50 and Cyp51 (Table 5). The 5'-promoter sequence of the P450 genes do not contain an apparent antioxidant responsive element. Therefore the induction of the CYPs most likely is not directly mediated by Nrf2 binding to the ARE. This suggests the involvement of a different transcription factor, most likely AP-1, also known to be activated by BHA. 
Figure 28. Principle component analysis of data from BHA and acrolein controls and treatments. C57BL/6 mice were fed with AIN-76A diet only (control) or supplemented with $0.45 \%$ BHA in AIN76A diet for 7 days. A second group of mice was fed with chow diet only (control) or administered $5 \mathrm{mg} / \mathrm{kg}$ acrolein by gavage daily for 7 days. RNA was extracted from the mice lever and changes in gene expression determined by microarray analysis. The two sets of data for the genes induced by either BHA or acrolein (increase by 2.0 or more) were normalized using the control mRNAs utilized by the EDGE system to scale the results. The control (housekeeping genes) map to position $(0,0)$. and the two sets of genes induced by either BHA or acrolein are different sets of gene products. 


\section{Figure 28}

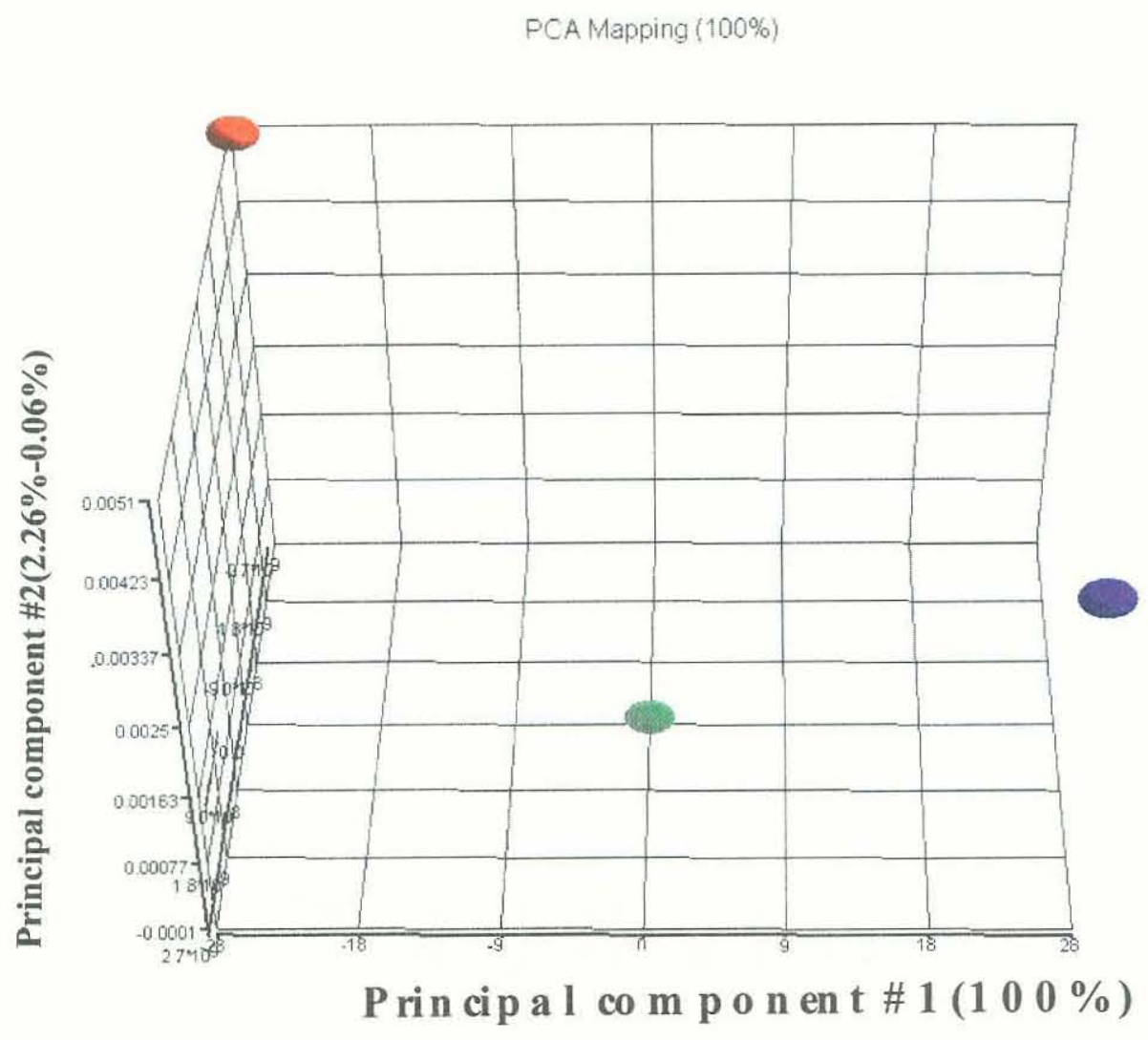


Acrolein treatment altered gene expression in mouse liver. Microarray analysis was

was also conducted to verify changes in gene expression in C57BL/6 mice liver, to identify xenobiotic metabolizing genes induced by acrolein. Table 6 shows a set of genes; of interest that were induced or repressed in response to acrolein treatment. Some aldehyde dehydrogenases, aldo-ketoreductases, as well as glutathione S-transferases were induced by acrolein (Table 6). Interestingly, like BHA, some cytochromes P450 were induced in response to acrolein. These include Cyp2c29, Cyp2c44, Cyp2el, and Cyp2j6 (Table 6 ). The mechanism through which cytochromes P450s are regulated by compounds known to activate Nrf2 like BHA and acrolein are still unknown.

For most of these genes of interest, the fold-change in gene expression caused by acrolein was lower than that observed for BHA. It should be noted that the mice were treated by gavage with only $5 \mathrm{mg} / \mathrm{kg}$ of acrolein. Treatment with a higher dose of acrolein resulted in the death of the mice. Therefore, the low level of change of $m R V A$ induction observed with acrolein could be because of insufficient levels of acrolein reaching the liver and therefore robust induction was not observed. Also, there are several xenobioticmetabolizing enzymes expressed in the gastrointestinal tract and the liver that could metabolize the acrolein before its induction effect is initiated. Most importantly, cells contain the non-protein peptide GSH. GSH can spontaneously or enzymatically conjugate with acrolein, causing a further reduction in acrolein levels. Acrolein is a highly reactive electrophile. It may have reacted with proteins and other macromolecules in the gastro intestinal tract, thereby reducing the amount of acrolein reaching the hepatocytes.

Quantitative real-time PCR confirmation of microarray results. To verify the 
Table 5. BHA-regulated xenobiotic-metabolizing enzyme genes in mouse liver

Biological Response/Gene

Acessien number fold change

Piase I Xenubiotic Metabolizing Enzymes: Crtochomes P450

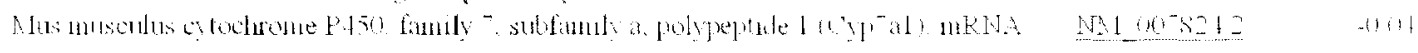

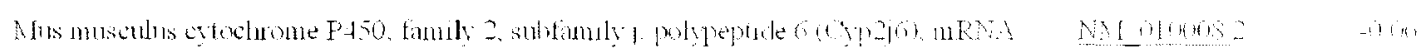

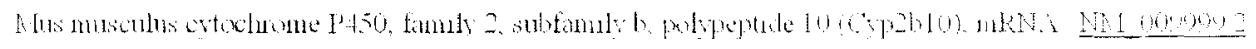

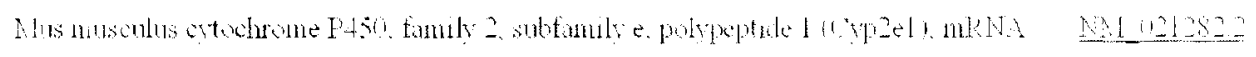

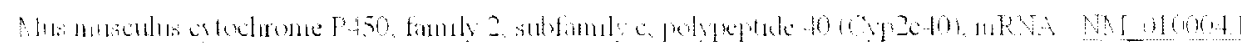

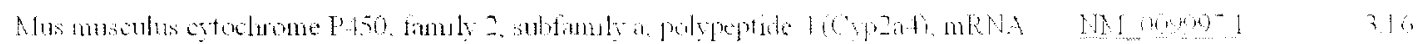

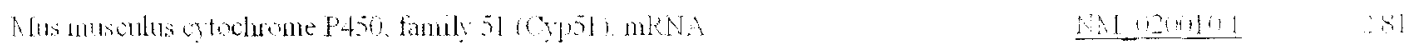

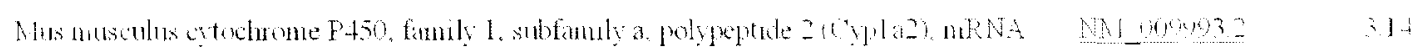

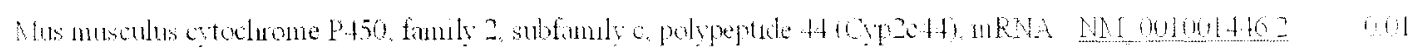

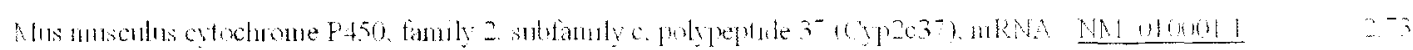

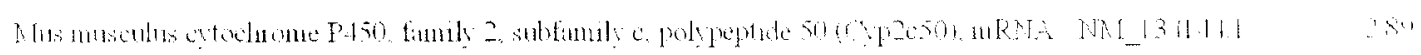

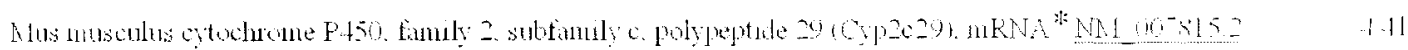

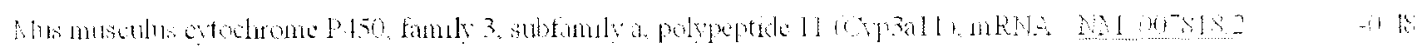

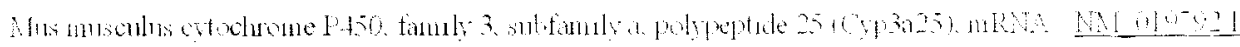

Other phase I Xenobiotic metabolising Enzymes: The AlDHs and IKRs

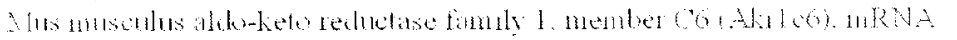

NII

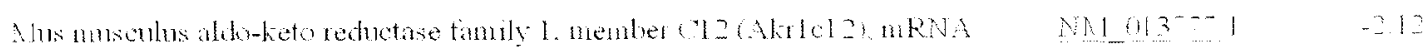

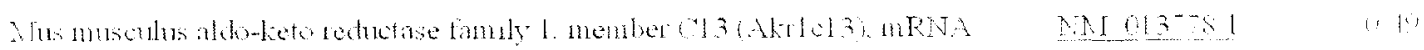

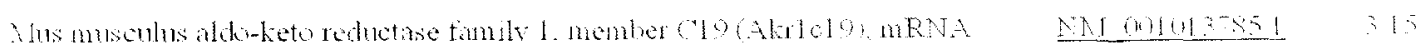

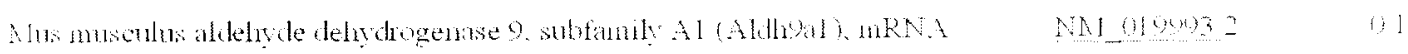

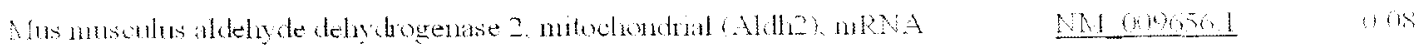

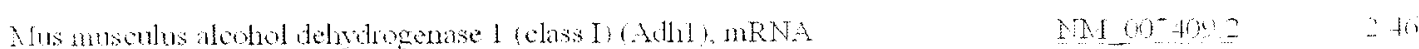

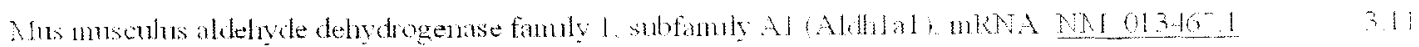

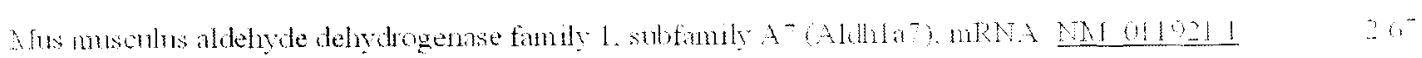

Phase II Renoliotic Metabolising Enzymes: The GSTs

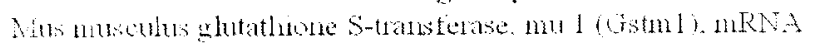

MO1058ב

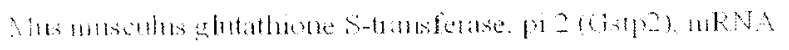

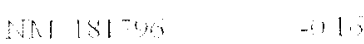

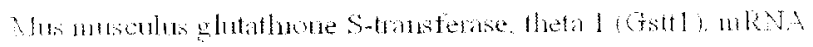

$\operatorname{MlOMES} 23^{-}$

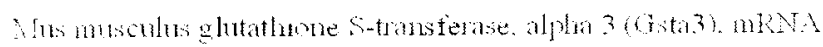

MO10302 
results from the microarray analysis, quantitative real-time PCR (qRT-PCR) was performed to examine the effects of acrolein and tBIIQ on gene expression. The genes selected for analyses were Cyp2c29, Cyp3a11, Cyp2a5, Cyp1a2, GSTm1. ALDH1^1 and nQOR1. RNA samples from individual mice were reverse-transcribed using random hexamer primers to cDNA and then used for the $\mathrm{qR}$ T-PCR experiments. The $\mathrm{C}_{\mathrm{T}}$ value for the expression of each gene was normalized to $18 \mathrm{~S} \mathrm{rRNA}$ and the fold induction was then calculated. The RNA samples were not pooled; the data represent mRNA expression levels of livers from an individual mouse. The results are presented as box and whiskers plots. The box plots extend from the $25^{\text {th }}$ to the $75^{\text {th }}$ percentile. The line across the box shows the median distribution of samples $(\mathrm{n}=5)$ for each gene. For each point. a single $m R N \Lambda$ was analyzed in triplicate and the average is shown.

The average fold change in gene expression was Cyp2c29, 6-fold; (yp3al1, 1fold; ALDH1A1 16-fold; Cyp1a2, 3-fold; GSTm1, 22-fold; Cyp2a4, 33-fold. and nQOR1, 47-fold in the liver of mice fed AIN-76A diet supplemented with $0.45 \%$ BHA for 7 days relative to AIN-76A diet alone (Figure 29A). The average fold change in gene expression in the mice heart following BHA treatment was Cyp2c29, 2-fold; GSTm1, 1.4-fold; ALDH1A1, 1.4-fold and, nQOR-1, 1.5-fold (Figure 29B).Quantitative RT-PCR was also performed on samples from mice liver and heart that had been treated with saline or $5 \mathrm{mg} / \mathrm{kg}$ acrolein daily for 7 days in the mouse chow diet. Gene expression was verified for Cyp2c29, 1.6-fold; GSTm1, 0.96-fold; ALDH1 A1, 0.78-fold; Cyp2a5, 0.94fold and Cyp1a2, 0.93-fold in the liver (Figure 30A). Genes verified in the hearl were Cyp2c29, 0.94-fold; GSTm1, 0.78-fold; ALDH1A1, 0.81-fold and nQOR1, 0.66-fold (Figure 30B). Like with the previous samples, RNA samples used in this study were not 
Table 6. Acrolein-regulated genes in C5713L/6 mouse liver

Biological Response/Citne

Cecssion Number Follohinge

Phase I metabolism: The CYPs

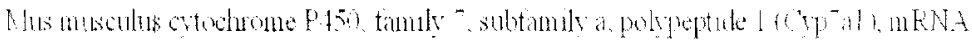

$\operatorname{Nin}-9+2$

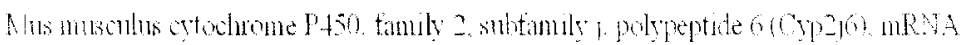

Menms

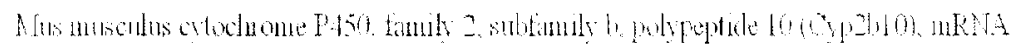

$x+100909=-60$

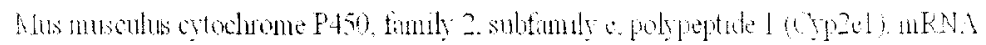

$\operatorname{lin} 102-2$

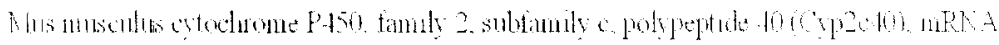

$\operatorname{lng} \operatorname{lng} \mid$

$\underline{M 01090-1}-6,13$

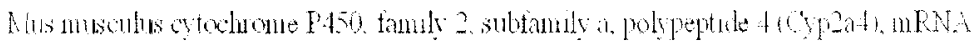

Nognol

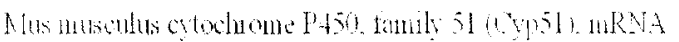

1210an?

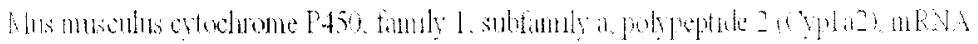

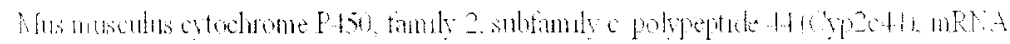

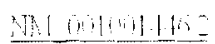

$-2$

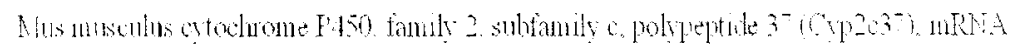

Nolmit

1

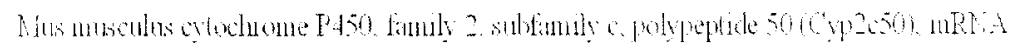

NoS13.14.1

16

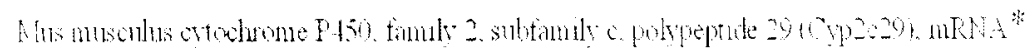

$\operatorname{Man}=215$

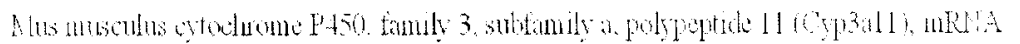

Motio

Other phase I metabolizing enzymes: ALOH and AKR family

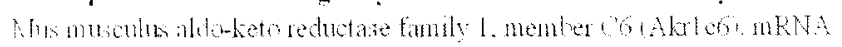

XIONL! $\quad 210$

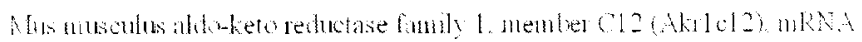

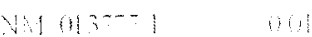

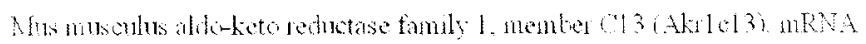

Notis

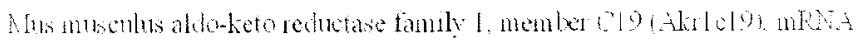

Yis 010131

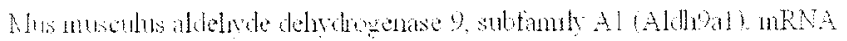

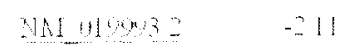

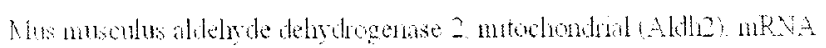

MNO606 -203

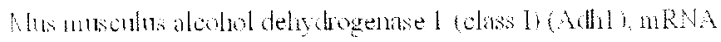

Nond

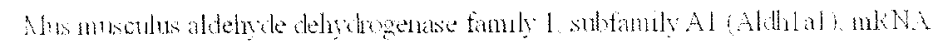

$M 010 \div !$

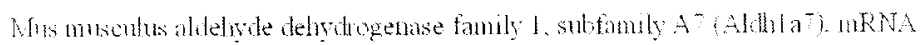

MN101011 - tot

Phase II Senobiutic netabolising Encymes: The GSTs

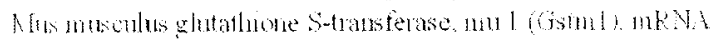

N10103: $=11$

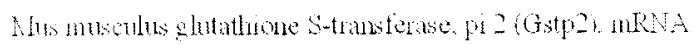

M 191

Mostis? $-1: 16$

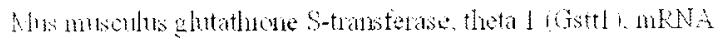

WHOBOE= 
pooled. We observed a lower level of induction of Cyp2c29 mRNA in the heart and liver samples from mice that were exposed of $5 \mathrm{mg} / \mathrm{kg}$ of acrolein by gavage; there was no change observed for Cyp3a11 in the same samples. Even though the expression of Cyp2c29 was lower in acrolein-fed mice heart and liver compared with BHA. the experimental levels were higher than for GST $m 1$ and $A \mathrm{LDH} 1 \mathrm{~A} 1$. Sinee these compounds normally acting through $\mathrm{Nfr} 2$ typically regulate GSTm1 and ALDHIA1, it is likely that Cyp2c29 is regulated differently from the Nrf2 target genes. We speculate that (yp2c29 is regulated by the oxidative stress-sensitive transcription factor, $\mathrm{AP}^{\mathrm{P}}-1$.

\section{Analysis of gene expression following acrolein administration by inhalation.}

Acrolein is a major environmental pollutant. The sources of acrolein include cigarette smoke. smoke from car exhaust and wild fire (Beauchamp et al., 1988). We performed a preliminary study to determine if the exposure to acrolein by inhalation (5-ppm. 6 hrs per day for 5 days) affects gene expression in the heart and liver of mice. We selected 5 genes based on our previous observation that the expression of these genes were changed following oral administration of acrolein or BHA. The average fold induction of gene Expression was Cyp2c29, no change; GSTm1, 1.2-fold; ALDH1a1, 1.5-fold: nQOR1. 2.4-fold and HO-1, 2.3-fold in mice liver (Figure 31 A). In the heart, we observed no change in gene expression for Cyp2c29, ALDH1a1, nQOR-1. A minimal fold change was observed for HO-1, 1.4-fold and GST'm1, 1.3-fold; in mice heart (17igure 31 B). These low levels of induction of mRNA suggest that either the level of acrolein in the inhalation chamber was not high enough to cause induction through $\mathrm{Nrf2}$ and AP-1 or, the inhaled acrolein is not reaching the heart and liver at concentrations high enough to cause a 
Figure 29. Quantitative real-time PCR analysis of gene expression in C57BL/6 mice heart and liver following treatment acrolein. Mice were treated by gavage with saline (control) or $5 \mathrm{mg} / \mathrm{kg}$ acrolein by gavage daily for 7 days. RNA was extracted from the heart and liver, reverse transcribed to cDNA and used for qRT-PCR analysis of gene cxpression. The fold induction is shown in a box and whiskers plot. The boxes extend from the $25^{\text {th }}$ to the $75^{\text {th }}$ percentile, the line across represents the median distribution of samples $(\mathrm{n}=5)$ for each gene. For each point, $m R N \Lambda$ sample from a single mouse liver was analyzed in triplicate and the average is shown. 
Figure 29
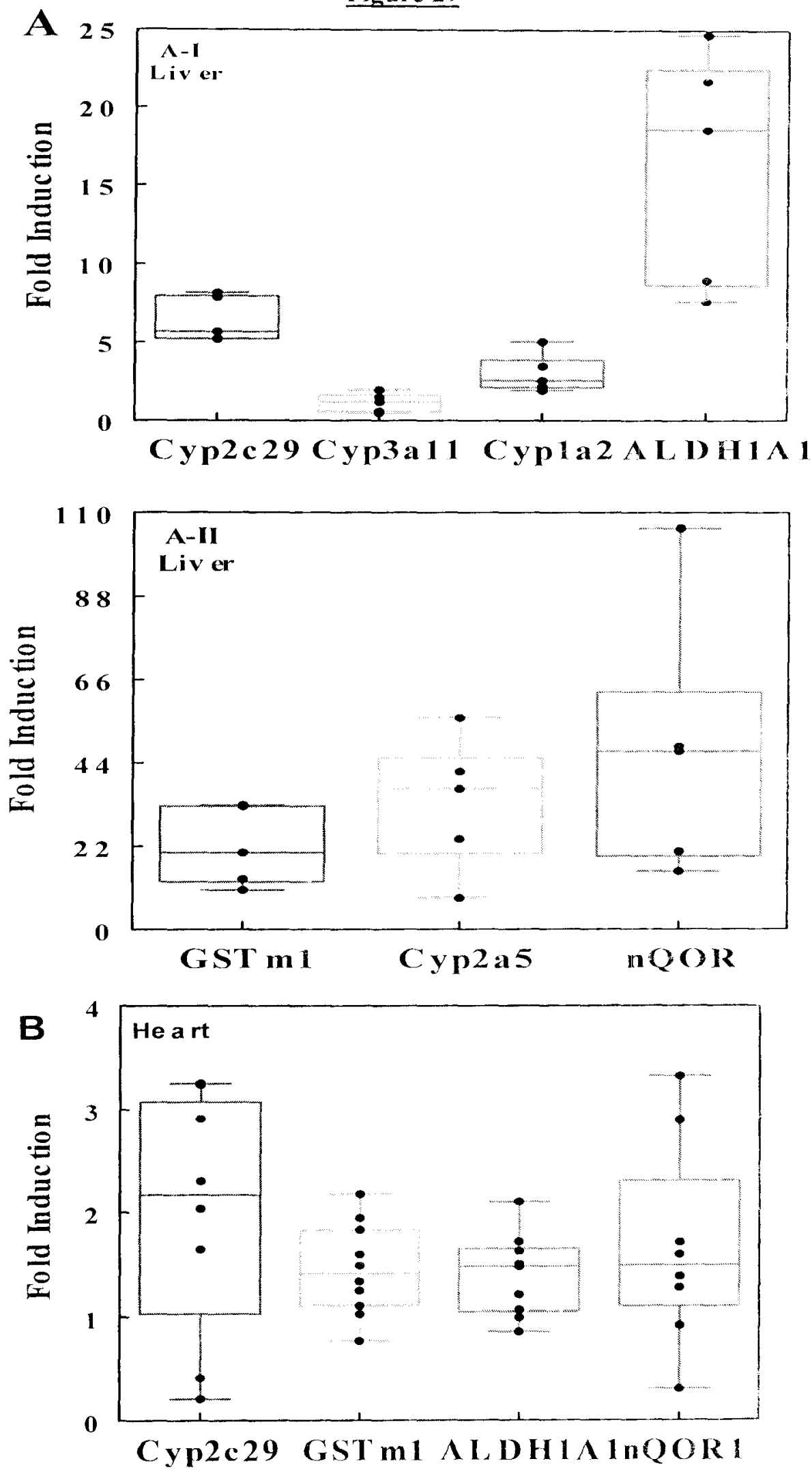
Figure 30. Quantitative real-time PCR analysis of gene expression in C57BL/6 mice heart and liver following treatment acrolein. Mice were treated by gavage with saline control) or $5 \mathrm{mg} / \mathrm{kg}$ acrolein by gavage daily for 7 days. RN $\mathrm{A}$ was extracted from the heart and liver, reverse transcribed to cDNA and used for qRT-PCR analysis of gene cxpression. The fold induction is shown in a box and whiskers plot. The boxes extend fom the $25^{\text {th }}$ to the $75^{\text {th }}$ percentile, the line across represents the median distribution of samples $(n=5)$ for each gene. For each point, mRNA sample from a single mouse liver was analyzed in triplicate and the average is shown. 
Figure 30
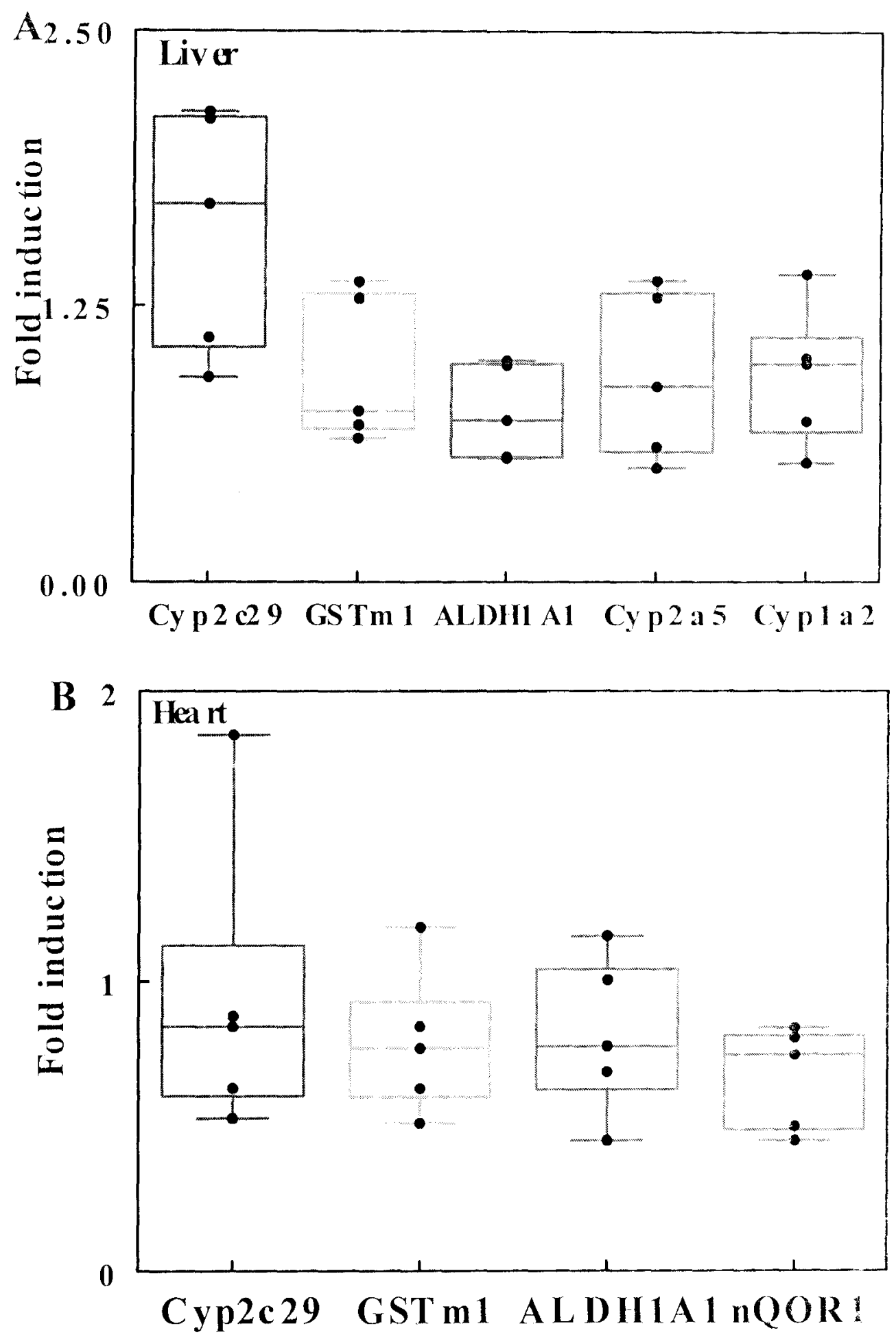
robust induction in gene expression.

BHA induces 9-anthracene aldehyde metabolism in mouse liver microsomes. We demonstrated by microarray and qRT-PCR that feeding of C57BL/6 mice with $0.45 \%$ BI A or $5 \mathrm{mg} / \mathrm{kg}$ of acrolein for 7 days caused an induction of Cyp2c29. By using liver microsomes from BHA-fed mice liver, we performed metabolism studies using 9- $\wedge$ A as substrate. We observed that BHA-fed mice liver microsomal oxidation of 9-A $\triangle$ was induced 3-fold compared with the control. This induction was statistically significant at p 0.005. There was also a small but significant increase in the reduction of $9-\Lambda \wedge$ to $9-$ anthracene methanol $(\mathrm{p}<0.05$, Figure 32$)$. This suggests that BHA indaced the expression of microsomal $\mathrm{P} 450$ s responsible for 9-A A metabolism. In our published study (Amunom et al., 2007), we demonstrated that mouse liver microsones oxidize both 9- $\mathrm{A}$ and 4-HNE and that this oxidation activity was inhibited by several $\mathrm{P} 450$ inhibitors; miconazole (general P450 inhibitor), phenytoin (Cyp2c29 inhibitor) and troleandomycin (Cyp3a inhibitor). Taken together, these data suggest that the treatmeat of mice with BHA induced the expression of hepatic P450s like Cyp2c29 (6.4-fold), which we have shown to be capable of metabolizing 4-HNE. The expression of $\mathrm{Cyp} 2 \mathrm{c} 29$ was also induced 1.6-fold by acrolein indicating the possibility of substrate-dependent transcriptional regulation. It is possible that during oxidative stress, when acrolein and 4 HNE levels increase, some P450s are induced and contribute to the further metabolism of these lipid aldehydes.

BHA induced Cyp2c29 protein levels in mouse liver. In addition to measuring the 
Figure 31. Quantitative real-time PCR analysis of gene expression in C57BL/6 mice following treatment acrolein by inhalation. Mice fed chow diet were treated with acrolein by a 6-hour daily dose of normal air (control) or air containing 5-ppm acrolein for 5 days. RNA was extracted from the heart and liver, reverse transcribed to cDNA and used for qRT-PCR analysis of gene expression. The fold induction is shown in a box and whiskers plot. The boxes extend from the $25^{\text {th }}$ to the $75^{\text {th }}$ percentile, the line across represents the median distribution of samples $(n=4)$ for each gene. For each point. $m R N A$ sample from a single mouse liver was analyzed in triplicate and the average is shoun. Fold induction for Cyp2c29. GSTm1, ALDH1A1, nQOR1 and HO-1 in $\Lambda$. Mice liver and B. Mice heart following exposure to air containing 5-ppm acrolein. 
Figure 31
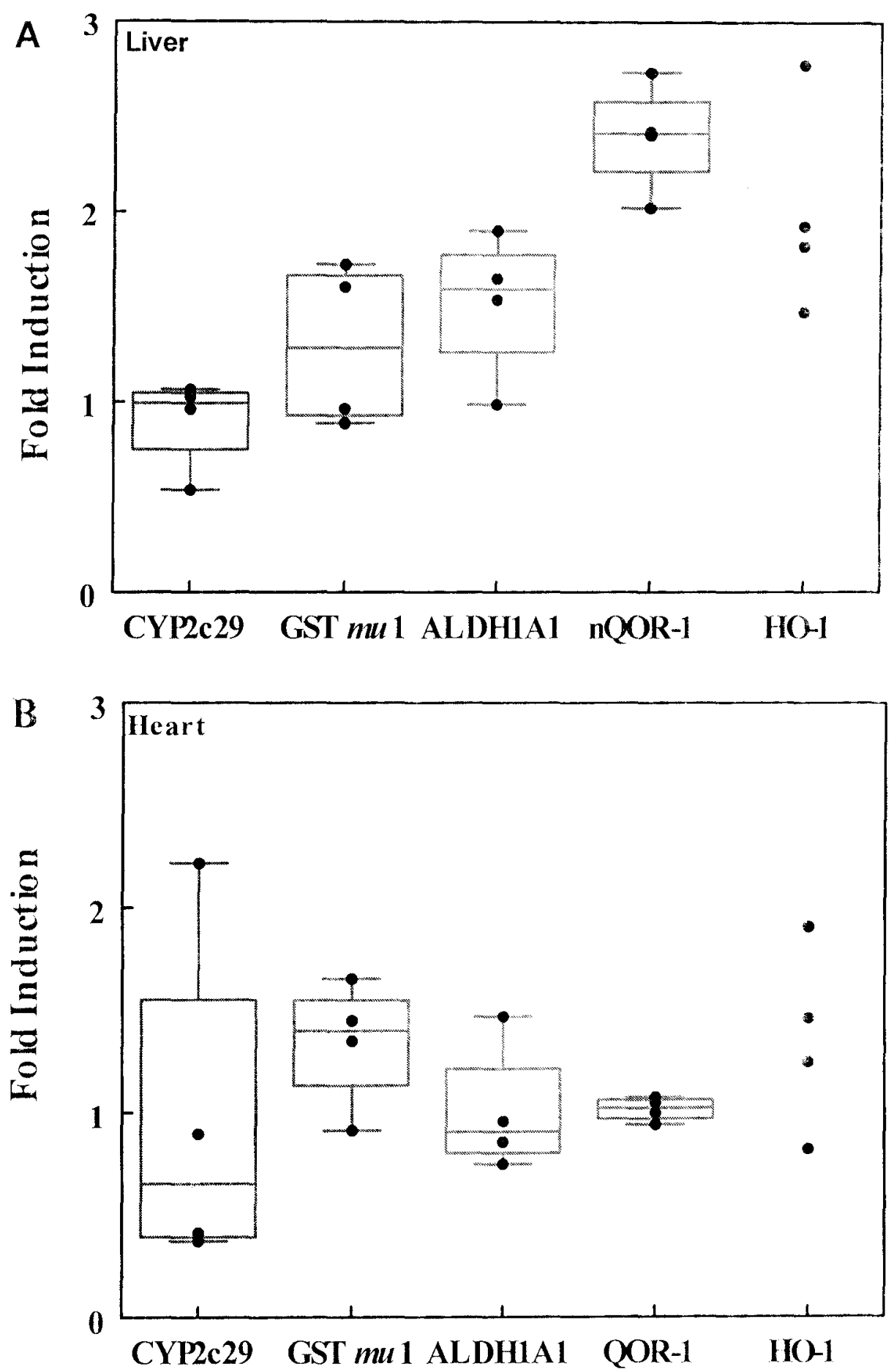
mRN $\Lambda$ levels in mice liver (control vs. BHA), we measured Cyp2c29 (52 kDa) protein level in liver microsomes. A Western blot analysis of microsomes from C57131/6 mice liver with antibodies generated against Cyp2c29 (Goldstein JA., PhD. NILI IS, lriangle Park, NC), revealed a 2.5-3.0-fold increase of this P450 in BHA-fed mice (Figure 33A). The Cyp2c29 antibody cross-reacted with the Cyp2c39. However, (yp2c29-specilic change could be distinguished from Cyp2c39, because the Cyp2c39 antibody did not cross-react with Cyp2c29 (Figure 33B). The Cyp2c29 antibody did not cross-react with other members of the Cyp2c class of P450s that included Cyp2c37, Cyp2c38. Cyp2c40. Cyp2c44, Cyp2c50, Cyp2c54, Cyp2c55, Cyp2c65, Cyp2c66 and Cyp2c70. This is important because the mouse Cyp2c class has about $75 \%$ identity the results confirmed the specificity of the Cyp2c29 antibody used (Figure 33C). Having previously demonstrated that Cyp2c29 metabolizes 4-HNE and that BIIA induces this P450 by both microarray and qRT-PCR, taken together, the results suggest that $B H A$ and acrolein induce Cyp2c29 expression. It is possible that the protein level of other P450s were induced in the microsomal samples; however, they were not individually determined.

\section{Discussion}

To identify genes that are induced following exposure to BI $\mathrm{A}$ and acrolein. microarray analysis was performed on 1200 genes and the expression pattern compared between the control and acrolein- or BHA-fed C57BL/6 mice. Based on our analysis, several genes were induced by either acrolein or BHA in mouse liver; we observed a higher induction of gene mRNA in the BHA-fed mice than acrolein-fed mice.

Cytochromes P450 constitute a superfamily of enzymes that motabolize lipophilic 
Figure 32. Induction of cytochrome $\mathbf{P 4 5 0}$ activity in mouse liver microsomes by BHA treatment. Mice were fed with AIN-76A (control) diet or AIN-76A diet containing $0.45 \%$ BHA (treated) for 7 days and microsomal fractions prepared from the liver. Cytochrome P450 (50 nM) activity in the microsomes were analyzed by measuring the oxidation of 9-AA to 9-ACA and reduction to 9-AMeOH in the presence of $\mathrm{NADPH}$ regenerating system at $37^{\circ} \mathrm{C}$. ** Significantly different from control, $\mathrm{p}=0.005$; *significantly different from control, $\mathrm{p}<0.05$. 
Figure 32

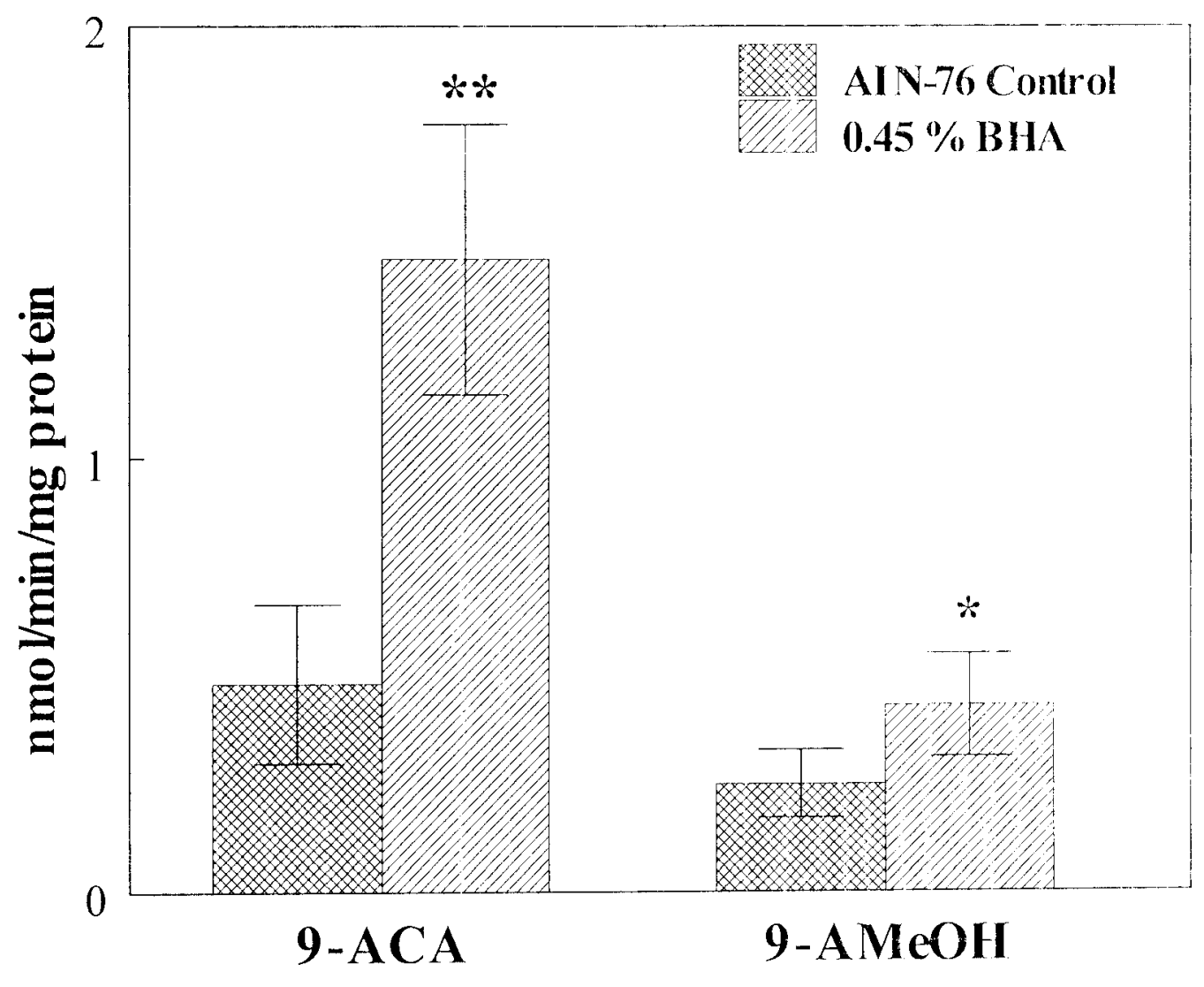


compounds. Some CYPs also function as biosynthetic enzymes. While humans have 57 P450 genes, mice have 102. In this study, we observed that some P450s were induced in the BHA- or acrolein-fed mouse liver samples. Most importantly Cyp2e29, Cypla2, and Cyp2a4 were strikingly induced. Cyp2c29 is a murine P450, abundantly expressed in the liver and other extra hepatic tissue including the heart, lungs, brain and intestine (I cuo et al., 1998). We have previously demonstrated that this P450 metabolizes 4-IINI: (yp2at (98\% sequence identity with Cyp2a5) is expressed in the liver and olfactory mucosa but not in the heart (Su and Ding, 2005). BIIA induced this P450 in mouse liver. which we demonstrated was also able to metabolize 4-HINE. Induction of P450s by BHA and acrolein were of interest to us since these compounds are predominantly associated with the induction of the expression of genes that encode enzymes involved in phase II xenobiotic metabolism. BHA and acrolein induce gene expression by utilizing a group of trainscription factors referred to as oxidative stress-sensitive transcription factors as mediators. Acrolein activates the JNK signaling pathway (Ranganna et al., 2002). In vivo. BHA is O-demethylated to $\mathrm{BH}$ Q and $\mathrm{BH}$ Q can undergo redox cycling gencrating hydrogen peroxide (oxidative stress) causing the activation of JNK. The activation of JNK can either result in the phosphorylation and activation of $\mathrm{c}$-Jun or the phosphorylation and activation of $\mathrm{Nrf} 2$. Activation of these transeription factors result in the induction of expression of target genes.

The involvement of Nrf2 in cytochrome P450 gene regulation has not been extensively documented. Some studies have suggested a possible role of Nrf2 in P450 gene expression. For example, Hu et al. (2004 and 2006) performed microarray analysis of gene expression by sulforafane (SFN, a compound known to induce gene expression 
Figure 33. BHA induces the expression of Cyp2e29 in mice liver. Mouse liver microsomal fractions from AIN-76A controls and $0.45 \% \mathrm{BHA}$ supplemented $\mathrm{AIN76-fed}$. were clectrophoresed on a 10\% SDS-polyacrylamide gel. Resolved proteins were transferred to nitrocellulose membrane and immunoblotted for the presence of cytochromes P450. A. The membrane was immunoblotted using antibodies against (y) 2029 and immunoreactive bands detected by enhanced chemiluminescence; lanes 1 and 14, protein standard $(2 \mu \mathrm{L})$; lanes 2 and 13. E. coli expressed Cyp2c29; lanes 3 to 6 . Cyp2229 in control microsomes; lanes 7 to 12, Cyp2c29 in BHA-treated microsomes. BI iA-CI, BHA-control liver; BHA-TL, BHA-treated liver. B. The membrane was immunoblotted with an antibody against Cyp2c29. C. Members of the mouse Cyp2e family were immunoblotted with an antibody against Cyp2c29 to check for crossreactivity. Twenty micrograms of protein was loaded per sample well. 
A

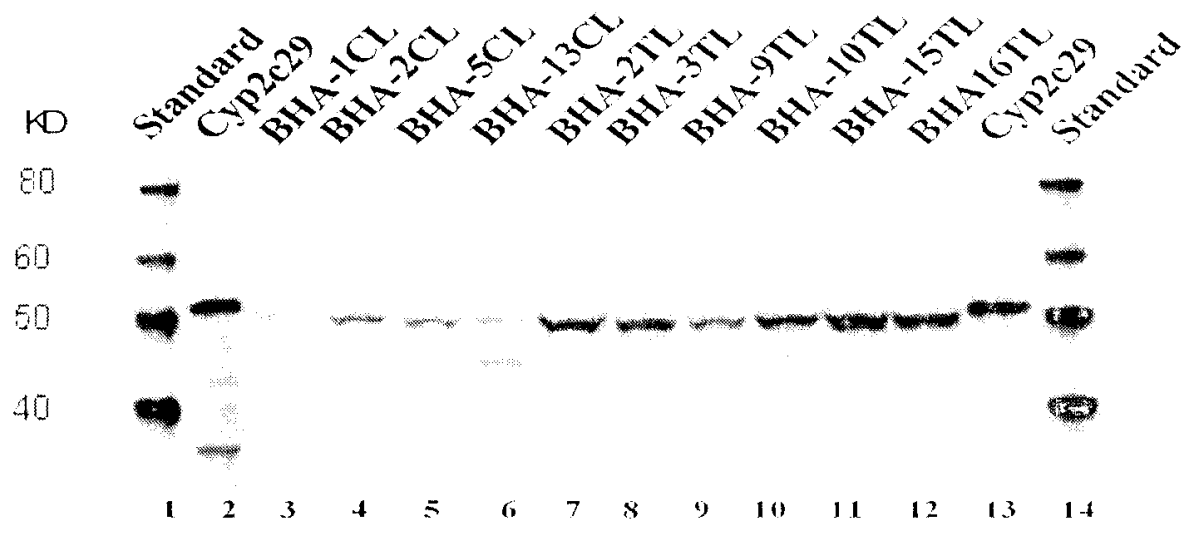

B

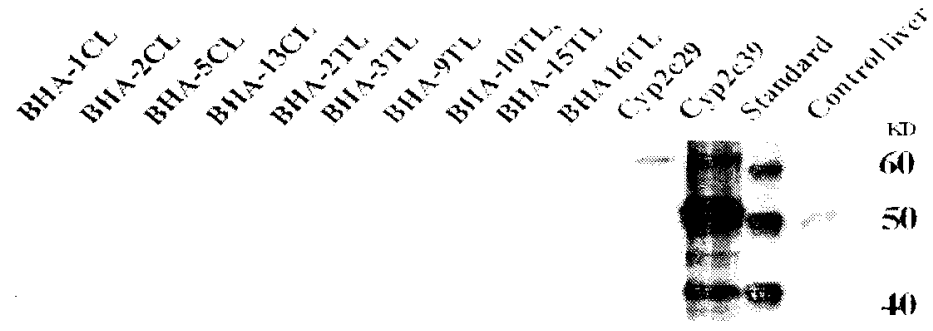

c

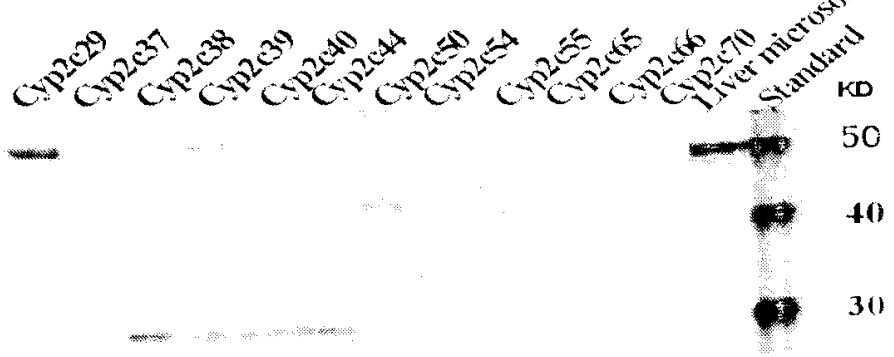


through Nrf2). In these rat studies, several P450s were induced: CYP1 CYP2B, CYP4A and CYP39A. This observation led these authors to suggest a possible role of Nrf2 in the regulation of expression of the above-mentioned P450s. In addition, studies have shown that Nrf2 regulates the induction of Cyp2a5 in I)BA/2 mice ( $\triangle$ buBakar et al.. 2004; 2007).

GSTs are a family of cytosolic enzymes that mainly function to detoxify by conjugation through Michael addition of GSH to electrophilic compounds. BHA or acrolein induced GSTm1, GST $\pi$, GST $\tau$ by at least 2-fold. ALDH was also induced at least 2-fold. GST and ALDH are known acrolein and 4-HNE metabolizing enzymes. Recently, we also demonstrated that some P450s (CYP2c29, CYP3A4, CYP2J2. CYP2B6) are good oxidative and reductive catalysts for 4-HNE. It is possible that the induction of these genes by BHA and acrolein serves as a protective role against the toxic effects of these lipid aldehydes.

In addition to treatment of mice with acrolein by gavage, we analyzed RN $\Lambda$ samples from the heart and liver of mice that had received acrolein by inhalation. The results from this study suggested that 5-ppm acrolein failed to robustly induce gene expression in mice heart and liver. This may be due to insufficient amounts of acrolein in the smoke or insufficient amount of acrolein reaching the target organs to induce gene expression.

As a follow up to the microarray analysis and qRT-PCR, we performed 9-A A metabolism assay with microsomes from BHA-fed mice liver and observed a 3 -fold induction of 9-AA oxidation activity compared with the control. Phenytoin. a high affinity substrate for Cyp2c29 was a potent inhibitor of this enzyme reaction. This 
confirmed the observation that BHA-induced P450 gene expression in mousc liver, specifically Cyp2c29. Additional verification of the induction of P450 expression was conducted by Western blot analysis of liver microsomes prepared from BHA-treated mice liver. The results revealed a 2- to 3-fold average induction in the level of (yp2c2) in BHA-fed mouse liver compared with control microsomal samples. Taken together. these results demonstrate that $\mathrm{BHA}$ and acrolein induce xenobiotic metabolizing enzymes, including Cyp2c29, which metabolizes the lipid aldehydes, suggesting the occurrence of substrate-dependent transcriptional regulation of this gene. 


\section{CHAPTER IV}

\section{TRANSCRIPTIONAL REGULATION OF THE MOUSE CYP2C29 GENE}

\section{INTRODUCTION}

Alteration in the regulation of $\mathrm{P} 450$ expression is a major source of variability in the metabolism of xenobiotics and endogenous compounds. Induction of P450 expression can lead to alterations in drug efficacy and create the potential for drug-drug interactions (Sueyoshi and Negishi, 2001). In our study using the microarray analysis of gene cxpression, we observed that Cyp2c29 was induced following treatment of mice with either BHA or acrolein for 7 days. This observation was further confirmed by $Q$ RT-PCR and Western blotting. This result is particularly interesting since we have previousiy shown that this $\mathrm{P} 450$ is capable of metabolizing 4-HNE to 4-hydroxynonenoic acid and to a lesser extent 1,4-dihydroxynonene. The induction of Cyp2c29 gene expression by BHA and acrolein suggests substrate-dependent regulation of gene expression through the participation of the oxidative stress-sensitive transcription factors such as AP-I and Nrf2. (yp2c29 is the first mouse Cyp2c to be sequenced and characterized (Matsunaga et al. 1994). Its complete coding region contains 490 amino acids. The deduced amino acid sequence of Cyp2c29 exhibits $83 \%$ identity with that of the rat CYP2C7, and it is a homolog of the human CYP2C9 (Guo et al., 2006). Cyp2c29 is expressed at high levels in mousc liver (Matsunaga et al., 1994) and extra-hepatic tissue including the heart. small intestine (Zhang et al., 2003) and mouse brain (Volk et al. 1995). Cyp2o29 catalyes the 
metabolism of several structurally diverse compounds; the oxidation of $m$ - and $p$ tolualdehyde to toluic acids (Watanabe et al., 1994), the metabolism of the anti-epileptic drug, phenytoin (Volk et al., 1995) and the oxidative hydrolysis of the coumarin derivative scoparone (Meyer et al., 2001). Recently we demonstrated that (yp2c2) is capable of metabolizing aldehydes namely, 4-HNE and 9-anthracene aldehyde (Anunom et al., 2007).

The mechanisms governing the regulation of hepatic cylochrome P450 gene expression are diverse. The use of gene promoters in transfection studies has facilitated the understanding of these mechanisms of regulation. The study by Jackson et al. (2004) has documented transcriptional regulation of Cyp2c29 by the constitutive active androstane receptor (CAR). In this study, it was determined that phenytoin, acting through CAR, increased Cyp2c29 mRNA and protein levels in mouse liver. Cyp2c29 expression in the liver is decreased in hepatocyte nuclear factor 1-aipha (INF/ $1 \iota$ ) nul! mice (Cheung et al., 2003) implicating HNF $1 \alpha$ in Cyp2c29 basal expression.

AP-1 family members include Fos, Jun and activating transcription factor (ATT). The AP-1 transcription factors bind to the DNA sequence known as the TPA (12-Otetradecanoylphorbol 13-acetate)-response element (TRE), as different dimeric combinations of basic leucine zipper proteins from the Jun (c-Jun, JunB, and IunD) and Fos (c-Fos, FosB, Fra-1, and Fra-2). The TRE sequence was originally described in the human collagenase gene promoter and has the sequence $5^{\prime}-\Gamma \mathrm{G} \Lambda(\mathrm{C} / \mathrm{G}){ }^{\prime} \mathrm{TCA}-3^{\prime}$ (Angel 't al., 1987). The activity of the AP-1 transcription factors is regulated by components of the mitogen-activated protein (MAP) kinase cascade. The MAPKs are evolutionarily conserved proteins that allow cell-surface receptors to act upon several regulatory targets 
within the cell. Three cascades composed of a MAPKK kinase or MEK kinase. a MAPK kinase (MEK) and a MAPK regulate the activity of MAPKs. Mammals express at least four groups of MAPKs; ERK1/2, JNK1/2/3, p38 and ERK5. The targets of the stressactivated kinase, JNK, include JunD, c-Jun, ATF and ELK-1. These proteins are activated following exposure to oxidative stress or other cell stresses.

Transcription factor Nuclear factor erythoid-2 related factor $2(\mathrm{Nrf} 2)$ is a basic leucine zipper (bZip) protein. Nrf2 binds to is canonical antioxidant response element (ARE) as a heterodimer with other bZip proteins notably small Maf, Jun, and ATF. The ARE consensus sequence initially described by Rushmore et al (1991) is 5"GTGACNNNGC-3'. It was later observed that the bases flanking the core ARE sequence also influence the function of the ARE. The sequence was therefore expanded to 5'TMAnnRTGAYnnnGCRwww-3'; M represents A or C, R represents A or G. Y represents C or T, W represents A or T, S represents G or C (Wasserman and Fahl. 1997). By performing point mutation studies, it was determined that the "CC" in the ARI core sequence is an absolute requirement of a functional ARE (Rushmore et al., 1991). It has also been demonstrated in the human c-Ha-ras gene that in addition to the flanking sequence, the trinucloetide "NNN" within the core ARE also influences the recruitment of proteins to the ARE (Miller and Ramos, 2005).

Compounds that cause oxidative stress in the cell have heen shown to activate both AP-1 and Nrf2. Treatment of cells with 4-HNE results in the depletion of GSH, the production of peroxide and the activation of the INK (Uchida et al.. 1998). Acrolein activates the MAP kinase signaling cascade resulting in the activation of JNK, p38 and ERK1/2 (Ranganna et al., 2002). Several studies have also shown that BHA and its 
metabolite $\mathrm{tBHQ}$ activate $\mathrm{AP}-1 . \mathrm{BH} A$ induced the rat glutamate-cysteine ligase and glutathione synthetase, two enzymes involved in the synthesis of GSH, through the activation of AP-1 (Yang et al., 2002).

In addition to activating AP-1, acrolein, 4-HNE and BHA also cause the release of Nrf2 from Keap-1 and allow translocation of Nrf2 from the cytoplasm to the nucleus. BH $\mathrm{A}$ is the prototypical Nrf2 activator and has been used by several groups to induce gene expression via Nrf2. A study by Yuan et al. (2006) demonstrated that BHA regulated the ARE-mediated induction of heme oxygenase-1 gene expression through Nrf2 coupled with ERK and JNK signaling pathways in HepG2 cells. Upon activation. JNK phosphorylates Nrf2 at Serine-40 causing the release of Nrf2 from Kcapl. These observations imply that in addition to AP-1 activation, the MAP' kinase cascade can also activate $\mathrm{Nrf2}$.

The core ARE sequence strikingly resembles the consensus TRl: implying inat sequences that resemble these response elements have to be tested for their function by determining which transcription factors are recruited to these cis-elements. As stated above, we observed that Cyp2c29 is induced by BHA and to a lesser extent by acrolcin. We also confirmed by Western blotting that Cyp2c29 protein levels were 2-fold higher in liver microsomal fractions prepared from mice treated with BHA compared with untreated mice. We therefore hypothesize that Cyp2c29 gene expression is regulated by BHA and acrolein through the oxidative stress-sensitive transcription factors. To test this hypothesis, we cloned and analyzed the 5'-flanking sequence of the Cyp2c29 gene for transcriptional regulation by the oxidative stress-sensitive transcription factors. Using MatInspector (http://www.genomatix.de) and TFSEARCH 
(http://www.cbrc.jp/research/db/TFSEARCH.html), we scanned 3000 bases of the Cyp2c29 promoter for putative transcription factor binding sites. A putative TRE was observed at $-1249 \mathrm{bp}$, upstream of the Cyp2c29 transcription start site. This sequence strikingly resembles the TRE and contains the consensus ARE described by Rushmore et al in 1991 . We subsequently analyzed the 3000 bp $5^{\circ}$-flanking sequence, as well as the TRE for regulation of Cyp2c29 gene expression. We observed that induction of ( yp2c29 is mediated by transcription factor AP-1.

\section{MATERIALS AND METHODS}

Chemicals. Tert-BHQ, SP600125 (JNK inhibitor), and okadaic acid (phosphatase inhibitor) were purchased from Sigma Chemical Co, Inc. (St. Louis, MO) and dissolved in dimethyl sulfoxide (DMSO). Acrolein was purchased from Sigma Chemical Co and diluted to the required concentrations in phosphate buffered saline. The luciferase assiy reagent and cell culture lysis reagent $(5 \mathrm{X})$ were purchased from Promega (Madison, WI). When reagents were prepared in DMSO, the maximum concentration of DMSO per $\mathrm{ml}$ of media on treated cells was $0.4 \%(\mathrm{v} / \mathrm{v})$.

Plasmids used for transfection. Plasmid GL-3 basic vector was purchased from Promega (Madison, WI). Cyp2c29 promoter constructs were prepared by a similar method as described by Jackson et al., 2004. Mouse genomic DNA was purchased from Promega (Madison, WI) and used in PCR experiments to generate $3034 \mathrm{bp}$ of the Cyp2c29 5' flanking sequence. This region contains +23 bp of the ( $y p 2 c 29$ gene, as well as, 3011 base pairs of the Cyp2c29 5'-flanking sequence. The downstream primer: 5'TGGATCTGGTCGTGTTCCTAGC- 3 ' introduced an Noo I site, while the upstream 
primer: 5' -ACACAATTTGGTTTTGGTTA - 3' introduced a Kpn I site to the upstream region of the $3034 \mathrm{bp} \mathrm{PCR} \mathrm{product.} \mathrm{A} 600 \mathrm{bp}$ fragment of the Cyp2c29 5-FS was also generated. The upstream primer, 5'-CCCGGGGATAGTGGTTATCACTGAATAG-3' introduced a Smal site and the down stream primer $5{ }^{-}$

CTCGAGCTGTACTGGGGCATATAAAG-3' introduced an Xho1 restriction enzyme site. The amplicons were recovered into $\mathrm{pCR}^{18} 4 \mathrm{Blunt}^{\mathrm{B}}-\mathrm{TOPO}^{\mathrm{Bg}}$ vector (Invitrogen, Carlsbad CA). After sequence verification by comparison with genomic DNA sequence data, the KpnI and $\mathrm{Ncol}$ sites were used to remove the Cyp2c29-304.3 bp promoter region and inserted it into the pGL3-Basic vector to generate the reporter plasmid pCyp2c29-3.0Luciferase reporter plasmid (pCyp2c29-3.0Luc). Ir. JA. Goldstein (NIEHS, Triangle Park NC) provided the pGL3 luciferase reporter plasmid containing 1500 bp of the Cyp2c29 promoter (pCyp2c29-1.5Luc). Plasmid 0.164GSTYaLuc (p0.164GSTYa-Luc) containing 164 bases of the rat GST Ya minimal promoter cloned in front of the luciferase reporter gene was generated by Dr. K. Cameron Falkner (University of Louisville). This construct has been extensively used in the Prough Laboratory to drive the expression of genes by various enhancer elements. The plasmid p0.164-GSTYa Luc was used to generate the shorter Cyp2c29 fragments lacking the Cyp2c29 native promoter. The restriction enzymes Smal and $\lambda$ hol were used to remove a 600 bp region of the Cyp2c29 5'flanking sequence and inserted into p0.164-(iSTYaluc upstream of the rat GST Ya promoter to generate pCyp2c29-600Luc. Dr. CB. Pickett and T. Nguyen (Schering-Plough Research Institute, Kenilworth, New Jersey) provided the expression plasmids for c-Fos (pRSV-cFos) and c-Jun (pRSV-c-Jun). Dr. KS. Ramos (University of Louisville) provided the Nrf2 expression plasmid (pCl-Nrf2neo). Plasmid 
0.164GSTYa-ARELuc (0.164Ya-ARELuc) containing 164 bases of the rat GST Ya minimal promoter and the consensus antioxidant response clement cloned upstream of the luciferase reporter gene was used as a positive control for Nrf2-dependent regulation of gene expression.

A luciferase reporter plasmid containing 30 bp fragment of the Cyp2c29 promoter region (pCyp2c29-TRELuc) or mutants of the TRE (pCyp2c29-AP1Mut1, p Cyp2c29)GCMut3) were generated by the technique of primer annealing. We also generated a 30 bp fragment containing the human collagen 'TRE. The 30 bp oligonucleotides were obtained from Integrated DNA Technologies, Inc. (Coralville. IA) and the sequences are shown in Table 7. For each fragment, a Kpnl restriction enzyme site was included at the 5 '-end and a Nhe 1 site at the 3'-end. The olignucleotides were re-suspended in $10 \mathrm{mM}$ Tris-EDTA (pH 8) and phosphorylated using T4 polynucleotide kinase according to the manufacturer's instructions (Promega, Madison WI). Phosphorylated oligonucleotides were cleaned with the QIAquick nucleotide removal protocol (Qiagen, (Germantown MD) according to the manufacturer's instructions. The primers were annealed in bufter $(1 \mathrm{mM}$ Tris pH 8, $50 \mathrm{mM} \mathrm{NaCl}, 10 \mathrm{mM}$ FIT T, Sigma Chemical Co, St. Louis MO) by heating at $95^{\circ} \mathrm{C}$ for $2 \mathrm{~min}$ and gradual cooling to $25^{\circ} \mathrm{C}$ (room temperature) for $45 \mathrm{~min}$ in the Amplitron $\mathbb{B}$ II Thermolyne thermocycler. Each double-stranded DN $\Lambda$ was ligated into Kpnl-and Nhel-digested p0.164Ya-Luc (Figure 34) using T4 I)N $\wedge$ ligase, according to the manufacturer's instructions (Promega, Madison WI).

Transient transfection of HepG2 cells and measurement of luciferase activity. The human hepatoblastoma cell line HepG2 (HB8065. American Type Culture Collection. 
Table 7

Oligonucleotides showing the Cyp2e29 putative TPA (12-()-tetradecanoylphorbol 13-acetate)-response element (TRE), wild type and mutant sequences, and the human collagenase TRE.

\begin{tabular}{|c|c|}
\hline Oligonucleotide & Sequence \\
\hline \multicolumn{2}{|l|}{ Cyp2c29TRE } \\
\hline Forward & 5'-ATCACTGAATAGTGACCTAGCACATAGTCA-3' \\
\hline Reverse & 5'-CTAGCTGACTATGTGCTAGGTCACTATTCAGTGGTAC-3' \\
\hline \multicolumn{2}{|c|}{ Cyp2c29-Mut-TRE } \\
\hline Iorward & 5'- ATCACTGAATAGGAGACTAGCACATAGTCA-3' \\
\hline \multicolumn{2}{|l|}{ Cyp2c29-Mut-GC } \\
\hline Forward & 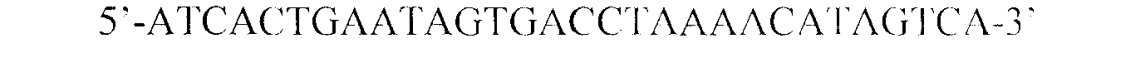 \\
\hline \multicolumn{2}{|l|}{ Collagenase TRE } \\
\hline Forward & 5'-CAAAGCATGAGTCAGACACCTCG-3' \\
\hline Reverse & 5'-CTAGCGAGGTGTCTCACTCATGC'TTGGTAC'-3 \\
\hline
\end{tabular}

The underlined nucleotides in Cyp2c29 TRE were mutated to determine their role in the induction of reporter plasmid in response to transfected Fos and Jun expression plasmids. The underlined sequence in the collagenase TRE is the core sequence. These oligonucleotides were cloned in front of the luciferase gene in p0.164GSTYa-Luc to generate recombinant reporter plasmids, and used in transfection experiments. 
Figure 34. The modified p0.164-GSTYa Luciferase plasmid showing the luciferase gene, the minimal rat GST Ya promoter (164 bases) and the Cyp2c29-TRE ( 30 bases). The Cyp2c29-TRE was replaced with mutants of the TRE (pCyp2c29-AP1Mut or pCyp2c29-GC-mut), 600 bases of the Cyp2c29 promoter (pCyp2c29-0.6Luc), or the human collagenase TRE (pCol-TRELuc). 
Figure 34
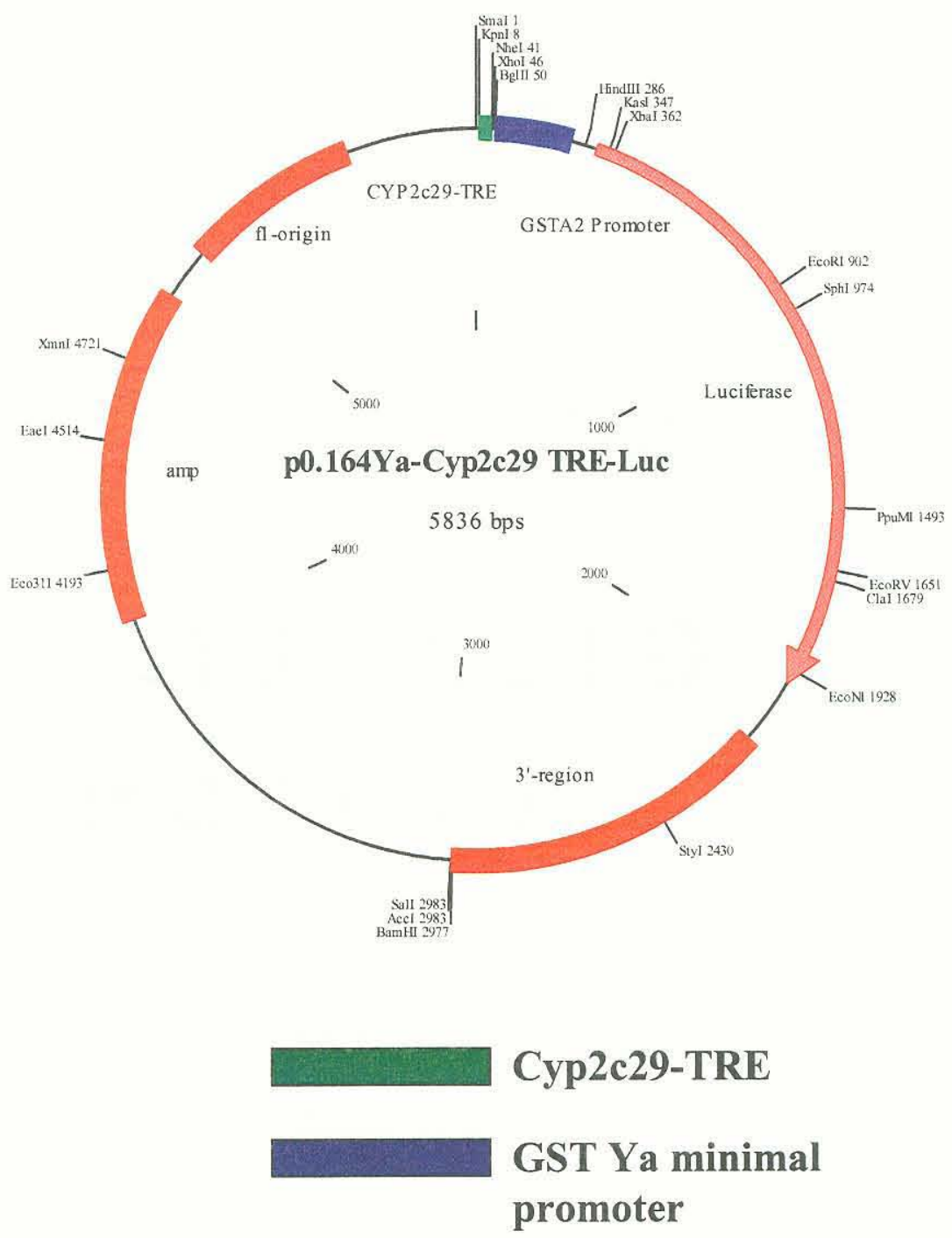
Transient transfection of HepG2 cells and measurement of luciferase activity. The human hepatoblastoma cell line HepG2 (HB8065. American Type Culture Collection. Rockville, MD) was maintained in Eagle's minimal essential media with 10\% fetal bovine serum (HyClone, Logan UT), antibiotic-antimycotic solution (1X, contains penicillin, streptomycin and fungizone; Invitrogen, Carlsbad CA) and nonessential amino acids (1X; Mediatech Inc. Herndon VA). For transfection experiments, cells were plated at a density of 150,000 cells per well in 12-well plates. Twenty-four hours after plating, cells were transfected using $4 \mu \mathrm{g} / \mathrm{mL}$ LipofectAMINE (Invitrogen, Carlsbad, CA) with either the reporter plasmid pCyp2c29-3.0Luc, pCyp2c29-1.5Luc, pCyp2c29-0.6Luc and pCyp2c29-TRE and its mutants, p0.164GSTYa-ARELuc, or pCol- TRELuc $(100 \mathrm{ng} / \mathrm{mL})$ The cells were also cotransfected with pRSV-cfos (3.5-50 ng/mL), pRSV-cJun (3.5-50 $\mathrm{ng} / \mathrm{mL}$ ). and a $\beta$-galactosidase expression plasmid (pCMV- $\beta$ Gal) in $1 \mathrm{~mL}$ of serum free medium. After an overnight incubation at $37^{\circ} \mathrm{C}$, the cells were overlaid with $1 \mathrm{~mL}$ media containing $10 \%$ FBS and then treated with $4 \mu \mathrm{L}$ of $12.5 \mathrm{mM}$ tBHQ in DMSO. The treatment of cells with acrolein $(0.2 \mathrm{nM}$ and $0.4 \mathrm{nM})$ was performed in normal and serum free media. Seventeen hours later (overnight) the cells were harvested with $100 \mu \mathrm{L}$ of cell lysis buffer (Promega, Madison, WI). The $\beta$-galactosidase and luciferase activities were determined as described by Falkner et al. (1998). The data are expressed as luciferase activity relative to $\beta$-galactosidase activity to correct for transfection efficiency. All transient transfection experiments were performed in triplicate, and experiments were repeated at least twice to confirm results. 
Statistical Analysis. Experiments were conducted in triplicate and means ts standard deviations were determined. Statistical comparisons among treatment groups were determined using analysis of variance (ANOVA) or a Student's $t$ test.

\section{RESULTS}

Cloning and sequencing of the 5'-flanking sequence of $\mathrm{Cyn} 2 \mathrm{c29}$. The sequence of the $3.0 \mathrm{~kb}$ product of the Cyp2c29 5'-flanking sequence (5'-FS) is shown (Figure 35). This sequence was generated by PCR and analyzed for transcription factor binding sites using MatInspector Version 3.2 and TFSearch.html. The phenytoin-responsive module (PHREM), characterized by the Goldstein Laboratory (NIEHS, Triangle Park NC) is located at $-1.371 \mathrm{~Kb}$ upstream of the Cyp2c29 translational start site. This module contains a CAAT enhancer binding protein (C/EBP) binding site. The PHREM is responsible for the constitutive androstane receptor-dependent induction of Cyp2c29 by the anti-epileptic phenytoin (Jackson et al., 2004). The $3.0 \mathrm{~kb} 5$ '-FS of Cyp2c29 also contains putative binding sites for AP-1, NF-kB, the coactivator $\mathrm{p} 300$, signal transducer and activator of transcription (STAT), specificity protein (SP-1), pregnane X receptor (PXR), myeloid zinc finger protein (MZF) and heat shock factor (HSF) (Figure 35).

Functional analysis of the 5'-flanking sequence of Cyp2c29. Microarray analysis, qRT-PCR and Western blotting analysis demonstrated that treatment of C57BL/6 mice with BHA or acrolein resulted in the induction of Cyp $2 \mathrm{c} 29$, both at the mRNA and the protein level (Chapter III). To determine the oxidative stress-sensitive transcription factors responsible for Cyp2c29 induction, we co-transfected HepG2 cells with luciferase 
Figure 35. The $3.43 \mathrm{~Kb}$ of the Cyp2c29 5'-flanking sequence. The sequence shown is the +3 to -3043 bases of the Cyp2c29 5'-FS. The underlined nucleotides represent putative transcription factor binding sites identified by MatInspector and TFsearch software. The phenytoin responsive module (PHERM) is shown. The box shows nucleotides that were cloned into the p0.164Ya-Cyp2c29-TRE-Luc. The transcription start site is italicized. 


\section{Figure 35}

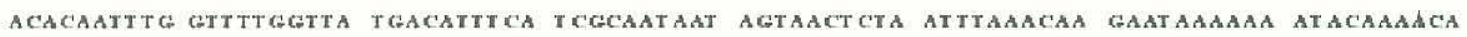
ACTTTTTCE CCEACACAAT ACACTCAACE ACTCACACTT CCTCAACTAA tTtCTCCTCA CTCATCTCAT TTCTCTCTCQ TCAGTIATCT GACCTACATI CACTTCTACA CT CATATGAA CGCAACAAAC CCAATATTTI TCTTAACTAA AATCTTAACT

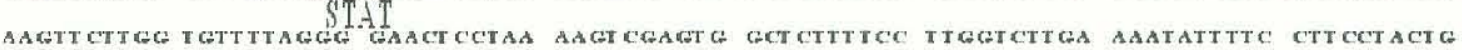

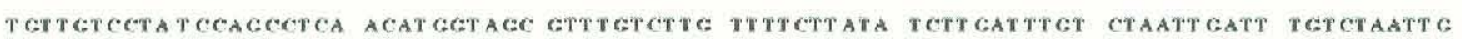

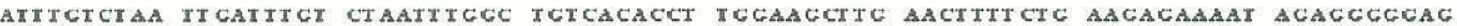
NF. $\mathrm{B} B$

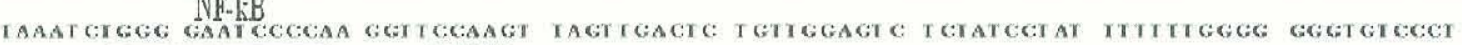

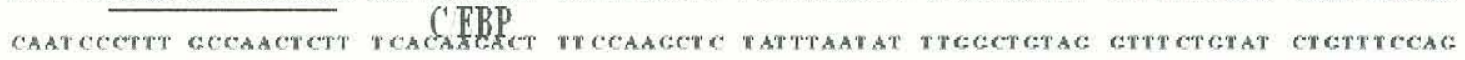

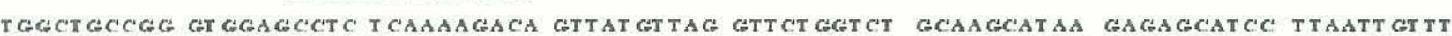

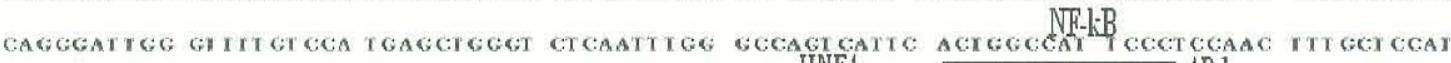

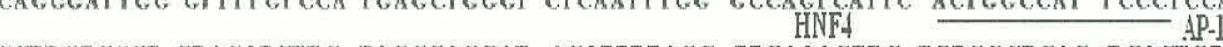
CCTIGTCCCT GACATCTTE TAGGCAGGAT ACATTTTAGE TTGAAAGTTC TGTGCGTGAG TCACTCTCTT TATTTCTCCA

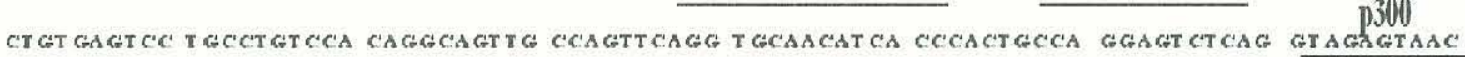
ICCCATAGAC ACCCT CTCAC CTCCTCTTIG AATAATTCT TAAATAGAGA GAGTAGTCCA TGACACAAAA GAGGGACCAT TTCAGADGAC GAAGATCACT AGGAGTCATA ATCACCAACA ACAACCCTCE TAAACAAAGT GTCTTTATAA TCTCAAACTC

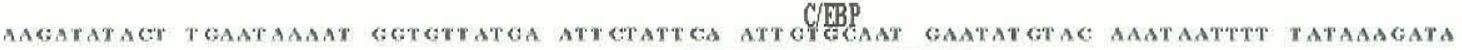
TAAAAT CACT TIAAAAT GT G I GAT GATAAA T GAACAGACA ACTTAATAAA T GAAATAAAA TGAAAAAAAA ACGCTCAAGA AAAATGGTCT GAACAAGAGA CCTTT CATCT TTGTTAGAGT TACAGTGATT GCTGATATTC CATCCATCAT CAACAGCTCC$$
\text { ST.AT }
$$

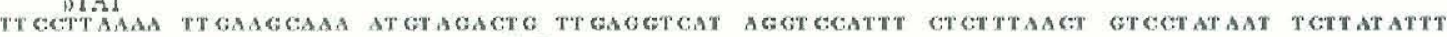
TATAAACAAA CACATCATCC AATCCATTAA AATCACTTAT ATGI CACTCA AATTCCACCA CAACAAATAT CTCTACACGC

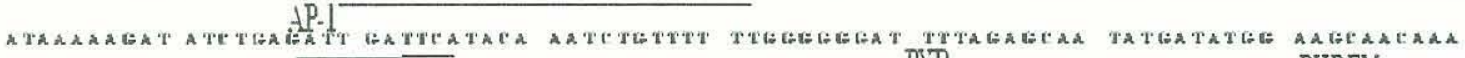

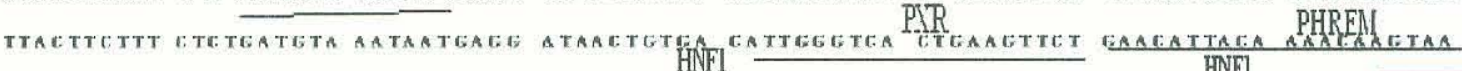

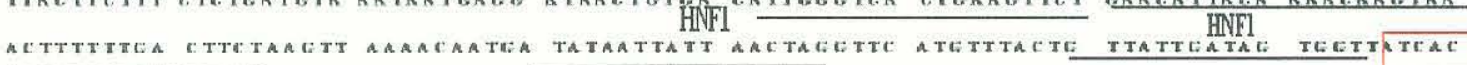

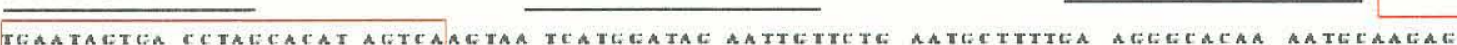

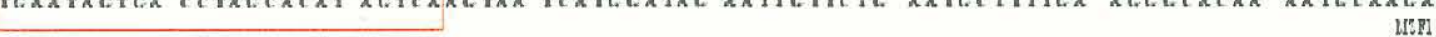

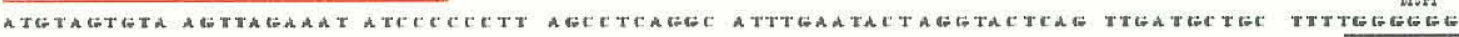
AGEOTTAEET EETATEAATT ETTATTTTETETETATAEAA TTTTETTTAB EEAGTTTEAT ATETECATTAG TEEAAAETEE AEAATTTTAA GAETTTTETT TAAGAATET ATTEGAAAET EAGAGTAETA AECATECTEA TTAGATAEEC ATAGTEGATT TTAAATTETT ECAECTATEA EETETAAEAE AETEAEAETT ETTTTTETTT EAECAECTTT AGAAAAECAA TAETEATETT TEGTEETTAA ETTABEATAG GTEABTEAEA TETATECTTT ETTTTETTAG TTTTATATTT ATEAAEAGTE AAATAAEGAE

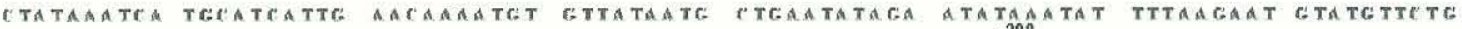

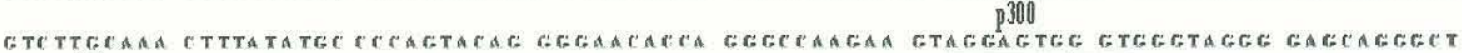

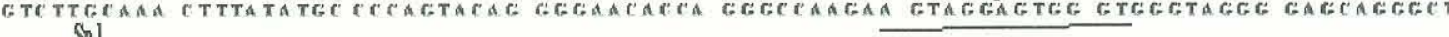
Sp

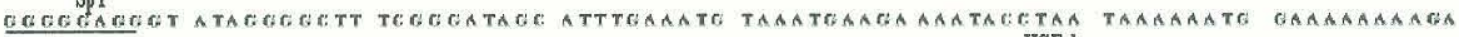
ATETATEATE ATTETETTEC ATAAATAEAT TTETAGETAT TEGEGEAATE EAGEAGANGA ATTETEAEET TEAAEAEAAE

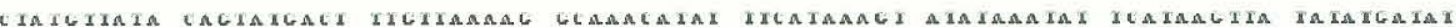

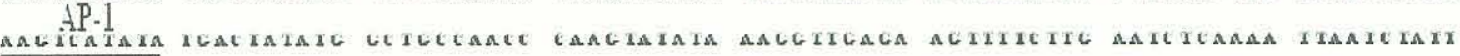
ACTICTCAAC AATAACTCCA TATTACAAC ATCTICATTI ACITITATCA CCACTACTIA CACACCAGTC TETACTCTRA

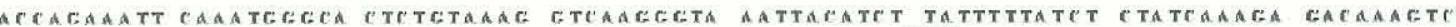

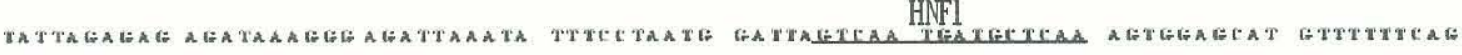

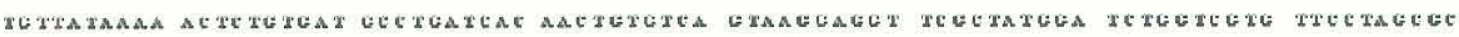
xEAATS 
reporter plasmids containing different lengths of the Cyp2c29 5'-FS generated by deletion, and Fos and Jun (AP-1) or Nrf2 expression plasmids. Luciferase activity from the pCyp2c29-3.0 reporter plasmid gradually increased with the increase in cotransfected AP-1. However, the levels were lower than the basal activity seen in the absence of AP-1 (Figure 36). There was a 2-fold increase in luciferase activity from the pCyp2c29-600 luciferase reporter plasmid in the presence of $50 \mathrm{ng}$ and $100 \mathrm{ng}$ of Fos and Jun suggesting that this sequence is regulated by AP-1. The luciferase activity returned to control levels when the cells were transfected with $150 \mathrm{ng}$ of AP-1 expression plasmids.

The reporter plasmid pCyp2c29-TRE contains a 30 base pair fragment of the Cyp2c29 promoter. The highest fold induction (6-fold) was obtained when HepG2 cells were transfected with this reporter plasmid in the presence of $50 \mathrm{ng}$ of the Fos and Jun expression plasmids. Luciferase activity then decreased with increased amounts of Fos and Jun expression plasmids (Figure 36). The decrease in luciferase activity with increasing cotransfection of the Fos and Jun expression plasmids was unexpected. This may have been caused by limiting coactivators or the formation of nonproductive protein complexes at higher AP-1 concentration. Unlike Fos and Jun, Nrf2 did not induce luciferase activity even when the cells were treated with tBHQ (data not shown).

\section{Transcription factor AP-1 induced reporter activity through a Cyp2c29 TRE. As} shown in Figure 36, the pCyp2c29-TRE reporter plasmid showed maximum induction in the presence AP-1 transcription factor. According to the results of MatInspector and TFSEARCH result, this fragment contains a putative AP-1 binding site (TRE, $89 \%$ ). However, this site also closely resembles the consensus ARE (Table IV). We therefore 
Figure 36. Deletion analysis of the 5'-flanking sequence of the Cyp2c29 gene.

I weiferase constructs were prepared with different length fragments of the $5^{3}$-FS of the $(y) 2029$ gene. A. Schematic representation of the different deletion constructs of the C $20295^{\prime}$-flanking sequence. B. The constructs were tested by transient cotransfection with fos and Jun expression plasmids in HepG2 cells. The normalized luciferase activity, expressed as relative light units divided by the $\beta$-galactosidase activity. is the mean $\mathrm{SI}$ ) of three wells. Data was analyzed by Anova followed by a Dunnett test. *** Significantly dilicrent irom control, $\mathrm{p}<0.001 ; * *$ Significantly different from control, $\mathrm{p}<0.05$. 


\section{Figure 36}
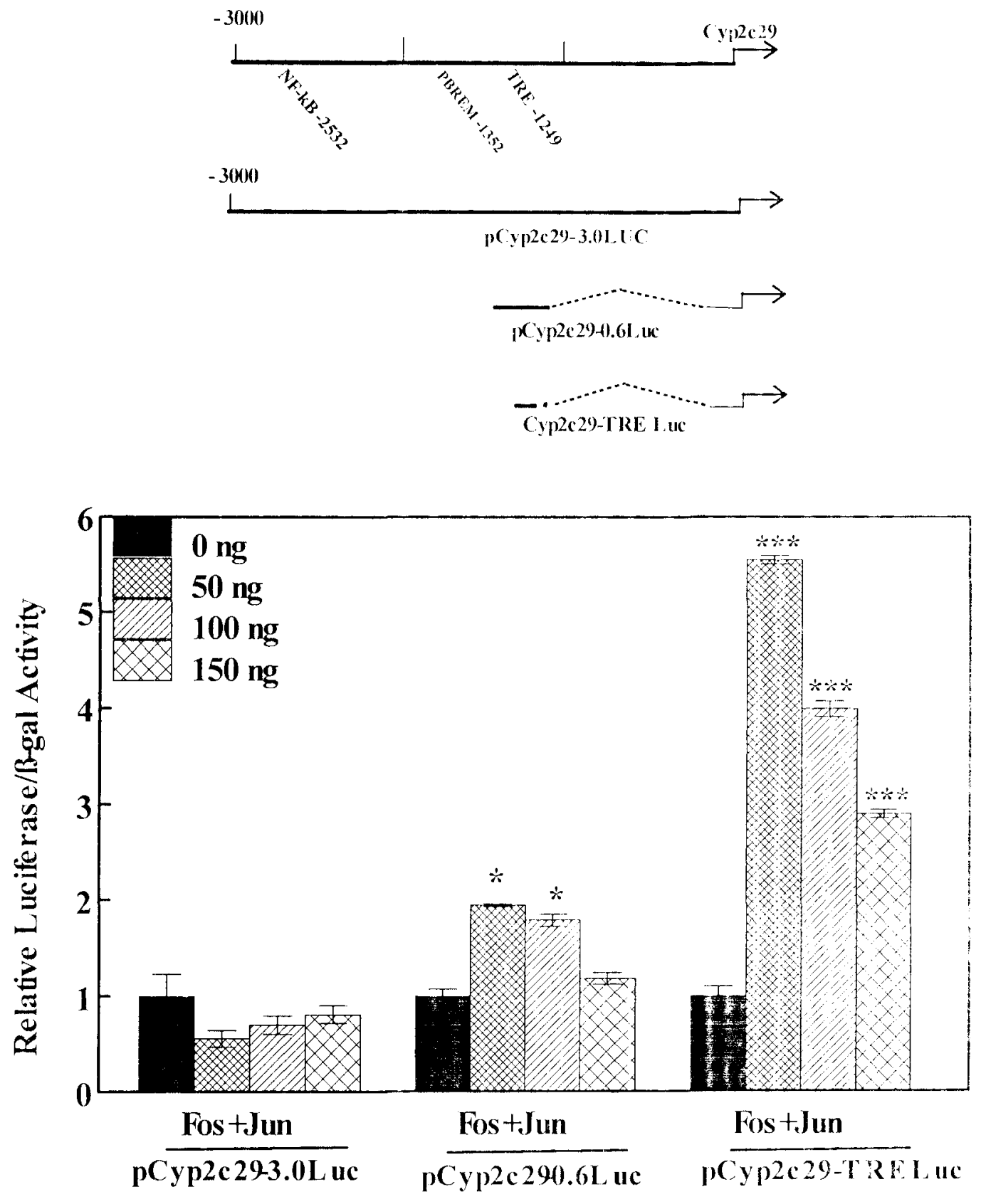
subjected this fragment (pCyp2c29-TRE) to further analysis in the presence of $\Lambda \mathrm{P}-1$ and Nrf2.

In the previous experiment, we observed the highest reporter gene expression when IepG2 cells were co-transfected with the lowest combination of Fos and Jun expression plasmids $(50 \mathrm{ng})$. We therefore decided to transfect cells with lower anounts of AP-1; Fos (3.5-60 ng) and Jun (3.5-60 ng) expression plasmids. The highest induction of luciferase activity (8-fold) was observed when the cells were cotransfected with Fos (3.5 ng) and Jun (3.5 ng) expression plasmids (Figure 37). In addition to responding to AP-1, the $\mathrm{Cy} 2 \mathrm{c} 29 \mathrm{TRE}$ sequence of interest resembles the consensus $A R \mathrm{~F}$ Therefore, to determine if Nrf2 contributes to Cyp2c29 induction. HepC2 cells were transfected with the Cyp2c29-TRE Lue reporter plasmid and the Nrf2 and $\mathrm{AP}-1$ expression plasmid, and luciferase activity measured (Figure 37). Surprisingly, Nrf2 did not affect luciferase activity even in the presence of Fos or Jun (data not shown). This obscrvation indicates that the induction of luciferase activity is in response to an $\mathrm{AP}-1$ RE and not an Nrf2-ARE interaction.

A positive control for AP-1-mediated induction of gene expression was pertormed by transfecting HepG2 cells with a Col-TRE luciferase reporter plasmid. This plasmid contains the human collagenase TRE (Table 7). Luciferase activity increased by 1.5 to 2 fold in the presence of $15-60 \mathrm{ng}$ the Fos or Jun expression plasmid (Figure 38). A cotransfection of the Fos and Jun expression plasmid caused an increase in luciferase activity with the highest induction of 2.75 -fold observed in the presence of $3.5 \mathrm{ng}$ lios and $3.5 \mathrm{ng}$ Jun expression plasmids. The collagenase TRE thereforc interacts with a fios Jun heterodimer to mediate the induction of luciferase activity observed. 


\section{Figure 37. Differential activation of the Cyp2c29-TRE Luciferase reporter in}

IIepG2 cells by AP-1 proteins. HepG2 cells were transfected with pCyp2c29-TRLL uc reporter plasmid and the expression plasmid for Fos (3.5-60 ng) and Jun (3.5-60 ng). Twenty four hours after transfection, the cells were harvested and the lysate assayed for $\beta$-galactosidase and luciferase activity. The data represent the mean \pm SD of three wells. Experiments were repeated at least three times with similar results. Statistical signiticance was determined using Anova followed by the Dunnett post-test. *** Significantly different from control, $\mathrm{p}<0.001 ; * *$ significantly different from control. 0.001 
Figure 37

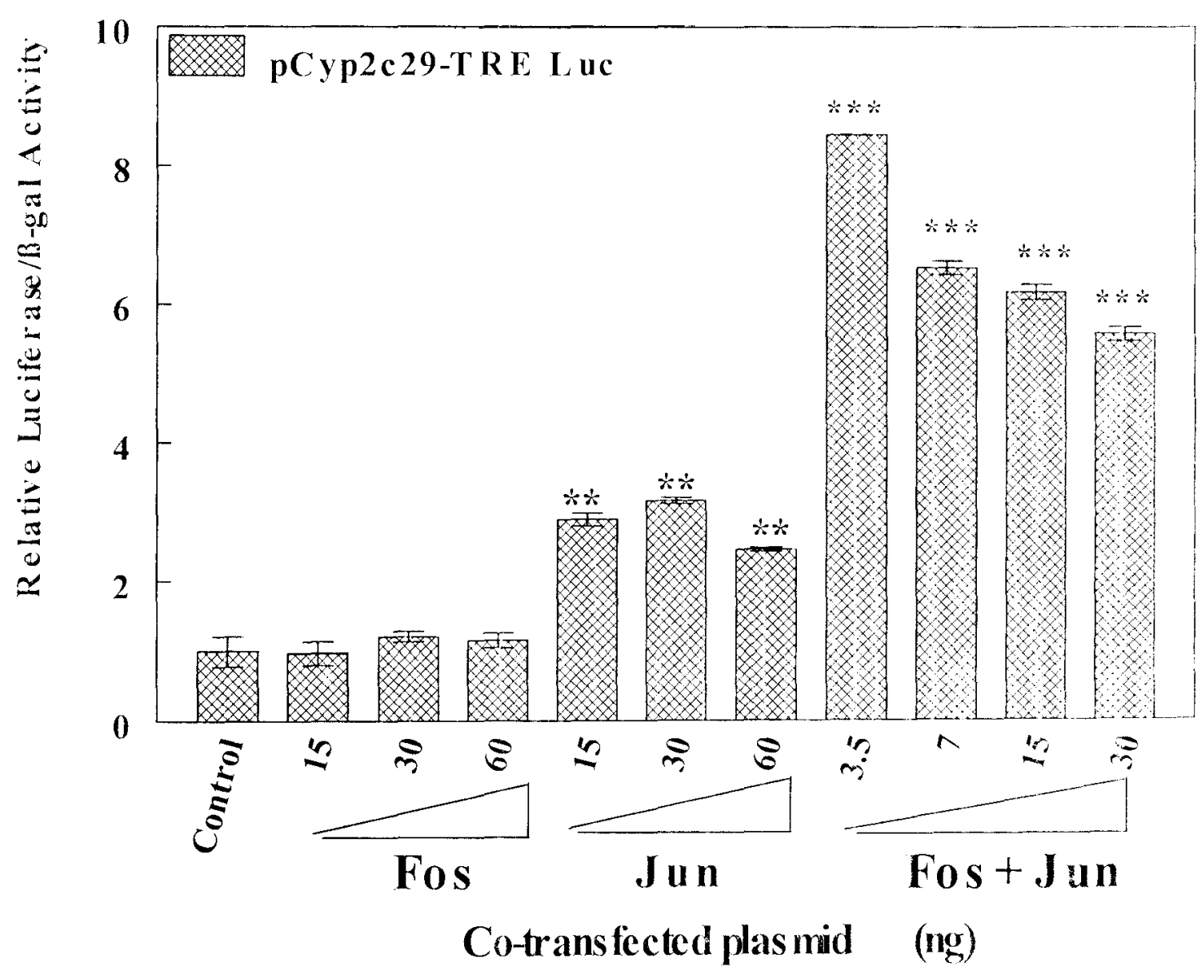


Figure 38. Induction of Collagenase-TRE Luciferase reporter activity following cotransfection of Fos and Jun in IIepG2 cells. HepG2 cells were transfected with pcolTRLI, . reporter plasmid and the expression plasmid for los (3.5-60 ng), Jun (3.5-60 $n g)$, and $\mathrm{Nrf}$. The cells were maintained for 24 hrs and harvested. The cell lysates were assayed for $\beta$-galactosidase and luciferase activity. The data represent the mean $\pm \mathrm{SD}$ of three wells. Experiments were repeated at least three times with sinilar results. Statistical significance was determined using Anova followed by the Dunnett post test, * $p<0.001$ 
Figure 38

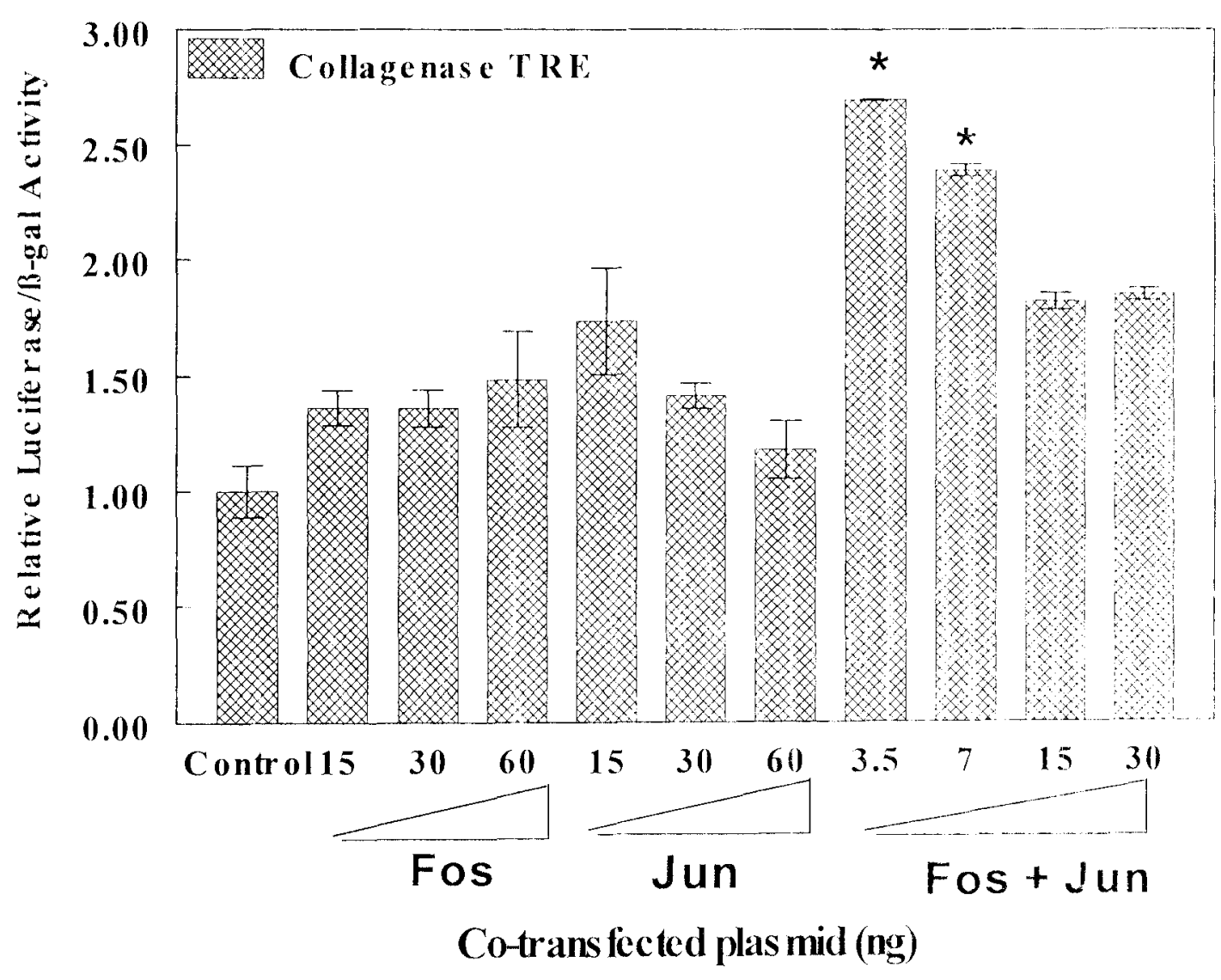


In a similar experiment, $\mathrm{HepC} 2$ cells were transfected with $\mathrm{pCy}$ 202-TRE 1 . UC and treated with $0.2 \mathrm{nM}$ or $0.4 \mathrm{nM}$ acrolein. There was no change in luciferase activity at $0.2 \mathrm{nM}$ acrolein. However at $0.4 \mathrm{nM}$ acrolein treatment, there was a modest but inconsistent increase in luciferase reporter activity (data not shown). The treatment of HepG2 cells with higher concentrations of acrolein caused cell death as determined by a decrease in the $\beta$-galactosidase activity in the acrolein-treated cells.

\section{The core and proximal nucleotides of the TRE contribute to AP-1-dependent}

induction of Cyp2c29. To determine the contribution of the nucleotides in the Cyp2c29 TRE sequence in the induction of luciferase activity, HepG2 cells were transiected with the Cyp2c29-TRE (wild-type) or the AP-1 mutant reporter plasmid (Table 7).

In the presence of AP-1, we observed a 2.5-fold increase in luciferase activity from Cyp2c29-TRE (Figure 39). This activity was modestly increased when the cells were treated with $50 \mu \mathrm{M}$ tBHQ. There was no effect of co-transfection of $\mathrm{Nr} 2$ alone. even when the cells were treated with $\mathrm{BBHQ}$. This suggests that Nrf2 may not interact with the Cyp2c29 TRE. The core TRE sequence within the Cyp2c29-TRL-Luc was mutated to generate the Cyp2c29AP-1Mut1 luciferase plasmid. This mutation obliterates the Fos/Jun binding site. The increase in luciferase activity as scen with the wild-1ype TRE: in the presence of AP-1was lost when the cells were translected with the Cyp2c29AP-1Mutl reporter plasmid. As expected. there was no change in luciferase activity in the presence Nrf2, Fos/Jun/Nrf2, Jun alone or Jun/Nrf2 expression plasnids.

In addition to the AP-1 mutation, the "GC" dinucleotide which is proximal to the $3{ }^{\circ}$-end of the Cyp2c29 TRE was mutated to determine its effect on AP-1 mediated 
Yigure 39. Mutation of the core TRE results in the ablation of AP-1-dependent Iranscriptional induction of Cyp2 $\mathbf{c 2 9}$. HepG2 cells were transfected with p $\mathrm{Cyp} 2 \mathrm{e} 29-$ IRI: L uc (wild type), or pCypp2c29-APIMUT1 (mutant) reporter plasmid and the expression plasmid for Fos, Jun and Nrf2. The cells were treated with DMSO or 5()$\mu \mathrm{M}$ IBIIQ in DMSO for 16 (overnight) hrs and then harvested. The cell lysates were assayed for lucifirase and $\beta$-galactosidase activity. The data shown is the mean $\pm \mathrm{SD}$ of three wells. txperiments were repeated two times with similar results. Statistical signilicance was determined using the Students $t$-test. ***significantly different from the AP-1 mutant in the absence of tBHQ treatment, $\mathrm{p}<0.001$. 
Figure 39

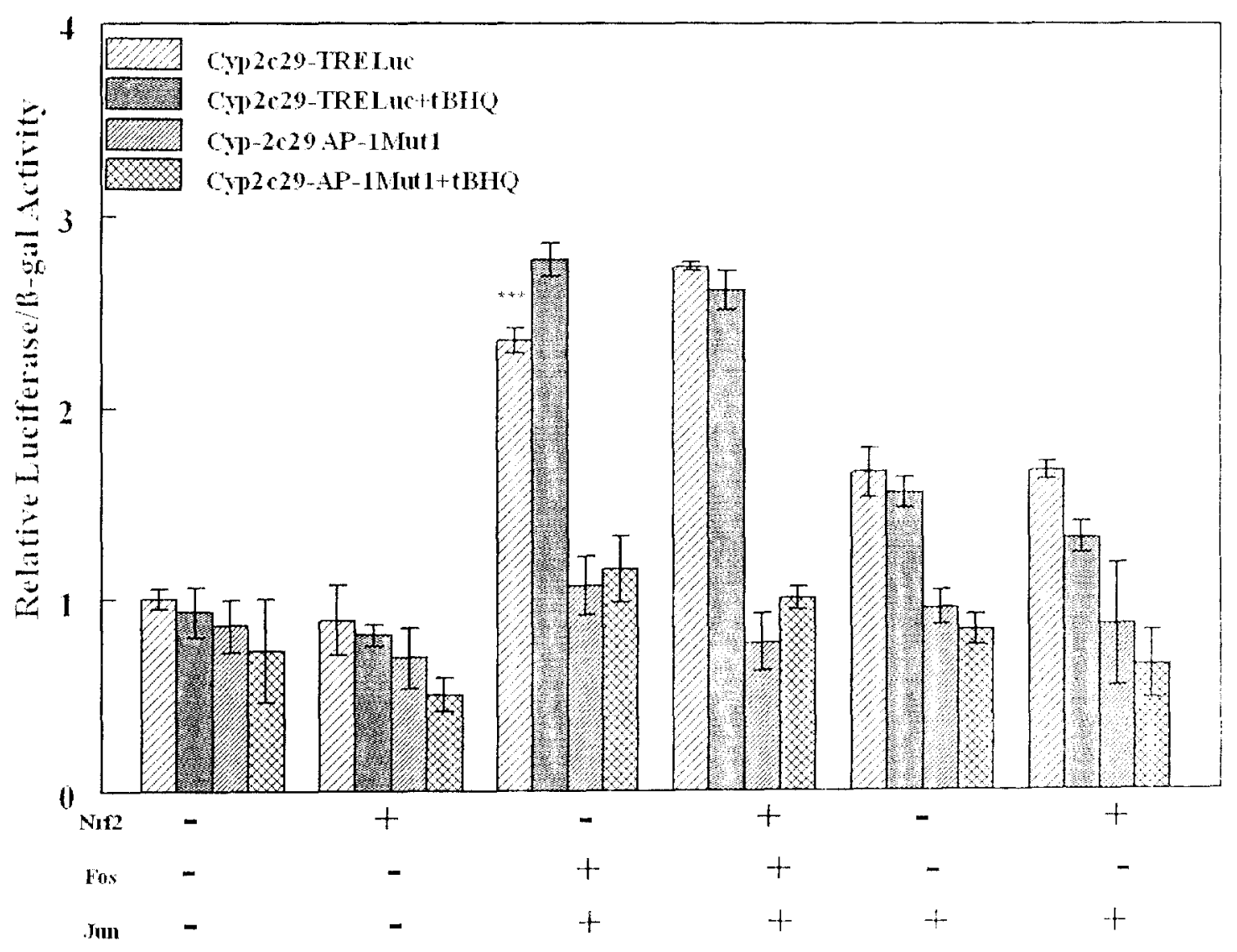


induction of luciferase activity. This " $\mathrm{GC}$ " is an obligate requirement for a functional ARE (Rushmore et al., 1991). There was no significant difference in basal luciferase activity between the wild-type Cyp2c29 TRE and the GC-mutant (Figure 40). $\Lambda$ cotransfection of the AP-1 expression plasmids caused an 8-fold increase in luciferase activity from the Cyp2c29-GC-mut plasmid compared with 2.5-fold increase from the wild-type TRE plasmid. This suggests the presence of the "GC" cis-acting element results in negative regulation of induction of the Cyp2c29-TRE luciferase activity by AP1. but mutation of the element results in even higher inducible expression of the gene. Over-expression of $\mathrm{Nrf} 2$ had no effect on luciferase activity, but these cells express $\mathrm{Nr} 2$. Induction by BHA in Nrf2 null mice is actually increased significantly over wild-type mice suggesting that Nrf2 may ameliorate AP-1 signaling in the expression of this genc.

In order to compare the response from the Cyp2c29 TRE to that of the con census ARE, HepG2 cells were transfected with the p0.164-GSTYa-ARELuc reporter plasmid. This plasmid contains the antioxidant response element of the rat GST Yat promoter and has been extensively used in the Prough Laboratory as a positive control for the $\triangle R$ :Nif2-dependent induction of gene expression. Luciferase activity was measured following cotransfection of the Fos, Jun or Nr2 expression plasmid (Figure 41). First. there was a significant increase in basal luciferase activity following co-transfection of the Jun $(p<0.05)$, Fos and Jun, Nrf2 or Nrf2 and Jun $(p<0.01)$ and the lios expression plasmids $(p>0.05)$. Second, following treatment with $\mathrm{BBI}$ IQ. we observed a further increase in luciferase activity; 11-fold (Jun; $p<0.01$ ), 21-fold, Fos and Jun $(p<0.0$ !). 28fold, Nrf2 $(p<0.01)$ and 38-fold. Nrf2 and Jun $(p<0.01)$ compared with the p0.164YaARE alone treated with $\mathrm{tBHQ}$. These data confirm previous observations that fos or Jun 
Figure 40. Mutation of the "GC" dinucloctide results in the induction of $\triangle P$ - 1 dependent transcriptional induction of Cyp2c29. HepG2 cells were transfected with P(y)2029-TRELuc (wild type), or Pcyp2c29-GCMUT3 (mutant) reporter plasmid and the expression plasmid for Fos, Jun and Nrf2. The cells were treated with I)MSO or 50 HM IBHQ in DMSO for 16 (overnight) hrs and then harvested. The cell lysates were assayed for luciferase and $\beta$-galactosidase activity. The data shown is the nean $\pm \mathrm{SD}$ of three wells. Experiments were repeated two times with similar results. Statistical significance was determined using the Students $t$-test. *** Significantly different from the Cy 2029-TRE Luc activity in the absence of tBHQ treatment, $p<0.001$. 
Figure 40

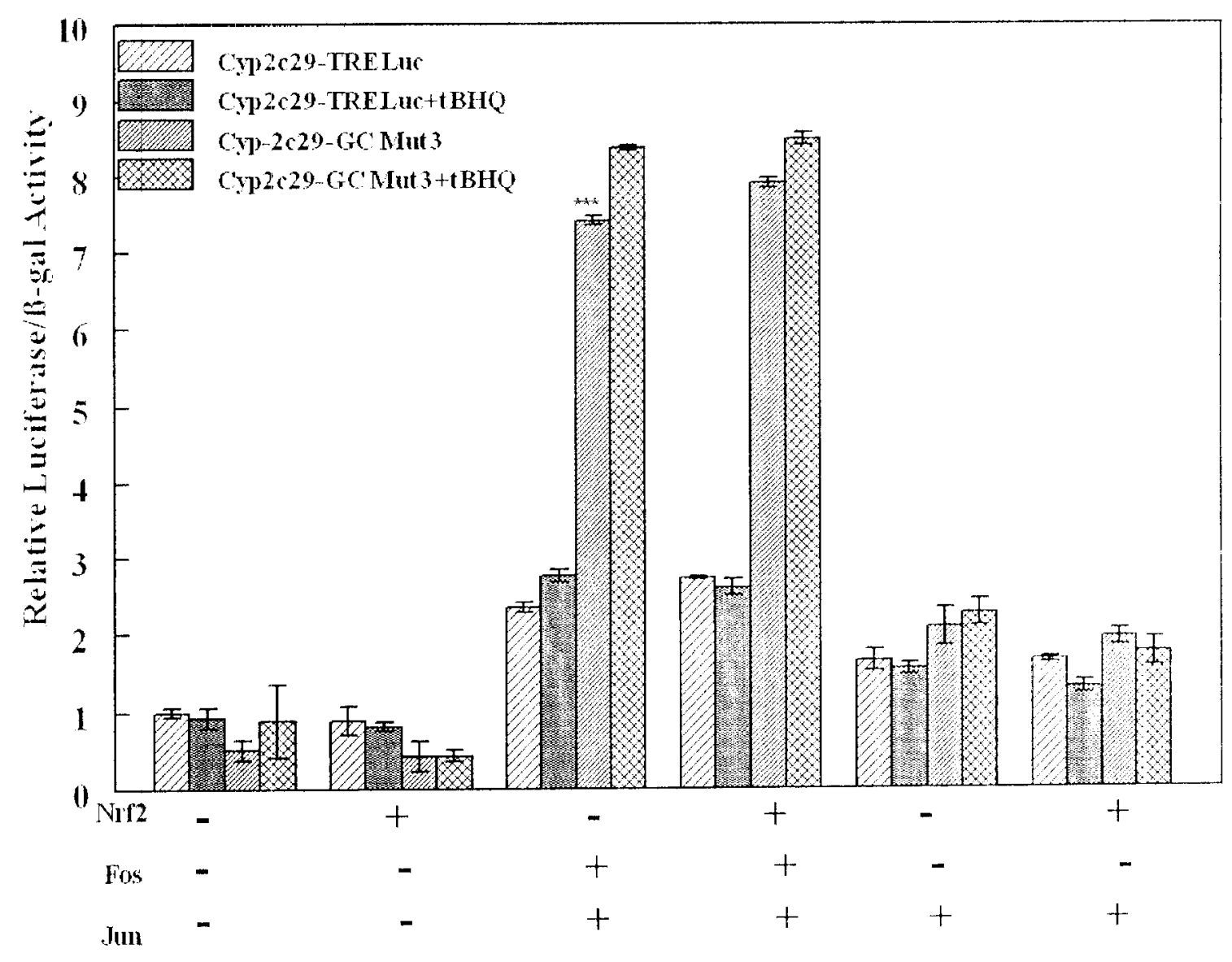


Figure 41. Effect of Nrf2 and AP-1 on ARE-dependent activation of p0.164GST YaARE-L uciferase activity. HepG2 cells were transfected with p0.164-(iST Ya-ARL L Lue eporter plasmid, Nrf2 and AP-1 expression plasmids. Luciferase activity in HepG2 cells was measured after treatment with DMSO or $50 \mu \mathrm{M}$ tBHIQ in DMSO. The data is the riative luciferase $/ \beta$-gal activity for three wells. Experiments were repeated at least four times with similar results and statistical analysis performed by Anova followed by the Dumnet post test.* $(\mathrm{p}<0.05)$ and $* * *(p<0.01)$ significantly different from basal vehicle treatment. $\dagger \uparrow$ And $\uparrow \uparrow$ significantly different from the basal tBHQ treatment, $\mathrm{p}<0.01$. 
Figure 41

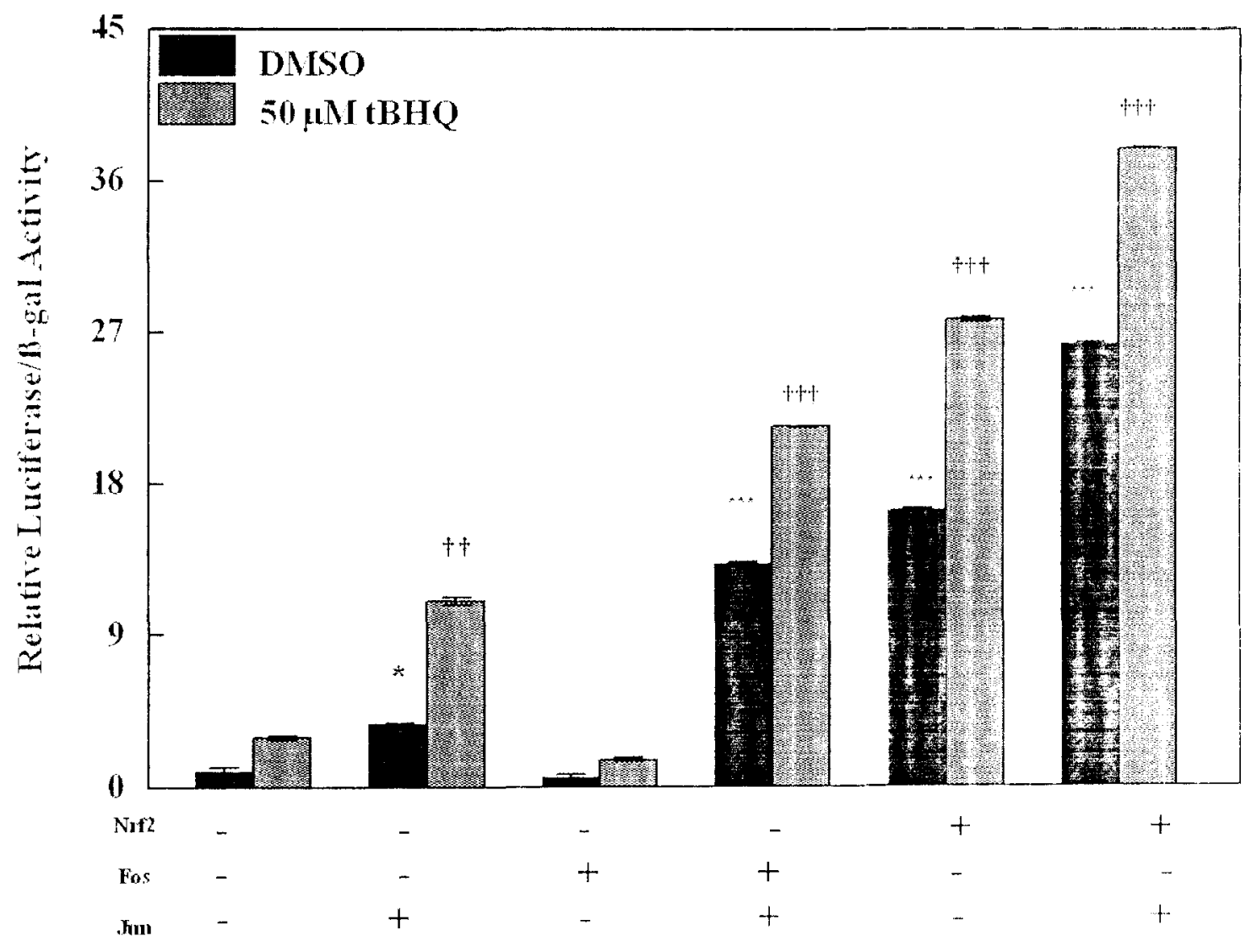


can synergize with Nrf2 to potentiate the GSTA2 reporter gene expression under control of this ARE (Nguyen et al., 2003).

\section{The effect of MAP kinase inhibitors and phosphatase inhibitors on AP-1-dependent} activation of luciferase activity. AP-1 (Yang ef al., 2002) and Nrl2 (Yuan el al.. 1996) are activated by components of the MAP kinase cascade. To determine which kinases are involved in AP-1 activation resulting in the induction of luciferase activity, HepG2 cells were transfected with pCol- TRE Luc, the Cyp2c29-TRE Luc or p0.164 Ya-ARE I.uc. The transfected cells were then treated with the JNK inhibitor SP600125 (Bennett et al., 2001), the protein phosphatase inhibitor okadaic acid (Takai et al., 1987) or the IRK inhibitor PD098059 (Dudley et al., 1995). SP600125 functions to inhibit INK-mediated phosphorylation of Jun, thereby inhibiting Jun activation. Treatment of the transfected I IepG2 cells with the JNK or the ERK inhibitor caused a 40-50\% inhibition of luciferase activity of the Cyp2c29 TRE luciferase reporter plasmid and a 50-60\% inhibition in the collagenase TRE reporter activity (Figure 42). The protein phosphatase inhibitor, okadai: acid caused an increase in luciferase activity, 4-fold for Cyp2c29-TRE and 3-fold for collagenase TRE. The GST Ya antioxidant response element was also inhibited by $50 \%$ by the INK inhibitor SP600125 or the ERK inhibitor PB098059, and induced 1.4-fold by the protein phosphatase inhibitor okadaic acid. These data support the observation that Cyp2c29 induction is mediated by AP-1 and that this transcription factor requires phosphorylation for activation.

\section{Regulation of the cyp2c29 5' flanking sequence in mouse primary hepatocytes.}


Mouse primary hepatocytes were transfected with luciferase reporter plasmids containing the different Cyp2c29 5'FS fragments, and the cells treated for 16 hrs with tBHIQ. We observed a 3 -fold induction of luciferase activity with the reporter plasmid containing $3.0 \mathrm{~kb}$ of the Cyp2c29 5'-FS (Figure 43). In addition, we observed a 5-fold increase in luciferase activity with pCyp2c29-0.6Luc compared with the basal pCyp2c29-3.0 luc activity. In a separate experiment, treatment with $\mathrm{BBHQ}$ also caused induction of the Cyp2c29-TRE in mouse primary hepatocytes (data not shown). We observed that induction of the luciferase activity was more robust in mouse primary hepatocytes than in HepG2 cells (Figure 39). Tert-BHQ is proposed to induce gene expression by undergoing redox cycling in the presence of enzymes capable of one-electron reduction of tBHQ (Kahl et al., 1989). This reaction produces reactive oxygen species (oxidative stress) which activate the MAP kinase cascade subsequently activating Nrf2 and $\Lambda$ P-1. It is possible that the enzyme system required for this process is absent in Hep(i2 cells. thereby causing the reduced induction of AP-1-mediated reporter activity observed. Altcrnatively, there might be other transcription factors required to mediate the induction of $\mathrm{Cyp} 2 \mathrm{c} 29$ by tBHQ and acrolein, which are absent in HepG2 cells.

Cyp2c29 is induced by BHA in $\mathrm{Nrf}^{+/+}$and $\mathrm{Nrf2}^{-/-}$mice liver. We have so far made the following observations for Cyp2c29: 1. Its expression is induced by $\mathrm{BHA}$ and acrolein in mice liver. 2. The Cyp2c29-TRE is induced by Fos/Jun and not by Nrf2. 3. There is a further induction of the Cyp2c29-TRe reporter activity following mutation of the "( $\mathrm{GC}$ " dinucleotide at the 3'-proximal region of the Cyp2c29-TRL: To furiher investigate the 


\section{ligure 42. Effect of protein kinase and phosphatase inhibitors on Cyp2c29-TRL}

luciferase reporter activity. HepG2 cells were transfected with collagenase TRE,

Cyp2029-TRE or GST Ya ARE luciferase reporter plasmids. Cells were treated for $16 \mathrm{~h}$ with $25 \mathrm{uM}$ of JNK inhibitor SP600125, $40 \mathrm{nM}$ protein phosphatase innibitor okadaic acid or $50 \mu \mathrm{M}$ ERK inhibitor, PD098059. Cells were harvested and lysates assayed for $\beta$ yalactosidase and luciferase activities. The relative luciferase activity was calculated by nomalizing the change in luciferase activity following treatment to the vehicle treated controls. Data represent the mean \pm S.D. of three wells and was analyzed by ANOVA followed by the Dunnett test. ${ }^{*}>0.05$; ** $p<0.01$, significantly different from the vehicle tared control. 
Figure 42

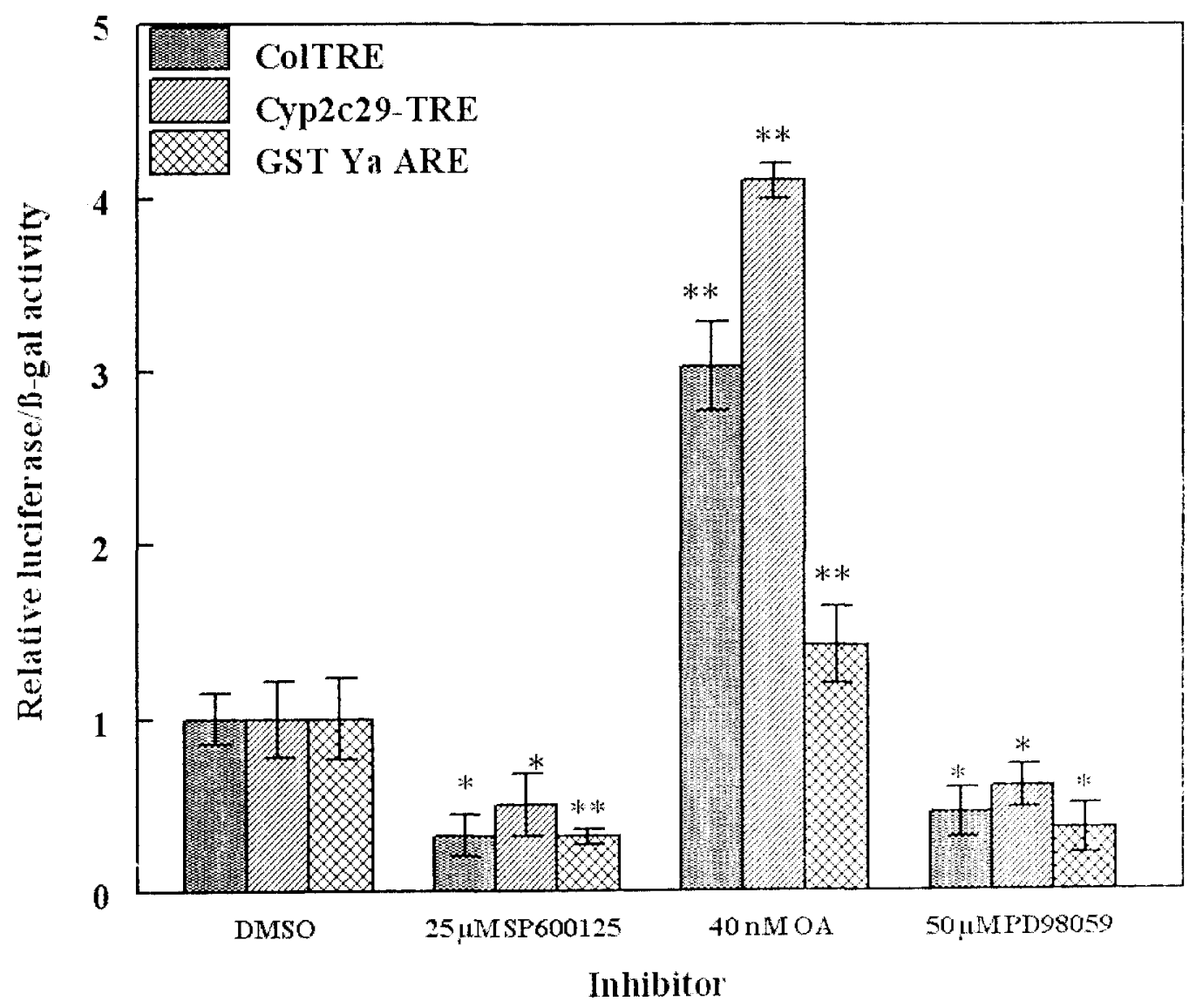




\section{Figure 43. Luciferase reporter activity in response to tBIIQ in mouse primary}

hepatocytes. Mouse primary hepatocytes were transfected with pCyp?c29-3.0 I uc. p(yp2c29-1.5 Luc or pCyp2c29-604. After 24 hours, the ce!ls were treated for 16 hours with vehicle or $50 \mu \mathrm{M}$ tBHQ. Cells were then harvested and lysates assayed for $\beta$ galactosidase and luciferase activities. Data represent the mean \pm S.D. of three wells. Statistical analysis was performed by ANOVA followed by the Dunnett post test. *** Signilicantly different from the vehicle treated pCyp2c29-3.0Luc, $\mathrm{p}<0.001$. 
Figure 43

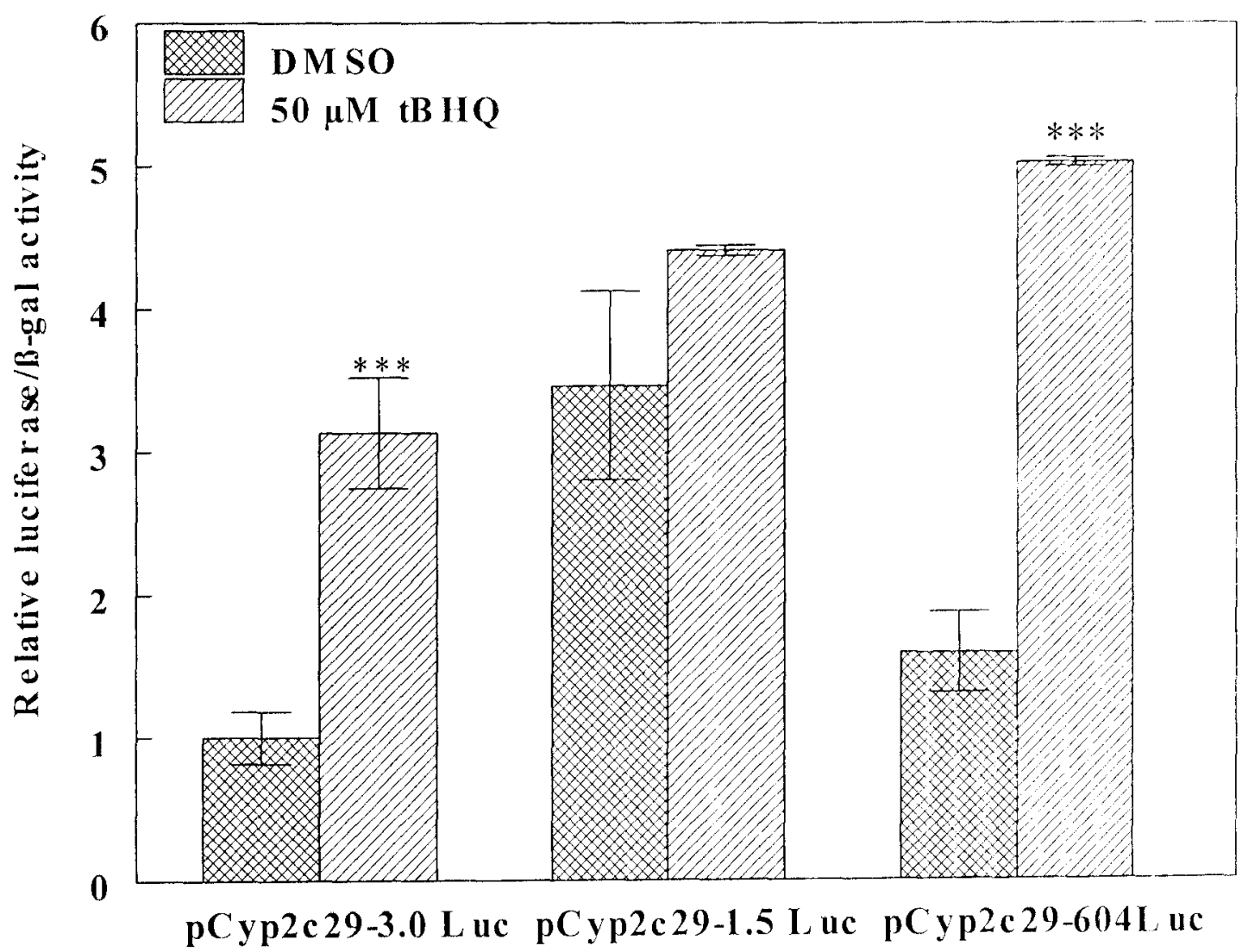


role of Nrf2, we conducted qRT-PCR with RNA from wild-type and $\mathrm{Nrf2}^{-1-}$ mice liver fed BIIA.

C57BL/6 wild-type and $\mathrm{Nrf} 2^{-/-}$mice were treated with BHA for 7 days and RNA extracted from liver samples of the same animals. Following cIDNA synthesis, the mouse liver samples were analyzed for changes in gene expression by quantitative real-time PCR. The following observations were made (Figure 44): (iS Tm 1 was induced on average 10-fold; heme oxygenase 1,3-fold: NADPH:quinone oxidoreductase. 17-fold and Cyp2c29, 6-fold. In the Nrf2 ${ }^{-/-}$animals, GSTm1 and quinone oxidoreductase were induced only 2-fold and no induction was observed for heme oxygenase 1. Interestingly. a further increase in induction was observed for Cyp2c29 (17-fold) in the $\mathrm{Nr} 2^{-/-}$mice liver. The Hayes laboratory has conducted studies looking at Nrf2-dependent regulation of gene expression. They have observed that administration of isothiocyanates which are activators of $\mathrm{Nrf} 2$, to $n r f 2^{+/+}$and $n r f 2^{-1-}$ mice produced a $\sim 1.5$-fold increase in NAD(P)H:quinone oxidoreductase 1 (NQO1) and glutathione S-transferase (GS I) activities in stomach, small intestine, and liver of wild-type mice but not in mutant mice. The increase in transferase activity was associated with elevated levels of GSTA1/2, GSTA3, and GSTM1/2 subunits (McWalter et al., 2004). This is in agreement with the induction of GSTm1 and NQOR1 caused by BHA in wild-type mice. Unlike the other genes, Cyp2c29 was further induced in $\mathrm{Nrf}^{-/-}$mouse liver supporting that this enzyme is regulated by a different transcription factor, most likely AP-1. Taken together, we conclude that while Nrf2 induces the expression of (SSTm1. HO-1 and nQOR-1. Cyp2c29 is induced by transcription factor AP-1. 
Figure 44. Quantitative real-time PCR analysis of gene expression in wild-type and $\mathrm{Nrf}^{-1-}$ mice liver following treatment with BHA. Wild-type mice were fed with AIN$76 \wedge$ diet only (control, $\mathrm{n}=4$ ), or supplemented with $0.45 \%$ BHA (treated, $\mathrm{n}=7$ ) ad libitum for 7 days. Nrf2 ${ }^{-/}$mice were fed with chow diet only (control, $n=3$ ), or supplemented with $0.45 \%$ BIIA (treated, $n=3$ ) for 7 days. RNA was extracted from the liver, reverse transcribed to cDNA and used for qRT-PCR analysis of gene expression. The fold induction is shown in a box and whiskers plot. The boxes extend from the $25^{\text {th }}$ to the $75^{\text {th }}$ percentile, the line across represents the median distribution of samples for each gene. For each point, a single mRNA was analyzed in triplicate and the average is shown. The whic shows the average fold induction for each gene in the liver of wild-type or $\mathrm{V}_{\mathrm{f}}$ inice. 
Figure 44
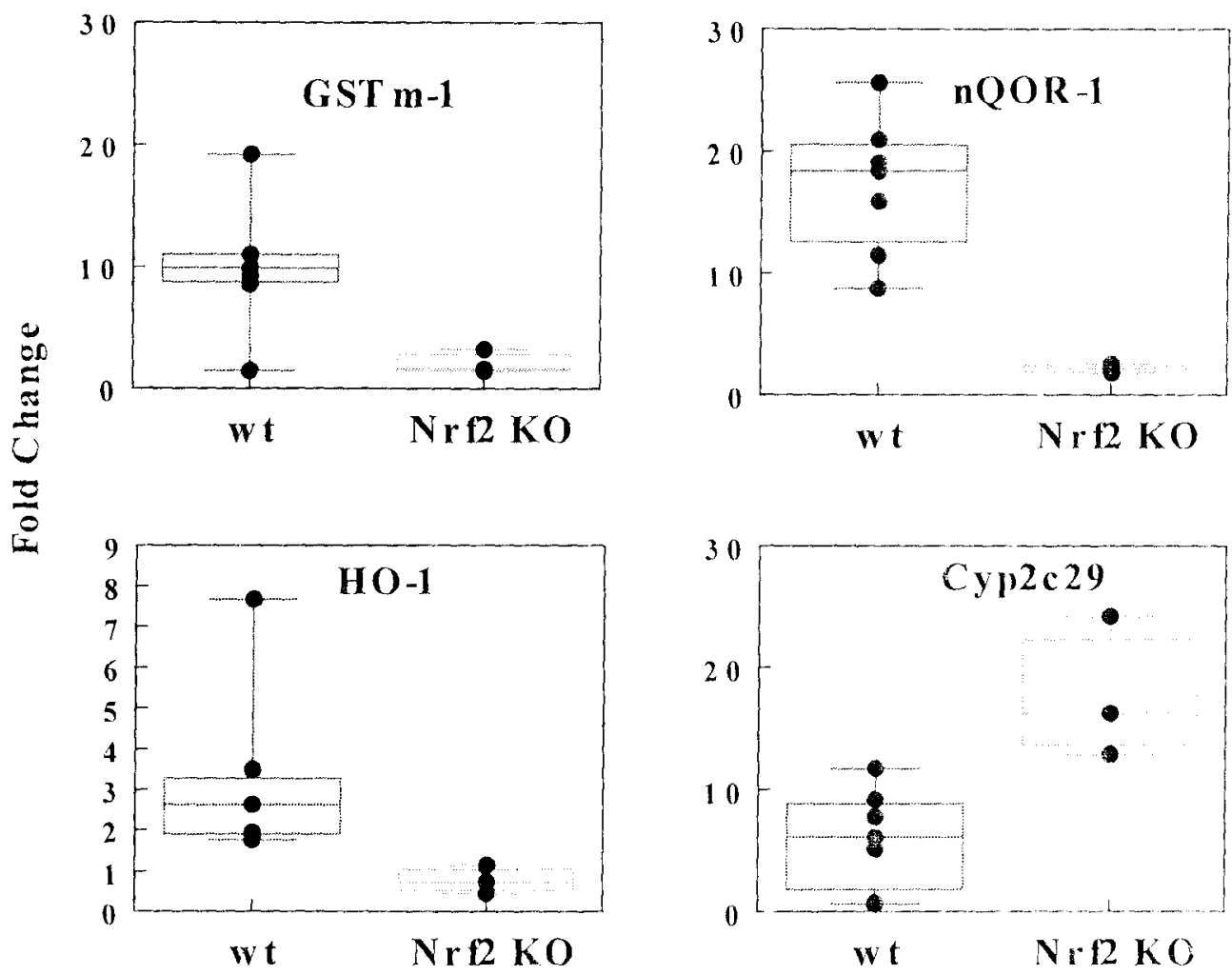

\begin{tabular}{|l|c|c|}
\hline \multirow{2}{*}{ Gene } & \multicolumn{2}{|c|}{ Average fold induction } \\
\cline { 2 - 3 } & $\mathbf{N r f}^{+/+}$ & $\mathbf{N r f}^{-1}$ \\
\hline GSTm1 & 10.1 & 2.1 \\
\hline HO-1 & 3.1 & 0.8 \\
\hline nQOR-1 & 17.2 & 2.2 \\
\hline Cyp2c29 & 6.0 & 17.8 \\
\hline
\end{tabular}




\section{DISCUSSION}

Cytochromes P450 play an important role in the metabolism of xenobiotics as well as endogenous compounds. P450s also function in the synthesis of important endogenous biomolecules. Cytochromes P450 are expressed in several organs and tissues including the liver, heart, brain, lungs, and kidneys. The regulation of P450 expression is a major source of variability in the metabolism of xenobiotics and endogenous compounds. Cyp2c29 is a major mouse P450, expressed in hepatic, as well as cxtrahepatic tissue. It is among the $\mathrm{P} 450$ s recently demonstrated to be able to metabolize 4 HNE. This P450 was also induced following the exposure of mice to BHA or acrolcin in liver.

Analysis of the 5-flanking sequence of Cyp2c29 revealed several putative transcription factor binding sites including a putative TRE located at -1249 bp upstream of the Cyp2c29 transcription start site. This observation prompted us to examine whether the transcription factors Nrf2, Fos or Jun are capable of regulating Cyp2c29 induction in response to $\mathrm{tBHQ}$ and acrolein.

We examined the induction of several Cyp2c29 5'-FS-derived luciferase reporter plasmids in the presence of exogenous Nrf2, Fos and Jun. The luciferase activity was induced in the presence of Jun alone or to a higher extend by Fos and Jun expression plasmids, suggesting that a Fos-Jun heterodimer and a Jun homodimer may be responsible for Cyp2c29 induction. Even though the Cyp2c29 TRE resenbled the consensus ARE, it did not respond to the presence of over-expressed Nrf2 or treatment with $\mathrm{tBHQ}$. We therefore concluded that the induction of $\mathrm{Cyp} 2 \mathrm{c} 29$ in response to $\mathrm{BH} \mathrm{A}$ and acrolein is mediated by the oxidative stress-sensitive transcription factor $A P-1$. 
We used a mutation strategy to determine the role of the oligonucleotides within and close to the Cyp2c29-TRE in the induction of gene expression. We also mutated the core TRE from "GTGAC" to "GGAGA". This mutation resulted in the complete ablation of the Fos/Jun-mediated luciferase activity. By mutating this sequence, the binding of $A \mathrm{P}-1$ to the TRE is most likely inhibited, thus resulting in the lack of change in luciferase activity in the presence of Fos and Jun. Conversely, we observed that mutation of the dinucleotide "GC" to AA resulted in a higher induction of luciferase activity by Fos and Jun, suggesting that the "GC" dinucleotide is not the optimal sequence for the AP-1 mediated response.

Analysis of mRNA levels from wild type and $\mathrm{Nrf}^{-/-}$mice liver demonstrated a further induction of Cyp2c29 in $\mathrm{Nrf}^{-/-}$mice following treatment of mice with BHIA. This suggests that Nrf2 might be acting indirectly to induce Cyp2c29) induction. In future studies, an enzyme mobility shift assay (EMSA) will be conducted to verify ios and iun binding to the Cyp2c29 TRE and the role of Nrf2 in protein-IDN $\Lambda$ complex formation. This is necessary in light of the study published by Ngueyn et al.. 1994. In the study looking at antioxidant response element-dependent regulation of GST $\mathrm{Al}$ gene expression, the authors observed that deletion of the "GC" in the ARI: found in the GST Ya promoter resulted in a further induction of luciferase activity by TPA. The authors did not comment on this observation.

Substrate-dependent induction of cytochrome P450 gene expression is common. Phenytoin. a substrate for Cyp2c29, has been shown to be able to induce the expression of this P450 (Jackson et al., 2004). We have shown that acrolein is also able to induce Cyp2e29. It is likely that 4-HNE which is a lipid aldehyde as is acrolein may also be able 
to induce Cyp2c29 gene expression. Since we observed that acrolein induced the expression of several genes involved in lipid aldehyde metabolism (Figure 29, 30. 32 A), it is possible that acrolein could regulate its level in vivo by inducing the expression of enzymes responsible for its metabolism. This could hold true for 4-HNl: which is also a lipid aldehyde.

Cytochromes P450 metabolize xenobiotics, endogenous compounds, as well as synthesize important metabolic and/or signaling molecules, making the regulation of CYP expression critical. Only a few P450s have been shown to be regulated by $\Lambda \mathrm{P}-1$; for example CYP2J2, which is an arachidonic acid epoxygenase, is induced by c-Jun and inhibited by Fos in HepG2 cells (Marden et al., 2003). Cyp4a2 is an arachidonic acid (1)hydroxylase. More recently, the promoter of this $\mathrm{P} 450$ has been determined to be upFregulated by Jun in HepG2 cells (Fiala-Beer et al., 2007). We have shown that (yp2c2) is also regulated by AP-1.

In our microarray analysis of gene expression (Chapter III), BH $\triangle$ and acrolcin induced several P450s. These include Cyp2c29, Cyp2c40, Cyp2c50 and Cyp3a23. In addition, CYP39Al is induced 6-fold following 6 hours of treatment of human colorectal cancer cells with $60 \mu \mathrm{M}$ 4-HNE (West and Marnett, 2005). The incehanism of induction of these P450s by these compounds is unknown. But, for Cyp2c29, we have at least demonstrated that this appears to be regulated by AP-1.

In conclusion, by using cell-based assays, we have determined that the induction of Cyp2c29 expression by compounds that activate oxidative stress-sensitive transcription factors is mediated by AP-1 acting at a TRE located at -1249 bp upstream of the Cyp2c29 transcription start site. 


\section{CHAPTER V}

\section{DISCUSSION AND CONCLUSIONS}

Prior to this study, the role of P450s in the metabolism of lipid aldehydes had not been clearly defined. A study in PPAR $\alpha$ knock out mice demonstrated that the Cyp4a class of P450s is capable of metabolizing 4-FINE to 4,9-dihydroxy-2-nonenoic acid, the omega-hydroxylated metabolite of 4-hydroxynonenoic acid (Guerand et al., 1999). No other reports have been published for P450s in lipid aldehyde metabolism. We incubated 4-HNE with rat primary hepatocytes and observed rapid metabolism of 4-HNE. Several different P450 inhibitors inhibited this metabolism. Based on this observation. we hypothesized that P450s are lipid aldehyde metabolizing enzymes capable of metabolizing 4-HNE. Metabolic studies were then designed with individual P450s expressed in E. coli and 4-HNE or 9-anthracene aldehyde in the presence of NADPH or an NADPH regenerating system. An NADPH regencrating system was not used in the 4HNE incubation reactions because we observed non-specific interactions of 4-HINE with components of the NADPH regenerating system. The use of HPIC allowed for the separation of 4-HNE metabolites that were then identified by gas chromatography and electrospray ionization -mass spectrometry. In addition to residual 4-HNL, three major metabolites were generated by $\mathrm{P} 450$ s. These metabolites were eluted with a retention time of 56 minutes, 58 minutes and 61 minutes from the HPLC colunn. $A$ very polar metabolite was eluted from the column ( $t R=5 \mathrm{~min}$ ). This metabolite is believed to be 
$\left[^{3} \mathrm{H}\right]-\mathrm{H}_{2} \mathrm{O}$. The metabolite peak corresponding to our authentic $\mathrm{HN} \mathrm{A}$ standard $(\mathrm{R}:-58$ minutes) was positively identified as 4-hydroxynonenoic based on common retention time in gas chromatography and mass spectrometry. CYP3 $\triangle 4$, Cyp2C29, CYP2136 and CYP2B4 generated the 4-hydroxynonenoic acid. Interestingly, the metabolite that eluted just prior to 4-hydroxynonenoic acid ( $\mathrm{tR}=56$ minutes) was identified as 1 , 4 -dihydroxy2-nonene, a reduced product of 4-HNE. The 1,4-dihydroxy-2-nonene was generated by CYP3A4, CYP2B6, CYP2J2 and Cyp2c29. While some P450s were able to generate both 4-hydroxynonenoic acid and 1,4-dihydroxy-2-nonene, others such as CYP2B4 only generated 4-hydroxynonenoic acid. CYP2E1 did not metabolize 4-IINE. These reactions were confirmed by the inhibition of metabolite formation in the presence of 12450 inhibitors (Amunom et al., 2007). Furthermore, we observed metabolism of 4-HNL by mouse liver microsomes, a process inhibited by different chemical inhibitors of 1450 s, namely miconazole, phenytoin and troleandonycin. The metabolism of 4-HNT: in microsomes was not inhibited by cyanamide, an aldehyde dehydrogenase inhibitor (Figure 14). Aldehyde dehydrogenases are typically located in the cytosol or mitochondria (Vasiliou et al., 2000). Failure to inhibit microsomal 4-HNL mutabolism with the aldehyde dehydrogenase inhibitor implies that the microsomes were not contaminated with the cytosol fraction.

Primary cultures of rat hepatocytes also metabolized 4-INNE to 4hydroxynonenoic acid by oxidative reactions, 1,4-dihydroxy-2-nonene through reductive reactions and glutathione-conjugated 4-HNE through GSH conjugation reactions (Hartley et al., 1995). Based on the use of inhibitors, the authors concluded that aldehyde dehydrogenases were the major catalysts of the oxidative reaction, but our results suggest 
that some P450s are sensitive to the known inhibitors of aldehyde dehydrogenases (100) $\mu \mathrm{M}$ benomyl caused $65 \%$ inhibition of P4503A4) and alcohol dehydrogenase ( $1 \mu \mathrm{M} 4$ methylpyrazole caused $98 \%$ inhibition of P4503A4, Table 2). Previous researchers may have under-estimated the role that P450s play in 4-HNE metabolism in past studies.

Mercapturic acid conjugates of IINA and DHN have been identified in rat urine (Alary et al., 2003) indicating that these are detoxification metabolites of 4-HNE. P450s therefore contribute to the metabolism and disposition of 4-HNE. to less reactive intermediates which can then be subjected to further metabolism. On the other hand. acrolein is metabolized in rats to several metabolites including oxalic acid, malonic acid. 3-hydropropionic acid and other N-acetyl-conjugated species (Parent et al.. 1998). In addition, acrylic acid, glycidol and glyceraldehydes have been observed in rat liver microsomal fractions (Patel et al., 1980). These are phase I metabolic products of acrolein. It is possible that $\mathrm{P} 450$ s contribute to acrolein metabolism by generating these products. However, we have not investigated this possibility.

In addition to 4-HNE, we determined that the $\alpha, \beta$-unsaturated aldehyde. 9anthracene aldehyde, is also metabolized by cytochromes $\mathrm{P} 450$ to generate 9 -anthracenc carboxylic acid and 9-anthracene methanol, the oxidized and reduced metabolites of 9anthracene aldehyde, respectively. In metabolic studies, Cyp2c29 metabolized both 9anthracene aldehyde and 4-HNE with a pattern of mixed competitive inhibition indicating that 4-HNE and 9-anthracene aldehyde are alternate or competitive substrates of Cyp2c29. Cyp2c29 is a mouse P450 expressed in hepatic and extra hepatic tissue that was previously reported to oxidize a cannabinoid aldehyde to its acid (Yamamoto et al.. 
1995). In my dissertation research, we showed that this P450 can also metabolize both 4 HNE and 9-anthracene aldehyde.

Cardiovascular tissues including heart. smooth muscle and endothelium express a variety of P450 enzymes that in humans include two gene families of epoxygenases (CYP 2C8, 2C9, 2C10,2J2) which gencrate the regio- and stereo-specific epoxyeicosatrienoic acids (EETs) and $\omega$-hydroxylases belonging to the CYP $+\Lambda$ family which form subterminal and $\omega$-terminal hydroxyeicosatetraenoic acids (HETLs). Together the products of these enzymes play an important role in regulating vascular tone and homeostasis (Fleming, 2001). In these functions, the role of human CYP2C9 appears to be particularly critical since sulfaphanazole, a selective inhibitor of ( Y P2C9. inhibits responses attributed to the endothelium-derived hyperpolarizing factor (EDHF) and potentiates nitric oxide mediated relaxation (Fleming, 2001). On the basis of these observations it has been suggested that CYP2C9 is the EDHF generating CY?. I Ience. our observation that mouse Cyp2c29 metabolizes 4-HNE suggests that in addition to mediating or regulating $\mathrm{NO} / \mathrm{PGI} 2$-independent vasodilation, $\mathrm{CYP} 2 \mathrm{C} 9$ and related forms of P450 may have an important role in preventing oxidative injury. Alternatively. competitive inhibition of Cyp2c29 by 4-HNE suggest that conditions associated with high levels of oxidative stress and the generation of lipid peroxidation products could prevent or attenuate EDHF generation and thus compromise endotheliun-dependent relaxation in coronary, mesenteric, and renal arteries, where EDHF-mediated rcsponses are particularly critical. Hence, 4-HNE-dependent inhibition of CYP2C forms could link the development of hypertension with oxidative stress such as that associated with atherosclerotic lesions formation. Clearly further physiological studies are warranted to 
understand fully the role of this and related CYP isotorms in the metabolism of reactive carbonyls.

In addition to the metabolism of 4-HNE, we investigated the role of lipid aldehydes in regulating the expression of xenobiotic metabolizing enzymes in mouse heart and liver by microarray and quantitative real-time PCR. Acrolein is generated in vivo from lipid peroxidation and is a prevalent environmental pollutant. C57BL/6 mice were treated with acrolein by gavage or inhalation to mimic the natural routes of acrolin exposure in humans. A separate group of mice was also treated with BIIA for comparison with the acrolein exposure. In our microarray analysis of gene expression, we observed differences in the magnitude of basal gene expression between control animals from the acrolein-treated group (chow diet) and the BHA-treated group (AIN-76A dict). It is possible that the diets caused the differences observed. To address this ambiguity, we conducted a principle component analysis of the two control groups. The control data from both sets of controls were normalized to a common group of diagnostic genes and then compared with the chronic acrolein and BHA treatments (Figure 28). The genes in the BHA and acrolein treated groups separated into two different groups suggesting that different genes were affected by the BHA and acrolein treatment.

Several P450s were induced by BHA in mouse liver: Cypla2, ( yp2a4, (yp2e24) Cyp2c37. Cyp2c44, Cyp2c50 and Cyp51, and acrolein: Cyp2c29, Cyp2c44. Cyp2el and Cyp2j6. Other studies have also shown that compounds that induce $\mathrm{Nrf} 2$ induce the expression of some P450s. For example, in the study of GST induction in (D)-1 mice, Pr450 and $P_{3}-450$ mRNA were induced 3-5-fold in the liver and intestine after BHA treatment (Pearson et al., 1988). In addition, the expression of (YP1 А, CYP3А, CYP2B. 
CYP4A and CYP39A was induced by the Nrf2 activator sulforafane (Hu el al., 2004). and Cypla2, Cyp2a4, Cyp2a12, Cyp3a13, and Cyp4a10 by 3H-1,2-dithiole-3-thione in Nrf2- wild type, but not Nrf2 knock out mice (Kwak et al., 2003). More recently, 4-IINI: caused a 6-fold induction of CYP39A1 in human colorectal carcinoma cells (West and Marnett, 2005). Even though these P450s are induced, it is widely known that the promoter sequence of $\mathrm{P} 450 \mathrm{~s}$ does not contain an antioxidant element, the cis element that binds $\mathrm{Nr} 2$ to induce gene expression. It is therefore evident that a separate mechanism exists for P450 induction by these compounds.

The glutathione $S$-transferases catalyze the conjugation of GSH to electrophilic compounds. BHA induced GSTa3, GSTm1 and GSTt1, while GSTm1 was induced by acrolein. This corresponds with other studies that have determined this family of enzyme to be induced by Nrf2-activating compounds (Thimmulappa et al., 2002).

NADPH:quinone oxidoreductase 1. Heme oxygenase 1 and some members of the aldehyde dehydrogenase and aldoketoreductase family were also induced by both $\mathrm{BH} \mathrm{A}$ and acrolein. Just like GSTs, these enzymes are believed to be regulated by Nrf2 (Kwak et al., 2003; Thimmulappa et al., 2002).

My studies have provided the following observations related to Cyp2c29. (1) It metabolizes 4-HNE; (2) Cyp2c29 mRNA is induced in mice liver by BHA and acrolein; (3) Cyp2c29 protein is induced in mouse liver microsomes after 7 days of $\mathrm{BH} / \mathrm{A}$ treatment, and (4) BHA induced expression of Cyp2c29 in Nrf2 null mice. 'Transfection experiments with Cyp2c29-promoter luciferase reporter constructs indicated that Cyp2c29 transcription was regulated by AP-1 and not by the Nr'2 transcription factor. Through a computer-based search of putative response elements and deletion analysis. 
the AP-1-dependent regulation of Cyp2c29 was mapped to a 30-base pair region of the Cyp2c20 promoter containing an $\Lambda \mathrm{P}-1$ response element (TRE) from -1,238 to -1249). This TRE responded to the expression of exogenous fos and Jun as indicated by an induction of luciferase activity. Mutation of the core nucleotides of the TRL resulted in the loss of luciferase activity. Surprisingly, when we mutated the "G( (") $^{-}$dinucleotide which is immediately 5' of the Cyp2c29 TRE, we observed a 3-fold increase in luciferase activity. This implies that the "GC" dinucleotide is not required for optimal induction of Cyp2c29 by the AP-1 transcription factors; in fact, they serve to negatively regulate Cyp2c29 gene expression. Furthermore, qR'T-PCR analysis was performed on samples obtained from wild-type and $\mathrm{Nrf} 2 \%$ mouse liver. $\mathrm{N} \Lambda \mathrm{DPH}$ quinone oxidoreductase, heme oxygenase 1, and glutathione $S$-transferase were induced in the liver from BllA-led wildtype mice liver and not in the liver from $\mathrm{Nrf}^{-/-}$mouse liver. Conversely. Cyp2c29 was induced in the liver of wild-type BH $\Lambda$-fed mice liver and further induced in BHA-led $\mathrm{Nrf}^{-1}$ mice liver. We conclude that while NADPH quinine oxidoreductase, neme oxygenase 1 , and glutathione $S$-transferase are predominantly regulated by the $\mathrm{Nr} \cdot \mathrm{P}-\mathrm{ARI}$ system. Cyp2c29 is most like regulated by AP-1, accounting for the further induction of Cyp2c29 observed in $\mathrm{Nrf}^{-/-}$mouse liver. As we have demonstrated. the expression of P450s in the liver is altered in response to compounds that cause the activation of transcription factor AP-1. During oxidative stress. when the levels of lipid aldehydes are reported to be increased. this may also alter the levels of $\mathrm{P} 450$ s being expressed. by activating AP-1. Consequently, there could be differences in P450 activities in different organs resulting in alterations in the biosynthesis of biomolecules by the same P450s or differences in xenobiotic metabolism. 
In conclusion, P450s are lipid aldehyde metaholizing enzymes capable of oxidative and/or reductive metabolism of 4-HNE and 9-anthracene aldehyde. BHA and acrolein induce the expression of some P450s. For Cyp2c29, this induction is mediated by $\mathrm{AP}-1$ transcription factors, a mechanism not yet reported for any other P450s. 


\section{REFERENCES}

Abu-Bakar,A., Satarug,S., Marks,G.C., Lang,M.A., and Moore.M.R. 2004. Acute cadmium chloride administration induces hepatic and renal CYP2A5 mRNA, protein and activity in the mouse: involvement of transcription factor NRF2 Toxicology Letters 148: 199-210.

Abu-Bakar,A., Lamsa,V., Arpiainen,S., Moore,M.R., Lang,M.A., and Hakkola.J. 2007. Regulation of CYP2A5 gene by the transcription factor nuclear factor (erythroidderived 2)-like 2. Drug Metabolism and Disposition 35: 787-794.

Alary,J., Bravais,F., Cravedi,J.P., Debrauwer,L., Rao,D., and Bories,G. 1995. Mercapturic Acid Conjugates As Urinary End Metabolites of the LipidPeroxidation Product 4-Hydroxy-2-Nonenal in the Rat. Chemical Research in Toxicology 8: 34-39.

Amunom,I., Stephens,L.J., Conklin,D.J., Srivastava,S., Bhatnagar,A., and Prough.R.A. Several cytochromes P450 Are aldehyde monooxygenases. 12, 118-123. 2005. Layafette, IN , U. Purdue Press. Enzymology and Molecular Biology of Carbonyl Metabolism. Weiner, $\mathrm{H}$.

Amunom,I., Stephens,L.J., Tamasi,V., Cai,J., Pierce,W.M., Conklin,D..l. Hatnagar, A., Srivastava,S., Martin,M.V., Guengerich,F.P., and Prough,R.A. 2007. Cytochromes $\mathrm{P} 450$ catalyze oxidation of alpha,beta-unsaturated aldehydes 1. Archives of Biochemistry and Biophysics 464: 187-196.

Angel,P., Baumann,I., Stein,B., Delius,H., Rahmsdorf,H.J., and Herrlich.P. 1987. 12-OTetradecanoyl-Phorbol-13-Acetate Induction of the Human Collagenase Gene Is Mediated by An Inducible Enhancer Element Located in the 5'-Flanking Region Molecular and Cellular Biology 7: 2256-2266.

Awasthi,Y.C., Sharma,R., Cheng,J.Z., Yang,Y., Sharma.A., Singhal,S.S., and Awasthi.S. 2003. Role of 4-hydroxynonenal in stress-mediated apoptosis signaling. Mol. Aspects Med. 24: 219-230.

Axelrod,J. 1955. The enzymatic deamination of amphetamine (benzedrine). J Biol. Chem. 214: 753-763.

Beauchamp,R.O., Andjelkovich,D.A., Kligerman,A.D., Morgan,K.T., and Heck,H.D. 1985. A Critical-Review of the Literature on Acrolein Toxicity. Crc Critical Reviews in Toxicology 14: 309-380. 
Benedetti,A., Comporti,M., and Esterbauer,H. 1980. Identilication of 4-Hydroxynoneal As A Cyto-Toxic Product Originating from the Peroxidation of Liver Microsomal Lipids. Biochimica et Biophysica Acta 620: 281-296.

Berhane,K. and Mannervik,B. 1990. Inactivation of the Genotoxic Aldehyde Acrolein by Human Glutathione Transferases of Class-Alpha. Class-Mu, and Class-Pi. Molecular Pharmacology 37: 251-254.

Black.S.D. 1992. Membrane topology of the mammalian P450 eytochromes. FASI:B J. 6: 680-685.

Boon,P.J.M., Marinho,H.S., Oosting,R., and Mulder,G.J. 1999. Glutathione conjugation of 4-hydroxy-trans-2,3-nonenal in the rat in vivo, the isolated perfused liver and erythrocytes. Toxicology and Applied Pharmacology 159: 214-223.

Boor,P.J. 1983. Allylamine Cardiotoxicity - Metabolism and Mechanism. Advances in Experimental Medicine and Biology 161: 533-541.

Chauret,N., Gauthier,A., Martin,J., and Nicoll-Griffith.D.A. 1997. In vitro comparison of cytochrome P450-mediated metabolic activities in human, dog. cat, and horse. Drug Metab Dispos. 25: 1130-1136.

Cheung,C., Akiyama,T.E., Kudo,G., and Gonzalez.1.J. 2003. Hepatic expression of cytochrome $\mathrm{P} 450$ s in hepatocyte nuclear factor 1 -alpha (HNFI alpha)-deficient mice. Biochemical Pharmacology 66: 2011-2020.

Chun,Y.J., Shimada,T., and Guengerich.F.P. 1996. Construction of a human cytochrome P450 1A1: rat NADPH-cytochrome P450 reductase fusion protein cDNA and expression in Escherichia coli, purification, and catalytic propertics of the enzyme in bacterial cells and after purification. Arch. Biochem. Biophys. 330: 48-58.

Cummings,S.W., Ansari,G.A.S., Guengerich,F.P., Crouch,L.S., and Prough,R.A. 1985. Metabolism of 3-Tert-Butyl-4-Hydroxyanisole by Microsomal Fractions and Isolated Rat Hepatocytes. Cancer Research 45: 5617-5624.

Davis,R.J. 2000. Signal transduction by the JNK group of MAP kinases. Cell 103: 239252.

de Zwart,L.L., Hermanns,R.C., Meerman.J.H.. Commandeur.J.N., and Vermeulen.N.P. 1996. Disposition in rat of [2-3H]-trans-4-hydroxy-2,3-nonenal. a product of lipid peroxidation. Xenobiotica 26: 1087-1100.

Dean,W.L. and Gray,R.I. 1982. Hydrodynamic properties of monomeric cytochromes P450LM2 and P-450LM4 in n-octylglucoside solution. Biochem. Biophys. Res. Commun. 107: 265-271.

DeLozier,T.C., Tsao,C.C., Coulter,S.J., Foley,J., Bradbury,J.A., Zeldin,D.C., and Goldstein.J.A. 2004. CYP2C44, a new murine CYP2C that metabolizes 
arachidonic acid to unique stereospecific products. J. Pharmacol. Exp. Ther. 310 : 845-854.

deZwart,L.L., Hermanns, R.C.A., Meerman,J.H.N., Commandeur,J.N.M., and Vermeulen,N.P.E. 1996. Disposition in rat of [2-H-3]-trans-4-hydroxy-2,3nonenal, a product of lipid peroxidation. Xenobiotica 26: 1087-1 100.

Eckl,P.M., Ortner,A., and Esterbauer,H. 1993. Genotoxic properties of 4-hydroxyalkenals and analogous aldehydes. Mutat. Res. 290: 183-192.

Engel.K.H., Ramming,D.W., Flath,R.A., and Teranishi,R. 1988. Investigation of Volatile Constituents in Nectarines .2. Changes in Aroma Composition During Nectarine Maturation. Journal of Agricultural and Food Chemistry 36: 1003-1006.

Esterbauer,H., Schaur,R.J., and Zollner,H. 1991. Chemistry and Biochemistry of 4Hydroxynonenal, Malonaldehyde and Related Aldehydes. Free Radical Biology and Medicine 11:81-128.

Feng,Z.H., Hu,W.W., and Tang,M.S. 2004. Trans-4-hydroxy-2-nonenal inhibits nucleotide excision repair in human cells: A possible mechanisn for lipid peroxidation-induced carcinogenesis. Proceedings of the National Academy of Sciences of the United States of America 101: 8598-8602.

Fiala-Beer,E., Lee,A.C., and Murray,M. 2007. Regulation of the rat CYP4 A2 gene promoter by c-Jun and octamer binding protein-1. International Joumal of Biochemistry \& Cell Biology 39: 1235-1247.

Fleming,I. 2001. Cytochrome P450 enzymes in vascular homeostasis. Circulation Research 89: 753-762.

Fraiser.L.H., Kanekal,S., and Kehrer.J.P. 1991. Cyclophosphamide Toxicity Characterizing and Avoiding the Problem. Drugs 42: 781-795.

Fry,J.R., Fentem,J.H., Salim,A., Tang,S.P.A., Garle,M.J., and Whiting,1).A. 1993. Structural Requirements for the Direct and Cytochrome-P450-Dependent Reaction of Cyclic Alpha,Beta-Unsaturated Carbonyl-Compounds with Glutathione - A Study with Coumarin and Related-Compounds. Journal of Pharmacy and Pharmacology 45: 166-170.

Fujioka,K. and Shibamoto,T. 2006. Determination of toxic carbonyl compounds in cigarette smoke. Environmental Toxicology 21: 47-54.

Glover,J.N.M. and Harrison,S.C. 1995. Crystal-Structure of the Heterodimeric Bzip Transcription Factor C-Fos-C.-Jun Bound to Dna. Nature 373: 257-261.

Goeptar,A.R., Tekoppele,J.M., Vanmaanen.J.M.S., Zoetemelk,C.E.M.. and Vermeulen,N.P.E. 1992. One-Electron Reductive Bioactivation of 2,3,5.6- 
Tetramethylbenzoquinone by Cytochrome-P450. Biochemical Pharmacology 43. 343-352.

GrahamLorence,S.E. and Peterson.J.A. 1996. Structural alignments of P450s and extrapolations to the unknown. Cytochrome P450, P`B 272: 315-326.

Gregory,R.B. and Berry.M.N. 1991. On the thyroid hormone-induced increase in respiratory capacity of isolated rat hepatocytes. Biochim. Biophys. Acta 1098: 6167.

Grune,T., Siems,W.G., and Petras,T. 1997. Identification of metabolic pathways of the lipid peroxidation product 4-hydroxynonenal in in situ perfused rat kidney. Journal of Lipid Research 38: 1660-1665.

Gu.J., Zhang,Q.Y., Genter,M.B., Lipinskas,T.W., Negishi.M., Nebert,D.W., and Ding.X. 1998. Purification and characterization of heterologously expressed mouse CYP2A5 and CYP2G1: role in metabolic activation of acctaminophen and 2.6dichlorobenzonitrile in mouse olfactory mucosal microsomes. J. Pharmacol. Exp. Ther. 285: 1287-1295.

Guengerich,F.P. and Martin,M. 1999. Expression of P450s. Methods in Enzymology 100: $x-y$.

Guengerich.F.P. 2000. Pharmacogenomics of cytochrome P450 and other en:ymes involved in biotransformation of xenobiotics. Drug Development Research 49: 4 16.

Guengerich,F.P. 2004. Cytochrome p450: What have we learned and what are the future issues?. Drug Metabolism Reviews 36: 159-197.

Guengerich,F.P. and Martin,M.V. 2006. Purification of cytochromes P450: products of bacterial recombinant expression systems. Methods Mol. Biol. 320: $31-37$.

Gueraud,F., Alary,J., Costet,P., Debrauwer,L., Dolo,L., Pineau,T., and Paris,A. 1999. In vivo involvement of cytochrome P450 4A family in the oxidative metabolism of the lipid peroxidation product trans-4-hydroxy-2-nonenal, using PPAR alphadeficient mice. Journal of Lipid Research 40: 152-159.

Hartley,D.P., Ruth,J.A., and Petersen,D.R. 1995. The Hepatocellular Metabolism of 4Hydroxynonenal by Alcohol-Dehydrogenase. Aldehyde Dehydrogenase, and Glutathione-S-Transferase. Archives of Biochemistry and Biophysics 316: 197205.

Hartley,D.P., Ruth,J.A., and Petersen.D.R. 1995. The hepatocellular motabolisn of 4 hydroxynonenal by alcohol dehydrogenase, aldehyde dehydrogenase. and glutathione S-transferase. Arch. Biochem. Biophys. 316: 197-205. 
Hauptlorenz,S., Esterbauer.H., Moll,W., Pumpel,R. Schauenstein,E., and Puschendorf,B. 1985. Effects of the lipidperoxidation product 4-hydroxynonenal and related aldehydes on proliferation and viability of cultured thrlich ascites tumor cells. Biochem. Pharmacol. 34: 3803-3809.

Hayes,J.D. and McLellan,L.I. 1999. Glutathione and glutathione-dependent enzymes represent a Co-ordinately regulated defence against oxidative stress. Free Radical Research 31: 273-300.

Ilayes,K.R., Vollrath,A.L., Zastrow,G.M., McMillan,B.J., Craven.M., Jovanovich.S. Rank,D.R., Penn,S., Walisser.J.A., Reddy,J.K., Thomas,R.S., and Bradlield (.$\wedge$. 2005. EDGE: A centralized resource for the comparison, analysis, and distribution of toxicogenomic information. Molecular Pharmacology 67: 13601368.

Henly,D.C., Phillips.J.W., and Berry.M.N. 1996. Suppression of glycolysis is associated with an increase in glucose cycling in hepatocytes from diabetic rats. I. Biol. Chem. 271: 11268-11271.

Hu,R., Hebbar,V., Kim,B.R., Chen,C., Winnik,B., Buckley,B., Soteropoulos,P., Tolias.P. Hart,R.P., and Kong,A.N.T. 2004. In vivo pharmacokinetics and regulation of gene expression profiles by isothiocyanate sulforaphane in the rat. Journal of Pharmacology and Experimental Therapeutics 310: 263-271.

Hubatsch,I., Ridderstrom,M., and Mannervik,B. 1998. Human glutathione transfercise A4-4: an Alpha class enzyme with high catalytic efficiency in the conjugation of 4-hydroxynonenal and other genotoxic products of lipid peroxidation. Biochemical Journal 330: 175-179.

jackson,J.P., Ferguson,S.S., Moore.R., Negishi,M., and Goldstein,I.A. 2004. The constitutive active/androstane receptor regulates phenytoin induction of $(y p 2029$. Mol. Pharmacol. 65: 1397-1404.

Jackson,J.P., Ferguson,S.S., Moore,R., Negishi,M., and Goldstein.J.A. 2004. The constitutive active/androstane receptor regulates phenytoin induction of Cyp 2029 2. Molecular Pharmacology 65: 1397-1404.

Jakoby,W.B. and Ziegler,D.M. 1990. The Enzymes of Detoxication. Journal of Biological Chemistry 265: 20715-20718.

Jurgens,G., Chen,Q., Esterbauer,H., Mair,S., Ledinski,G., and Dinges,H.P. 1993. Immunostaining of human autopsy aortas with antibodics to modified apolipoprotein B and apoprotein(a). Arterioseler. Thromb. 13: 1689-1699.

Kahl,R., Weinke.S., and Kappus,H. 1989. Production of Reactive (oxygen Species Due to Metabolic-Activation of Butylated Hydroxyanisole. Toxicology 59: 179-19.t. 

Karin,M. 1999. The beginning of the end: I kappa B kinase (IKK) and NF-kappa B
activation. Journal of Biologicai Chemistry 274:27339-27342. nonenal, a toxic product of.J. 1997. Metabolic activation of

cytochromes.

Kwak MK. Watological Chemistry 272: 2261 and inhibitor of P450 2003. Moduayashi,N., Itoh, K., Motohashi,H. Yamam -22616.

through the Keapl of gene expression by cancer chemoto,M., and Kensler.T.W. Survival. Journal 1 Nrf2 pathway - Identification of novereventive dithiolethiones

( of 4-hydroxynonenal, a cyto, J., Debrauwer,L., and Cravedi,J.P. 2000. Metabolism cut liver slices. Toxicology Letters $114: 203-214$. peroxidation, in rat precision-

Levine,W.G. and Raza,H. 1988. Mechanism of Azoreduction of

Dimethylaminoazobenzene by Rat-Liver Nadph-Cytochrome-P-450 Reductase and Partially Purified Cytochrome-P-450 - Oxygen and Carbon-Monoxide

Sensitivity and Stimulation by Fad and Fmn
2. Drug Metabolism and Disposition 16: 441-448.

Licas,D.T. and Szweda,L.I. 1999 . D

reperfusion: Age-dependent Declines in mitochondrial respiration during cardiac

Proceedings of the National Academy of Scicha-ketoglutarate dehydrogenase.

96: 6689-6693.

Mangelsdorf,D.J., Thummel,C., Beato,M., Herrlich,P.. Schutz,G., Umesono,K.,

Blumberg,B., Kastner,P., Mark,M., Chambon,P., and Evans,R.M. 1995. The

Nuclear Receptor Superfamily - the 2Nd Decade. Cell 83: 835-839.

Mansuy,D. 1994. Cytochromes P-450 and Model Systems - Great Diversity of Catalyzed-

Reactions. Pure and Applied Chemistry 66: 737-744.

Marden,N.Y., Fiala-Beer,E., Xiang,S.H., and Murray,M. 2003. Role of activator protcin-

1 in the down-regulation of the human CYP2J2 gene in hypoxia. Biochemical Journal 373: 669-680.

Marini.S.. Grasso,E., Longo,V., Puccini,P., Riccardi.B., and Gervasi,P.G. 2003. 4Biphenylaldehyde and 9-anthraldehyde: two fluorescent substrates for determining P450 enzyme activities in rat and human. Xenobiotica 33:1-11.

Markesbery,W.R. and Lovell,M.A. 1998. Four-hydroxynonenal, a product of lipid peroxidation, is increased in the brain in Alzheimer's disease. Neurobiology of Aging 19: 33-36.

Matsubara,T., Prough,R.A., Burke,M.D., and Estabrook,R.W. 1974. The preparation of microsomal fractions of rodent respiratory tract and their characteri/ation. Cancer 
Res. 34: 2196-2203.

Matsunaga,T., Watanabe,K., Yamamoto,I., Negishi,M., Gonzalez,F.J., and Yoshimura,H. 1994. cDNA cloning and sequence of CYP2C29 encoding P-450 MUT-2, a microsomal aldehyde oxygenase. Biochim. Biophys. Acta 1184: 299-301.

Matsunaga,T., Watanabe,K., Yamamoto,I., Negishi,M., Gonzale $\%, F . J .$, and Yoshimura.II. 1994. Cdna Cloning and Sequence of Cyp2C29 Encoding P-450-Mut-2, A Microsomal Aldehyde Oxygenase. Biochimica et Biophysica Acta-Biocnergetics 1184: 299-301.

Matsunaga,T., Iwawaki,Y., Watanabe,K., Yamamoto,I., Kageyama,T., and Yoshimura.H. 1995. Metabolism of delta 9-tetrahydrocannabinol by cytochrome P450 isozymes purified from hepatic microsomes of monkeys. Life Sci. 56: 2089-2095.

Matsunaga,T., Iwawaki, Y., Watanabe,K., Yamamoto,I., Kageyama,T., and Yoshimura.H. 1996. Microsomal aldehyde oxygenase (MAIDO): purification and characterization of a cytochrome $\mathrm{P} 450$ isozyme responsible for oxidation of 9 anthraldehyde to 9-anthracenecarboxylic acid in monkey liver. I. Biochem. (Tokyo) 119: 617-625.

Matsunaga,T., Tanaka,H., Komura,A., Watanabe,K., Yamamoto,I., and Yoshimura.H. 1997. Microsomal alcohol oxygenase: purification and characterization of a cytochrome $\mathrm{P} 450$ responsible for oxidation of 7 -hydroxy-delta 8 tetrahydrocannabinol to 7-oxo-delta 8-tetrahydrocannabinol in guinea pig liver. Arch. Biochem. Biophys. 348: 56-64.

Matsunaga,T., Shibayama,K., Higuchi,S., Tanaka,H., Watanabe, K.. and Yamamoto.l. 2000. Characterization of microsomal alcohol oxygenase catalyzing the oxidation of 7-hydroxy-delta 8-tetrahydrocannabinol to 7-oxo-delta 8-tetrahydrocannabinol in rat liver. Biol. Pharm. Bull. 23: 43-46.

Maurice,M., Pichard,L., Daujat,M., Fabre,I., Joyeux.H., Domergue.J.. and Maurel,P. 1992. Effects of imidazole derivatives on cytochromes P450 from human hepatocytes in primary culture. FASEB J. 6: 752-758.

McCracken,E., Graham,D.I., Nilsen,M., Stewart,J., Nicoll,I.A.R., and Horsburgh,K. 2001. 4-hydroxynonenal immunoreactivity is increased in human hippocampus after global ischemia. Brain Pathology 11: 414-421.

McWalter,G.K., Higgins,L.G., McLellan,L.I., Henderson,C.J., Song,L.J., Thornalley,P.J., Itoh,K., Yamamoto,M., and Hayes,J.D. 2004. Transcription factor nrt2 is essential for induction of $\mathrm{NAD}(\mathrm{P}) \mathrm{H}:$ quinone oxidoreductase 1, glutathione S-transferases, and glutamate cysteine ligase by broccoli seeds and isothiocyanates. Journal of Nutrition 134: 3499S-3506S. 
Meyer,R.P., Hagemeyer,C.E., Knoth.R., Kurz,G., and Volk,B. 2001. Oxidative hydrolysis of scoparone by cytochrome P450CYP2C29 reveals a novel metabolite 1. Biochemical and Biophysical Research Communications 285: 32-39.

Miller,K.P. and Ramos,K.S. 2005. DNA sequence determinants of nuclear protein binding to the c-Ha-ras antioxidant/electrophile response element in vascular smooth muscle cells: identification of $\mathrm{Nrf2}$ and heat shock protein 90 beta as heterocomplex components. Cell Stress \& Chaperones 10: 114-125.

Montine,K.S., Kim,P.J., Olson,S.J., Markesbery,W.R., and Montine, T.J. $1997.4-$ hydroxy-2-nonenal pyrrole adducts in human neurodegenerative disease 3. Journal of Neuropathology and Experimental Neurology 56: 866-871.

Munsch,N., Recondo,A.M.D., and FRA YSSIN.C 1973. Effects of Acrolein on DnaSynthesis In-Vitro. Febs Letters 30: 286-290.

Narimatsu,S., Watanabe,K., Matsunaga,T., Yamamoto,I., Imaoka,S., Funac, Y.. and Yoshimura,H. 1990. Cytochrome P-450 isozymes in metabolic activation of delta 9-tetrahydrocannabinol by rat liver microsomes. Drug Metab Dispos. 18: 9:43948.

Narimatsu,S., Watanabe,K., Yamamoto,I., and Yoshimura,H. 1991. Sex difference in the oxidative metabolism of delta 9-tetrahydrocannabinol in the rat. Biochem. Pharmacol. 41: 1187-1194.

Narimatsu,S., Watanabe,K., Matsunaga,T., Yamamoto,I., Imaoka,S., Funae, Y., and Yoshimura,H. 1992. Cytochrome P-450 isozymes involved in the oxidative metabolism of delta 9-tetrahydrocannabinol by liver microsomes of adult female rats. Drug Metab Dispos. 20: 79-83.

Nebert,D.W., Adesnik,M., Coon,M.J., Estabrook,R.W., Gonzalez,F.J., Guengerich,F.P., Gunsalus,I.C., Johnson,E.F., Kemper,B., Levin,W., Phillips,I.R., Sato,R., and Waterman,M.R. 1987. The P450 Gene Superfamily - Recommended Nomenclature. Dna-A Journal of Molecular \& Cellular Biology 6: 1-11.

Neri,F., Mari,M., Menniti,A.M., and Brigati,S. 2006. Activity of trans-2-hexenal against Penicillium expansum in 'Conference' pears. Journal of Applied Microbiology 100: 1186-1193.

Olefsky,J.M. 2001. Nuclear receptor minireview series. Journal of Biological Chemistry 276: $36863-36864$.

Omura,T. and Sato,R. 1964. The carbon monoxide-binding pigment of liver microsomes. I. Evidence for its hemoprotein nature. J. Biol. Chem. 239: 2370-2378.

Pappa,A.E., Kupfner,I.G., and Vasiliou,V.K. 2000. Polymorphism and species differences of the corneal ALDH3A1.Investigative Ophthalmology \& Visual Science 41: S873. 
Parent,R.A., Paust,D.E., Schrimpl,M.K.. Talaat,R.E.. Doane,R.A. Caravello.H.F. Lee.S.J., and Sharp,D.E. 1998. Metabolism and distribution of 12.3-C-14]acrolcin in Sprague-Dawley rats - II. Identification of urinary and fecal metabolites. Toxicological Sciences 43: 110-120.

Patel,J.M., Wood,J.C., and Leibman,K.C. 1980. The Biotransformation of Allyl Alcohol and Acrolein in Rat-Liver and Lung Preparations. Drug Metabolism and Disposition 8: 305-308.

Pearson,W.R., Reinhart,J., Sisk,S.C., Anderson,K.S., and Adler,P.N. 1988. 'TissueSpecific Induction of Murine Glutathione Transferase Messenger-Rnas by Butylated Hydroxyanisole. Journal of Biological Chemistry 263: $13324-13332$.

Peterson,F.J., Holtzman,J.L., Crankshaw,D., and Mason,R.P. 1988. 2 Sitcs of Azo Reduction in the Monooxygenase System. Molecular Pharmacology 34: 597-603.

Picklo,M.J., Montine,T.J., Amarnath,V., and Neely,M.D. 2002. Carbonyl toxicology and Alzheimer's disease. Toxicology and Applied Pharmacology 184: 187-197.

Pinkus,R., Weiner,L.M., and Daniel,V. 1996. Role of oxidants and antioxidants in the induction of AP-1, NF-kappa B, and glutathione S-transferase gene expression 6. Journal of Biological Chemistry 271: 13422-13429.

Poli,G. and Schaur,R.J. 2000. 4-Hydroxynonenal in the pathomechanisms of oxidative stress. IUBMB. Life 50: 315-321.

Prestera,T., Talalay,P., Alam,J., Ahn.Y.I., Lee,P.J.. and Choi, A.M.K. 1995. Parallei Induction of Heme Oxygenase-1 and Chemoprotective Phase-2 Lnyencs by Electrophiles and Antioxidants - Regulation by Upstream Antioxidant-Responsive: Elements (Are). Molecular Medicine 1: 827-837.

Ramana,K.V., Bhatnagar,A., Srivastava,S., Yadav,U.C., Awasthi,S.. Awasthi, Y.C.. and Srivastava.S.K. 2006. Mitogenic responses of vascular smooth muscle cells to lipid peroxidation-derived aldehyde 4-hydroxy-trans-2-nonenal (IINE): role o: aldose reductase-catalyzed reduction of the INE-glutathione conjugates in regulating cell growth. J. Biol. Chem. 281: 17652-1766().

Ranganna,K., Hayes,B.E., Milton,S.G., and Yatsu,F.M. 2000. Acrolein activates mitogen-activated protein kinase $(\mathrm{M} \wedge \mathrm{PK})$ signal transduction pathways in rat vascular smooth muscle cells (SMCs). Faseb Joumal 14: A1455.

Remmer.H., Greim,H., Schenkman,I.B., and Estabrook.R.W. 1967. Methods for the elevation of hepatic microsomal mixed function oxidase levels and cytochrome 450. Methods in Enzymology 10: 703-708.

Robinson-Rechavi,M., Garcia,H.E.. and Laudet.V. 2003. The nuclear receptor superfamily. Journal of Cell Science 116:585-586. 
Robinson,M.J. and Cobb,M.H. 1997. Mitogen-activated protein kinase pathways. C'ument Opinion in Cell Biology 9: 180-186.

Schell,M.J., Maurice.M., Stieger,B., and Hubbard,A.L. 1992. 5'nucleotidase is sorted to the apical domain of hepatocytes via an indirect route. J. Cell Biol. 119:11731182.

Schneider.C., Tallman,K.A., Porter,N.A., and Brash.A.R. 2001. Two distinct pathways of formation of 4-hydroxynonenal. Mechanisms of non-enzymatic transformation of the 9- and 13-hydroperoxides of linoleic acid to 4-hydroxyalkenals. (vol 276, po 20831, 2001). Journal of Biological Chemistry 276: 32392.

Shinmura,K., Bolli,R., Liu,S.Q., Tang, X.L., Kodani,E., Xuan,Y.T.. Srivastava,S., and Bhatnagar,A. 2002. Aldose reductase is an obligatory mediator of the late phase of ischemic preconditioning. Circ. Res. 91: 240-246.

Siems,W.G., Grune,T., Beierl,B., Zollner,H., and Esterbauer,H. 1992. The metabolism of 4-hydroxynonenal, a lipid peroxidation product, is dependent on tumor age in Ehrlich mouse ascites cells. EXS 62: 124-135.

Siems, W.G., Zollner,H., Grune,T., and Esterbauer,H. 1997. Metabolic fate ol 4hydroxynonenal in hepatocytes: 1,4-dihydroxynonene is not the main product. Journal of Lipid Research 38: 612-622.

Sies,H. 1991. Oxidative Stress - from Basic Research to Clinical-Application. American Journal of Medicine 91: S31-\$38.

Silva,J.M. and Obrien,P.J. 1989. Allyl Alcohol-Induced and Acrolein-Induced Toxicity in Isolated Rat Hepatocytes. Archives of Biochemistry and Biophysics 275: 551558.

Skett.P. and Bayliss,M. 1996. Time for a consistent approach to preparing and culturing hepatocytes? Xenobiotica 26: 1-7.

Sladek,N.E. Metabolism and pharmacokinctic behavior of cyclophosphamide and related oxazaphosphorines. 79-156. 1994. Anticancer Drugs: Reative Metabolism and Drug Interactions.

Srivastava,S., Conklin.D.J., Liu,S.Q., Prakash,N., Boor,P..I., Srivastava,S.K., and Bhatnagar,A. 2001. Identification of biochemical pathways for the metabolism of oxidized low-density lipoprotein derived aldehyde-4-hydroxy trans-2-nonenal in vascular smooth muscle cells. Atherosclerosis 158: 339-350.

Srivastava,S., Conklin,D.J., Liu,S.Q., Prakash,N., Boor,P.J., Srivastava,S.K., and Bhatnagar, A. 2002. Identification of biochemical pathways for the metabolism of oxidized low-density lipoprotein derived aldehyde-4-hydroxy trans-2-nonenal in vascular smooth muscle cells. Atherosclerosis 158: 339-360. 
Standford Research Institute. International. Acrolein. Acrylic acid. 1978. Directory of Chemical Procedures, United States of America, SRI International. 426

Steinbrecher.U.P., Zhang,H.F., and Iougheed,M. 1990. Role of Oxidatively Modified Ldl in Atherosclerosis. Free Radical Biology and Medicine 9: 155-168.

Sueyoshi,T. and Negishi,M. 2001. Phenobarbital response elements of cytochrome P450 genes and nuclear receptors. Annual Review of Pharmacology and Toxicology 41: 123-143.

Thimmulappa,R.K., Mai,K.H., Srisuma,S., Kensler,T.W., Yamamato,M.. and Biswal.S. 2002. Identification of Nrf2-regulated genes induced by the chemopreventive agent sulforaphane by oligonucleotide microarray. Cancer Rescarch 62:51965203.

Thomas,R.S., Rank,D.R., Penn,S.G., Craven,M.W., Drinkwater,N.R., and Bradtield.C.A. 2002. Developing toxicologically predictive gene sets using cDNA microarrays and Bayesian classification. Cytochrome P450, Pt C 357: 198-205.

Thweatt,W.D., Harward,C.N., and Parrish,M.E. 2007. Measurement of acrolein and 1.3butadiene in a single puff of cigarette smoke using lead-salt tunabie diode laser infrared spectroscopy. Spectrochimica Acta Part A-Molecular and Biomolecular Spectroscopy 67: 16-24.

Uchida,K., Szweda,L.I., Chae,H.Z., and Stadtman,E.R. 1993. Immunochemical Derection of 4-Hydroxynonenal Protein Adducts in Oxidized Hepatocytes. Proceedings of the National Academy of Sciences of the United States of America 90: 87428746 .

Uchida,K., Kanematsu.M., Morimitsu,Y., Osawa,T., Noguchi,N., and Niki.E. 1998. Acrolein is a product of lipid peroxidation reaction - Formation of free acrolein and its conjugate with lysine residues in oxidized low density lipoproteins 99. Journal of Biological Chemistry 273: 16058-16066.

Uchida,K., Shiraishi,M., Naito,Y., Torii.Y., Nakamura,Y.. and Osawa,?. 1999. Activation of stress signaling pathways by the end prodact of lipid peroxidation 4-hydroxy-2-nonenal is a potential inducer of intracellular peroxide production 14. Journal of Biological Chemistry 274: 2234-2242.

Uchida,K. 2003. 4-Hydroxy-2-nonenal: a product and mediator of oxidative stress Progress in Lipid Research 42: 318-343.

Visser,A.J.W.G. and Muller,F. 1979. Absorption and Fluorescence Studies on Neutral and Cationic Isoalloxazines. Helvetica Chimica Acta 62: 593-608.

Wasserman,W.W. and Fahl,W.E. 1997. Functional antioxidant responsive elements 3. Proceedings of the National Academy of Sciences of the United States of America 94: $5361-5366$. 
Watanabe.K., Narimatsu,S., Yamamoto,I., and Yoshimura,H. 1991. Oxygenation mechanism in conversion of aldehyde to carboxylic acid catalyzed by a cytochrome P-450 isozyme. J. Biol. Chem. 266: 2709-2711.

Watanabe,K., Hirahashi,N., Narimatsu,S., Yamamoto,I., and Yoshimura,H. 1991. Mouse hepatic microsomal enzyme that catalyzes oxidation of 11 -oxo-delta 8tetrahydrocannabinol to delta 8-tetrahydrocannabinol-11-oic acid. Drug Metah Dispos. 19: 218-221.

Watanabe,K., Kimura,J., Iwawaki,Y., Matsunaga,T.. Yamamoto.I., and Yoshimura,II. 1994. Metabolic Reaction of Tolualdehydes by Microsomal Aldehyde Oxygenase (Maldo) in Lung. Japanese Journal of Toxicology and Environmental I lealth 40: 11.

Watanabe,K., Matsunaga,T., Yamamoto,I., and Yashimura,H. 1995. Oxidation of tolualdehydes to toluic acids catalyzed by cytochrome P450-dependent aldehyde oxygenase in the mouse liver. Drug Metab Dispos. 23: 261-265.

West,J.D. and Marnett,L.J. 2005. Alterations in gene expression induced by the lipid peroxidation product, 4-hydroxy-2-nonenal. Chemical Research in Toxicology 18: $1642-1653$.

Witz, G. 1989. Biological Interactions of Alpha,Beta-Unsaturated Aldehydes. Free Radical Biology and Medicine 7: 333-349.

Yang, Y., Sharma,R., Sharma,A., Awasthi,S., and Awasthi, Y.C. 2003. Lipid peroxidation and cell cycle signaling: 4-hydroxynonenal, a key molecule in stress mediated signaling. Acta Biochim. Pol. 50: 319-336.

Yuan,X.L., Xu,C.J., Pan,Z., Keum,Y.S., Kim,J.H., Shen,G.X., Yu.S.W., Oo,K.l... Ma,J.J., and Kong,A.N.T. 2006. Butylated hydroxyanisole regulates AREmediated gene expression via Nrf2 coupled with ERK and JNK signaling pathway in HepG2 cells. Molecular Carcinogenesis 45: 841-850.

Zhang,Q.Y., Dunbar,D., and Kaminsky,L.S. 2003. Characterization of mouse smal] intestinal cytochrome P450 expression. Drug Metabolism and Disposition 31 : 1346-1351. 


\section{APPENDIX}

\section{LIST OF ABBREVIATIONS}

4-HNE: 4-hydroxy-2-nonenal

5'-FS: 5'-flanking sequence

9-AA: 9-anthracene aldehyde

9-^CA: 9-anthracene carboxylic acid

9-AMeOH: 9-anthracene methanol

$A F-1$ : activation function-1

AF-2: activation function-2

AIN76A: American institute of nutrition diet 76A

AP-1: activator portien 1

ALDH: aldehyde dehydrogenase

AR: aldose reductase

ARE: antioxidant response element

BHA: butylated hydroxy anisole

CAR: constitutive androstane receptor

CPM: counts per minute

CYP: cytochrome P450

DHN: 1,4-dihydroxy nonene

DPLC: dilauroylphosphatidylcholine 
(iC/MS: gas chromatography-mass spectrometry

(iST: glutathione $S$-transferase

GS-HNE: glutathione conjugate of 4-HNE

HNA: 4-hydroxynonenoic acid

HPI, : high performance liquid chromatography

Kcap 1: Kelch-like ECH-associated protein 1

NADPH: nicotinamide adenine dinucleotide phosphate, reduced form

NADPH:CYPOR: NADPH/cytochrome P450 oxidoreductase

NFkB: nuclear factor $\mathrm{kB}$

P450: cytochrome P450

RNA: ribunucleic acid

SD: standard deviation

tR: retention time

PXR: pregnane $\mathrm{X}$ receptor

PCR: polymerase chain reaction

PPAR: peroxisome proliferator activated receptor

QRT-PCR: quantitative real-time PCR

RXR: retinoic acid receptor

TBHQ: tertiary butylated hydroquinone

TCA: trichloroacetic acid

TRE: TPA (12-O-tetradecanoyl-phorbol-13 acetate) response element 


\section{CURRICULUM VITAE}

Name: Immaculate Amunom

Education

B.S., Life Sciences

University of Buea- Cameroon (1998)

M. S., Biochemistry

University of Buea Cameroon (2000)

Ph.D., University of Louisville School of Medicine (2008)

Louisville KY

Awards

Graduate Student Travel Award, The American Society for Pharmacology and Experimental Therapeutics (ASPET), 2006.

Integrated Program in Biomedical Sciences (IPIBS) Fellowship 2002-2004.

The Annual James Graham Brown Cancer Center Retreat, Condict Moore Student Research Prize, U. of Louisville 2004.

Professional Societies

International Society for the Study of Xenobiotics (ISSX).

American Society for Pharmacology and Experimental Therapeutics (ASPLT).

Ohio Valley Society of Toxicology (OVSOT)

Publications

"The Role of Metabolism in Protection Against Cardiotoxic Compounds", R.A. Prough, I. Amunom, and D.J. Conklin, Sustain 13:6-11 (2006). Review.

"Several Cytochromes P450 are Aldehyde Monooxygenases", I. Amunom. I ... Stephens, D.J. Conklin, S. Srivastava, A. Bhatnagar, and R.A. Prough.

Enzymology and Molecular Biology of Carbonyl Metabolism (ed., H. Weiner),

12:118-123, U. Purdue Press, Lafayette, IN (2005). Review. 
"Cytochromes P450 Catalyze the Oxidation of $\alpha, \beta$-unsaturated Aldehydes" I. Amunom, L.J. Stephens, V. Tamasi, J. Cai, D.J. Conklin, A. Bhatnagar, S. Srivastava, M.V. Martin, F. P. Guengerich, and R.A. Prough, Archives of Biochemistry and Biophysics 464(2): 187-96 (2007).

Manuscripts In Preparation

"P450 3A4 Reduces $\alpha, \beta$-unsaturated Aldehydes to Akohols" I. Amunom, L. I. Stephens, J. Cai, S. Srivastava, F. P. Guengerich and R.A. Prough.

"P4502c29 is Regulated Through the Action of AP-1 transcription factor" I.

Amunom, J. A. Goldstein and R. A. Prough.

$\wedge$ bstracts

"Murine P4502c29 is an Aldehyde Dehydrogenase" R.A. Prough. D... Conklin, L.J., Stephens and I. Amunom, (2004) $12^{\text {th }}$ International Meeting on the Enzymology, and Molecular Biology of Carbonyl Metabolism, Burlington. VT, July $7-11$.

"Murine P4502c29 Metabolizes Endogenous Lipid Aldchydes" 1. Amunom. I... Stephens and R.A. Prough, (2004) $7^{\text {th }}$ International ISSX Meeting, Drlig Metabolsim Reviews 36, Abstract No. 151.

"Induction of Cytochromes P450 by Nrf2 activators: Implications for aldehyde metabolism" I. Amunom, L.J. Stephens, D.J. Conklin, and R.A. Prough. (2006) Experimental Biology, Abstract No 176.11, April 1-5.

"Aldehyde Metabolsim is Regulated by Nuclear Factor E2-related Factor?" I. Amunom, L.J. Stephens, D.J. Conklin, A. Bhatnagar, and R.A. Prough. (2006) $13^{\text {th }}$ International Meeting on the Enzymology and Molecular Biology of Carbonyl Metabolism, Abstract AL-1, Nashville, IN, July 11 - 15.

"Cis-Regulatory Elements of Sexual Stage Gene Expression: Laboratory and Field Characterization of Pfs 25 " Mbacham W.F., Amunom I., Golightly L.M. Daily J., Sullivan T.J., Harris DS., Ruel K., Laserson K., Dechering K., Yong S. Enyong P., Titanji V.P.K., and Wirth D.F. (2000) University of Yaounde I. Cameroon. 